\title{
Recovery of Glycols, Sugars, and Related Multiple -OH Compounds from Dilute-Aqueous Solution by Regenerable Adsorption onto Activated Carbons
}

\author{
Daniel Chinn \\ Ph.D. Thesis \\ Department of Chemical Engineering \\ University of California, Berkeley \\ and \\ Environmental Energy Technologies Division \\ Ernest Orlando Lawrence Berkeley National Laboratory \\ University of California \\ Berkeley, CA 94720
}

June 1999

This work was supported by the Assistant Secretary for Energy Efficiency and Renewable Energy, Office of Industrial Technologies, Division of Advanced Industrial Concepts, of the U.S. Department of Energy under Contract No. DE-AC03-76SF00098. 


\section{DISCLAIMER}

This report was prepared as an account of work sponsored by an agency of the United States Government. Neither the United States Government nor any agency thereof, nor any of their employees, make any warranty, express or implied, or assumes any legal liability or responsibility for the accuracy, completeness, or usefulness of any information, apparatus, product, or process disclosed, or represents that its use would not infringe privately owned rights. Reference herein to any specific commercial product, process, or service by trade name, trademark, manufacturer, or otherwise does not necessarily constitute or imply its endorsement, recommendation, or favoring by the United States Government or any agency thereof. The views and opinions of authors expressed herein do not necessarily state or reflect those of the United States Government or any agency thereof. 


\section{DISCLAIMER}

Portions of this document may be illegible in electronic image products. Images are produced from the best available original document. 
Recovery of Glycols, Sugars, and Related Multiple -OH Compounds from Dilute-Aqueous Solution by Regenerable

Adsorption onto Activated Carbons

by

Daniel Chinn

B.S. (University of Washington) 1994

A dissertation submitted in partial satisfaction of the

requirements for the degree of

Doctor of Philosophy

in

Chemical Enyineering

in the

GRADUATE DIVISION

of the

UNIVERSITY OF CALIFORNIA AT BERKELEY

Committee in charge:

Professor C. Judson King, Chair

Professor Clayton J. Radke

Professor Tadeusz Patzek

Spring 1999 


\section{Recovery of Glycols, Sugars, and Related Multiple - OH Compounds from Dilute-Aqueous Solution by Regenerable Adsorption onto Activated Carbons}

Copyright (C 1999

by

Daniel Chinn

The U.S. Department of Energy has the right to use this document for any purpose whatsoever including the right to reproduce all or any part thereof. 


\author{
Abstract \\ Recovery of Glycols, Sugars, and Related Multiple -OH Compounds \\ from Dilute-Aqueous Solution by Regenerable \\ Adsorption onto Activated Carbons \\ by \\ Daniel Chinn \\ Doctor of Philosophy in Chemical Engineering \\ University of California at Berkeley \\ Professor C. Judson King, Chair
}

The present research explores the use of adsorption onto activated carbons as a means to recover glycerol, glycols, and sugars from dilute-aqueous solution. Due to the extreme hydrophilicity and nonvolatility of these multiple $-\mathrm{OH}$ compounds, current separation processes require evaporation of all the water. A more energy-efficient and soluteselective process would therefore be of interest to many industries. Our work is focused on (1) understanding the mechanisms of adsorption onto carbons, (2) assessing the degree of adsorption reversibility with precision, and (3) implementing a bench-scale recovery process that results in a higher product concentration and reduction of the energy load for final purification.

Batch-equilibrium uptakes and isosteric heats of adsorption of several multi $-\mathrm{OH}$ solutes and alcohol analogs on activated carbon were measured. Adsorption-equilibrium experiments were also performed on activated carbons from different source materials and/or with different degrees of surface oxidation obtained by controlled, chemical 
treatment. From these results, it appears that the adsorption mechanism is largely characterized by solution-phase nonidealities and dispersion interactions. The $-\mathrm{OH}$ group(s) on the adsorbate, and any oxygen-bearing functional groups on the carbon surface seem to interact with water preferentially, thereby resulting in weaker attraction to the carbon surface.

Thermogravimetric Analysis (TGA) was introduced as a novel analytical tool for assessing the composition and thermal stability of the adsorbed phase on carbons. TGA, combined with batch solvent-regeneration experiments, demonstrated that acetone and methanol are effective for in-situ recovery of multiple - $\mathrm{OH}$ compounds previously adsorbed on carbon surfaces. Acetone, however, remains on the carbon surface up to relatively high temperatures. This can lower capacity for subsequent loadings.

Adsorption and regeneration experiments were also implemented in a fixed-bed arrangement. By suitable choices of operating parameters we have succeeded in focusing (concentrating) the product to a factor of 3 to 6 times the initial feed concentration within an organic medium. With methanol as the solvent, the process could be cycled with minimal loss of bed capacity. From these findings, it appears that regenerable adsorption onto activated carbons has strong potential as means of recovering and concentrating multiple $-\mathrm{OH}$ compounds from dilute-aqueous solutions. 


\section{Summary of Conclusions}

The present research explores the recovery of glycols, sugars, and related multiple - $\mathrm{OH}$ compounds from aqueous solution by adsorption onto activated carbons. The importance of this work is as follows:

- The effects of the (1) $-\mathrm{OH}$ groups on the solute, and (2) carbon surface properties on adsorption have been identified, whereas previous studies in the literature on adsorption mechanisms for carbons were largely confined to aromatic solutes.

- A relatively novel technique, Thermogravimetric Analysis (TGA), was developed to characterize the composition and volatility of the adsorbed phase on carbons.

- A fixed-bed adsorption/solvent regeneration process was developed for recovery of aqueous, multiple $-\mathrm{OH}$ compounds, and potentially results in substantial energy savings over conventional, evaporation processes.

The results of this work can be of use in many industrial applications:

- Fermentation and wet corn-milling industries

- Food industries: sugar refineries, canneries, wineries, distilleries, and breweries

- Glycol production streams from the petrochemical industries

- Glycol recovery from spent aircraft deicer and from aưtomobile antifreeze and coolants 
Dedicated to my parents, Hansing and Ling

and to my uncle, Yuen K. Wong. 


\section{Acknowledgements}

In many ways, this is easily the most important part of the dissertation. In completing my research, no amount of theory or experimental results could ever compare to the support I received from the following individuals. I am truly grateful to each of them for making my stay here at Berkeley a memorable one, and this dissertation possible.

First and foremost I would like to thank my research advisor, Professor C. Judson King. He gave me sufficient freedom and confidence in conducting my research, yet was always ready to provide guidance when needed. It has definitely been a great honor to be a part of his laboratory. Special thanks go to Professor John Prausnitz, whose encouragement has greatly helped me through my qualifying exam. Professors Clay Radke and Tad Patzek also deserve recognition for agreeing to read this dissertation.

I acknowledge my past and present lab mates for their camaraderie, helpful ideas, and inspiration. These notable individuals are John Hecht, Dr. Scott Husson, Dr. James "Chip" Kilduff, and Dr. Scott Moor. I also thank Claire Law, an undergraduate research assistant, who helped me with many experiments.

Thanks go out to the folks at LBL as well: Garth Burns, John Kerr, Ravi Mukkamala, and Aline Rougier for generously providing access to the TGA and FTIR facilities.

On campus, life as a graduate student would have been hectic and unbearable if it was not 
for the sunny dispositions of Heather Campell, Aileen Harris, Ferne Kasarda, and Judie Powers. They have each helped me adjust to life here in the Department.

I also extend my thanks to my family members both in Seattle and in the Bay Area. Thanks go out to Mom and Dad for their love and support, and to my little sister Judy for having the courage to pursue her college studies in Los Angeles and Italy. I am grateful to my cousin Marcus Chinn, for his resourcefulness and computing expertise. I also thank Uncle Yuen and Aunt Hannah, for their support throughout my academic career. Many individuals here in the Bay Area were instrumental in insuring that I had a happy life outside the laboratory. Mrs. SuiSiu Tam, Dowdan Low, Uncle Derek, Uncle Enrique and Aunt Siu Ling, and my grandparents all looked out for me these past five years.

I am indebted to Professor J.C. Seferis, Dr. Sang-Beom Shim, and Louise Peterson from the Polymeric Composites Laboratory at the University of Washington. Each of them was a mentor to me, and first introduced me to the exciting world of research.

Last but not least, I thank Mike Sun for many years of friendship. Also, thanks to all of my academic brothers and sisters who came out and played basketball every week. Life as a graduate student could not have been more rewarding or exciting.

This research has been supported by the Assistant Secretary for Energy Efficiency and Renewable Energy, Office of Industrial Technologies, Division of Advanced Industrial Concepts of the U.S. Department of Energy under Contract No. DE-AC03-76SF00098. 
Abstract

Summary of Conclusions

Dedication

Acknowledgements

Table of Contents

List of Figures xiii

List of Tables $\quad$ xix

\section{Chapter 1. Introduction}

1.1 Industrial Applications

1.2 The Separation Problem $\quad 2$

1.3 Methods of Separation 3

1.3.1 Traditional Method: Evaporation of Water 3

1.3.2 Novel Methods of Separation 5

1.3.2.1 Membrane Processes $\quad 5$

1.3.2.2 Complexation with Ion-Pair Extractants 6

1.3.2.3 Complexation by Reversible Reaction 9

1.3.2.4 Sorption Technology: Fractionation of Sugars 10

1.4 General Description of Activated Carbons 11

$\begin{array}{ll}\text { 1.4.1 Manufacture } & 12\end{array}$

$\begin{array}{ll}\text { 1.4.2 Physical and Chemical Structures } & 12\end{array}$

$\begin{array}{ll}\text { 1.4.3 Economic Aspects and Uses } & 14\end{array}$

1.4.4 Liquid-Phase Adsorption on Carbons $\quad 16$

$\begin{array}{ll}\text { 1.4.4.1 General Observations } & 16\end{array}$

1.4.4.2 Adsorption Theory - Polanyi Model 17

1.4.4.3 Adsorption Theory - Thermodynamic Models 18

1.4.4.4 Adsorption Theory - Linear Solvation Energy 18

1.4.4.5 Adsorption Theory - Summary 
1.4.5 Motivation for Using Carbons in this Research

1.5 Multi -OH Compounds of Interest 22

1.5.1 Sugars (Glucose and Sucrose) 22

$\begin{array}{ll}\text { 1.5.2 Sugar Alcohols (Sorbitol) } & 24\end{array}$

$\begin{array}{ll}\text { 1.5.3 Glycerol } & 25 \\ & \end{array}$

1.5.4 Glycols (Ethylene and Propylene Glycols) 26

1.6 General Research Objectives

$\begin{array}{ll}1.7 \text { Overview of Dissertation } & 28\end{array}$

References for Chapter 1

\section{Chapter 2. Experimental Materials and Methods}

2.1 Materials

$\begin{array}{ll}2.1 .1 \text { Chemicals } & 34\end{array}$

2.1.2 Adsorbents 34

2.2 Methods of Carbon Pre-Treatment 35

2.2.1 Batch Heat Treatment $\quad 35$

2.2.2 Batch Acid-Oxidation 36

2.3 Analytic Methods 36

2.3.1 High Performance Liquid Chromatography (HPLC) 36

$\begin{array}{ll}\text { 2.3.2 Acid/Base Titration } & 38\end{array}$

$\begin{array}{ll}\text { 2.3.3 BET Analysis } & 38\end{array}$

2.3.3.1 Calculation of Surface Area $\quad 39$

2.3.3.2 Estimation of Pore-Size Distribution $\quad 40$

2.3.4 Thermogravimetric Analysis (TGA) 43

2.3.4.1 TGA Derivative Plot Construction $\quad 45$

2.4 Adsorption/Desorption Equilibrium Experiments 46

2.4.1 Experimental Methods $\quad 46$

2.4.2 Conventions $\quad 47$

2.4.3 Development of Material Balances $\quad 49$

2.4.4 Experimental Verification of Equilibrium 53

2.5 Acidic/Basic Site Titration of Carbons 
2.6 Fixed-Bed Analysis $\quad \cdots \quad 60$

$\begin{array}{ll}2.6 .1 \text { Experimental Methods } & 60\end{array}$

$\begin{array}{ll}2.6 .2 \text { Conventions } & 62\end{array}$

$\begin{array}{ll}\text { References for Chapter } 2 & 64\end{array}$

\section{Chapter 3. Properties of Adsorbents}

$\begin{array}{ll}3.1 \text { Overview } & 65\end{array}$

3.2 Water Uptake by Pore Filling in Adsorbents 65

$\begin{array}{ll}\text { 3.3 Nitrogen Adsorption Isotherms (BET Analysis) } & 67\end{array}$

3.3.1 Surface Areas of Adsorbents $\quad 67$

3.3.2 Pore-Size Distribution of Carbons $\quad 70$

3.4 Bulk Elemental Analysis of Adsorbents $\quad 72$

3.5 Acidic and Basic Site Density of Adsorbents $\quad 74$

$\begin{array}{ll}\text { 3.5.1 Acidic Sites } & 74\end{array}$

$\begin{array}{ll}\text { 3.5.2 Basic Sites } & 77\end{array}$

$\begin{array}{ll}\text { 3.6 Water Vapor Adsorption on Carbons } & 79\end{array}$

$\begin{array}{ll}\text { 3.7 Other Characterization Methods } & 81\end{array}$

3.8 Insights on Surface Chemistry $\quad 82$

$\begin{array}{ll}\text { 3.8.1 Acidic Sites } & 82\end{array}$

$\begin{array}{ll}\text { 3.8.2 Basic Sites } & 83\end{array}$

$\begin{array}{lr}\text { References for Chapter } 3 & 86\end{array}$

Chapter 4. Adsorption Equilibria

$\begin{array}{ll}4.1 \text { Overview } & 87\end{array}$

4.2 Effects of Solution Chemistry on Adsorption $\quad 89$

$\begin{array}{ll}\text { 4.2.1 The Gibbs Adsorption Equation } & 89\end{array}$

4.2.2 Solution-Phase Activity Coefficients $\quad 90$

4.2.3 Surface Tension Data for Aqueous Solutions $\quad 91$

$\begin{array}{ll}\text { 4.2.4 Calculated Results } & 93\end{array}$

4.2.5 Surface vs. Solution Interactions for Adsorption 95 
4.3 Effects of Temperature on Adsorption 98

4.3.1 Adsorption Isotherms at Several Temperatures 98

4.3.2 Heats of Adsorption from the Isosteric Method 101 $\begin{array}{ll}\text { 4.3.2.1 Background } & 101\end{array}$

4.3.3.2 Calculated Results $\quad 103$

4.3.3 Summary 106

4.4 Effects of Surface Chemistry on Adsorption 108

4.4.1 Data for Surface-Treated Carbons (Variable Surface Acidity) 108

4.4.1.1 Data for Glycols (EG,PG) and Glycerol $\quad 109$

4.4.1.2 Data for Glucose 113

4.4.1.3 Data for (Monomeric) Lactic Acid 113

4.4.2 Data for As-Received Carbons (Variable Source Material) $\quad 116$

4.4.3 Roles of Carbon-Surface Oxides on Adsorption - Discussion $\quad 118$

4.4.3.1 Evidence for Polar Interactions 121

4.4.3.2 Evidence for Dispersive Interactions with Basal Plane $\quad 122$

4.4.3.3 Evidence for Electron Donor-Acceptor Interactions 123

4.4.3.4 Evidence for Preferential Affinity for Water 125

$\begin{array}{ll}\text { 4.4.4 Summary } & 125\end{array}$

$\begin{array}{ll}\text { References for Chapter } 4 & 127\end{array}$

Chapter 5. Solvent Regeneration of Activated Carbons

$\begin{array}{ll}5.1 \text { Overview } & 129\end{array}$

5.2 Current Regeneration Methods $\quad 129$

5.2.1 Thermal Regeneration 130

5.2.2 Regeneration by Reversible Reaction 131

5.2.3 Regeneration by Solvents 131

5.3 Solvent Regeneration - Fundamental Concepts 132

$\begin{array}{ll}\text { 5.3.1 Equilibrium Standpoint } & 132\end{array}$

$\begin{array}{ll}\text { 5.3.2 Individual Uptakes of Solute } & 134\end{array}$

5.4 Selection of Regenerants $\quad 140$

5.5 Completeness of Regeneration: Glycols and Glycerol 144

5.5.1 Wet vs. Dry Regeneration 144

5.5.2 Adsorption Equilibria from Water-Organic Mixtures $\quad 152$

5.5.3 Effect of Displacer Concentration and Phase Ratio on $\quad 156$

Regeneration 
5.6 Solvent Regeneration - Summary

References for Chapter 5

Chapter 6. Thermogravimetric Analysis (TGA) of Active Carbons

6.1 Overview

6.1.1 Sample TGA Data

6.1.2 Background on Thermal Desorption of Carbons

6.1.3 TGA for Studying Desorption of Multi-OH Compounds

6.2 Regenerability of Carbons

6.2.1 TGA Results for Pure Solvents on Carbons 167

6.2.2 Sample Data for Batch Regeneration 169

6.2.3 Wet vs. Dry Regeneration 172

6.2.4 Batch Reloading Experiments $\quad 179$

6.2.5 Carbon Regenerability - Summary 185

6.3 Thermal Stability of Adsorbed Phase and Desorption Kinetics 186

6.3.1 Temperature of Maximum Desorption, $T_{\max } \quad 186$

6.3.1.1 Effect of Surface Loading on $\mathrm{T}_{\max } \quad 186$

$\begin{array}{ll}\text { 6.3.1.2 Effect of Carbon Type on } \mathrm{T}_{\max } & 188\end{array}$

6.3.1.3 $T_{\max }$ for Various Solutes 191

6.3.2 First-Order Kinetics Model for Thermal Desorption 198

6.3.2.1 Background and Model Development 198

6.3.2.2 Sample Data - Effect of Heating Rate on $T_{\max } \quad 203$

6.3.2.3 Results for Alcohols and Multi-OH Solutes 205

6.3.2.4 Discussion 208

6.3.3 Thermal Stability of Adsorbed Phase - Summary 209

$\begin{array}{ll}\text { References for Chapter } 6 & 211\end{array}$

Chapter 7. Fixed-Bed Adsorption and Regeneration

$\begin{array}{ll}7.1 \text { Overview } & 212\end{array}$

7.2 Fixed-Bed Loading: Breakthrough Analysis 212

$\begin{array}{ll}\text { 7.2.1 Representative Data } & 212\end{array}$

7.2.2 Shape of Breakthrough Curves 214

7.2.3 Theoretical-Plate Concepts from Chromatography 215 
7.3 Fixed-Bed Solvent Regeneration: Elution Analysis

7.3.2 Local-Equilibrium Analysis of Focusing Effect

7.4 Mass Balances from Fixed-Bed Experiments

7.4.1 Mass Balance from Breakthrough Curves

7.4.2 Mass Balance from Elution Curves

7.4.3 Completeness of Regeneration

7.4.4 Comparison with Batch Adsorption Data

7.5 Product Recovery from Solvent Regeneration

7.5.1 Width of Product-Stream Cut

7.5.2 Energy Requirements

7.6 Optimization of the Focusing Effect 238

7.6.1 Effect of Carbon Choice 238

7.6.2 Effect of Volumetric Flowrate 240

7.6.3 Effect of Particle-Size Distribution 242

7.7 Cycling of Adsorption/Regeneration Stages 246

7.7.1 Acetone as the Regenerant $\quad 246$

7.7.2 Methanol as the Regenerant 251

7.8 Two-Solute Systems for Fixed-Bed Processes 253

7.8.1 Differential Displacement with Concentrated Regenerants 253

7.8.2 Differential Displacement with Dilute Regenerants - $\quad 257$

7.8.3 Solute Fractionation: Summary and Recommendations 260

$\begin{array}{ll}\text { References for Chapter } 7 & 262\end{array}$

Chapter 8. Conclusions and Process Implications

8.1 Adsorption Mechanisms 263

8.2 Carbon Regenerability and Product Recovery 265

$\begin{array}{ll}\text { 8.3 Process Considerations } & 266\end{array}$

Appendices

$\begin{array}{ll}\text { Appendix A. List of Chemicals } & 268\end{array}$ 
Appendix B. Sensitivity and Error Analysis

$\begin{array}{ll}\text { Appendix C. Curve Fitting of Isotherms } & 275\end{array}$

Appendix D. Numerical Integration of Fixed-Bed Data 280

Appendix E. Experimental Data 284

\section{List of Figures}

Fig. 1.3.2-(A). Mechanism of organoboronate complexation with propylene glycol (Broekhuis et al., 1996).

Fig. 1.3.2-(B). Reversible chemical reaction between aldehyde and cis-vicinal glycol (Broekhuis et al., 1994).

Fig. 1.4-1. Structural representation of (a) graphite and (b) activated carbon.

Fig. 1.4-2. Pie chart showing 1987 usage of active carbons (by liquid-phase application) in the United States.

Fig. 1.5-1. Schematic representation of multi $-\mathrm{OH}$ compounds of interest.

Fig. 2.3.4-1. Equipment schematic for Thermogravimetric Analysis (TGA), from PerkinElmer Series 1020 TGA-7 instruction manual.

Fig. 2.4-1. Adsorption isotherms $\left(25^{\circ} \mathrm{C}\right)$ for glucose on untreated $\mathrm{F} 400$ carbon, dry and pre-wetted.

Fig. 2.4-2. Adsorption rate experiments $\left(25^{\circ} \mathrm{C}\right)$ for ethylene glycol and glucose on untreated F-400 carbon.

Fig. 2.4-3. Desorption rate experiments $\left(25^{\circ} \mathrm{C}\right)$ for ethylene glycol loaded on untreated F400 carbon, with water, acetone, and methanol as solvents.

Fig. 2.4-4. Adsorption and desorption isotherms $\left(25^{\circ} \mathrm{C}\right)$ for glucose on untreated $\mathrm{F} 400$ carbon.

Fig. 2.6-1. Schematic of equipment used for fixed-bed experiments.

Fig. 3.3-1. Nitrogen adsorption isotherms (77K) for several carbons. 
Fig. 3.3-2. Pore-size distributions for several carbons.

Fig. 3.5.1-(A). Examples of surface oxide groups on carbons (You et al., 1994).

Fig. 3.5.1-(B). Oxidation of 9,10-dihydrophenanthrene by nitric acid (Vinke et al., 1994).

Fig. 3.5.1-(C). Oxidation of diphenylmethane by nitric acid (Vinke et al., 1994).

Fig. 3.6-1. Water vapor uptake as a function of surface acidity for several carbons.

Fig. 3.8.1-(A). Reaction scheme for proton uptake onto chromene/free radical sites.

Fig. 3.8.1-(B). Reaction scheme of proton addition onto pyrone structures.

Fig. 3.8.1-(C). Reaction scheme of direct protonation of carbon basal planes.

Fig. 4.1-1. Composite isotherms $\left(25^{\circ} \mathrm{C}\right)$ for multi $-\mathrm{OH}$ compounds on heat-treated $\mathrm{F} 400$ carbon.

Fig. 4.2-1. Surface excesses of multi - $\mathrm{OH}$ solutes, alcohols, and regenerants onto the liquid-vapor interface $\left(25^{\circ} \mathrm{C}\right)$, as predicted by the Gibbs Adsorption Equation. $\quad 94$

Fig. 4.2-2. Composite uptakes $\left(25^{\circ} \mathrm{C}\right)$ of alcohols and multi $-\mathrm{OH}$ solutes on $\mathrm{F} 400$ carbon.

Fig. 4.3-1. Composite isotherms of sucrose on F400 carbons for several temperatures.

Fig. 4.3-2. Composite isotherms of ethylene glycol (EG) and propylene glycol (PG) on F400 carbon for several temperatures.

Fig. 4.3-3. Isosteric heat of adsorption of multi $-\mathrm{OH}$ compounds on $\mathrm{F} 400$ carbon as a function of loading.

Fig. 4.3-4. Isosteric heat of adsorption of alcohols on F400 carbon as a function of loading.

Fig. 4.4-1. Composite isotherms $\left(25^{\circ} \mathrm{C}\right)$ for ethylene glycol (EG) adsorbing onto $\mathrm{F} 400$ carbons with various surface treatments.

Fig. 4.4-2. Composite isotherms $\left(25^{\circ} \mathrm{C}\right)$ for propylene glycol (PG) adsorbing onto F400 carbons with various surface treatments.

Fig. 4.4-3. Composite isotherms $\left(25^{\circ} \mathrm{C}\right)$ for glycerol adsorbing onto $\mathrm{F} 400$ carbons with various surface treatments. 
Fig. 4.4-4. Composite isotherms $\left(25^{\circ} \mathrm{C}\right)$ for glucose adsorbing onto $\mathrm{F} 400$ carbons with various surface treatments.

Fig. 4.4-5. Composite isotherms $\left(25^{\circ} \mathrm{C}\right)$ for (monomeric) lactic acid adsorbing onto F400 carbons with various surface treatments.

Fig. 4.4-6. Composite isotherms $\left(25^{\circ} \mathrm{C}\right)$ for ethylene glycol (EG) adsorbing onto wood (WVB), extruded peat (RO 0.8), bituminous coal ( $\mathrm{F} 400)$, and pyrolyzed polymer (A572) based carbons.

Fig. 4.4-7. Composite isotherms $\left(25^{\circ} \mathrm{C}\right)$ for glucose adsorbing onto wood (WVB), extruded peat (RO 0.8), and bituminous coal (F400) based carbons.

Fig. 4.4-8. Composite isotherms $\left(25^{\circ} \mathrm{C}\right)$ for glucose adsorbing onto untreated and heattreated WVB carbon.

Fig. 5.3-1. Composite isotherms $\left(25^{\circ} \mathrm{C}\right)$ for $\mathrm{EG}$ and glycerol on $\mathrm{F} 400 / \mathrm{HT}$ carbon, from two different solvents.

Fig. 5.3-2. Composite and individual isotherms $\left(25^{\circ} \mathrm{C}\right)$ for $\mathrm{EG}$ on $\mathrm{F} 400 / \mathrm{HT}$ carbons.

Fig. 5.3-3. Composite and individual isotherms $\left(25^{\circ} \mathrm{C}\right)$ for $\mathrm{PG}$ on $\mathrm{F} 400 / \mathrm{HT}$ carbons.

Fig. 5.3-4. Composite and individual isotherms $\left(25^{\circ} \mathrm{C}\right)$ for glycerol on $\mathrm{F} 400 / \mathrm{HT}$ carbons.

Fig. 5.3-5. Composite and individual isotherms $\left(25^{\circ} \mathrm{C}\right)$ for sucrose on $\mathrm{F} 400 / \mathrm{HT}$ carbons.

Fig. 5.4-1. \%RE $\left(25^{\circ} \mathrm{C}\right)$ for sucrose-loaded $\mathrm{F} 400$ carbons as a function of initial displacer concentration.

Fig. 5.4-2. Acetone uptake $\left(25^{\circ} \mathrm{C}\right)$ with simultaneous sucrose displacement from $\mathrm{F} 400$ carbon, as a function of equilibrium acetone concentration.

Fig. 5.5-1. Reversible vs. composite uptake $\left(25^{\circ} \mathrm{C}\right)$ for "wet" vs. "dry" acetone regeneration of EG-loaded F400/HT carbons.

Fig. 5.5-2. Reversible vs. composite uptake $\left(25^{\circ} \mathrm{C}\right)$ for "wet" vs. "dry" methanol regeneration of EG-loaded F400/HT carbons.

Fig. 5.5-3. Reversible vs. composite uptake $\left(25^{\circ} \mathrm{C}\right)$ for "wet" vs. "dry" acetone regeneration of PG-loaded F400/HT carbons. 
Fig. 5.5-4. Reversible vs. composite uptake $\left(25^{\circ} \mathrm{C}\right)$ for "wet" vs. "dry" methanol regeneration of PG-loaded F400/HT carbons.

Fig. 5.5-5. Reversible vs. composite uptake $\left(25^{\circ} \mathrm{C}\right)$ for "wet" vs. "dry" methanol regeneration of glycerol-loaded F400/HT carbons.

Fig. 5.5-6. Composite isotherms $\left(25^{\circ} \mathrm{C}\right)$ for $\mathrm{EG}$ on $\mathrm{F} 400 / \mathrm{HT}$ carbons, with varying acetone content in the solvent.

Fig. 5.5-7. Composite uptake $\left(25^{\circ} \mathrm{C}\right)$ for $\mathrm{EG}$ on $\mathrm{F} 400 / \mathrm{HT}$ carbons at $\mathrm{X}_{\mathrm{f}}=0.06 \mathrm{~g} / \mathrm{g}$, plotted as a function of water content in the solvent.

Fig. 5.5-8. \%RE $\left(25^{\circ} \mathrm{C}\right)$ for $\mathrm{EG}$ on $\mathrm{F} 400 / \mathrm{H}$ 'T carbon, "wet" regenerated by acetone-water solutions, plotted as a function of phase ratio.

Fig. 5.5-9. \%RE $\left(25^{\circ} \mathrm{C}\right)$ for EG on F400/HT carbon, "dry" regenerated by acetone-water solutions, plotted as a function of phase ratio.

Fig. 6.1-1. TGA weight-change thermogram for F400/HT carbon loaded with EG $\left(\mathrm{q}=161 \mathrm{mg} / \mathrm{g}\right.$ ). Heating rate: $10^{\circ} \mathrm{C} / \mathrm{min}$.

Fig. 6.1-2. TGA derivative plot (of Fig. 6.1-1) with bare carbon reference.

Fig. 6.2-1. TGA derivative plots for acetone, methanol, and water on F400/HT carbon. Heating rate: $10^{\circ} \mathrm{C} / \mathrm{min}$.

Fig. 6.2-2. TGA derivative plots for (1) EG-loaded ( $q=23 \mathrm{mg} / \mathrm{g}$ ) F400/HT carbon, (2) Dry MeOH- regenerated F400/HT, and (3) bare carbon reference. Heating rate: $10^{\circ} \mathrm{C} / \mathrm{min}$.

Fig. 6.2-3. TGA derivative plots for (1) Wet acetone-regenerated F400/HT carbon, (2) Dry acetone-regenerated F400/HT carbon, and (3) bare carbon reference. Heating rate: $10^{\circ} \mathrm{C} / \mathrm{min}$. Original sample was EG-loaded ( $\mathrm{q}=113 \mathrm{mg} / \mathrm{g}$ ) F400/HT carbon. 174

Fig. 6.2-4. TGA derivative plots for (1) Wet MeOH-regenerated F400/HT zarbon, (2) Dry MeOH-regenerateá F400/HT carbon, and (3) bare carbon reference. Heating rate: $10^{\circ} \mathrm{C} / \mathrm{min}$. Original sample was EG-loaded ( $\mathrm{q}=155 \mathrm{mg} / \mathrm{g}$ ) F400/HT carbon. 175

Fig. 6.2-5. TGA derivative plots for (1) Wet acetone-regenerated F400/HT carbon, (2) Dry acetone-regenerated F400/HT carbon, and (3) bare carbon reference. Heating rate: $10^{\circ} \mathrm{C} / \mathrm{min}$. Original sample was $\mathrm{PG}-$ loaded (q=163 mg/g) F400/HT carbon. 176

Fig. 6.2-6. TGA derivative plots for (1) Wet MeOH-regenerated F400/HT carbon, (2) Dry MeOH-regenerated F400/HT carbon, and (3) bare carbon reference. Heating rate: $10^{\circ} \mathrm{C} / \mathrm{min}$. Original sample was $P G$-loaded ( $q=195 \mathrm{mg} / \mathrm{g}$ ) F400/HT carbon. 177 
Fig. 6.2-7. TGA derivative plots for (1) Loaded (from 0.82 wt.\% EG) F400/HT carbon, (2) Wet $\mathrm{MeOH}$-regenerated F400/HT carbon, (3) Reloaded (from 0.82 wt.\% EG), with (4) bare carbon reference. Heating rate: $15^{\circ} \mathrm{C} / \mathrm{min}$.

181

Fig. 6.2-8. TGA derivative plots for (1) Loaded (from 11 wt.\% EG) F400/HT carbon, (2) Wet MeOH-regenerated F400/HT carbon, (3) Reloaded (from 11 wt.\% EG), with

(4) bare carbon reference. Heating rate: $15^{\circ} \mathrm{C} / \mathrm{min}$.

182

Fig. 6.2-9. TGA derivative plots for (1) Loaded (from $0.89 \mathrm{wt} . \%$ glycerol) F400/HT carbon, (2) Wet MeOH-regenerated F400/HT carbon, (3) Reloaded (from 0.89 wt.\% glycerol), with (4) bare carbon reference. Heating rate: $15^{\circ} \mathrm{C} / \mathrm{min}$.

Fig. 6.2-10. TGA derivative plots for (1) Loaded (from 7.2 wt.\% glycerol) F400/HT carbon, (2) Wet MeOH-regenerated F400/HT carbon, (3) Reloaded (from 7.2 wt.\% glycerol), with (4) bare carbon reference. Heating rate: $15^{\circ} \mathrm{C} / \mathrm{min}$.

Fig. 6.3-1. TGA derivative plots for F400/HT carbon with varying degrees of EG loading, with bare carbon reference. Heating rate: $40^{\circ} \mathrm{C} / \mathrm{min}$.

Fig. 6.3-2. TGA derivative plots for EG-loaded on F400/HT ( $\mathrm{q}=23 \mathrm{mg} / \mathrm{g}$ ), WVB ( $\mathrm{q}=40$ $\mathrm{mg} / \mathrm{g})$, and $\mathrm{RO} 0.8(\mathrm{q}=53 \mathrm{mg} / \mathrm{g})$ carbons. Heating rate: $10^{\circ} \mathrm{C} / \mathrm{min}$.

Fig. 6.3-3. TGA derivative plots for EG-loaded on F400/HT ( $q=23 \mathrm{mg} / \mathrm{g}$ ), WVB ( $\mathrm{q}=40$ $\mathrm{mg} / \mathrm{g}$ ), and RO $0.8\left(\mathrm{q}=53 \mathrm{mg} / \mathrm{g}\right.$ ) carbons. Heating rate: $40^{\circ} \mathrm{C} / \mathrm{min}$.

Fig. 6.3-4. TGA derivative plots for EG-loaded on A563 ( $\mathrm{q}=31 \mathrm{mg} / \mathrm{g}$ ), A572 ( $\mathrm{q}=52$ $\mathrm{mg} / \mathrm{g}$ ), and A575 (q=43 $\mathrm{mg} / \mathrm{g})$. Heating rate: $10^{\circ} \mathrm{C} / \mathrm{min}$.

Fig. 6.3-5. TGA derivative plots for EG-loaded on A563 ( $\mathrm{q}=31 \mathrm{mg} / \mathrm{g}$ ), A572 ( $\mathrm{q}=52$ $\mathrm{mg} / \mathrm{g}$ ), and $\mathrm{A} 575(\mathrm{q}=43 \mathrm{mg} / \mathrm{g})$. Heating rate: $40^{\circ} \mathrm{C} / \mathrm{min}$.

Fig. 6.3-6. Plot of $T_{\max }$ vs. normal boiling point $\left(T_{n b p}\right)$ for various adsorbates, with data from Suzuki et al. (1977). Heating rate: $6-10^{\circ} \mathrm{C} / \mathrm{min}$.

Fig. 6.3-7. Plot of $T_{\max }$ vs. normal boiling point $\left(T_{n b p}\right)$ for various adsorbates, with data from Senf and Frank (1990). Heating rate: $20^{\circ} \mathrm{C} / \mathrm{min}$.

197

Fig. 6.3-8. Plot of $T_{\max }$ vs. normal boiling point $\left(T_{n b p}\right)$ for various adsorbates, on different adsorbents. Heating rate: $10^{\circ} \mathrm{C} / \mathrm{min}$.

Fig. 6.3-9. Plot of $T_{\max }$ vs. normal boiling point $\left(T_{n b p}\right)$ for various adsorbates, on different adsorbents. Heating rate: $20^{\circ} \mathrm{C} / \mathrm{min}$.

Fig. 6.3-10. TGA derivative plots for EG-loaded F400/HT carbon ( $q=23 \mathrm{mg} / \mathrm{g}$ ) at $10^{\circ} \mathrm{C}$, $20^{\circ} \mathrm{C}$, and $40^{\circ} \mathrm{C} / \mathrm{min}$, with bare carbon reference. 
Fig. 6.3-11. Linear regression to obtain first-order kinetic parameters for desorption. Data are for EG-loaded F400/HT (q=23 mg/g).

Fig. 6.3-12. Linear correlation of $E_{d}$ and molecular weight for all solutes in present study.

Fig. 7.2-1. Breakthrough curves for ethylene glycol (EG), propylene glycol (PG), and glycerol on F400/HT carbon.

Fig. 7.2-2. Effect of volumetric flowrate on the breakthrough curve of 5 wt. \% ethylene glycol (EG) on F400/HT carbon.

Fig. 7.2-3. Comparison of breakthrough curve of 5 wt. \% ethylene glycol on Ambersorb 572 versus F400/HT carbon.

Fig. 7.3-1. Elution curves for ethylene glycol (EG), propylene glycol (PG), and glycerol on F400/HT carbon.

Fig. 7.3-2. Fixed-bed solvent regeneration ( $85 \mathrm{wt} . \%$ acetone) of sucrose from F400/HT carbon.

Fig. 7.3-3. Fixed-bed solvent regeneration ( $75 \mathrm{wt} . \%$ methanol) of sorbitol from F400/HT carbon.

Fig. 7.3-4. Local-equilibrium analysis for fixed-bed methanol regeneration of glycerol from $\mathrm{F} 400 / \mathrm{HT}$ carbon

Fig. 7.4-1. TGA derivative plot for an (originally) EG-loaded F400/HT carbon, regenerated by $\mathrm{MeOH}$ in a fixed bed. Heating rate: $10^{\circ} \mathrm{C} / \mathrm{min}$.

Fig. 7.5-1. Calculated energy requirements for separation by complete solvent evaporation.

Fig. 7.6-1. Effect of surface oxidation on the focusing effect of ethylene glycol (EG) on F400 carbon.

Fig. 7.6-2. Effect of volumetric flowrate on the focusing effect of ethylene glycol (EG) on F400/HT carbon.

Fig. 7.6-3. Effect of particle-size distribution on the focusing effect of ethylene glycol (EG) from F400/HT carbon.

Fig. 7.6-4. Comparison of ethylene glycol (EG) focusing by acetone for beds packed with Ambersorb 572 versus F400/HT carbon. 
Fig. 7.7-1. Bed capacity of F400/HT carbon for ethylene glycol (EG) up to 10 loading cycles (acetone as regenerant).

Fig. 7.7-2. Effluent analysis showing residual acetone throughout all 10 loading cycles.

Fig. 7.7-3. Bed capacity of F400/HT carbon for ethylene glycol (EG) up to 4 loading cycles (methanol as regenerant).

Fig. 7.8-1. Elution profile of a F400/HT bed loaded from 4.7 wt. \% sucrose/ 4.2 wt. \% glycerol, regenerated by $50 \mathrm{wt}$. \% ethanol.

Fig. 7.8-2. Elution profile of a F400/HT bed loaded from $4.5 \mathrm{wt}$ \% propylene glycol (PG) $/ 4.3$ wt. \% glycerol, regenerated by $50 \mathrm{wt}$. \% acetone.

Fig. 7.8-3. Elution profile of a F400/HT bed loaded from $6.7 \mathrm{wt}$. \% propylene glycol (PG)/ 5.2 wt. \% glycerol, regenerated by 2 wt. \% acetone.

Fig. 7.8-4. Elution profile of a F400/HT bed loaded from $4.2 \mathrm{wt}$ \% propylene glycol (PG)/ 3.7 wt. \% glycerol, regenerated by 5 wt. \% acetone.

\section{List of Tables}

Tab. 1.2-1. Relative volatility of a $5 \mathrm{wt}$. \% glycol and glycerol solution.

Tab. 1.5-1. Some physical properties of multi $-\mathrm{OH}$ ccmpounds.

Tab. 2.1-1. Adsorbent source material and activation.

Tab. 2.3-1. HPLC columns and operating conditions.

Tab. 2.3.4-1. Constants $(j=5)$ for the Lagrange 11-point differentiation formula. 46

Tab. 3.2-1. Pore volume in carbons accessible to water. 65

Tab. 3.2-2. Physical properties of Ambersorbs (Rohm and Haas, 1992). 66

Tab. 3.3-1. BET parameters and surface areas of carbons. 69

Tab. 3.4-1. Bulk elemental analysis of active carbons (Kilduff and King, 1997). 72

Tab. 3.4-2. Bulk elemental analysis of Ambersorbs. 
Tab. 3.5-1. Acidic site densities for carbons.

Tab. 3.5-2. Basic site densities for carbons.

Tab. 4.2-1. Activity coefficient data $\left(25^{\circ} \mathrm{C}\right)$ for solutes in aqueous solution.

Tab. 4.2-2. Surface tension data $\left(25^{\circ} \mathrm{C}\right)$ for aqueous systems.

Tab. 4.2-3. Relative contributions of surface interactions to adsorption $\left(25^{\circ} \mathrm{C}\right)$.

Tab. 4.3-1. Parameters for calculating heats of adsorption.

103

Tab. 5.3-1. Activity coefficient data for solutes in nonaqueous systems.

Tab. 5.4-1. Candidate solvents for regeneration of carbons.

Tab. 5.4-2. Sucrose solubility $\left(25^{\circ} \mathrm{C}\right)$ in acetone-water mixtures.

Tab. 6.2-1. TGA for wet vs. dry regeneration of glycol-loaded F400/HT carbon. 178

Tab. 6.2-2. TGA for reloading of EG and glycerol on F400/HT carbon.

Tab. 6.3-1. Effect of heating rate on $\mathrm{T}_{\max }$ of EG-loaded F400/HT carbon.

Tab. 6.3-2. Thermal desorption parameters of solutes loaded on F400/HT carbon. 207

Tab. 6.3-3. Thermal desorption parameters of solutes loaded on other carbons. 207

Tab. 7.2-1. Fixed-bed operating parameters for data in Fig. 7.2-1.

Tab. 7.3-1. Local-equilibrium analysis for glycerol recovery by methanol regeneration: parameters.

Tab. 7.4-1. Completeness of fixed-bed regeneration.

Tab. 7.4-2. Comparison between fixed-bed and batch loading.

Tab. 7.5-1. Recovery of eluted solute from fixed-bed regeneration.

Tab. 7.6-1. Fixed-bed operating parameters for data in Fig. 7.6-1.

Tab. 7.6-2. Fixed-bed operating parameters for data in Fig. 7.6-4.

Tab. 7.7-1. Water usage during rinse stages of fixed-bed cycling, for acetone regeneration of EG-loaded F400/HT bed. 


\section{Chapter 1. Introduction}

\subsection{Industrial Applications}

There are numerous cases where the need arises for the removal and/or recovery of multiple hydroxyl-bearing $(-\mathrm{OH})$ compounds from aqueous solution. Streams that contain compounds such as glycerol, glycols, and sugars are found in many industries. Sugars come from natural sources, and appear in both process and waste streams from beet and cane sugar refineries, canneries, wineries, distilleries, and breweries. Ethylene and propylene glycols are petrochemical products and appear in many waste streams as well. There is a large-scale need to recover ethylene glycol from spent aircraft deicer and from anti-freeze and coolants for motor vehicles. Glycerol is produced in dilute aqueous solution from soap manufacturing and from processing of fats and oils. The processing of grains also produces glycerol, glycols, and sugars in waste streams.

The wet corn-milling and fermentation industries, which have been explored for the production of glycols and glycerol, would also need an effective recovery process for multi - $\mathrm{OH}$ compounds. In wet corn milling, starch is first hydrolyzed into a mixture of monosaccharides, which could be used as a feedstock for fermentation and/or chemical conversion processes (Busche, 1985). The catalytic hydrogenation of sorbitol to produce ethylene and propylene glycols, lactic acid, and glycerol with various selectivities was recently reported by Tronconi et al. (1992). Glycerol may also be produced by the direct

fermentation of sugar, in the presence of yeast and alkaline sulfites (Lawrie, 1928). Since the products in the fermentation broth are typically dilute (1-5 wt. \%), the large-scale 
commercialization of a fermentation process is largely dominated by economics of the recovery method (Busche, 1983).

\subsection{The Separation Problem}

Despite all of these instances where recovery of multi $-\mathrm{OH}$ compounds from water is required, the actual separation process proves to be a challenging one. Most of the difficulties associated with the separation are due to the hydrophilic nature of multi-OH compounds. Glycols and glycerol are miscible with water in all proportions and are especially difficult to remove because of low volatility and inability to form a solid phase readily. Sugars are also highly soluble in water; for example, $204 \mathrm{~g}$ of sugar can dissolve in $100 \mathrm{~g}$ of water at $20^{\circ} \mathrm{C}$ (Wankat, 1994). Table $1.2-1$ below lists the normal boiling points of the glycols and glycerol, along with the relative volatility of water to solute $\left(\alpha_{w s}\right)$ for a $5 \mathrm{wt} . \%$ aqueous solution.

TABLE $1.2-1$

Boiling Points and Relative Volatility of a $5 \mathrm{wt}$. \% Glycol and Glycerol Solution

\begin{tabular}{|c|c|c|}
\hline COMPOUND & $\mathrm{T}_{\mathrm{bp}}\left({ }^{\circ} \mathrm{C}\right)$ & $\alpha_{\mathrm{WS}}{ }^{*}$ \\
\hline Ethylene Glycol & 198 & 334 \\
\hline Propylene Glycol & 187 & 197 \\
\hline Glycerol & 290 & Essentially Infinite** \\
\hline
\end{tabular}

*Data for calculations taken from Gmehling, J. et al. (1988) and Smith and Van Ness (1987).

**A vapor pressure of $0 \mathrm{~mm} \mathrm{Hg}$ was assigned to glycerol at $27.85^{\circ} \mathrm{C}$ (Lawrie, 1928).

As suggested in Table 1.2-1 the separation of glycols and glycerol from dilute aqueous solution by vaporization requires evaporation of all the water, and is therefore highly 
energy intensive. Evaporation is currently the separation method of choice in the manufacture of glycol, glycerol, and sugar. However, because of the greater dilution of the feeds and the presence of other heavy substances, evaporation would be prohibitively expensive for fermentation processes (Busche, 1983) and for recovery from dilute waste streams.

The challenge is therefore to develop a method of separation to remove the multi $-\mathrm{OH}$ solute from aqueous solution selectively. The interactions between the separating agent and the multi $-\mathrm{OH}$ solute should be reversible, yet sufficiently strong in comparison with both water-solute and water-agent interactions. A high selectivity is important, since many streams containing glycols, glycerol, and sugars will frequently have nonvolatile impurities as well (salts, heavy metals, etc.). In order for such a process to be economically feasible, there should be minimal consumption of chemicals with a concurrent reduction or elimination of the energetic penalty associated with evaporating all of the solvent, water. Also, in the product, the compound of interest should be significantly more concentrated than in the feed.

\subsection{Methods of Separation}

\subsubsection{Traditional Method: Evaporation of Water}

By far, the most common industrial-scale method of separating glycols, glycerol, and sugars from water is evaporation. Since its invention in 1846 , the multiple-effect evaporator has been universally used in industry to evaporate water (Clarke, c19911998). Performing the evaporation with multiple effects allows for substantial energy 
savings, since the overhead vapor in the first, high-pressure stage provides energy for the subsequent stages. In both glycerol and glycol production, the final stage of product refining is done by steam-vacuum distillation (Morrison, c1991-1998; Forkner et al., c1991-1998).

As noted in a recent study in Germany (Jehle et al., 1995), multiple-effect evaporation is currently used to recover ethylene glycol from coolant liquids. Aqueous streams consisting of 20-40 wt. \% ethylene glycol are first passed through a multi-stage distillation process at atmospheric or reduced pressure. For the final stage, a thin-film vacuum evaporator separates the glycol overhead from the nonvolatile materials (e.g. oils and heavy metals). Research in glycol recovery is ongoing in Germany due to the high costs of waste treatment by incineration, $1500-3500 \mathrm{DM} /$ ton, or $\$ 869-\$ 2028 \mathrm{US} /$ ton (Jehle et al., 1995).

Despite being one of the most energy-intensive operations, evaporation will likely remain a prominent separation method in sugar processing. Nevertheless, much research effort is still devoted to increasing the efficiency of sugar recovery. Energy savings and capacity increases in sugar production could also be realized through the addition of process chemicals (Cuddihy et al., 1997). Some examples of process chemicals are biocides for milling, antiscalants for evaporators, and surfactants for crystallizers. 


\subsubsection{Novel Methods of Separation}

\subsubsection{Membrane Processes}

Two separation processes of increasing interest are based on using membranes: reverse osmosis (RO) and pervaporation (PV). In RO, high pressure is applied to the feed solution to force the flow of solvent through a semi-permeable membrane, against the normal direction of osmosis. $\mathrm{RO}$ is suited to removal of water from low-concentration feeds. In PV, one component diffuses through the membrane as a liquid and vaporizes on the other side, where a sweep gas or vacuum is applied. PV is suited to remove water from solutions with high solute content.

A glycol recovery process combining evaporation, RO, and PV was recently developed at the laboratory and bench scale by Jehle et al. (1995). The authors used a water-selective Polyvinyl Alcohol/Polyacrylonitrile (GFT) membrane for the PV process and a highrejection FT30HR (FilmTec) membrane for the RO process. A coolant solution containing $25 \mathrm{wt} . \%$ ethylene glycol is first evaporated, with $70 \mathrm{wt} . \%$ glycol as the bottoms product. The bottoms stream is then concentrated through PV, with the retentate product up to $95 \mathrm{wt}$ \%, which is suitable for reuse. Both the overhead product $(0.5 \mathrm{wt}$. $\%$ ) from the evaporation stage and the permeate product (1 wt. \%) from the PV stage are fed to the RO process. Finally, the permeate product of the RO process is sufficiently dilute $(0.05 \mathrm{wt} . \%)$ for waste disposal, while the retentate product $(7 \mathrm{wt} . \%)$ is recycled back to the evaporation stage. Overall, the authors reported an economical advantage over a purely evaporative process. 
Membrane separation processes are generally advantageous in terms of energy utility. However, they may prove problematic in the case of dilute solutions. From the above study RO was able to concentrate glycol (in the retentate stream) by several fold, yet an energetic penalty for removing a large amount of water remains. There are further, more fundamental issues associated with membrane processes: concentration polarization of solute (Wankat, 1994), membrane durability and permeability, and cost (Busche, 1983).

\subsubsection{Complexation with Ion-Pair Extractants}

In traditional liquid-liquid extraction, the solute in the aqueous phase is preferentially solubilized by another, water-immiscible solvent. Separation of the solute from the extract is then effected by distillation. In cases where the solvent is more volatile than water, extraction processes result in exchanging the boil-up of solvent for the boil-up of water.

Unfortunately, the hydrophilic nature of glycerol, glycols, and sugars greatly hampers finding any suitable solvent for effective extraction. At $25^{\circ} \mathrm{C}$, the partition coefficients of these solutes in solvents such as 2-ethylhexanol and diisobutyl ketone range from 0.006 to 0.08 (Randel et al., 1994; Broekhuis et al., 1996). To comlat this limitation, previous researchers in our laboratory (Randel et al., 1994; Broekhuis et al., 1996) have enhanced the degree of extraction by adding a complexing agent, organoboronate, to the solvent.

In this new extraction scheme, an organoboronate anion is paired with an organic cation 
(Aliquat 336) in the organic phase (2-ethylhexanol). The organoboronate achieves its selectivity by a steric effect; it targets the cis-vicinal - $\mathrm{OH}$ groups of the glycol, something that water cannot do. The actual complexation mechanism for propylene glycol (PG) is shown schematically in Figure 1.3.2-A, where a planar, five-member ring structure is formed with the elimination of the two hydroxyl groups in the form of water.

To recover the original glycol product, the organoboronate is protonated into its original form by acidification (e.g. with $\mathrm{CO}_{2}$ or mineral acids), causing release of $\mathrm{PG}$ into the aqueous phase. The extractant can be regenerated by stripping $\mathrm{CO}_{2}$ with nitrogen at high temperatures or by contact with a high-pH aqueous solution. Although the scheme in Figure 1.3.2-A is shown for PG, stoichiometric (1:1) extraction of other cis-vicinal diols such as fructose, glycerol, and sorbitol into the organic phase has been demonstrated by Randel et al. (1994). Broekhuis et al. (1996) observed stoichiometric overloading (> 1:1) of PG in several organoboronate/diluent systems. This phenomenon was attributed to aggregation of the ion-pair extractant (i.e., formation of reverse micelles) in the organic phase.

The above method has the great advantage of being selective for the multi $-\mathrm{OH}$ solute. However, the extractant-regeneration step, as it is developed so far, has several shortcomings. First, recovery of PG was observed to be incomplete (ca. $80 \%$ ) with backextraction into water. Second, the temperature needed for stripping the $\mathrm{CO}_{2}$ results in a substantial loss (ca. $-40 \%$ ) of extractant capacity. Regeneration by basic solutions avoids such degradation, at the expense of adding more chemicals and potential risk of 


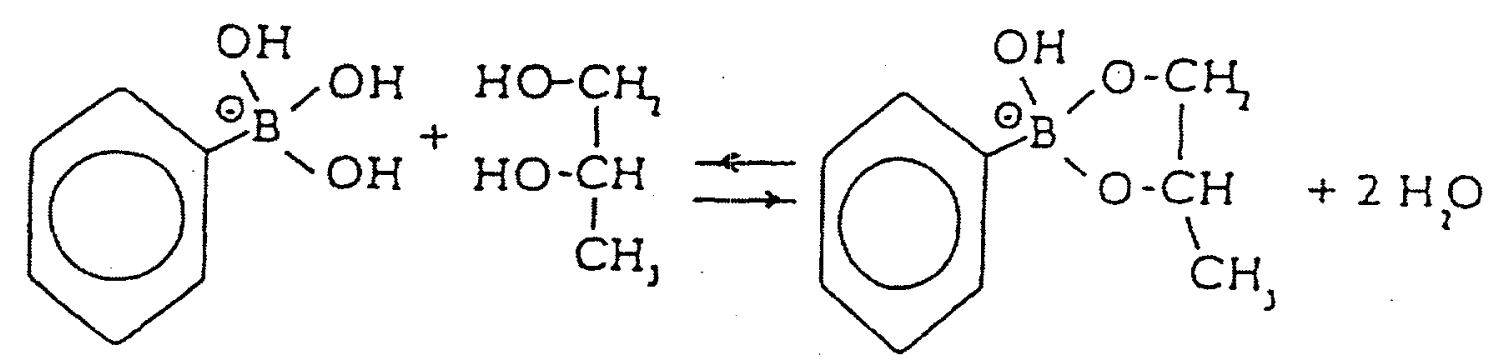

(A)

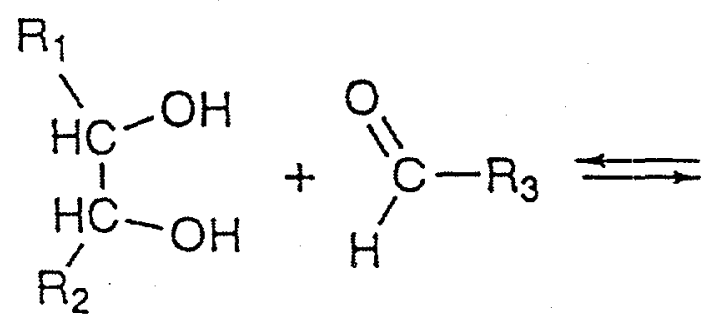<smiles>[R7]C1OC([13CH2]O[18OH])OC1[R2]</smiles>

(B)

Figure 1.3.2-(A) Mechanism of organoboronate complexation with propylene glycol (Broekhuis et al., 1996). (B) Reversible chemical reaction between aldehyde and cisvicinal glycol (Broekhuis et al., 1994). 
coextracting the organoboronate along with the $\mathrm{CO}_{2}$ (Broekhuis et al., 1996).

\subsubsection{Complexation by Reversible Reaction}

Another strategy for selectively removing glycols from water is to react them reversibly to form a product that lacks hydroxyl or polar groups. One possible scheme is shown in Figure 1.3.2-B, where a cis-vicinal glycol (e.g. PG) and an aldehyde are reacted under acidic conditions to form a more volatile compound, a dioxolane (Broekhuis et al., 1994). The glycol product is then recovered by hydrolysis of the dioxolane, with concurrent recycle of the aldehyde reagent.

Broekhuis et al. (1994) studied the equilibrium, kinetics, and process simulations for the reversible reaction of PG with formaldehyde and acetaldehyde. Due to unfavorable chemical and phase equilibria, the authors recommended a process combining reaction with extraction into an organic solvent, as being preferable to reactive distillation. The extractive route has the advantage of overcoming the problem of high volatility of the aldehyde reagent. Simulations using ChemCAD ${ }^{\mathrm{TM}}$ (Chemstations, Inc.) showed that such a process requires $42 \%$ of the energy needed for a triple-effect evaporation process (Broekhuis et al., 1994).

Although they are not yet sufficiently developed for commercial use, separation methods based on reversible reaction appear to be technically feasible. However, the reduced energy load would be offset to some degree by increased capital and reagent costs. Also, extra care must be exercised to insure that reaction byproducts do not form and 
accumulate anywhere in the process. As with the ion-pair extraction process, a substantial amount of water would still have to be evaporated overhead in the final glycol purification stage.

\subsubsection{Sorption Technology: Fractionation of Sugars}

Adsorption processes have traditionally been used to remove contaminants from liquid streams. The use of liquid-phase adsorption for the separation of bulk liquids on a commercial scale is a relatively new concept. One of the first commercial adsorption processes for bulk separations was the 1964 UOP Molex process for recovery of $n$ parrafins (Gembicki et al., c1991-1998). Currently, a commercial adsorption method to recover multi-OH compounds such as glycerol and glycols does not appear to have been developed. However, there has been substantial work with adsorption systems for the recovery of sugars in complex mixtures.

Carbohydrates are capable of forming stable complexes with alkali and alkaline-earth metals. Differences in the solubility or stability of these complexes can permit largescale separation of one carbohydrate from another (Rendleman, 1966). The most common adsorbents use ${ }^{1}$ for large-scale sugar separation are zeolites and cationexchange polymeric resins (Gembicki et al., c1991-1998). In fructose recovery, most of these adsorbents will be in the $\mathrm{Ca}^{2+}$ form, although one type of zeolite in the $\mathrm{K}^{+}$form showed selectivity for glucose over fructose (Gembicki et al., c1991-1998).

Since 1978, the UOP Sarex process has been used to recover fructose from aqueous 
solutions of fructose, glucose, and polysaccharides (Gembicki et al., c1991-1998). The demand for fructose is largely driven by the use of high-fructose corn syrup (HFCS) in the soft-drink industry. In another study, a semi-continuous chromatographic system (based on a $\mathrm{Ca}^{2+}$ charged resin) was used to separate fructose from a stream of inverted sugar beet molasses (Barker and Joshi, 1991). Since cations from the beet molasses displaced the $\mathrm{Ca}^{2+}$ ions from the resin (thereby lowering the capacity), the authors suggested addition of a calcium nitrate solution between cycles to maintain the calcium form of the resin.

Ion-exchange methods appear to be well suited for fractionation among sugars. However, these methods may not be effective or economical for recovery from dilute solutions. Also, the formation of metal complexes appears to be characteristic of carbohydrates, and not of other related multi-OH compounds such, as glycols and glycerol. This research explores the possibility of using activated carbon, which has proven in the past to be applicable to many compounds, as an adsorbent for multi-OH compounds.

\subsection{General Description of Activated Carbons}

In this section, we present a brief overview of what activated carbon is, how it is manufactured, and some of its fundamental characteristics. Several texts offer more detailed descriptions (Bansal et al., 1988; Jankowska et al., 1991). Also included is some of the earlier experimental work that has provided motivation for using carbons in our work with multi $-\mathrm{OH}$ compounds. 


\subsubsection{Manufacture}

Active carbon is best described as an amorphous, carbon-based material that is manufactured to possess a high degree of porosity and large internal surface area. It is made in a two-step process: (1) pyrolysis of virtually any organic raw material (coal, wood, petroleum, peat, etc.) at high temperature in the absence of oxygen, and (2) activation by steam or chemical agents. The pyrolysis step eliminates volatile materials from the carbons and results in an irregular pattern of aromatic sheets with interstices that give rise to pores. In the activation step, the porous structure becomes more developed with further generation of pores of random shape and size. It is during this latter step that active carbons develop such high internal surface areas (ca. $1000 \mathrm{~m}^{2} / \mathrm{g}$ ).

\subsubsection{Physical and Chemical Structures}

Figure 1.4-1 shows a schematic representation that contrasts the structures of (a) graphite and (b) activated carbon. Both are characterized by layers of linked aromatic units, although the activated carbon has a disordered, "turbostratic" structure. This irregular ordering of aromatic rings leads to the random positioning of electron clouds and to the creation of unpaired electrons and incompletely saturated vacancies (Bansal et al., 1988). The overall structure of active carbon is, thus, said to be heterogeneous. its properties as an adsorbent for a wide variety of both gases and liquid are largely attributed to its unique structure.

Active carbons also possess a chemical structure as well. Depending on the raw material and method of activation, various heteroatoms (hydrogen, oxygen, nitrogen, sulfur, etc.) 

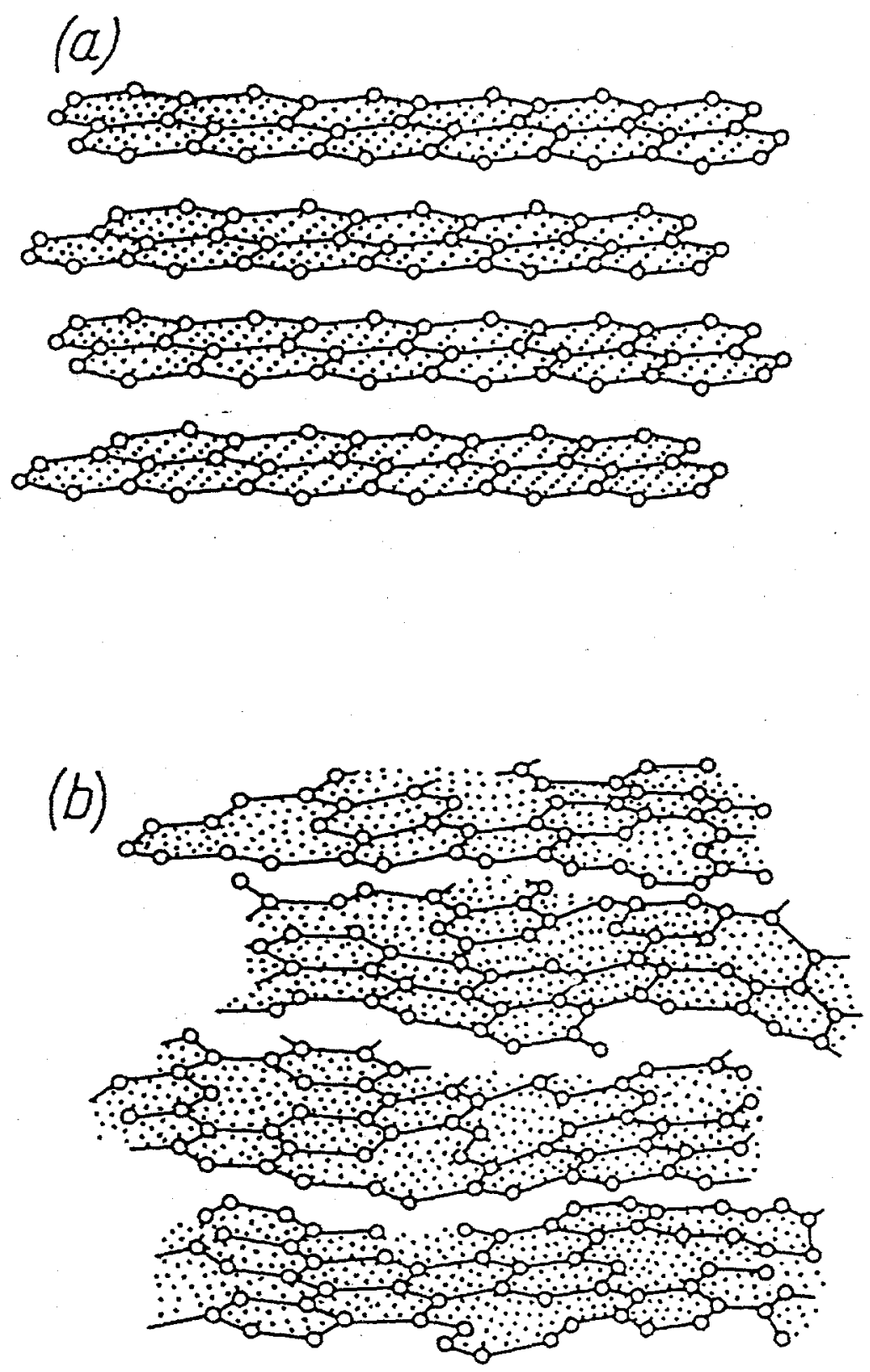

Figure 1.4-1. Structural representation of (a) graphite and (b) activated carbon (Jankowska et al., 1991). 
may be found in active carbons. Typically, these heteroatoms will form stable surface complexes near the edges of the aromatic layers, although some elements such as oxygen have been known to be incorporated in the basal planes. There is a substantial amount of research devoted to the study of these surface groups and the roles they play in adsorption. Chapter 3 discusses the structures and properties of these surface groups, as determined from both spectroscopic and chemical analyses.

\subsubsection{Economic Aspects and Uses}

Activated carbons are used on a global basis for a large number of applications. In 1990, the world production capacity of active carbon (excluding China and Eastern European nations) was approximately 375,000 metric tons (Baker et al., c1991-1998). About 40\% of this amount was produced by the United States, where most (ca. $80 \%$ ) of the active carbons were used in liquid-phase applications. Compared to most synthetic adsorbents, active carbons are relatively inexpensive, with most prices in the range of $\$ 0.70$ to $\$ 5.50 / \mathrm{kg}$ (Baker et al., c1991-1998).

Figure 1.4-2 shows the 1987 uses of liquid-phase activated carbon in the United States (Baker et al., c1991-1998). As expected, most of the applications are associated with the removal of impurities from aqueous solution. The types of impurities removed are as diverse as the number of applications, ranging across halogenated pollutants and volatile organic compounds (VOCs), dyes and odors, caffeine, and even blood and stomach toxins (Baker et al., c1991-1998). A classical example of using carbons to recover an inorganic compound is the adsorption of gold (as a cyanide complex) from low-grade 


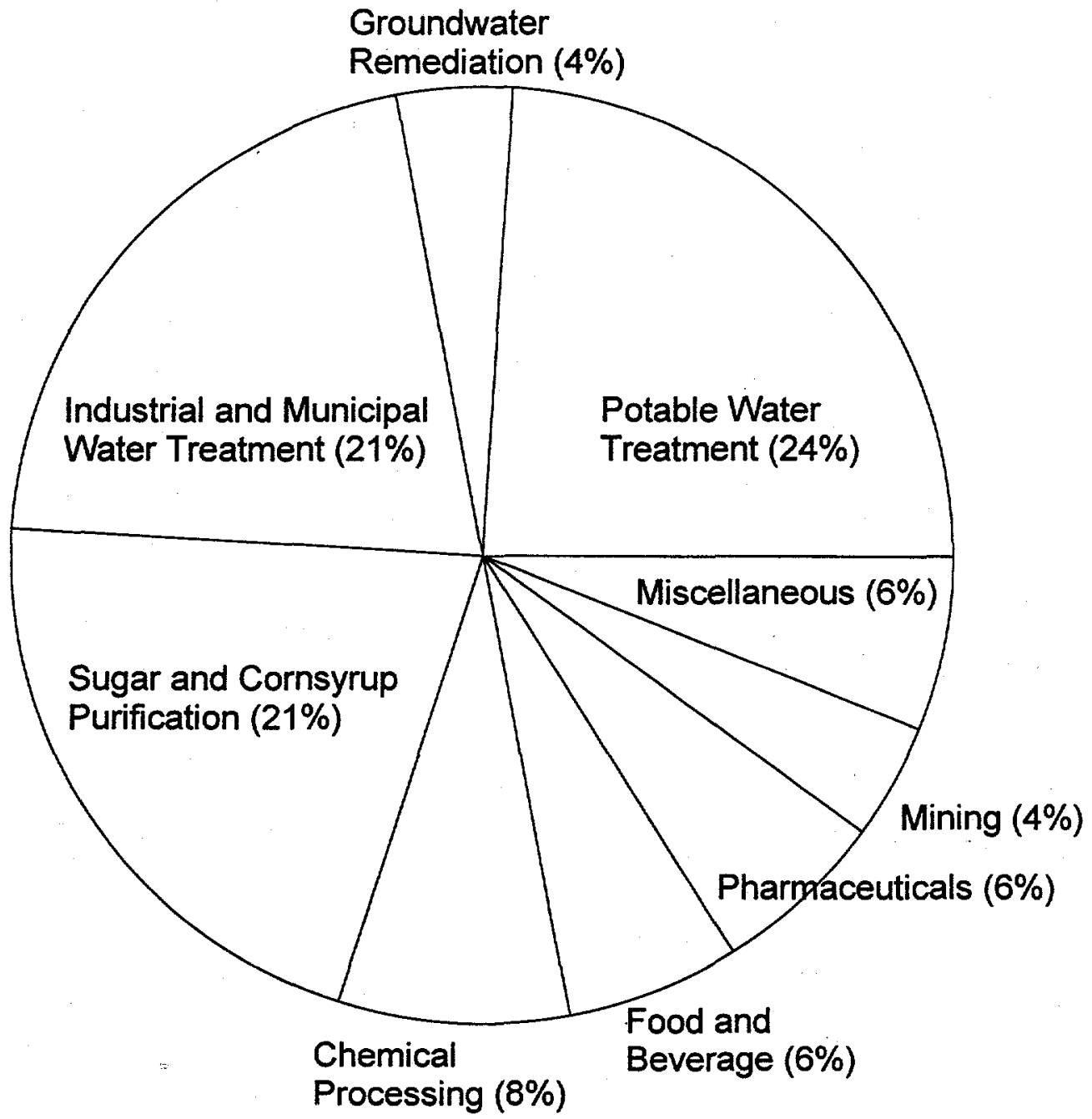

Figure 1.4-2. Pie chart showing 1987 usage of active carbons (by liquid-phase application) in the United States (Baker et al., c1991-1998). 
ores.

\subsubsection{Liquid-Phase Adsorption on Carbons}

\subsubsection{General Observations}

Most researchers agree that the ability of carbons to adsorb a wide variety of compounds is attributed to: (1) physical adsorption of the compounds onto the surface, and (2) the lack of affinity of the compounds for the solvent. For these reasons, chlorinated-organic solvents and aromatic compounds are more effectively adsorbed than water-soluble compounds such as alcohols and aldehydes (Stenzel, 1993). Many researchers also report greater degrees of adsorption with increasing molecular weight of the solute (Abe et al., 1981; Jankowska et al., 1991).

The chemical nature of the carbon can also play a large role in adsorption from solution. The literature regarding the effect of surface oxides on the adsorption of various compounds is quite large. As will be discussed in Chapter 3, these surface groups may have acidic or basic properties, and will affect the degree of adsorption differently depending on the nature of the solute. Reviews on the effects of surface chemistry on the adsorption of compounds such as cationic/anionic dyes, aromatics, fatty acids, surfactants, amino acids, and hydrocarbons are given by Cookson (1975) and Bansal et al. (1988). Some of the mechanistic insights on adsorption gained from these studies is discussed in more detail in Chapter 4.

In addition to the affinity of the adsorbate for the surface, the effects of both solution- 
phase interactions and surface chemistry make adsorption from solution considerably more complicated than gas adsorption. Nevertheless, several researchers have attempted to draw parallels between adsorption from vapors and adsorption from solution. Others have attempted to describe liquid-phase adsorption from rigorous application of thermodynamics and statistical mechanics. Although each method or theory has its own shortcomings, collectively they allow for the prediction of equilibrium data to some degree. We now briefly explore some of the better-known adsorption theories.

\subsubsection{Adsorption Theory - Polanyi Model}

The Polanyi theory was originally developed as a "pore-filling" model for gas adsorption (Polanyi, 1916), but has been modified to describe adsorption from solution (Hansen and Fackler, 1953). In the model, a temperature-independent adsorption potential ( $(\varepsilon)$ exists at any point in the proximity of the solid surface. The adsorption potential is related to the lowering of the potential energy of the solute, which results from dispersive interactions with the surface. Points with the same $\varepsilon$ form equipotential surfaces that together with the solid surface enclose an "adsorption space" of volume $V(\varepsilon)$. The plot of $V(\varepsilon)$ vs. $\varepsilon$ for a single vapor adsorption isotherm is called a characteristic curve of the adsorbent. Combined with an appropriate scaling factor that is related to the polarizabilites of the solute and solvent, the characteristic curve may be used to predict isotherms for all other compounds. Researchers have used this model to predict isotherms for adsorption of partially-miscible (Wohleber and Manes, 1971a), miscible (Wohleber and Manes, 1971b), and solid-phase solutes (Rosene and Manes, 1976) from aqueous solution. Although the Polanyi theory claims the ability to predict isotherms for the full range of 
concentrations, it does have several shortcomings. Being a model based entirely on dispersion forces between solute and surface, the Polanyi model does not correlate well for highly-polar compounds such as acetic acid and dioxane (Wohleber and Manes, 1971b). Deviations from Polanyi model were attributed to specific interactions with the carbon surface. Other researchers have questioned the thermodynamic origin of the theory and the fact that it arbitrarily divided. solutes into solid, partially-miscible, and completely miscible. This arbitrary division does not seem to provide a uniform account for the adsorption process, which must ultimately depend on molecular forces (Radke and Prausnitz, 1972).

\subsubsection{Adsorption Theory - Thermodynamic Models}

Other researchers have attempted to develop "generalized isotherms" from a rigorous thermodynamic and statistical mechanical basis. Radke and Prausnitz (1972) developed a new three-parameter empirical equation for fitting isotherms $\left(25^{\circ} \mathrm{C}\right)$ of several compounds in the concentration range of $10^{-5}$ to $10^{-1} \mathrm{M}$. From the data, the authors established a semiquantitative, corresponding-states correlation that was based on lateral solute-surface and parallel solute-solute mean-force interactions. Data for p-cresol and pchlorophenol on carbons did not coincide with the generalized plots for propionitrile, acetone, and 2-propanol. This was attributed to specific interactions between the aromatic compounds and the carbon surface.

\subsubsection{Adsorption Theory - Linear Solvation Energy Model}

Several models were developed to predict the relative adsorbabilities of various solutes 
onto carbon, rather than entire isotherms. Kamlet et al. (1985) described the adsorption capacity (at infinite dilution) of 37 different aliphatic solutes onto a Pittsburgh CAL activated carbon, based on solvatochromic parameters of the solute:

$$
\begin{gathered}
\log (\mathrm{A})=-1.93+\frac{3.06 \mathrm{~V}}{100}+0.56 \pi^{*}-3.20 \beta \\
\mathrm{r}=0.974
\end{gathered}
$$

where $\mathrm{A}$ is the ratio of the amount adsorbed $(\mathrm{mg} / \mathrm{g})$ to the equilibrium concentration in solution $(\mathrm{mg} / \mathrm{L})$ at infinite dilution; $\mathrm{V}$ is the solute molar volume $\left(\mathrm{cm}^{3} / \mathrm{mol}\right) ; \pi^{*}$ is a dimensionless parameter that scales solute dipolarity/polarizability, and $\beta$ is a dimensionless parameter that scales solute hydrogen bond acceptor (HBA) basicities. The correlation has several interesting trends that are consistent with experimental observations. Compounds with lower solubility in water (high $V$ or small $\beta$ ) exhibit greater adsorbability. In addition, compounds with high values of $\pi^{*}$ (which actually favors solubility) will also exhibit greater adsorbability. The correlation can accommodate multi-functional solutes with additional modifications but fails for aromatic compounds. The latter case may be attributed to additional specific interactions with the surface, a phenomenon that appears to have greatly hampered the modeling process for many researchers.

\subsubsection{Adsorption Theory - A Summary}

A unifying theory to describe adsorption of all compounds from solution is clearly not yet 
available. Although some models do manage to predict equilibrium data for a limited number of solutes, the important effects of specific interactions between the adsorbate and surface (i.e., the role of surface chemistry) cannot be ignored. The adsorption process is also largely dictated by the nature of the solute as well. In the case of multifunctional solutes (such as sugars and glycols), several factors other than dispersion forces may influence their uptakes onto carbons. Therefore, much of the future research on adsorption from solution will continue to rely on experimentation.

\subsubsection{Motivation for Using Carbons in This Research}

\subsubsection{The Research Challenge}

Given the hydrophilicities of multi -OH compounds, it is somewhat surprising that they are adsorbed as well as they are from water by carbons. One objective of the present research was to determine the rationales for the degrees of uptake. There are several other important issues that should be addressed in working with carbons. With the exception of phenol and its derivatives, the mechanism of adsorption for multi-functional compounds remains an unexplored area. A huge body of equilibrium data exists in the literature for various compounds adsorbing onto carbons, yet results are largely correlated to empirical curve-fit equations. Consequently, there is little or no physico-chemical basis for the selection or design of carbons to achieve a desired liquid-phase separation. Published work with carbons is also scarce with regards to engineering issues, such as regenerability or reuse of the carbons, and recovery of the adsorbed solute. 


\subsubsection{Some Preliminary Results}

Evidence of carbons having some affinity for sugars has been available since the pioneering days of liquid chromatography. Columns packed with carbons were capable of fractionating among an aqueous mixture of mono- to hexa-saccharides, using ethanol as a developer (Binkley, 1955). These early results suggested that the adsorption of sugars was reversible.

Actual equilibrium data for sugars adsorbing onto active carbon, where available, have demonstrated a substantial uptake capacity. Abe et al. (1983) measured adsorption isotherms of 13 saccharides and 4 polyhydric alcohols onto a single type of carbon. They attempted to correlate parameters in the adsorption equations to physical properties of the solutes, such as molecular refraction, and the number of carbon and oxygen atoms. Reisinger and King (1994) measured adsorption of glucose onto 15 different activated carbons, and observed significant differences in capacity among carbons. At an equilibrium glucose concentration of $1 \mathrm{wt} . \%$, the capacities ranged from $15-200 \mathrm{mg}$ glucose/g dry carbon. For some of the carbons, the adsorption and desorption isotherms were superimposable, which is consistent with the notion of reversibility: A recent article showed comparable adsorption isotherms of 1,3-propanediol on an active carbon and silica zeolite (Schlieker et al., 1992).

These studies suggest that activated carbons are promising adsorbents for recovery of sugars from dilute aqueous solution, and possibly for other related compounds (glycols and glycerol) as well. A vital aspect of the research would be to examine the effects of 
both surface chemistry and the properties of the adsorbate to gain insights on the adsorption mechanism and a rational basis for selection or design of industrial-scale systems.

\subsection{Multi - OH Compounds of Interest}

In the following descriptions, the compounds shown in parentheses were chosen as representative solutes for our experiments. Figure 1.5-1 is a schematic that shows the chemical structures of the multi $-\mathrm{OH}$ compounds of interest. Some of the physical properties of these compounds are shown in Table 1.5-1 at the end of this section.

\subsubsection{Sugars (Glucose and Sucrose)}

Sucrose, or table sugar, is a white crystalline substance with a sweet taste. It is one of the purest substances available in bulk quantities, and is the most common food additive with a virtually unlimited shelf life. Sucrose is a disaccharide that yields glucose and fructose upon hydrolysis. Glucose is an aldohexose that is widely found in nature, and is the most fundamental energy source for humans and animals. Over $50 \%$ of the dry weight of the earth's biomass consists of glucose polymers (McMurry, 1988).

The many $-\mathrm{OH}$ groups on sugars account for their large solubility in water. The hydroxyl groups of sucrose are weakly acidic, with a $\mathrm{pK}_{\mathrm{a}}$ of 12.6 at $19^{\circ} \mathrm{C}$ (Windholz et al., 1983). For monosaccharides such as glucose, the chemistry associated with the $-\mathrm{OH}$ groups is similar to that of alcohols and aldehydes/ketones. For example, glucose may be reduced to a sugar alcohol, oxidized to an aldaric acid, or reacted with an alcohol to form 
(A)

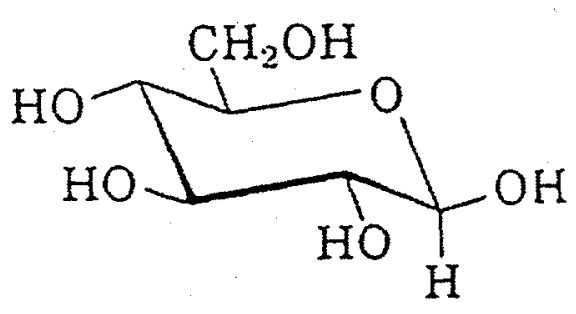

(B)

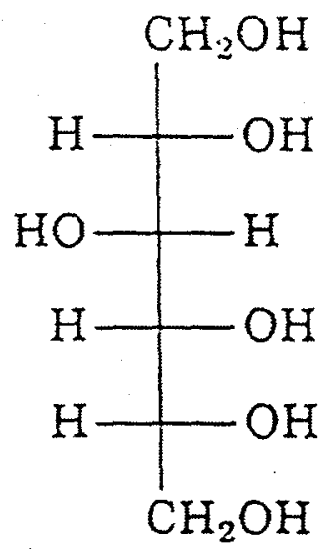

(C)

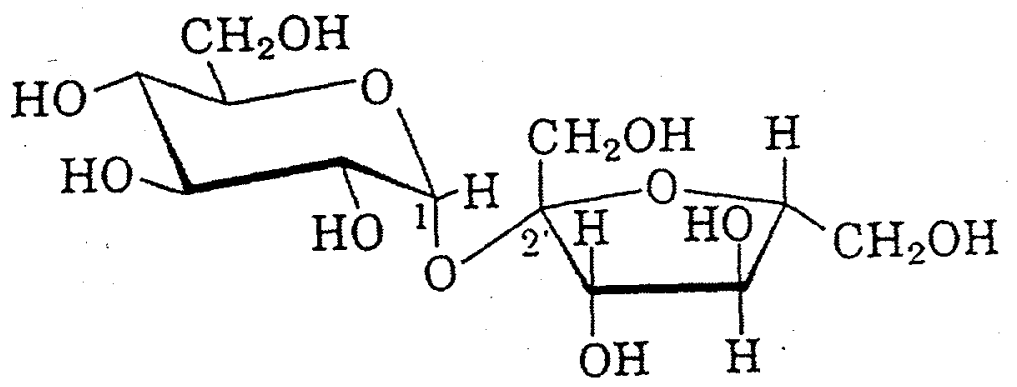

(D)
$\mathrm{CH}_{2}-\mathrm{CH}_{2}$
I
$\mathrm{OHOH}$

(E)

(F)

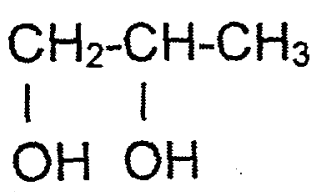

$\mathrm{CH}_{2}-\mathrm{CH}-\mathrm{CH}_{2}$ $\begin{array}{ll}1 & 1\end{array}$ $\mathrm{OH} \mathrm{OH} \mathrm{OH}$

Figure 1.5-1. Schematic representation of multi $-\mathrm{OH}$ compounds of interest. Key: (A) glucose, (B) sorbitol, (C) sucrose, (D) ethylene glycol, (E) propylene glycol, and (F) glycerol (drawings A-C are from McMurry, 1988). 
a glycoside (McMurry, 1988).

In the United States, sucrose is produced from both cane sugar (in tropical regions) and beet sugar (in temperate climates). During the period of 1993-1995, sugar production in the United States was estimated to be about 6.2 million tons/year (Toth, c1991-1998). The current market price for sucrose is $\$ 0.36 / \mathrm{lb}$ (Hoffman, 1998).

\subsubsection{Sugar Alcohols (Sorbitol)}

Sorbitol is a water-soluble, crystalline compound with a sweet taste. It is found naturally in fruits (e.g. apples, plums, pears), but is synthesized commercially by high-pressure hydrogenation of glucose (Lawson, c1991-1998). Sorbitol and mannitol (another sugar alcohol) have the greatest industrial significance among the straight-chain reduced sugars (Lawson, c1991-1998).

As with sugars, the multiple $-\mathrm{OH}$ groups on sorbitol account for its high solubility in water and its weakly acidic character $\left(\mathrm{pK}_{\mathrm{a}}\right.$ of 13.6 at $18^{\circ} \mathrm{C}$, Lawson, c1991-1998). Sorbitol may react to form cyclic ethers, esters, and acetals. Also, it may be oxidatively fermented back to a monosaccharide, or reduced by catalytic hydrogenolysis to form glycols and glycerol (Lawson, c1991-1998).

Sorbitol frequently finds use in various food industries, replacing sucrose as the bulking agent. Also, foods based on sugar alcohols are safe for diabetics. Aqueous sorbitol solutions serve as humectants, softeners, and plasticizers in a variety of applications. 
In 1995 the total amount of sugar alcohols produced in the United States, including both liquid and crystalline forms, was roughly 0.2 million tons (Lawson, c1991-1998). Currently, the market price for crystalline sorbitol in the United States is about $\$ 0.78 / \mathrm{lb}$ (Hoffman, 1998).

\subsubsection{Glycerol}

Glycerol is the backbone of fats and oils in all animals and vegetables. It is a clear, viscous, hygroscopic liquid. Currently, about $70 \%$ of the glycerol produced in the United States comes from hydrolysis of natural triglycerides, such as soaps, fatty acids, and fatty esters (Martin and Murphy, c1991-1998). Alternative routes of synthesis involve combination of propylene with $\mathrm{Cl}_{2}, \mathrm{O}_{2}$, or $\mathrm{HOCl}$, followed by hydrolysis of the intermediate products to form glycerol (Martin and Murphy, c1991-1998).

Glycerol also has characteristics of sugars, being a triose and having a sweet taste (Lawrie, 1928; Martin and Murphy, c1991-1998). It is also a weak acid, and forms salts with alkali metals. Glycerol has reactive properties characteristic of both primary and secondary alcohols, and can form esters, ethers, amines, aldehydes, halides, and even unsaturated compounds such as acrolein.

The uses of glycerol are in the thousands, with drugs and oral care products being the most common applications. Another major use of glycerol is in tobacco processing, where it helps retain moisture in the tobacco leaves. Other applications include lubricants, urethane polymers, and cosmetics. In 1991, about 0.13 million tons of crude 
glycerol were produced in the United States (Martin and Murphy, c1991-1998). The current market price of glycerol is between $\$ 0.45$ and $\$ 0.55 / \mathrm{lb}$ (Hoffman, 1998).

\subsubsection{Glycols (Ethylene and Propylene Glycol)}

Ethylene glycol (EG) is a low-volatility, colorless and odorless compound. It is synthesized by hydration of ethylene oxide under acidic, basic, or neutral conditions, depending on the desired selectivity for EG as opposed to higher-molecular-weight glycols such as di- and triethylene glycol (Forkner et al., c1991-1998).

The hydroxyl groups on ethylene and propylene glycols undergo the typical alcohol chemistry to give a wide range of derivatives (for example, aldehydes, halides, carboxylic acids, ethers, and esters). Glycols may also react with dicarboxylic acids to form linearpolyester polymers (Forkner et al., c1991-1998; Martin and Murphy, c1991-1998). Glycols are also able to condense with one another through the $-\mathrm{OH}$ groups, forming higher-glycol polymers with entirely different properties and uses.

The most common uses of EG are for automobile antifreeze and polyester synthesis. It also finds much use in water-based formulations such as aircraft deicer and as a coolant for compressors, heating and venting systems, and air conditioners. In 1995, EG production in the United States was ranked $32^{\text {nd }}$ largest among all chemicals, at 2.6 million tons (Chemical and Engineering News, 1996). Its current market price is $\$ 0.26 / 1 b$ (Hoffman, 1998). 
Propylene glycol (PG) is a clear, viscous liquid with a slight odor and bitter taste. All PG is commercially produced by high-pressure, high-temperature hydration of propylene oxide (Martin and Murphy, c1991-1998). Industrial grade PG finds use as antifreeze, a heat-transfer fluid, a solvent, and a precursor to high-performance, unsaturated polyester resins. Unlike EG, PG is safe for human and animal consumption and therefore finds use as a humectant, preservative, and stabilizer in foods and pharmaceuticals. The 1995 production level of PG in the United States amounted to about 0.5 million tons (Chemical and Engineering News, 1996). Its current market price is between $\$ 0.65$ and $\$ 0.68 / 1 \mathrm{~b}$ (Hoffman, 1998).

TABLE 1.5-1

Some Physical Properties of Multi - OH Compounds

\begin{tabular}{|c|c|c|c|c|}
\hline COMPOUND & $\mathrm{MW}$ & $\mathrm{T}_{\mathrm{BP}}\left({ }^{\mathrm{O}} \mathrm{C}\right)$ & $\rho\left(20^{\circ} \mathrm{C}\right)$ & SOLUBILITY $\left(25^{\circ} \mathrm{C}\right)$ \\
\hline $\mathrm{EG}$ & 62 & 198 & 1.12 & $\begin{array}{c}\text { water, acetone, } \\
\text { alcohols }\end{array}$ \\
\hline$\overline{\mathrm{PG}}$ & 76 & 187 & 1.03 & $\begin{array}{l}\text { water, acetone, } \\
\text { alcohols }\end{array}$ \\
\hline Glycerol & 92 & 290 & 1.26 & water, alcohol \\
\hline Glucose & 180 & $\mathrm{mp}: 83$ & 1.56 & $\begin{array}{c}\text { water }(50 \mathrm{wt.} \%) \\
\text { methanol (1 wt. \%) }\end{array}$ \\
\hline Sorbitol & 182 & $\mathrm{mp}: 93$ & 1.29 & $\begin{array}{c}\text { water (70 wt.\%), acetone, } \\
\text { methanol }\end{array}$ \\
\hline Sucrose & 342 & $\mathrm{mp}: 169-186$ & 1.59 & water (66 wt. \%) \\
\hline
\end{tabular}

Sources: Forkner et al., c1991-1998; Lawson, c1991-1998; Martin and Murphy, c1991-1998; Morrison, c1991-1998; Windholz et al., 1983.

\subsection{General Research Objectives}

Our research focuses on the use of activated carbons for the recovery of glycols, glycerol, 
and sugars from dilute aqueous solution. The primary goal is to obtain a sufficient understanding of the underlying chemical, thermodynamic, and transport phenomena during adsorption to enable rational selection of both adsorbents and methods of implementation. Our experimental work is largely geared toward:

(1) Measuring and interpreting the adsorption properties of a variety of carbons in terms of adsorbent and/or adsorbate properties.

(2) Determining the degree of reversibility associated with adsorption and rationalizing the reasons for any irreversibility.

(3) Developing an economical method of recovering the adsorbed solute with concurrent regeneration of the carbon adsorbent for reuse.

Armed with chemical insight obtained from the studies of carbons, the designer should be in a better position to engineer synthetic polymeric adsorbents that are attractive for recovery of glycols and/or sugars.

\subsection{Overview of Dissertation}

Chapter 2 describes the experimental materials, methods of analysis, and techniques used in this work. Also included are preliminary data to demonstrate the attainment of equilibrium in our batch adsorption and regeneration experiments.

Chapter 3 discusses bulk and surface properties of the various carbonaceous adsorbents; namely, surface areas and pore-size distributions, elemental analysis, and surface 
acidity/basicity as determined by site-titration experiments. Some of the previous work that has defined the structure and chemical properties of the surface functional groups is also presented.

Chapter 4 presents equilibrium data for the multi -OH compounds (sugars, glycols, glycerol) adsorbing on a variety of active carbons. The effects of temperature, solutionphase nonidealities, and adsorbent properties on the adsorption behavior are explored.

Chapter 5 presents experimental data on batch regeneration of carbons loaded with sugars, glycols, and glycerol. Two key issues are addressed: (1) the effect of solvent choice, and (2) the effect of entrained water in the carbon on the apparent completeness of regeneration.

Chapter 6 discusses thermogravimetric analysis (TGA) data for a series of loaded and solvent-regenerated carbons. The results of TGA provide independent information on the adsorption/regeneration properties discussed in Chapters 4 and 5. The TGA data also provide insights on the energetics of adsorption, which are analyzed by means of a firstorder desorption model.

Chapter 7 presents experimental data for fixed-bed recovery of sugars, glycols, and glycerol from aqueous solution. The effects of carrier flowrate, and types of solvent and adsorbent will be discussed. Also presented are adsorption-regeneration cycling experiments for the recovery of ethylene glycol. Fractionation among several multi $-\mathrm{OH}$ 
solutes, although not pursued to great lengths in this work, is also discussed.

Finally, Chapter 8 summarizes the collective findings of this research and provides overall mechanistic insight into of how multi-OH solutes adsorb onto carbon surfaces.

We also review the relevant TGA, regeneration, and fixed-bed data and make suggestions for designing a large-scale recovery process. 


\section{References for Chapter 1}

Abe, I.; Hayashi, K.; Kitagawa, M. Bull. Chem. Soc. Jpn., 1981, 54, 3857-3858.

Abe, I.; Hayashi, K.; Kitagawa, M. Carbon, 1983, 21, 3, 189-191.

Baker, F.S.; Miller, C.E.; Repik, A.J.; Tolles, E.D. "Carbon (Activated)." In KirkOthmer Encyclopedia of Chemical Technology, $4^{\text {th }}$ edition; Kroshwitz, J.I.; Howe-Grant, M., Eds., John Wiley and Sons: New York, c1991-1998, Vol. 4, 1015-1037.

Bansal, R.C.; Donnet, J.; Stoeckli, F. Active Carbon, Marcel Dekker, Inc.: New York, 1988.

Barker, P.E.; Joshi, K. J. Chem. Tech. Biotechnol., 1991, 52, 93-108.

Binkley, W.W. Advan. Carbohydrate Chem., 1955, 10, 55-94.

Busche, R.M Biotechnology and Bioengineering Symp., 1983, 13, 597-615.

Busche, R.M. Biotechnology Progress, 1985, 1(3), 165-179.

Broekhuis, R.R.; Lynn, S.; King, C.J. Ind. Eng. Chem. Res., 1994, 33, 3230-3237.

Broekhuis, R.R.; Lynn, S.; King, C.J. Ind. Eng. Chem. Res., 1996, 35, 1206-1214.

Chemical and Engineering News Internet site, 1996, "Production by the U.S. Chemical Industry." http://pubs.acs.org/hotartcl/cenear/960624/prod.html.

Clarke, M.A. "Sugar (Cane)." In Kirk-Othmer Encyclopedia of Chemical Technology, $4^{\text {th }}$ edition; Kroshwitz, J.I.; Howe-Grant, M., Eds., John Wiley and Sons: New York, c1991-1998; Vol. 23, 20-44.

Cookson, Jr., J.T. Water, 1975, 71(151), 376-386.

Cuddihy, J.A.; Rauh, J.S.; Porro, M.E. International Sugar Journal, 1997, 99, 78-84.

Forkner, M.W.; Robson, J.H.; Snellings, W.M. "Glycols (Ethylene Glycol and Oligomers." In Kirk-Othmer Encyclopedia of Chemical Technology, $4^{\text {th }}$ edition; Kroshwitz, J.I.; Howe-Grant, M., Eds., John Wiley and Sons: New York, c19911998, Vol. 12, 695-713.

Gembicki, S.A.; Oroskar, A.R.; Johnson, J.A. “Adsorption, Liquid Separation.” In KirkOthmer Encyclopedia of Chemical Technology, $4^{\text {th }}$ edition; Kroshwitz, J.I.; Howe-Grant, M., Eds., John Wiley and Sons: New York, c1991-1998, Vol. 1, 573-600. 
Gmehling, J.; Onken, U.; Rarey-Nies, J.R. Vapor-Liquid Equilibrium Data Collection, Dechema: Frankfurt, 1988.

Hansen, R.S. and Fackler, Jr., W.V. J. Phys. Chem., 1953, 57, 634-637.

Hoffman, J. Chemical Prices. Chemical Market Reporter, 1998, 254(8).

Jankowska, H.; Swiatkowski, A.; Choma, J. Active Carbon, Ellis Horwood Limited: England, 1991.

Jehle, W.; Staneff, Th.; Wagner, B.; Steinwandel, J. Journal of Membrane Science, $1995,102,9-19$.

Kamlet, M.J.; Doherty, R.M.; Abraham, M.H.; Taft, R.W. Carbon, 1985, 23(5), 549-554.

Lawrie, J.W. Glycerol and the Glycols: Production, Properties, and Analyses, The Chemical Catalog Company, Inc.: New York, 1928.

Lawson, M.E. "Sugar Alcohols." In Kirk-Othmer Encyclopedia of Chemical Technology, $4^{\text {th }}$ edition; Kroshwitz, J.I.; Howe-Grant, M., Eds., John Wiley and Sons: New York, c1991-1998, Vol. 23, 93-119.

Madnaik, S.D.; Jadhav, M.G. Energy Sources, 1996, 18, 333-343.

Martin, A.E.; Murphy, F.H. "Glycols (Propylene)." In Kirk-Othmer Encyclopedia of Chemical Technology, $4^{\text {th }}$ edition; Kroshwitz, J.I.; Howe-Grant, M., Eds., John Wiley and Sons: New York, c1991-1998, Vol. 12, 715-725.

McMurry, J. Organic Chemistry, $2^{\text {nd }}$ edition; Brooks/Colt: Belmont, California, 1988.

Morrison, L.R. "Glycerol." In Kirk-Othmer Encyclopedia of Chemical Technology, $4^{\text {th }}$ edition; Kroshwitz, J.I.; Howe-Grant, M., Eds., John Wiley and Sons: New York, c1991-1998, Vol. 12, 681-694.

Polanyi, M. Verh. deut. physik. Ges., 1916, 18, 55.

Radke, C.J.; Prausnitz, J.M. Ind. Eng. Chem. Fundam., 1972, 11(4), 445-451.

Randel, L.A.; Chow, T.; King, C.J. Solvent Extraction and Ion Exchange, 1994, 12, 765-778

Rendleman, Jr., J.A. Advances in Carbohydrate Chemistry, Wolfrom, M.L.; Tipson, R.T., Eds., Academic Press: New York, 1966, Vol. 21, 209-271.

Reisinger, H.; King, C.J. Unpublished results, 1994. 
Rosene, M.R.; Manes, M. J. Phys. Chem., 1976, 80(9), 953-959.

Schlieker, H.; Gunzel, B.; Deckwer, W. Chem.-Ing.-Tech., 1992, 8, 727-728.

Smith, J.M.; Van Ness, H.C. Introduction to Chemical Engineering Thermodynamics, $4^{\text {th }}$ edition, McGraw-Hill Inc.: New York, 1987.

Stenzel, M.H. Chemical Engineering Progress, September 1993, 36-43.

Toth, L. "Sugar (Economics)." In Kirk-Othmer Encyclopedia of Chemical Technology, $4^{\text {th }}$ edition; Kroshwitz, J.I.; Howe-Grant, M., Eds., John Wiley and Sons: New York, c1991-1998, Vol. 23, 79-86.

Tronconi, E.; Ferlazzo, N.; Forzatti, P.; Pasquon, I.; Casale, B.; Marini, L. Chemical Engineering Science, 1992, 47, 2451-2456.

Wankat, P.C. Rate Controlled Separations, Chapman and Hall: Great Britain, 1994.

Windholz, M.; Budavari, S.; Blumetti, R.F.; Otterbein, E.S., Eds., Merck Index, $10^{\text {th }}$ edition; Merck and Co., Inc.: New Jersey, 1983.

Wohleber, D.A.; Manes, M. J. Phys. Chem., 1971, 75(1), 61-64.

Wohleber, D.A.; Manes, M. J. Phys. Chem., 1971, 75(24), 3720-3723. 


\section{Chapter 2. Experimental Materials and Methods}

\subsection{Materials}

\subsubsection{Chemicals}

All chemicals used in this work, along with their sources and purity, are listed in Appendix A.

All aqueous solutions were made from distilled water that has been passed through a Milli-Q purification system (Millipore Corp.).

\subsubsection{Adsorbents}

Table 2.1-1 lists and describes the as-received adsorbents used in our work.

TABLE 2.1-1

Adsorbent Source Material and Activation Method

\begin{tabular}{||c|c|c|c||}
\hline ADSORBENT & SOURCE MATERIAL & VENDOR & ACTIVATION METHOD \\
\hline Ambersorb & Sulfonated DVBS* & Rohm \& Haas & Pyrolysis \\
\hline F400 & Bituminous Coal & Calgon & Steam \\
\hline Norit RO 0.8 & Extruded Peat & Norit & Steam \\
\hline WVB & Wood & Westvaco & Acid/Catalyst \\
\hline
\end{tabular}

*Divinyl Benzene-Styrene Copolymer

Three types of Ambersorb resins were used: A563, A572, and A575. All three are macroreticular, and differ primarily by specific surface area and sulfur content. Among 
the three varieties of activated carbon (F400, RO 0.8, and WVB), most of our work was done using F400 as the standard. Surface areas and other properties of all adsorbents are listed in Chapter 3. The following section describes two methods used to pretreat the carbons.

\subsection{Methods of Carbon Pretreatment}

\subsubsection{Batch Heat Treatment of Carbons}

Two 250-mL beakers, each filled with Milli-Q water and about $30 \mathrm{~g}$ of as-received carbon, were placed in a 220 Sonic Water Bath (Bransonic) for 30 seconds to remove solid fines. After the water was decanted, the slurry was dried overnight in a vacuum oven at $100^{\circ} \mathrm{C}$. The carbons were then ready for heat treatment in our lab furnace.

The furnace was a 55360/55600 Series Lab Tube Furnace (Lundberg/Blue M) with a Model 808/847 Digital Controller (Eurotherm Corp.). All materials specially designed for the furnace interior were obtained from Coors Ceramic Co. A Mullite Cast (47" L, 3" O.D., 2.75" I.D.) was fitted on the inside walls of the furnace. The $60 \mathrm{~g}$ of washed, asreceived carbon was divided onto five rectangular trays (77 $\mathrm{mm} \times 50 \mathrm{~mm} \times 11 \mathrm{~mm}$ ), and placed atop a Mullite Dee-Tubing Cast (18" L x 2.75" I.D.). The carbons were ready for heat treatment after the Dee-Tube was positioned at the center of the furnace.

Carbons were heated in a nitrogen purge stream, flowing through a Carrier Gas Purifier (Supelco) at 20 to $30 \mathrm{~mL} / \mathrm{min}$ with a back pressure of 4 to 5 psi. The carbons 
were initially heated at $10^{\circ} \mathrm{C} / \mathrm{min}$ to $100^{\circ} \mathrm{C}$. After an isothermal "soak" period of 24 hours, the temperature was further ramped $10^{\circ} \mathrm{C} / \mathrm{min}$ to $1000^{\circ} \mathrm{C}$. The temperature was maintained at $1000^{\circ} \mathrm{C}$ for 24 hours, after which the furnace was allowed to cool back to room temperature under nitrogen. The carbons were then stored in desiccators sealed under house vacuum for future use.

\subsubsection{Batch Acid-Oxidation of Carbons}

Heat-treated F400 carbon was slowly added to concentrated nitric acid (69.4 wt. \%) in a 500-mL Pyrex round-bottomed flask. For each batch, about $25 \mathrm{~g}$ of carbon were prepared per $250-300 \mathrm{~mL}$ acid. The entire suspension was mixed with a magnetic stirrer and maintained at $25^{\circ} \mathrm{C}, 50^{\circ} \mathrm{C}$, or $70^{\circ} \mathrm{C}$ using a $270 \mathrm{~W}$ Heater (Glas-Col Apparatus Co.) with Powerstat controller (The Superior Electric Co.). Treatments typically lasted 2 hours, although a few batches were oxidized from 7 to 9 hours. After oxidation, the carbons were rinsed exhaustively with boiling water until the $\mathrm{pH}$ of the extract was neutral according to PHydrion Paper (Micro Essential Laboratory, Inc.). The oxidized carbons were then stored in desiccators sealed under house vacuum until future use.

\subsection{Analytical Methods}

\subsubsection{High Performance Liquid Chromatography (HPLC)}

Liquid-phase solute concentrations in this work were measured by HPLC. Two different experimental setups were employed. The first unit was modular, consisting of a Series 10 Chromatograph Pump System (Perkin-Elmer), a Model 7125 - $20 \mu \mathrm{L}$ Sample 
Loop/Injector Port (Rheodyne), and a 3390A Integrator (Hewlett-Packard). Our more current equipment is the Series 1050 Chromatograph (Hewlett-Packard), which includes Autosampler, Variable Wavelength Detector, and a 35900E Multi-Channel Interface. This setup is fully automated and enables analysis on an IBM-486 computer with Chemstation Software A.02.02 (Hewlett-Packard). Both HPLC units have a R401 Differential Refractometer (Waters) as the working detector.

Several different chromatography columns were used for the analysis, depending on the sample. All experiments included use of a $4.6 \mathrm{~mm}$ x $30 \mathrm{~mm}$ Micro-Guard column (Biorad) to prevent accumulation of solid fines in the main column. Glycols, glycerol, and sugars dissolved in aqueous or acetone-water solutions were analyzed using either a Shodex DE-613 (Showa Denko) or Fast Acid (Biorad) column. Mixtures of glycols in methanol were measured with an Aminex HPX-87H (Biorad) column, chosen because of similarities in their retention times on the other columns. Milli-Q (Millipore) water was the mobile phase for the Shodex column and $0.01 \mathrm{~N}$ sulfuric acid for both Biorad columns. Table 2.3-1 summarizes the operating conditions and specifications for each column. 
TABLE 2.3-1

HPLC Columns and Operating Conditions

\begin{tabular}{||c|c|c|c||}
\hline COLUMN & DIMENSIONS & PACKING & FLOW (ML/MIN) \\
\hline Aminex HPX-87H & $7.8 \mathrm{~mm} \times 300 \mathrm{~mm}$ & Sulfonated DVBS* & 0.7 \\
\hline Fast Acid & $7.8 \mathrm{~mm} \times 100 \mathrm{~mm}$ & Sulfonated DVBS* & 1.2 \\
\hline Shodex DE-613 & $6 \mathrm{~mm} \times 150 \mathrm{~mm}$ & Polymethacrylate & 1.0 \\
\hline
\end{tabular}

*Divinyl Benzene-Styrene Copolymer

All calibration curves for the HPLC were obtained using external standards made from the appropriate adsorbate(s). Experiments with the Series 10 unit were done at ambient temperature, while all work with the 1050 unit was done at $60^{\circ} \mathrm{C}$. At least two separate injections were made for each sample run, with $2 \%$ or better reproducibility in the peak areas.

\subsubsection{Acid/Base Titration}

The titration equipment consisted of a 655 Dosimat (Metrohm), which can automatically deliver volumes of titrant within $0.01 \mathrm{~mL}$. A Ross $\mathrm{pH}$ Electrode (Orion), connected to a Model 601A Digital Ionalyzer (Orion), was capable of measuring within $0.01 \mathrm{pH}$ units. Sample solutions were well agitated by a magnetic stirrer and titrated to the end point with standardized acid $(\mathrm{HCl})$ or base $(\mathrm{NaOH})$. All stock $\mathrm{NaOH}$ solutions were standardized using $0.05 \mathrm{~N}$ potassium hydrogen phthalate.

\subsubsection{BET Analysis}

Specific surface areas of all adsorbents were measured using the method of Brunauer, 
Emmett, and Teller (BET). The apparatus consisted of a Model 201 BET Analyzer

(Porous Materials, Inc.) connected to a Model 1402-Duo Seal Vacuum Pump (The Welch

Scientific Co.). Glass sample tubes were designed by the College of Chemistry glass shop at the University of California, Berkeley.

The BET method involves measuring the adsorption isotherm of nitrogen vapor at its normal boiling point of $77 \mathrm{~K}$. About $0.1 \mathrm{~g}$ of dried carbon was placed in a $10-\mathrm{mL}$ sample tube, attached onto the BET apparatus, and immersed in a dewar containing liquid nitrogen. After the entire apparatus was evacuated to $20 \mu \mathrm{m} \mathrm{Hg}$, successive amounts of nitrogen gas were introduced into the system (up to $14.7 \mathrm{psia}$ ) through a separate valve. Initial and equilibrium pressures were measured during each nitrogen-addition step. The amount of nitrogen adsorbed onto the carbon is thus determined by difference.

Throughout the experiment, it was essential to maintain the liquid nitrogen level constant for adequate temperature control.

\subsubsection{Calculation of Surface Area for Carbons}

Relative pressure $\left(\mathrm{P} / \mathrm{P}_{\mathrm{o}}\right)$ and nitrogen volume adsorbed $(\mathrm{v})$ data are fitted to the nonlinear, multilayer BET equation (Adamson, 1967):

$$
v=\frac{v_{\text {max }} K x}{(1-x)[1+(K-1) x]}
$$


where $x=P / P_{o}\left(P_{o}=14.7 \mathrm{psia}\right), v$ is in $\mathrm{cm}^{3} / \mathrm{g}$ carbon, $K$ is a constant that is related to the potential energy difference between the liquid and first adsorbed layer, and $v_{\max }$ is the volume $\left(\mathrm{cm}^{3} / \mathrm{g}\right.$ carbon) needed for monolayer coverage. Parameter fitting is done with a Marquardt-Levenberg algorithm from Sigma Plot 1.02 (Jandel Scientific) software. Relative pressures up to 0.2 , which is just below the monolayer region for most active carbons, are used in the curve fitting.

Surface areas are calculated from $v_{\max }$, with the assumption that nitrogen has a projected area of $16.2 \AA^{2} /$ molecule (or $3483 \mathrm{~m}^{2} / \mathrm{g} \mathrm{N}_{2}$ ):

$$
\mathrm{SSA}=3483 \mathrm{v}_{\max } \rho_{\mathrm{N} 2}=4.36 \mathrm{v}_{\max }
$$

where $\rho_{\mathrm{N} 2}$ is $0.0012506 \mathrm{~g} / \mathrm{cm}^{3}$, the liquid nitrogen density at $77 \mathrm{~K}$. SSA is the specific surface area, given in $\mathrm{m}^{2} / \mathrm{g}$ dry carbon.

\subsubsection{Estimation of Pore-Size Distribution in Carbons}

Distributions of pore sizes in adsorbents can be estimated using data from nitrogen adsorption isotherms. The underlying theory assumes open ended, non-necking cylindrical pores in the solid. We therefore neglect the effects of adsorption-desorption hysteresis. At relative pressures near unity, all pores in the solid are filled with condensed nitrogen. Lowering of the relative pressure (desorption) results in two physical effects. First, capillaries of a certain radius are emptied of their condensate, 
following the Kelvin equation. Second, the pressure decrease leads to thinning of the physically adsorbed nitrogen layer in all pores. Our method of calculation is based on work by Barrett et al. (1951), and is briefly outlined below.

During desorption, the Kelvin equation (for a hemispherical meniscus) relates the relative pressure $\left(\mathrm{x}=\mathrm{P} / \mathrm{P}_{\mathrm{o}}\right)$ and radius $\left(\mathrm{r}_{\mathrm{K}}\right)$ :

$$
\log (\mathrm{x})=-\frac{2 \sigma \mathrm{V}_{\mathrm{m}}}{\mathrm{RTr}_{\mathrm{K}}}=-\frac{4.14}{\mathrm{r}_{\mathrm{K}}}
$$

where the "Kelvin radius" $\left(\mathrm{r}_{\mathrm{K}}\right)$ is in $\dot{\mathrm{A}}$, surface tension of liquid nitrogen $(\sigma)$ is 8.85 dyne/cm, molar volume $\left(\mathrm{V}_{\mathrm{m}}\right)$ is $34.65 \mathrm{~cm}^{3} / \mathrm{mol}$, and temperature $(\mathrm{T})$ is $77 \mathrm{~K}$. The thickness of the physically adsorbed layer is given by:

$$
t=3.54\left[\frac{-5}{\ln (x)}\right]^{1 / 3}
$$

where $t$ is the thickness in $\AA$ of the physically adsorbed nitrogen layer. The above correlation comes from analysis of silicas and aluminas by Dollimer et al. (1970). For each value of relative pressure, we can define: 


$$
r_{p}=r_{K}+t
$$

where $r_{p}$ is the total pore radius in $\AA$.

To calculate pore volumes, it is necessary to break up the isotherm data into increments of desorption steps, from the highest value of $\mathrm{P} / \mathrm{P}_{0}$ to the lowest. Pore volumes are calculated by using the following equation successively:

$$
\mathrm{V}_{\mathrm{p}, \mathrm{n}}=\left(\frac{\overline{\mathrm{r}}_{\mathrm{pn}}}{\overline{\mathrm{r}}_{\mathrm{Kn}}+\Delta \mathrm{t}_{\mathrm{n}}}\right)^{2}\left[\Delta \mathrm{V}_{\mathrm{n}}^{\mathrm{L}}-10^{-4} \Delta \mathrm{t}_{\mathrm{n}} \sum_{\mathrm{j}=1}^{\mathrm{n}-1} \mathrm{c}_{\mathrm{j}} \mathrm{A}_{\mathrm{pj}}\right]
$$

In the above equation, we define an average radius $\left(\overline{\mathrm{r}}_{\mathrm{p}}\right.$ or $\left.\overline{\mathrm{r}}_{\mathrm{K}}\right)$ between radii corresponding to the upper and lower values of $\mathrm{P} / \mathrm{P}_{\mathrm{o}}$ during each desorption step. The pore volume $V_{p, n}\left(\mathrm{~cm}^{3} / g\right.$ carbon) is determined from thinning of adsorbed layer $\Delta t_{n}$ of a previously emptied pore of average radius $\overline{\mathrm{r}}_{\mathrm{pn}} \cdot \Delta \mathrm{V}_{\mathrm{n}}^{\mathrm{L}}$ is the amount of condensate emptied from the pores ( $\mathrm{cm}^{3} / \mathrm{g}$ carbon), and is obtained by multiplying the vapor volume desorbed by the conversion factor 0.00154 . The summation represents the sum of average areas in unfilled pores down to, but not including, pores emptied of condensate in the $\mathrm{n}^{\text {th }}$ desorption step. Pore areas $\left(\mathrm{A}_{\mathrm{pj}}\right)$ are given in $\mathrm{m}^{2} / \mathrm{g}$ by: 


$$
A_{p j}=10^{4}\left(\frac{2 V_{p j}}{\overline{\mathfrak{r}}_{\mathrm{pj}}}\right)
$$

The parameter $c_{j}$ is an empirical correction factor that varies from 0.75 to 0.90 , depending on the value of $\overline{\mathrm{r}}_{\mathrm{pj}}$ (Barrett et al. 1951).

Pore-size distributions are commonly reported using two different methods. First, one may plot the cumulative pore volume versus the pore radius $r_{p}$. This plot includes all of the volume down to the lower limit of each $\Delta r_{p}$ increment. The second method is to divide all the $V_{p}$ values by the interval $\Delta r_{p}$ over which they were determined. A derivative plot results when $V_{p} / \Delta r$ is plotted against the average radius, $\overline{\mathrm{x}}_{\mathrm{p}}$. These plots reveal the pore size that contributes most to the overall pore volume.

\subsubsection{Thermogravimetric Analysis (TGA)}

Thermogravimetric analysis of the solid carbon was performed using a TGA-7 Series 1020 Thermogravimetric Analyzer (Perkin-Elmer). A schematic of the equipment is shown in Figure 2.3.4-1. About 15 to $30 \mathrm{mg}$ of adsorbent were placed on a platinum pan, which was suspended from a microbalance into a miniature tube furnace. The entire apparatus is then enclosed, with a purge stream of house nitrogen flowing through at 20 $\mathrm{cm}^{3} / \mathrm{min}$. After the nominal sample weight was determined, the relative weight (\%) of the sample was measured continuously as the furnace temperature was linearly ramped 


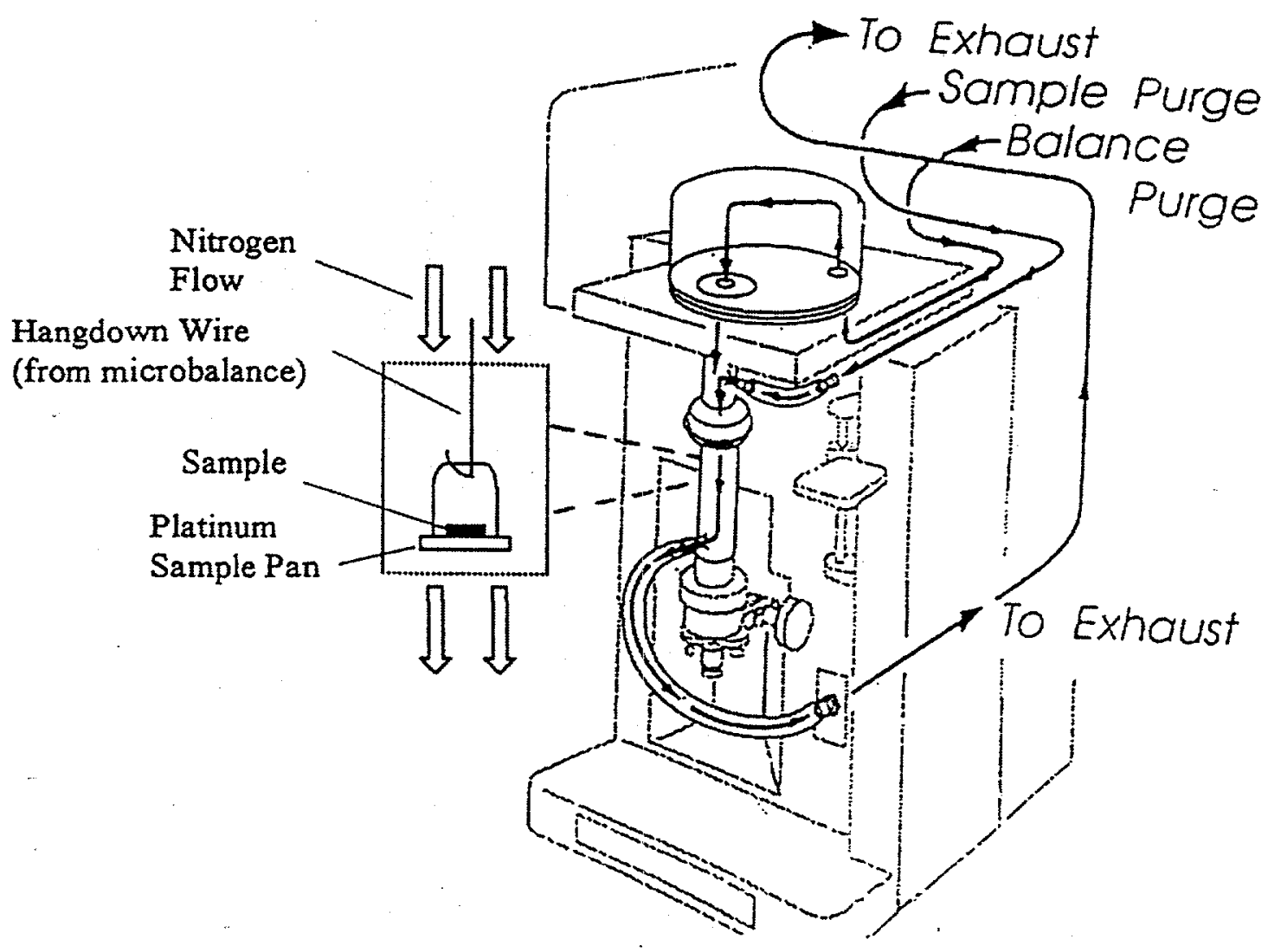

Figure 2.3.4-1. Equipment schematic for Thermogravimetric Analysis (TGA), from Perkin-Elmer Series 1020 TGA-7 instrument manual. Also shown is a schematic of the hanging pan arrangement inside the furnace. 
from ambient to $800^{\circ} \mathrm{C}$. Heating rates from $10^{\circ} \mathrm{C} / \mathrm{min}$ to $40^{\circ} \mathrm{C} / \mathrm{min}$ were typical. The TGA-7 reports temperature to within $0.01^{\circ} \mathrm{C}$ and can measure sample weights to within 1 $\mu g$.

TGA measures the weight of a sample as temperature is increased. The weight decreases to a greater extent for a given temperature increase when more material is desorbed over that temperature range. A useful method of interpreting TGA data is to plot the temperature derivative of sample weight against temperature. The resultant plot is similar to a chromatogram, in that peaks correspond quantitatively to amounts of different substances present in the sample.

\subsubsection{TGA Derivative Plot Construction}

TGA data are reported in increments of $0.5^{\circ} \mathrm{C}$ from ambient to $800^{\circ} \mathrm{C}$. To help reduce instrument noise in the derivative calculations, we averaged the sample weight(\%)temperature $\left({ }^{\circ} \mathrm{C}\right)$ data over an interval span of $5^{\circ} \mathrm{C}$. Differentiation was done numerically with an 11-point Lagrange formula applied throughout the entire temperature range:

$$
\left(\frac{d W T \%}{d T}\right)_{j}=\frac{1}{10 ! h} \sum_{i=0}^{10} A_{i j}(W T \%)_{i}
$$

where WT\% is the percentage of the nominal sample weight, $\mathrm{T}$ is temperature in ${ }^{\circ} \mathrm{C}$, and $\mathrm{h}$ is the interval span in ${ }^{\circ} \mathrm{C}$. The subscript $i$ denotes the value of WT\% at the $i^{\text {th }}$ position, 
while $j$ represents the position where the derivative is evaluated. The constants $A_{i j}$ are tabulated by Kopal (1961). Values for the central difference $(j=5)$ that were used in this work are shown in Table 2.3.4-1.

TABLE 2.3.4-1

Constants $(j=5)$ for the Lagrange 11-Point Differentiation Formula

\begin{tabular}{|l|c|c|c|c|c|}
\hline $\mathrm{A}_{05}$ & $-2,880$ & $\mathrm{~A}_{45}$ & $-3,024,000$ & $\mathrm{~A}_{85}$ & $-292,140$ \\
\hline $\mathrm{A}_{15}$ & 36,000 & $\mathrm{~A}_{55}$ & 0 & $\mathrm{~A}_{95}$ & 50,440 \\
\hline $\mathrm{A}_{25}$ & $-216,000$ & $\mathrm{~A}_{65}$ & $-1,401,960$ & $\mathrm{~A}_{105}$ & $-4,100$ \\
\hline $\mathrm{A}_{35}$ & 864,000 & $\mathrm{~A}_{75}$ & $1,048,560$ & & \\
\hline
\end{tabular}

\subsection{Adsorption/Desorption Equilibrium Experiments}

\subsubsection{Experimental Methods}

All of our batch equilibration work (adsorption, desorption, regeneration, strong acid/base uptake) was performed using similar methods. Known amounts of dried adsorbent and solutions of known initial composition were mixed in $20-\mathrm{mL}$ glass scintillation vials with foil or Teflon-lined screw caps. Solution-to-solid phase ratios were roughly 5:1 for adsorption experiments, and usually 10:1 to $15: 1$ for regeneration experiments. Equilibration was carried out at $25^{\circ} \mathrm{C}$ in water shaker baths with an agitation rate set at 120 strokes/min. Most experiments were done on reciprocating shakers: Versa-Bath S (Fisher Scientific) and Polystat Model 12050-00 Circulator (Cole-Parmer). An Orbit Shaker 3535 (Lab-Line), which lacked temperature control, was occasionally used to accommodate larger sample vials or during downtime of the standard shakers. 
After equilibration, samples of the solutions were carefully withdrawn using a $5-\mathrm{cm}^{3}$

Luer-Lok syringe and filtered with a $0.5-\mu \mathrm{m}$ Millex filter (Millipore). Aqueous samples were filtered with Millex-LCR while nonaqueous samples were filtered with Millex-SR. The liquid phase was then ready to be analyzed by HPLC.

The solid phase, after equilibration, was frequently isolated for further analysis or treatment. The wetted carbons were carefully scraped into a $15-\mathrm{mL}$ Pyrex, mediumfritted funnel (ASTM 40-60C) nested within a plastic centrifuge tube. Paraffin Film M (American National) was used to seal the tops while the samples were centrifuged on a Model HN-SII Centrifuge (Damon/IEC Division). All samples were centrifuged at 2000 rpm for 8 minutes. The solids were then weighed and stored for future work.

\subsubsection{Conventions for Adsorption/Desorption Work}

In this development, we consider a binary liquid solution in equilibrium with a solid (the adsorbent). Adsorption is defined as the extent to which one component (the solute) is enriched on the adsorbent surface relative to the other component (the solvent). We will use two quantitative measures of adsorption: the composite uptake and the individual uptake. Most of the concepts that follow originated from Kipling (1965).

Normally, adsorption from solution is measured from the difference in the bulk solute concentration, before and after equilibration. This defines the composite uptake: 


$$
\mathrm{q}_{2}=\frac{\mathrm{w}_{\mathrm{o}}\left(\mathrm{X}_{2 \mathrm{i}}-\mathrm{X}_{2 \mathrm{f}}\right)}{\mathrm{m}}
$$

where $\mathrm{m}$ is the dry mass of solid adsorbent ( $\mathrm{g}$ solid) obtained from a vacuum-sealed desiccator, $W_{0}$ is the total mass of solution ( $g$ solution), $X_{2 i}$ and $X_{2 f}$ are the initial and equilibrium solute weight fractions ( $\mathrm{g}$ solute/g solution), and $\mathrm{q}_{2}$ is the composite uptake ( $\mathrm{g}$ solute/g dry carbon). The composite uptake is a thermodynamic quantity equal to the surface enrichment of solute, and is readily determined from analysis of the liquid phase at equilibrium. We will define the individual uptake to distinguish (in physical terms) the adsorbed phase from the bulk phase.

The individual uptake is defined as the total amount of solute in the adsorbed phase. This includes the solute enriched on the solid surface (composite uptake) and solute taken up non-selectively during pore filling and/or held in interstices. Our convention for distinguishing the adsorbed phase from the bulk phase is as follows. All material retained with the solid after the centrifugation procedure (see section 2.4 .1 ) is part of the adsorbed phase, while everything else is bulk phase. Mathematically, this means:

$$
\mathrm{m}_{\text {wet }}=\mathrm{m}\left(1+\mathrm{Q}_{1}+\mathrm{Q}_{2}\right)
$$

where $m_{\text {wet }}$ is the total mass of the solid phase measured after centrifugation ( $\mathrm{g}$ solid), $\mathrm{Q}_{1}$ 
is the individual uptake for the solvent ( $\mathrm{g}$ solvent/g dry carbon), and $\mathrm{Q}_{2}$ is the individual uptake for the solute ( $\mathrm{g}$ solute/g dry carbon). The centrifugation method originated from previous work in our laboratory (Frierman, 1983), and is used to remove most of the interstitial fluid between solid particles, while retaining the liquid held in the pores. Note that in eq.(2.4.2-2), only the sum of the individual uptakes is directly measurable. We assume that the fluid held non-selectively in the solid pores has the same composition as that in the bulk at equilibrium. As will be shown, this assumption allows one to calculate individual uptakes from composite uptakes.

\subsubsection{Development of Mass Balances}

With our conventions stated above, we are ready to derive an expression for the individual uptake and the relationship between the composite and individual uptakes. The following derivation originates from Kipling (1965).

The first step is to perform a total mass balance on the system:

$$
\mathrm{w}_{\mathrm{o}}=\mathrm{w}_{1}+\mathrm{W}_{2}+\mathrm{mQ}_{1}+\mathrm{mQ}_{2}
$$

where $W_{1}$ and $W_{2}$ refer to the amount (g) of solvent and solute left in the buik phase after centrifugation, respectively.

The solute mass fractions may be re-written as: 


$$
\mathrm{x}_{2 \mathrm{i}}=\frac{\mathrm{w}_{2}+\mathrm{mQ}_{2}}{\mathrm{w}_{\mathrm{o}}} \quad \mathrm{x}_{2 \mathrm{f}}=\frac{\mathrm{w}_{2}}{\mathrm{w}_{1}+\mathrm{w}_{2}}
$$

Taking the difference in solute concentration between the initial and equilibrium values yields:

$$
X_{2 i}-X_{2 f}=\frac{w_{2}+m Q_{2}}{w_{1}+w_{2}+m_{1}+m Q_{2}}-\frac{w_{2}}{w_{1}+w_{2}}
$$

After some algebra and rearrangement of term;, we obtain:

$$
X_{2 i}-X_{2 f}=\frac{w_{1} Q_{2} m-w_{2} Q_{1} m}{w_{o}\left(w_{1}+w_{2}\right)}
$$

Finally, the desired form is obtained from further rearrangement of eq. (2.4.3-4):

$$
\mathrm{q}_{2}=\frac{\mathrm{w}_{\mathrm{o}}\left(\mathrm{X}_{2 \mathrm{i}}-\mathrm{X}_{2 \mathrm{f}}\right)}{\mathrm{m}}=\left(1-\mathrm{X}_{2 \mathrm{f}}\right) \mathrm{Q}_{2}-\mathrm{X}_{2 \mathrm{f}} \mathrm{Q}_{1}
$$

The composite uptake is so named since it is related to the difference between the individual solute uptake and the individual solvent uptake. 
By combining eqs. (2.4.2-2) and (2.4.3-5), we eliminate $Q_{1}$ and obtain an expression for the individual uptake of the solute:

$$
\mathrm{Q}_{2}=\frac{\mathrm{mq}_{2}+\left(\mathrm{m}_{\text {wet }}-\mathrm{m}\right) \mathrm{X}_{2 \mathrm{f}}}{\mathrm{m}}
$$

Eq. (2.4.3-6) provides a quick, convenient method of calculation. However it is flawed in that its accuracy is directly affected by uncertainties in $q_{2}$ and in the overall validity of our assumptions made. For some experiments, the centrifuged adsorbents were dehydrated by heating in a vacuum oven at $65^{\circ} \mathrm{C}$ and 0.3 atm overnight. Such conditions should be sufficient for minimal solute loss and selective removal all of the adsorbed and entrained water, since the vapor pressures of most multi $-\mathrm{OH}$ solutes are substantially lower that that of water. In this case, $\mathrm{Q}_{2}$ is approximately $\left(\mathrm{m}_{\mathrm{wet}}-\mathrm{m}\right) / \mathrm{m}$. Another method of directly determining $\mathrm{Q}_{2}$ is through TGA. Accurate values for the individual uptake are essential for defining the starting conditions for desorption and batch regeneration experiments.

Desorption is the inverse of adsorption. The direction of mass transfer is now from the adsorbent to the bulk solution. Experiments where conditions are more favorable for desorption will be referred to as "regeneration" experiments. Two methods of regeneration are the use of different temperatures and the use of different solvents between the adsorption and desorption stages. 
The mass-balance equations for desorption are easily developed, since the individual uptake after adsorption represents the total mass of solute in the system. With this in mind, the mass balance for desorption is:

$$
\mathrm{mQ}_{2}=\mathrm{mq}_{2}^{\prime}+\left(\mathrm{w}_{\mathrm{o}}^{\prime}+\mathrm{m}_{\mathrm{wet}}-\mathrm{m}\right) \mathrm{x}_{2 \mathrm{f}} \mathrm{f}^{\prime}
$$

The $\left.{ }^{\prime}\right)$ refers to conditions for the desorption experiment. Eq. (2.4.3-7) states that the solute originally on the adsorbent is re-distributed between the liquid and solid phases once equilibrium is reached. The quantity of interest is $\mathrm{q}_{2}^{\prime}$, the composite uptake after desorption:

$$
\mathrm{q}_{2}^{\prime}=\frac{\mathrm{mQ}_{2}-\left(\mathrm{W}_{\mathrm{o}}^{\prime}+\mathrm{m}_{\mathrm{wet}}-\mathrm{m}\right) \mathrm{X}_{2 \mathrm{f}}{ }^{\prime}}{\mathrm{m}}
$$

The individual uptakes, $Q_{1}{ }^{\prime}$ and $Q_{2}{ }^{\prime}$ are determined by applying eqs. (2.4.2-2) and (2.4.36) for desorption conditions. It is also useful to define the reversible composite uptake:

$$
\mathrm{q}_{2 \mathrm{rev}}=\mathrm{q}_{2}-\mathrm{q}_{2}^{\prime}
$$

This immediately leads to defining "percent regeneration," which indicates the relative amount of solute removed from the adsorbent during desorption: 


$$
\% R E=100\left(\frac{q_{2 r e v}}{q_{2}}\right)
$$

\subsubsection{Experimental Verification of Equilibrium Conditions}

In adsorption experiments, equilibrium can be achieved if both time and the degree of agitation are sufficient to insure adequate contact between liquid and solid phases. As all adsorbents used in our batch experiments were dry, it was important to demonstrate that 24 hours in the shaker bath is sufficient for complete wetting of the particles. Figure 2.4-1 compares two adsorption isotherms $\left(25^{\circ} \mathrm{C}\right)$ for glucose on untreated $\mathrm{F} 400$ carbon. The pre-wetted batch was prepared by immersion of dry carbons into boiling water for 30 minutes, followed by centrifugation to remove interstitial liquid. The results for both wet and dry batches are similar; therefore, the use of dry carbons in 24-hour equilibration experiments is justified.

Another characteristic of equilibrium is that the solute concentration in the bulk solution no longer changes with time. Figure 2.4-2 shows separate rate experiments $\left(25^{\circ} \mathrm{C}\right)$ for ethylene glycol (EG) and glucose adsorbing onto dry, untreated F400 carbon. All of the data points correspond to independent experiments. There is little scatter in the data, as the loadings determined after 24 hours are consistent with those found at longer times. 


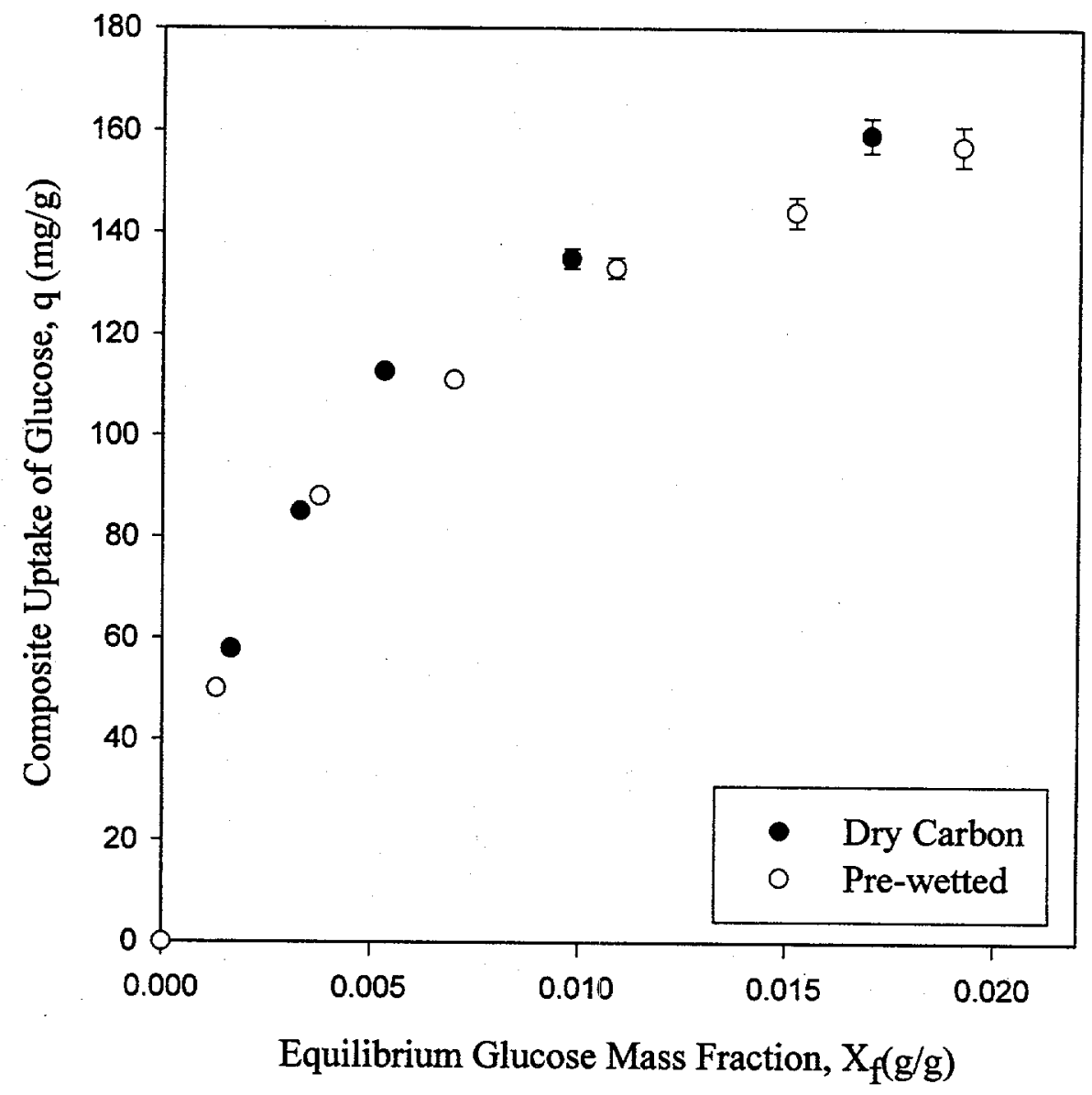

Figure 2.4-1. Adsorption isotherms $\left(25^{\circ} \mathrm{C}\right)$ for glucose on untreated $\mathrm{F} 400$ carbon, dry and pre-wetted. 


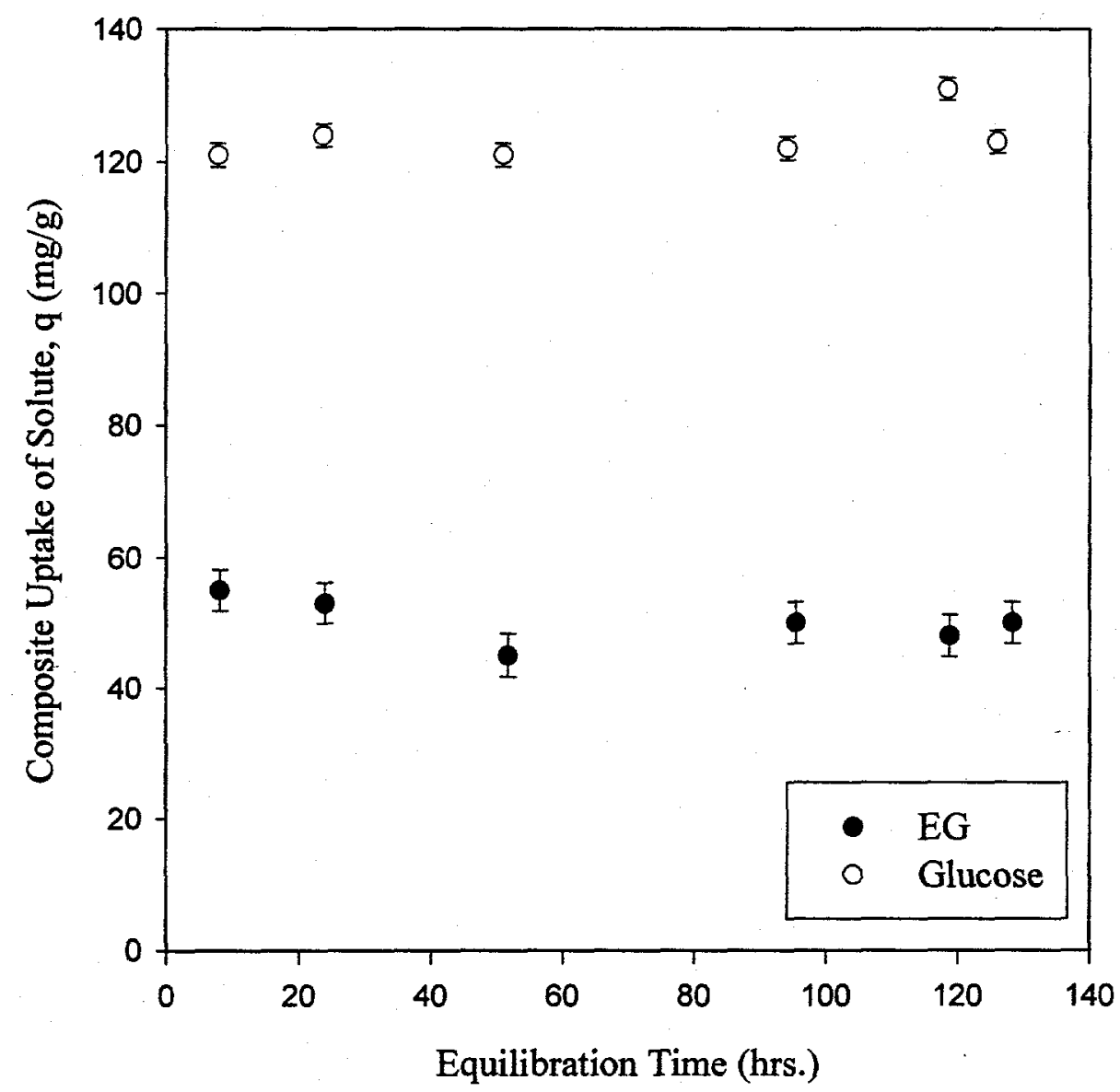

Figure 2.4-2. Adsorption rate experiments $\left(25^{\circ} \mathrm{C}\right)$ for ethylene glycol (EG) and glucose on untreated F400 carbon. All data points are independent experiments. 
Figure 2.4-3 depicts a rate experiment for the desorption of EG from untreated F400

carbon, using three different solvents. Each data set is a single experiment where EG was first loaded onto the carbon $(105,152$, and $143 \mathrm{mg} / \mathrm{g})$ from aqueous solution, and then equilibrated with $100 \mathrm{~mL}$ of water, acetone, or methanol respectively. The results for all three solvents are fairly consistent. Standard deviations from the average concentration in a given set ranged from $2 \%$ (for water) to $4.5 \%$ (for acetone).

One final criterion to establish equilibrium in batch adsorption experiments is to test whether the same final state can be obtained from both the adsorptive and desorptive directions of mass transfer. Figure 2.4-4 shows the superposition of adsorption and desorption isotherms $\left(25^{\circ} \mathrm{C}\right)$ for glucose on untreated $\mathrm{F} 400$. The desorption curve was obtained by equilibrating the carbons from the adsorption stage with water or dilute EG solutions. The results do not suggest any strong hysteresis effects up to equilibrium EG concentrations of $0.03 \mathrm{~g} / \mathrm{g}$, as both isotherms seem to match. Since the high affinity sites are expected to fill up at low concentrations, we can conclude from this data that the adsorption process is reversible. At higher concentrations, the results become unclear due to the great experimental uncertainty in the desorption points (arising from error propagation in measuring q). A detailed description of error analysis is provided in Appendix B. 


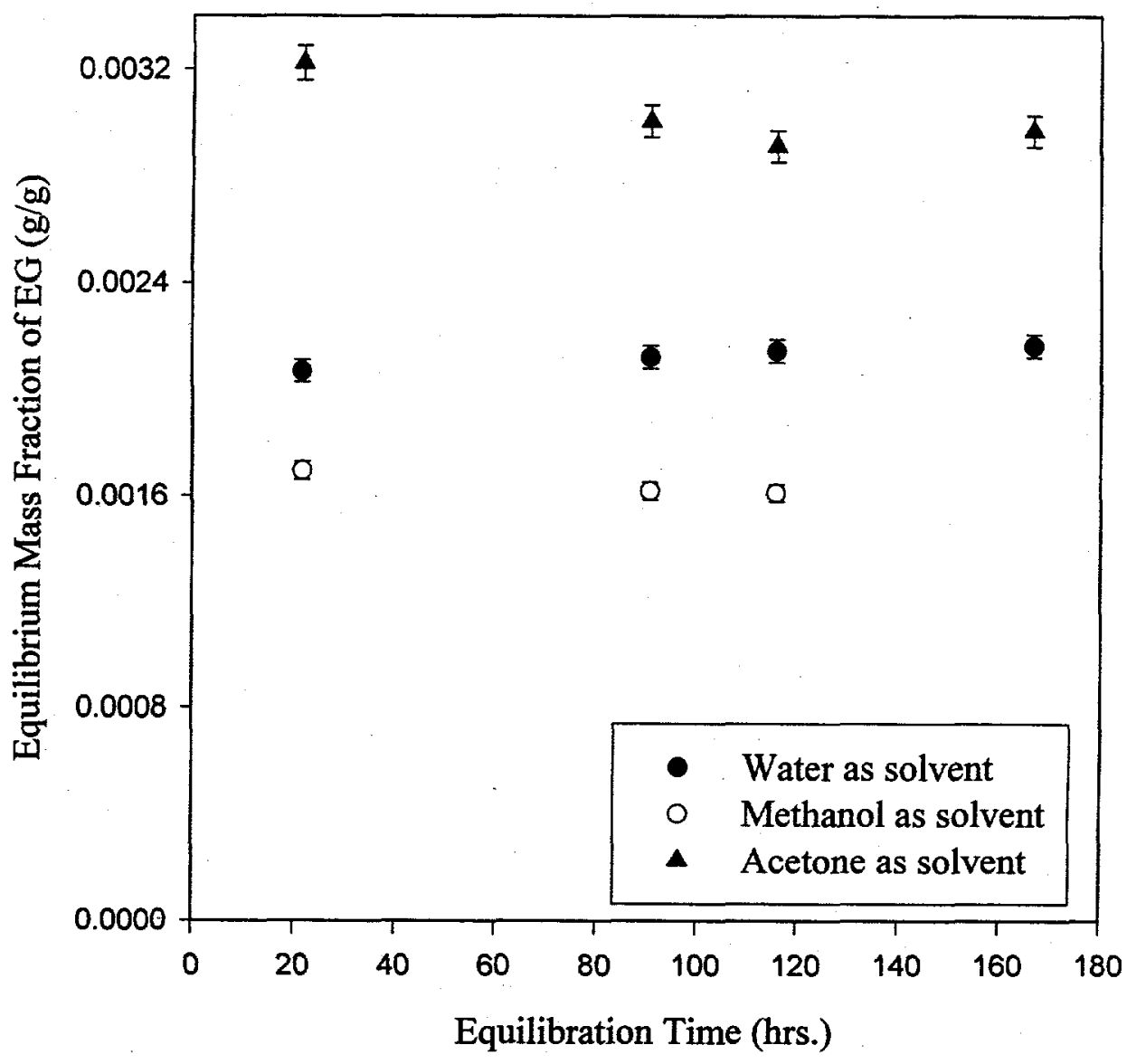

Figure 2.4-3. Desorption rate experiments $\left(25^{\circ} \mathrm{C}\right)$ for ethylene glycol (EG) on untreated F400 carbon. Original EG loadings for water, acetone, and methanol experiments were 105,152 , and $143 \mathrm{mg} / \mathrm{g}$, respectively. 


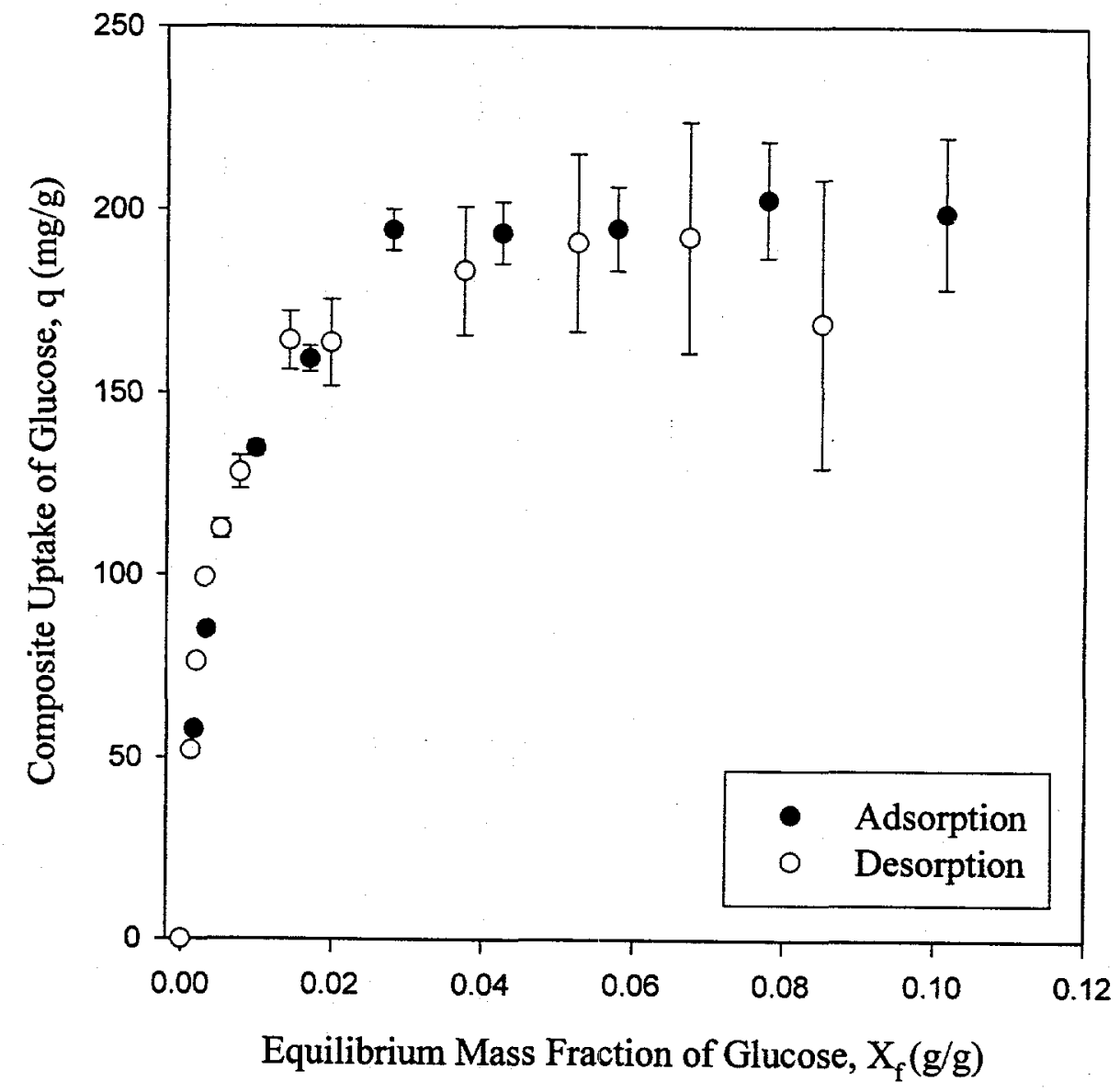

Figure 2.4-4. Adsorption and desorption isotherms $\left(25^{\circ} \mathrm{C}\right)$ for glucose loaded on untreated F400 carbon. All desorption data obtained from carbons loaded during the adsorption stage. 


\subsection{Acidic/Basic Site Characterization on Carbons}

The methods used for characterizing the surface acidity and basicity of carbons are similar to those of Bandosz et al. (1992). About $0.4 \mathrm{~g}$ of carbon was equilibrated with 20 g of $0.05 \mathrm{~N} \mathrm{HCl}$ or $0.05 \mathrm{~N} \mathrm{NaOH}$ using the apparatus and conditions for equilibration described previously in Section 2.4.1. The solutions were then carefully filtered, weighed, and made ready to be analyzed by potentiometric titration.

The total amounts of acidic and basic sites on the surface are determined analogously to the composite uptake:

$$
q^{*}=\frac{V_{o}\left(C_{i}-C_{f}\right)}{m}
$$

where $V_{o}$ is the volume of solution (acidic or basic) added to the carbon (L), $C_{i}$ and $C_{f}$ are the respective initial and final concentrations of the solution (eq./L), and $\mathrm{q}^{*}$ is the total site density (eq./g carbon). For this calculation, it is assumed that $\mathrm{HCl}$ and $\mathrm{NaOH}$ neutralize the basic and acidic sites on the carbon with a 1:1 mole ratio. Equilibrium acid or base concentrations are determined by potentiometric titration. This technique is described by Flaschka et al. (1969). 


\subsection{Fixed Bed Analysis}

\subsubsection{Experimental Methods}

Figure 2.6-1 highlights the equipment used for the fixed-bed experiments. Before use, 5 to $6 \mathrm{~g}$ of dried carbon were prewet by immersion into boiling water for 30 mins. The slurry of carbon was cooled to $25^{\circ} \mathrm{C}$, and then poured into a $1 \mathrm{~cm} \mathrm{x} 30 \mathrm{~cm}$ Chromaflex column (Kontes). During packing, the bed was gently tapped to insure the absence of air bubbles within the bed. Bed lengths were from 16 to $19 \mathrm{~cm}$ in our experiments. An adjustable plunger contained the inlet tubing to the bed, and was positioned in the liquid space of the bed about $5 \mathrm{~mm}$ above the carbons. The exit line from the column was connected to a 2211 Superrac Fraction Collector (LKB Bromma).

In adsorption (loading) experiments, the feed solution was passed through the bed using a Masterflex Model 7518-00 Pump (Cole-Parmer). Typical volumetric flowrates used in our experiments were 2.0 to $3.5 \mathrm{~mL} / \mathrm{min}$. The fraction collector was started once the solution front visibly mixed within the liquid space at the beginning of the bed. Fractions of the column effluent were collected automatically at fixed time intervals in $20-\mathrm{mL}$ glass scintillation vials. The composition of each liquid fraction was then determined by HPLC.

In regeneration experiments, the fraction collector was stopped after complete breakthrough of the feed solution. The solvent line was switched to that of the regenerating solvent, and then the entire procedure described above was repeated. 


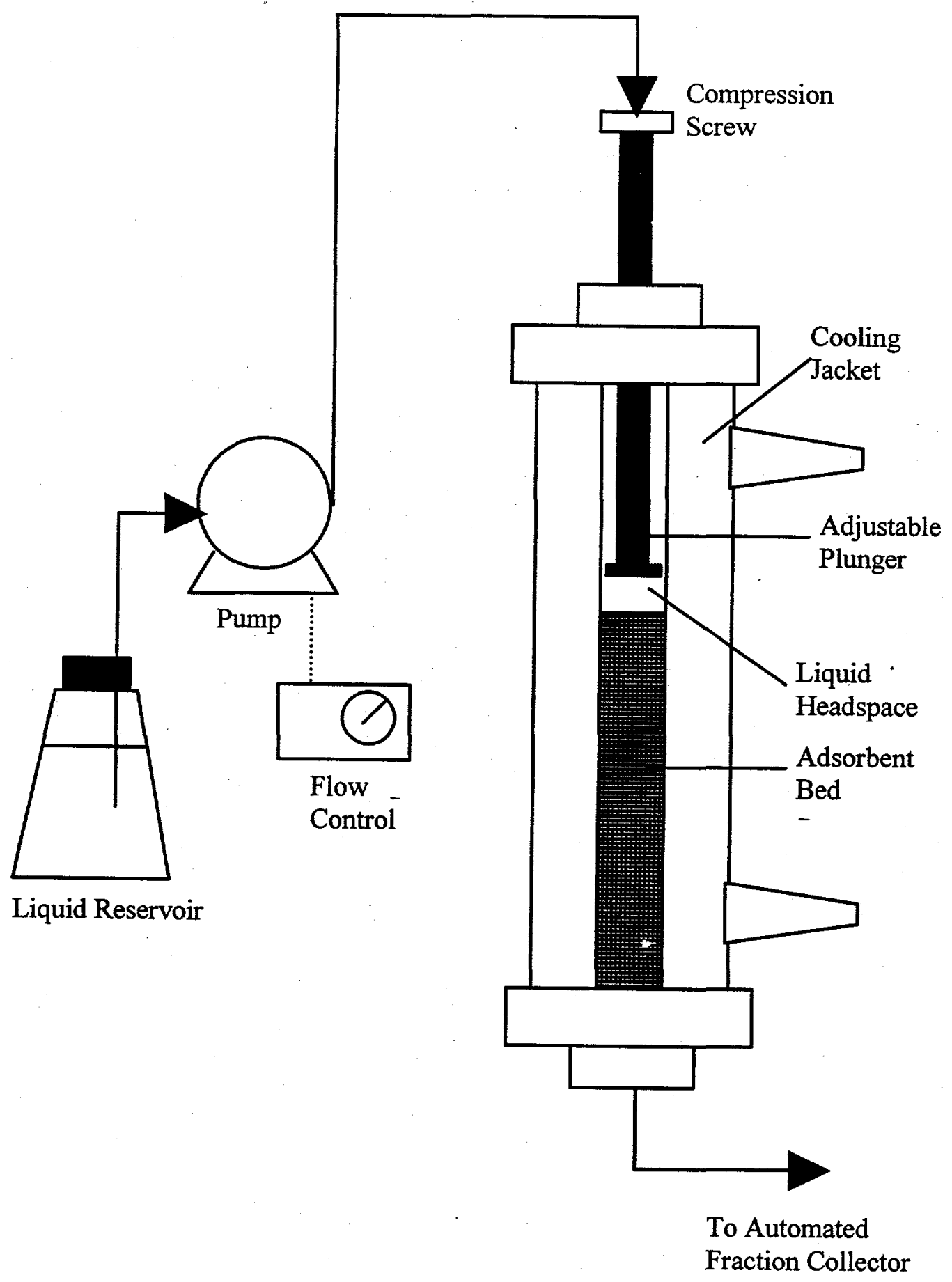

Figure 2.6-1. Schematic of equipment used for fixed-bed experiments. 
Typical flowrates during regeneration were lower, usually from 0.3 to $0.5 \mathrm{~mL} / \mathrm{min}$.

\subsubsection{Conventions for Fixed-Bed Work}

For both loading (breakthrough) and regeneration experiments, the relative concentration, $\left(\mathrm{C} / \mathrm{C}_{0}\right)$ is frequently plotted against the number of bed volumes, $\mathrm{BV}$. This represents the cumulative volumes of liquid processed through the bed. Our convention is the following:

$$
\mathrm{BV}=\frac{\mathrm{Ft}}{\frac{\pi}{4} \mathrm{D}_{\mathrm{T}}{ }^{2} \mathrm{~L} \varepsilon_{\mathrm{e}}}
$$

where $\mathrm{F}$ is the volumetric flowrate $(\mathrm{mL} / \mathrm{min}), t$ is time $(\mathrm{min}), \mathrm{D}_{\mathrm{T}}$ is the column diameter $(\mathrm{cm}), L$ is the bed length $(\mathrm{cm})$, and $\varepsilon_{\mathrm{e}}$ is the interstitial porosity. Zero bed volume $(\mathrm{t}=0)$ is defined when solution first contacts the carbon at the top of the bed.

The interstitial porosity, $\varepsilon_{\mathrm{e}}$, is defined as the volume of voids between particles per total bed volume. It is experimentally determined by: 


$$
\varepsilon_{\mathrm{e}}=1-\frac{\mathrm{m}_{\mathrm{dry}}\left(\frac{\mathrm{m}_{\mathrm{w}}}{\mathrm{m}_{\mathrm{d}}}\right)\left(\frac{1}{\rho_{\text {wet }}}\right)}{\frac{\pi}{4} \mathrm{D}_{\mathrm{T}}{ }^{2} \mathrm{~L}}
$$

where $m_{d r y}$ is the total dry carbon mass in the bed $(g),\left(m_{w} / m_{d}\right)$ is the characteristic ratio between the wet and dry mass for the particular type of carbon, and $\rho_{\text {wet }}$ is the solid density of fully wetted carbon. Densities are determined by measuring volume change upon submerging known weights of wetted carbons into water in $10-\mathrm{mL}$ graduated cylinders. Most of our fixed-bed work involved heat-treated F400 carbons, with $\varepsilon_{\mathrm{e}}$ equal to about 0.46 .

In our work, bed volumes were typically in the range of 6 to $7 \mathrm{~cm}^{3}$. The liquid headspace above the solids amounted to only $6 \%$ of the overall bed volume. 


\section{References for Chapter 2}

Adamson, A.W. Physical Chemistry of Surfaces, $2^{\text {nd }}$ edition. Interscience-John Wiley and Sons, Inc.: New York, 1961.

Bandosz, T.J.; Jagiello, J.; Schwarz, J.A. Analytical Chemistry, 1992, 64, 891-895.

Barrett, E.P.; Joyner, L.G.; Halenda, P.P. Journal of the American Chemical Society. 1951, 73, 373-380.

Dollimore, D.; Heal, G.R. Journal of Colloid and Interfacial Science, 1970, 33, 508.

Flaschka, H.A.; Barnard Jr., A.J.; Sturrock, P.E. Quantitative Analytical Chemistry: Vol. I. Barnes and Noble, Inc., 1969.

Frierman, M. M.S. Thesis, Department of Chemical Engineering, University of California, Berkeley, Berkeley, CA, 1983.

Kipling, J.J. Adsorption from Solutions of Non-Electrolytes. Academic Press: New York, 1965.

Kopal, Z. Numerical Analysis, $2^{\text {nd }}$ edition. John Wiley and Sons, Inc.: New York, 1961. 


\section{Chapter 3. Properties of Adsorbents}

\subsection{Overview}

This chapter summarizes some of the physical and chemical properties of the adsorbents used in our work. Classical methods such as BET-surface-area measurement, nitrogen porosimetry, and bulk elemental analysis are included. We have also measured surface acidity/basicity for a number of carbons, with different source materials and/or degrees of surface modification. Finally, we will review some of the related work that has provided much insight into the surface chemistry of activated carbons.

\subsection{Water Uptake by Pore-Filling in Adsorbents}

As discussed previously in Section 2.4 .2 , the total pore volume may be estimated by weighing the carbons after centrifugation, under conditions where most of the interstitial water has been removed. The pore volume accessible to water is a useful parameter, as it allows one to distinguish the amount of non-selectively held solute from solute actually sorbed onto the surface. Table 3.2-1 shows the results for the carbons used in our work.

TABLE 3.2-1

Pore Volume in Carbons Accessible to Water

\begin{tabular}{|c|c|}
\hline CARBON & $\begin{array}{c}\text { WATER UPTAKE } \\
\left(\mathrm{cm}^{3} / \mathrm{g} \text { carbon }\right)\end{array}$ \\
\hline F400/HT & $0.69 \pm 0.03$ \\
\hline F400/OX50/2 & $0.68 \pm 0.01$ \\
\hline F400/OX70/2 & $0.53 \pm 0.03$ \\
\hline F400/OX70/9 & $0.63 \pm 0.01$ \\
\hline
\end{tabular}


(Table 3.2-1 Continued)

\begin{tabular}{|c|c|}
\hline CARBON & $\begin{array}{c}\text { WATER UPTAKE } \\
\left(\mathrm{cm}^{3} / \mathrm{g} \text { carbon }\right)\end{array}$ \\
\hline WVB/unt & $1.46 \pm 0.01$ \\
\hline WVB/HT & $1.2 \pm 0.03$ \\
\hline RO 0.8 /unt & $0.98 \pm 0.02$ \\
\hline
\end{tabular}

In Table 3.2-1 (and all subsequent tables), the abbreviations are as follows: unt denotes as-received, $\mathrm{HT}$ denotes heat-treated at $1000^{\circ} \mathrm{C}$ for 24 hours, and $\mathrm{OX} / \mathrm{x} / \mathrm{y}$ denotes acidoxidized at a temperature of $\mathrm{x}^{\circ} \mathrm{C}$ for $\mathrm{y}$ hours. The uncertainties in the measurements were based on the standard deviation of between 2 to 24 independent weighings.

This procedure for assessing pore volume was not easily applied to the Ambersorb adsorbents, since after centrifugation the particles were still wet. The overall porosities of A563, A572, and A575 were obtained through nitrogen porosimetry (Rohm and Haas, 1992). These results, along with the bulk densities reported by the manufacturer, are reported in Table 3.2-2 below.

TABLE 3.2-2

Physical Properties of Ambersorbs (Rohm and Haas, 1992)

\begin{tabular}{|c|c|c|}
\hline ADSORBENT & $\begin{array}{c}\text { BULK DENSITY } \\
\left(\mathrm{g} / \mathrm{cm}^{3}\right)\end{array}$ & $\begin{array}{c}\text { TOTAL POROSITY } \\
\left(\mathrm{cm}^{3} / \mathrm{g}\right)\end{array}$ \\
\hline A563 & 0.53 & 0.60 \\
\hline A572 & 0.49 & 0.84 \\
\hline A575 & 0.55 & 0.72 \\
\hline
\end{tabular}




\subsection{Nitrogen Adsorption Isotherms (BET Analysis)}

The nitrogen adsorption isotherms $(77 \mathrm{~K})$ for a representative group of carbons are shown in Figure 3.3-1. All of the carbons exhibited Type II isotherms, which are characteristic of physical adsorption of the solute, with the formation of multilayers at higher relative pressures (Brunauer, 1945). Since all of the vapor condenses into bulk liquid when atmospheric pressure is reached, the isotherms tend toward infinity as $P / P_{0}$ approaches unity.

Figure 3.3-1 shows that the nitrogen adsorption isotherms are remarkably similar between the RO 0.8 and both varieties (heat-treated and oxidized) of F400 carbons. Both of these carbons were steam-activated during the manufacturing process. If their starting materials were similar in composition, then it might be expected that they share similar pore structures and surface properties. The observed similarity between the heat-treated and oxidized carbons supports the notion that the acid-oxidation was mild enough to leave the pore structure intact (Noh and Schwarz, 1990). Heat treatment appears to have lowered the nitrogen capacity for the WVB carbon, which was derived from wood and possesses a high oxygen content. In this case, heat treatment may have degraded part of the carbon, causing an increase in size or merging of some of the pores, with subsequent loss in overall surface area.

\subsubsection{Surface Areas of Adsorbents}

As discussed in Section 2.3.3.1, surface areas were obtained from fitting data to the nonlinear, multilayer BET equation. The surface areas determined from the linearized 


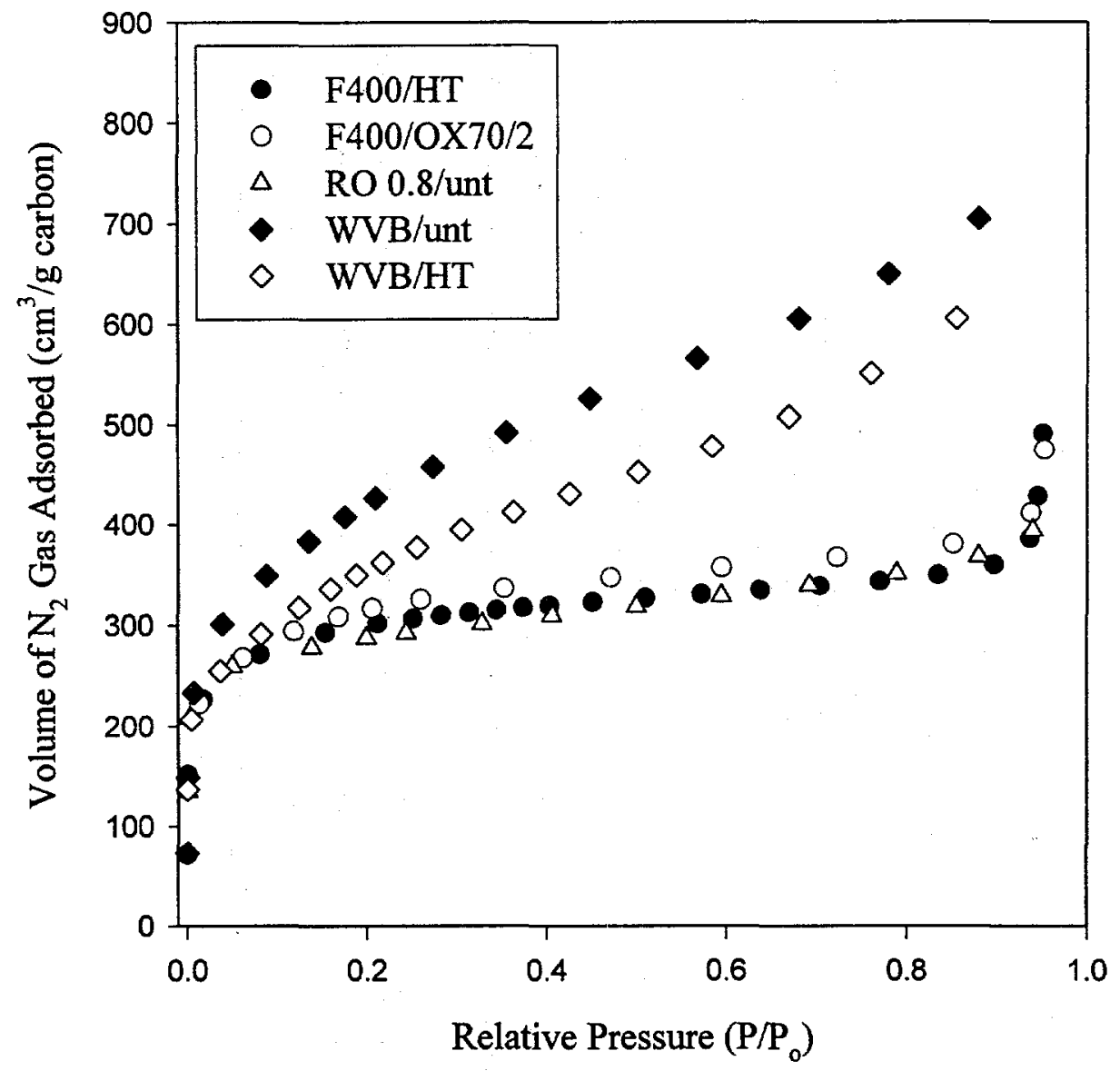

Figure 3.3-1. Nitrogen adsorption isotherms $(77 \mathrm{~K})$ for several representative carbons in our work. $\mathrm{P}_{0}$ corresponds to atmospheric pressure, 14.7 psia. 
form of the BET equation have similar values; however, this method tends to yield inconsistent values for the parameter $\mathrm{K}$ in eq. (2.3.3-1). Surface area results for all of the carbons, along with the parameters and associated errors based on the regression, are summarized in Table 3.3-1.

TABLE 3.3-1

BET Parameters and Surface Area of Carbons

\begin{tabular}{|c|c|c|c||}
\hline CARBON & $\mathrm{K}$ & $\mathrm{V}_{\mathrm{MAX}}\left(\mathrm{cm}^{3} / \mathrm{g}\right)$ & $\mathrm{SSA}\left(\mathrm{m}^{2} / \mathrm{g}\right)$ \\
\hline F400/unt & $4351( \pm 29 \%)$ & $253( \pm 5 \%)$ & 1103 \\
\hline F400/HT & $4906( \pm 26 \%)$ & $242( \pm 3 \%)$ & 1054 \\
\hline F400/OX50/2 & $5583( \pm 23 \%)$ & $239( \pm 3 \%)$ & 1040 \\
\hline F400/OX70/2 & $3285( \pm 19 \%)$ & $250( \pm 3 \%)$ & 1090 \\
\hline F400/OX70/9 & $4596( \pm 29 \%)$ & $199( \pm 4 \%)$ & 865 \\
\hline WVB/unt & $1373( \pm 38 \%)$ & $314( \pm 5 \%)$ & 1369 \\
\hline WVB/HT & $3318( \pm 15 \%)$ & $267( \pm 5 \%)$ & 1168 \\
\hline RO 0.8/unt & $9759( \pm 26 \%)$ & $253( \pm 5 \%)$ & 1103 \\
\hline
\end{tabular}

According to eq. 2.3.3-2, the percent-error associated with $V_{\max }$ is equal to the error in surface area. With the exception of the most severely oxidized sample (F400/OX70/9), all of the F400 surface areas are within $6 \%$ of each other. The adsorption properties of the F400 carbons can therefore be compared more on the basis of different surface chemistry, rather than on physical differences such as porosity and surface area.

The BET analysis was not performed on any of the Ambersorb adsorbents in our work, 
since data were directly available from the manufacturer. The surface areas of A563, A572, and A575 were reported to be $550 \mathrm{~m}^{2} / \mathrm{g}, 1100 \mathrm{~m}^{2} / \mathrm{g}$, and $800 \mathrm{~m}^{2} / \mathrm{g}$ (Rohm and Haas, 1992).

\subsubsection{Pore-Size Distribution of Carbons}

Pore-size distributions of some representative carbons, as determined from the BET analysis, are shown in Figure 3.3-2. The pore-volume derivative is plotted against the average pore radius, which enables one to determine the relative contribution of a given pore size to the overall pore volume. Most of the internal volume of RO 0.8 and the two F400 carbons (heat-treated and oxidized) is manifested in pores of radius $25 \AA$ or less. The WVB carbons appeared to have a much broader distribution of pores, ranging up to $75 \AA$. This might account for WVB having such a large capacity for holding water (about $1.5 \mathrm{~g} / \mathrm{g}$ dry carbon) compared to the other carbons. All carbons appeared to have maximum derivatives near radii of 10-15 $\AA$, which means that virtually all of the pore volume (and surface area) is attributed to micropores (IUPAC: radius $<10 \AA$ ).

As with any type of porosimetry experiment, the results shown in Figure 3.3-2 provide an approximation at best. In porous solids, the pores are not strictly non-irtersecting cylinders, but rather of irregular shape. Also, the concept of surface tension (and the Kelvin equation in general) becomes questionable when the pore radii approach the sizes of molecules (Barrett et al, 1951). Nevertheless, pore-size distributions derived from BET analysis are readily attainable and convenient for comparative studies. This technique could also complement classical mercury-intrusion methods, where the 


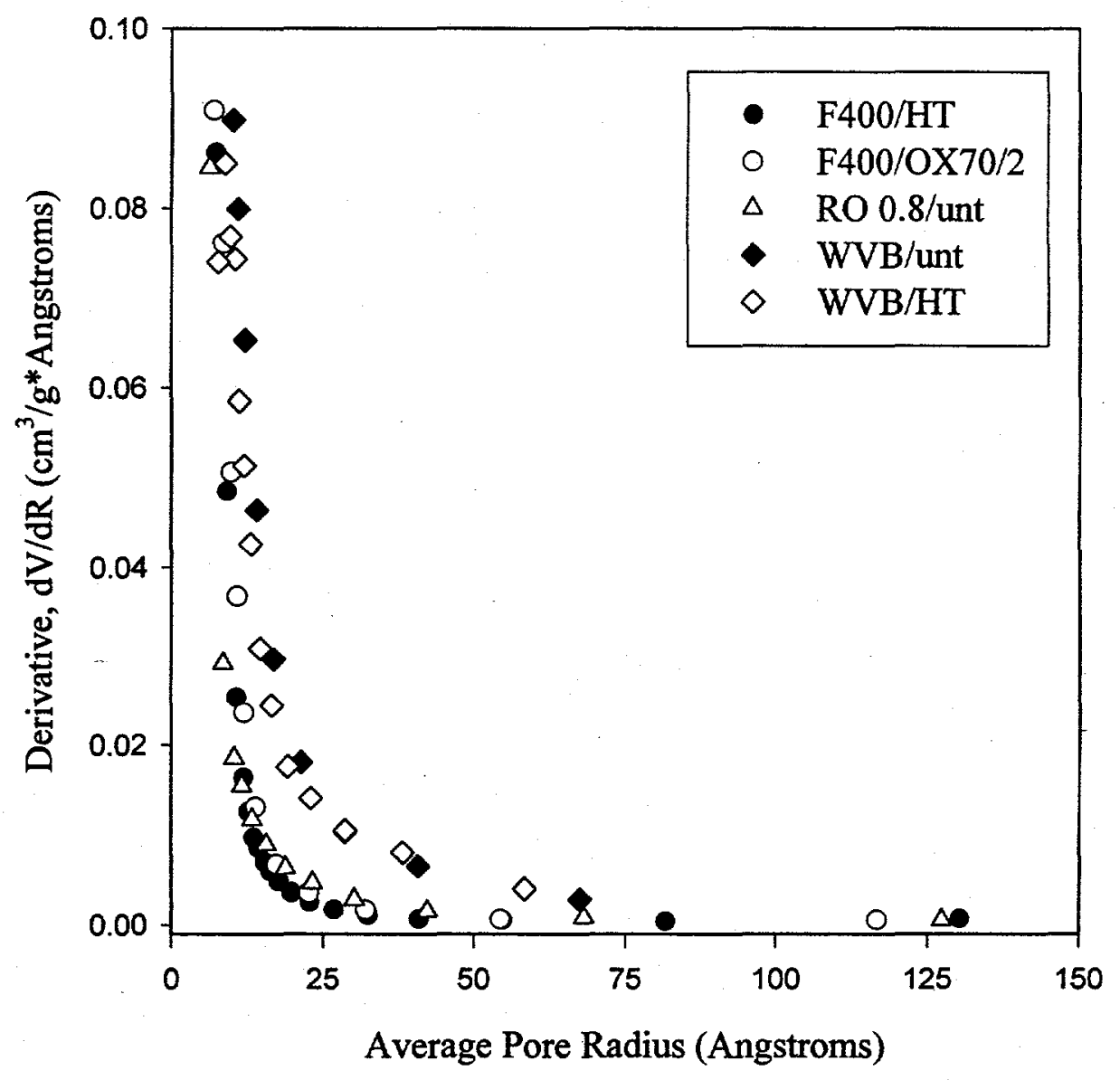

Figure 3.3-2. Pore-size distribution, as determined by nitrogen porosimetry, for several representative carbons in our work. 
minimum pore radius measurable is about $15 \AA$ (Munson, 1985).

\subsection{Bulk Elemental Analysis of Adsorbents}

Elemental analyses of as-received and surface-treated adsorbents were performed in the College of Chemistry Micro Analytical Laboratory at the University of California, Berkeley. The weight percentages of carbon, hydrogen, and nitrogen were determined with a Perkin-Elmer 240 Elemental Analyzer. The combined percentages of oxygen and sulfur were determined by difference. Before analysis, all adsorbents were dried in a vacuum oven to remove adsorbed water. Results for all activated carbons used in our work were originally done by Kilduff and King (1997), and are summarized in Table 3.41 below:

TABLE 3.4-1

Bulk Elemental Analysis of Active Carbons

\begin{tabular}{|c|c|c|c|c|c||}
\hline CARBON & C (WT\%) & H (WT\%) & N (WT\%) & O+S (WT\%) & ASH(WT\%) \\
\hline F400/unt & 92.85 & $<0.2$ & 0.80 & 0.05 & 6.30 \\
\hline F400/HT & 92.76 & $<0.2$ & 0.64 & 1.30 & 5.30 \\
\hline F400/OX50/2 & 89.32 & $<0.2$ & 0.71 & 5.27 & 4.70 \\
\hline F400/OX70/2 & 88.03 & $<0.2$ & 0.82 & 6.05 & 5.10 \\
\hline F400/OX70/9 & 86.48 & $<0.2$ & 0.85 & 7.17 & 5.50 \\
\hline WVB/unt & 87.57 & 1.77 & 0.27 & 8.59 & 1.80 \\
\hline WVB/HT & 93.42 & $<0.2$ & 0.28 & 3.20 & 3.10 \\
\hline RO 0.8/unt & 93.98 & $<0.2$ & 0.62 & 3.70 & 1.70 \\
\hline
\end{tabular}

Ash refers to the material remaining on the carbon after the elemental analysis (Munson, 
1985).

The sulfur contents of all carbons in this work are expected to be less than $1 \mathrm{wt} . \%$, based on measurements in the literature (Kilduff and King, 1997). As a result, Table 3.4-1 suggests that there is an increase in the overall oxygen content upon acid oxidation of asreceived carbons. Conversely, heat treatment of an oxygen-rich carbon such as WVB results is a substantial decrease (roughly 2.5 -fold) in overall oxygen content. As expected, carbons derived from coal (F400) have higher ash content (minerals or metals) than the wood and peat-based carbons (WVB, RO).

Elemental analysis was also performed with the Ambersorb adsorbents. The procedures are as discussed previously, with the substitution of sulfur for nitrogen in the direct elemental analysis. Oxygen content was therefore determined by difference. The ash content of the Ambersorbs was not measured, since it is typically less than $0.05 \mathrm{wt} . \%$ for these adsorbents (Rohm and Haas Co., 1992). Results of the elemental analysis for the as-received Ambersorbs are summarized in Table 3.4-2.

TABLE 3.4-2

Bulk Elemental Analysis of Ambersorbs

\begin{tabular}{|c|c|c|c|c||}
\hline \hline ADSORBENT & C (WT\%) & H(WT\%) & S (WT\%) & O(WT\%) \\
\hline A563 & 82.22 & 2.00 & 11.64 & 4.14 \\
\hline A572 & 93.31 & 0.58 & 3.20 & 2.71 \\
\hline A575 & 90.99 & 0.63 & 3.50 & 4.88 \\
\hline
\end{tabular}


The Ambersorbs appear to have a significantly higher hydrogen content (3-10 fold), but comparable carbon and oxygen contents to the activated carbons. Sulfur content is also high as expected, since the source material is sulfonated styrene-divinylbenzene copolymer.

The bulk elemental analyses of adsorbents are useful for comparing the chemical compositions of various adsorbents, as influenced by source material or surface treatments. However, differences is sorption behavior among adsorbents are usually attributed to surface, rather than bulk properties.

\subsection{Acidic and Basic Site Density of Adsorbents}

\subsubsection{Acidic Sites}

A substantial amount of research has been reported in the literature concerning the oxygen-bearing functional groups on activated carbons. Most, but not all, of these functionalities are associated with surface acidity. Figure 3.5.1-A shows a schematic representation of the oxygen-bearing groups believed to exist on activated carbons (You et al., 1994). These groups, some of which were consistent with infrared (IR) spectroscopic data, include carboxylic acid, lactone, quinone, carbonyl, and phenolic groups.

As Table 3.4-1 shows, oxygen appears to be added upon acid oxidation of carbons. This suggests the formation of new, surface oxides in addition to any oxidation of existing groups on the surface. It is believed that the mechanism of carbon oxidation occurs in the same manner as oxidation of aromatic hydrocarbons (Vinke et al., 1994). Figures 


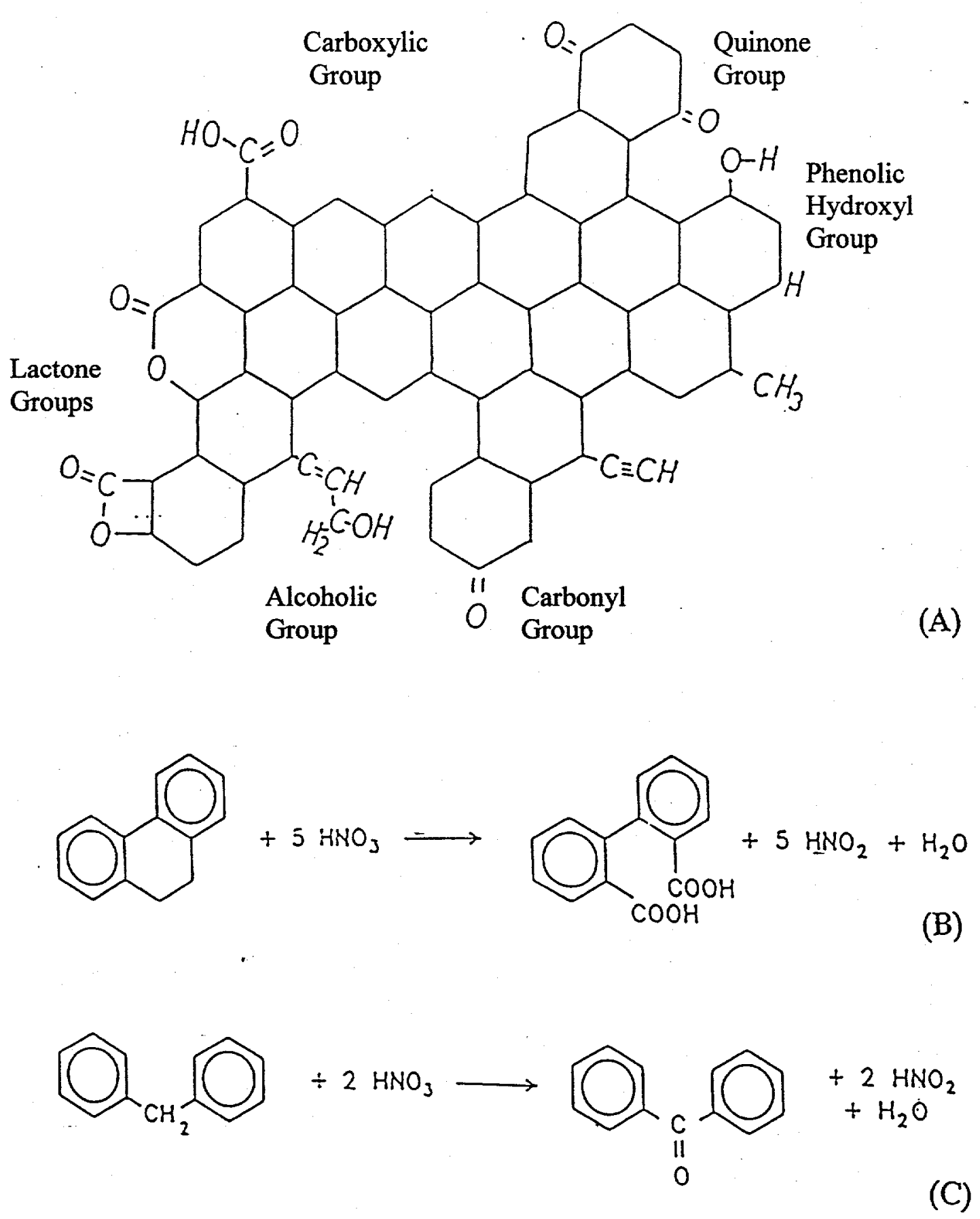

Figure 3.5.1-(A) Examples of surface oxide groups on active carbons (You et al., 1994).

(B) Oxidation of 9,10-dihydrophenanthrene by nitric acid (Vinke et al., 1994).

(C) Oxidation of diphenylmethane by nitric acid (Vinke et al., 1994). 
3.5.1-B and 3.5.1-C show oxidation reactions of 9,10-dihydrophenanthrene and diphenylmethane by nitric acid, which may be analogous to reactions during oxidation of carbons.

Calculation of acidic site densities, according to eq. (2.5-1), is highly dependent on the choice of the endpoint $\mathrm{pH}$ from the titration experiment. The $\mathrm{NaOH}$ solutions that were equilibrated with the carbons (to test for strong acidic sites) exhibited two sharp inflection points in the titration curves, at $\mathrm{pH}$ values about 8 and 4.5. An endpoint $\mathrm{pH}$ of 8.3 is characteristic of solutions where the alkalinity is due entirely to dissolved carbonate or bicarbonate, and is deemed "Phenolphthalein alkalinity" (Greenberg et al, 1985). The inflection observed at the endpoint $\mathrm{pH}$ of 4.5 is typically seen in industrial waste streams or complex systems, and is due to the presence of other bases (borates, phosphates, silicates, etc.). Titration to an endpoint $\mathrm{pH}$ of 4.5 is therefore regarded as a measure of total solution alkalinity. In our calculation of acidic site density, we report results at both endpoints.

Table 3.5-1 summarizes the acidic site densities measured for the various carbons used in this work. Tro independent runs on a given sample give densities lying usually within a few percent. Also included in Table 3.5-1 for comparison are the results reported by Kilduff and King (1997) for the same types of carbons. All results are reported on a milliequivalent per area basis (meq $/ 1000 \mathrm{~m}^{2}$ ) to account for the different carbon types and/or methods of surface treatment. Abbreviations are the same as in Table 3.2-1. ND means that the experiment was not performed in our work. 
TABLE 3.5-1

Acidic Site Densities for Carbons

\begin{tabular}{|c|c|c|c||}
\hline CARBON & $\begin{array}{c}\text { At } \mathrm{pH}=4.5 \\
\left(\mathrm{meq} / 1000 \mathrm{~m}^{2}\right)\end{array}$ & $\begin{array}{c}\text { At } \mathrm{pH}=8.3 \\
\left(\mathrm{meq} / 1000 \mathrm{~m}^{2}\right)\end{array}$ & $\begin{array}{c}\text { Kilduff }(1997) \\
\left(\mathrm{meq} / 1000 \mathrm{~m}^{2}\right)\end{array}$ \\
\hline F400/HT & 0.010 & 0.086 & 0.00 \\
\hline F400/OX50/2 & 0.65 & 0.82 & 0.60 \\
\hline F400/OX70/2 & 0.89 & 1.07 & 0.94 \\
\hline F400/OX70/9 & $\mathrm{ND}$ & $\mathrm{ND}$ & 1.71 \\
\hline WVB/unt & 0.44 & 0.632 & 0.57 \\
\hline WVB/HT & 0.159 & 0.281 & 0.31 \\
\hline RO 0.8/unt & 0.204 & 0.288 & 0.27 \\
\hline
\end{tabular}

Despite slight differences in experimental technique and adsorbent batches, most of the acidic site densities reported by Kilduff and King (1997) are consistent with our findings. Again, the choice of an endpoint $\mathrm{pH}$ during titration is an important, albeit arbitrary choice. Both sets of data clearly show that the surface becomes more acidic with increased oxidation temperature and time. As shown in Table 3.5-1, the surface acidity of F 400 could be raised by an order of magnitude by acid oxidation. Heat treatment appears to have the opposite effect for carbons with nominally high surface acidity. By comparing these trends with the data in Table 3.4-1, it can be argued that the bulk oxygen content of carbons correlate well with the density of surface acidic sites.

\subsubsection{Basic Sites}

In contrast to the $\mathrm{NaOH}$ solutions, the $\mathrm{HCl}$ solutions that were equilibrated with the carbons (to test for strong base sites) exhibited one strong inflection point ( $\mathrm{pH}$ around 8) 
in the titration curves. At $25^{\circ} \mathrm{C}$, a pH of 8.3 corresponds to stoichiometric neutralization of carbonic acid to bicarbonate in a solution of dissolved carbon dioxide, bicarbonates, and carbonates (Greenberg et al., 1985). Titration to an endpoint pH of 8.3 is therefore regarded as the standard measure for total acidity.

Table 3.5-2 lists the basic site densities measured for the carbons studied in our work, along with the results of Kilduff and King (1997).

TABLE 3.5-2

Basic Site Densities for Carbons

\begin{tabular}{|c|c|c|}
\hline \hline CARBON & $\begin{array}{c}\text { At } \mathrm{pH}=8.3 \\
\left(\mathrm{meq} / 1000 \mathrm{~m}^{2}\right)\end{array}$ & $\begin{array}{c}\text { Kilduff }(1997) \\
\left(\mathrm{meq} / 1000 \mathrm{~m}^{2}\right)\end{array}$ \\
\hline F400/HT & 0.546 & 0.37 \\
\hline F400/OX50/2 & 0.262 & 0.29 \\
\hline F400/OX70/2 & 0.198 & 0.22 \\
\hline F400/OX70/9 & ND & 0.11 \\
\hline WVB/unt & 0.134 & 0.18 \\
\hline WVB/HT & 0.366 & 0.26 \\
\hline RO 0.8/unt & 0.309 & 0.39 \\
\hline
\end{tabular}

Compared to the acid site densities, there appear to be larger deviations for the basic site densities for the as-received and heat-treated carbons. Batch-to-batch variations may have a larger influence on experimental results for these carbons. On the other hand, the acid-oxidized carbons have levels of surface acidity and basicity predominantly determined by the severity of oxidation. Consequently, the reproducibility of basic site 
density for oxidized samples appears better than in the unoxidized samples.

Compared to surface acidity, the densities of basic sites do not vary as greatly among different varieties of carbon. Our work shows that acid oxidation reduces the amount of basic sites. However, a 2 to 3 -fold reduction is observed only when the as-received sample is compared with the most severely oxidized sample. Unless the carbon has an initially high level of surface acidity/oxygen content, heat treatment does not appear to raise the number of basic sites significantly.

\subsection{Water-Vapor Adsorption on Carbons}

To verify that oxidized surfaces were indeed more hydrophilic, Kilduff and King (1997) performed water-vapor adsorption experiments. Dried batches of carbons were equilibrated through the vapor phase with a continuously-stirred saturated solution of sodium acetate $\left(\mathrm{CH}_{3} \mathrm{COONa}\right)$. All experiments were performed at $25^{\circ} \mathrm{C}$, and at a relative humidity of $22.5 \%$.

The data are presented in Figure 3.6-1, with the black dots corresponding to carbons used in our work. Although some scatter is seen in the data (possibly related to individual differences among carbon types), it is clear that more oxidized surfaces correspond to a greater affinity for water. The line drawn in Figure 3.6-1 represents an attempt to correlate water-uptake $\left(\mathrm{mg} / 1000 \mathrm{~m}^{2}\right)$ and acid-site $\left(\mathrm{meq} / 1000 \mathrm{~m}^{2}\right)$ data for all carbons by 


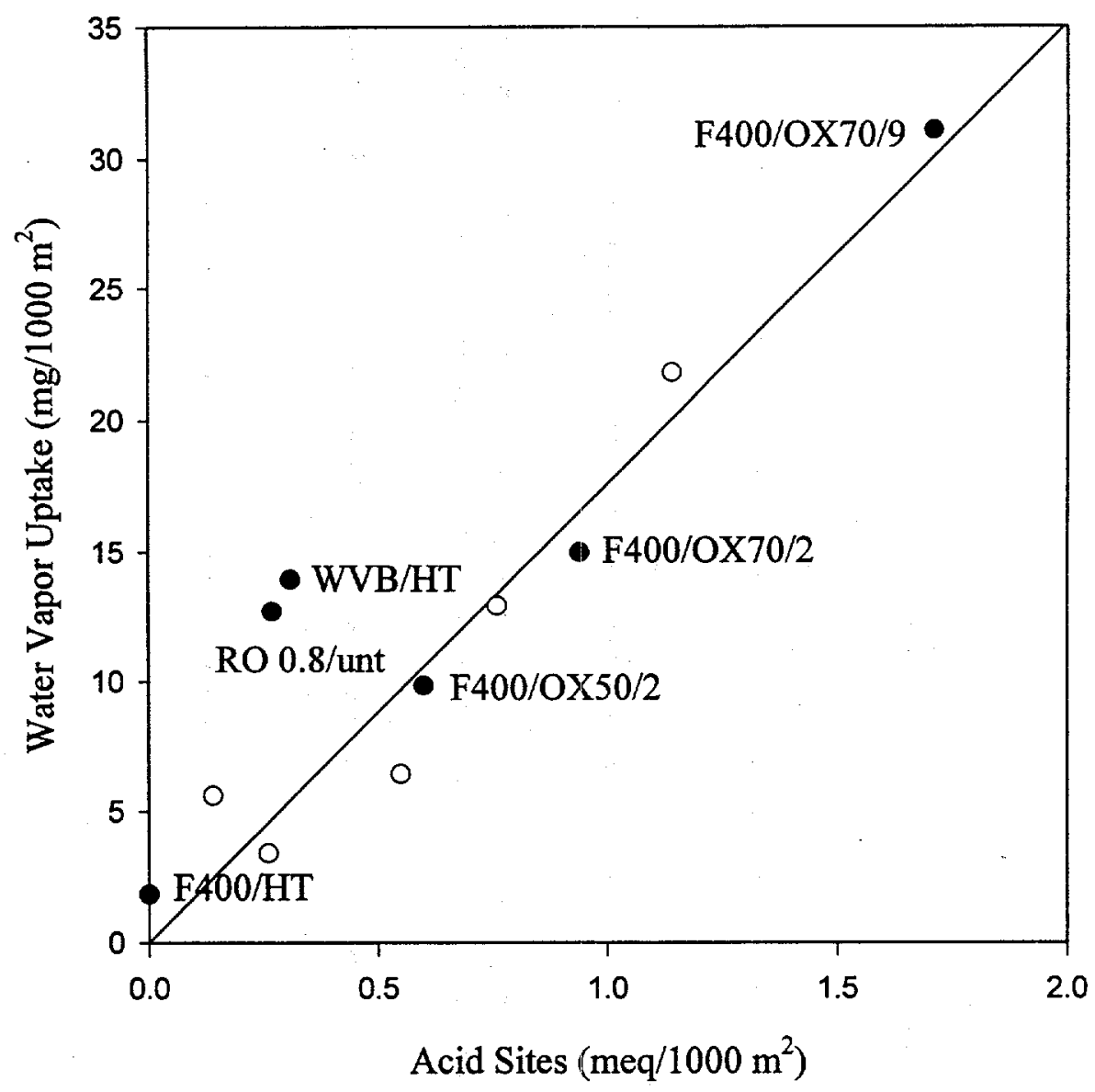

Figure 3.6-1. Water-vapor uptake $\left(25^{\circ} \mathrm{C}, \mathrm{RH}=22.5 \%\right)$ as a function of surface acidity for several carbons. Data in black correspond to carbons used in our work. Reference: Kilduff and King, 1997. 
linear regression:

$$
\begin{gathered}
{[\text { Water Uptake }]=0.015+17.56[\text { Acid Sites }]} \\
\qquad \mathrm{r}^{2}=0.88
\end{gathered}
$$

The results do not correlate well with the WVB/HT and RO 0.8/unt carbons, but do reasonably well for carbons of the same family with varying degrees of acidity (F400).

\subsection{Other Characterization Methods}

In addition to measuring acidic or basic site density by titration, two common methods of assessing surface oxide groups include Fourier Transform Infrared Spectroscopy (FTIR) and Linear Temperature-Programmed Desorption of carbons (LTPD).

Our efforts with the FTIR were of little success due to low signal-to-noise ratio and background absorption by the carbon. Work with both direct transmission and diffuse reflectance FTIR resulted in spectra that were indistinguishable between different carbons. One possible reason for our difficulties is the inherently low oxygen content of our F400 carbon samples (1-7 wt. \% O). Some researchers who reported sharp peaks for the carbonyl functionality (ca. $1700 \mathrm{~cm}^{-1}$ ) used carbons with much higher oxygen content of 9-30 wt. \% (Starsinic et al., 1983; Munson, 1985; Gomez-Serrano et al., 1994; Vinke et al., 1994). Problems could also have arisen from inadequate sample preparation. Optimum sample concentrations, grinding methods, sample size, etc. apparently varies from researcher to researcher. 
LTPD is a method very similar to TGA, except that the composition of the effluent gases is continuously measured, rather than the sample mass. Normally, researchers report the evolution of $\mathrm{CO}, \mathrm{CO}_{2}$, and $\mathrm{H}_{2} \mathrm{O}$ as carbons are heated linearly to a high temperature. The TGA equipment in our work was not equipped with a suitable detector to analyze the effluent gases. Consequently, our TGA work (Chapter 6) was focused more on characterizing the adsorbed phase rather than the carbon itself.

\subsection{Insights on Surface Chemistry}

\subsubsection{Acidic Sites}

Many researchers have succeeded in combining several methods (site titration, FTIR, and LTPD) to provide much insight on the surface acidity of activated carbons. Using both site titration and LTPD, Otake and Jenkins (1993) demonstrated that a linear relationship exists between the $\mathrm{NaOH}$ neutralizing capacity of a carbon and the total moles of oxygen desorbing as $\mathrm{CO}_{2}$. This was found to be true for carbons oxidized by air and nitric acid. They also hypothesized that nitric-acid oxidation led to the preferential formation of "distant" carboxylic acid groups, which were able to neutralize $\mathrm{NaOH}$ and $\mathrm{Ba}(\mathrm{OH})_{2}$ in a nearly $1: 1$ ratio. On the other hand, high-temperature oxidation by air led to the preferential formation of "adjacent" carboxylic (or carboxyl anhydride) groups, which neutralized $\mathrm{Ba}(\mathrm{OH})_{2}$ at a 2:1 ratio. No correlation was found between surface acidity and oxygen desorbing as $\mathrm{CO}$; as a result, these groups did not appear to contribute to surface acidity.

FTIR has provided further evidence that carboxylic acid sites are mainly responsible for 
the surface acidity of carbons. Most researchers report three important regions in the FTIR spectra when working with carbons: a peak at $1220 \mathrm{~cm}^{-1}$ associated with C-O linkages, a $1580 \mathrm{~cm}^{-1}$ peak associated with aromatic, $\mathrm{C}=\mathrm{C}$ bond stretches, and a peak at $1720 \mathrm{~cm}^{-1}$ associated with $\mathrm{C}=\mathrm{O}$ stretches (Kinoshita, 1988). Researchers typically assign the $1720 \mathrm{~cm}^{-1}$ peak to carboxylic acid groups, based on the reactive nature of oxidized carbons. The $1720 \mathrm{~cm}^{-1}$ peak was found to diminish as the carbon was: neutralized by $\mathrm{NaOH}$ (Starsinic et al., 1983; Munson, 1985), reduced by $\mathrm{LiAlH}_{4}$ (Munson, 1985), or reacted with ammonia (Vinke et al., 1994). Similarly, it was found that the $1720 \mathrm{~cm}^{-1}$ peak increased upon the various modes of oxidation: air (Starsinic et al., 1983), nitric acid (Vinke et al., 1994), and hydrogen peroxide (Gomez-Serrano et al., 1994).

\subsubsection{Basic Sites}

Compared to acidic surface sites, there has been less work done on the study of basic surface sites. Figures 3.8.1-A, B, and C show three separated mechanisms proposed in the literature (Leon y Leon et al., 1992), whereby a proton can be accepted by a functional group on the carbon. Figure 3.8.1-A depicts acid adsorption onto chromene structures or free radical sites via solution-phase oxidation/reduction reactions. The ionic products generated are resonance-stabilized. Figure 3.8.1-B shows aid adsorption onto pyrone-type structures, where the basic site is made up of two non-neighboring oxygens. The positive charge is resonance-stabilized if the two oxygen atoms are located on different rings of a given graphite layer. Finally, Figure 3.8.1-C shows a situation where a proton is directly accepted by a site on the carbon basal plane. In this mechanism, oxygen-bearing sites do not affect the adsorption of acid. Basic sites are therefore 
<smiles>[R]c1ccc(C)c(C)c1CC(C)O[PH2+]</smiles>

and/or

(A)

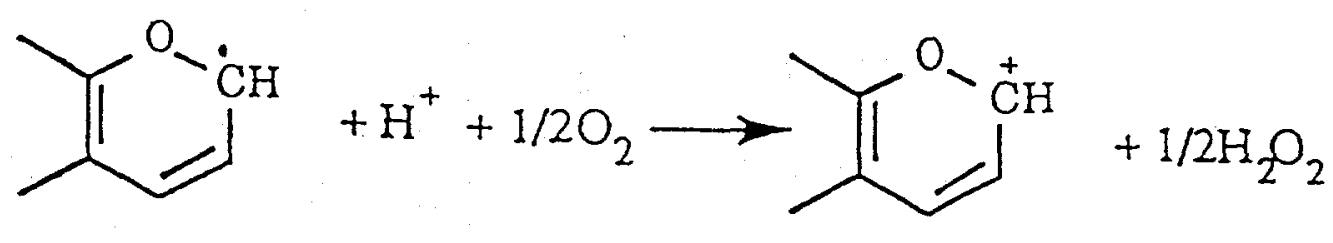

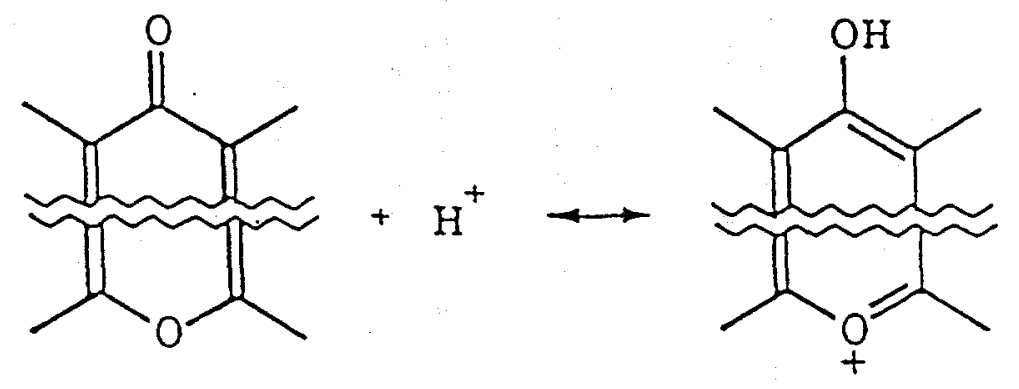

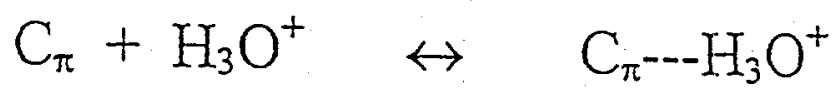

Figure 3.8.1-(A). Addition of a proton onto chromene and free-radical sites via an oxidation/reduction reaction. (B) Proton addition onto adjacent, resonance-stabilized pyrone structures. (C) Direct protonation of carbon basal plane, leading to an electron donor-acceptor complex. (All mechanisms taken from Leon y Leon et al., 1992). 
located at $\pi$ electron-rich regions, and form electron donor-acceptor (EDA) interactions with $\mathrm{H}_{3} \mathrm{O}^{+}$. Leon y Leon et al. (1992) postulated that carbons with high oxygen content ( $\geq 1$ wt. \%) adsorb $\mathrm{HCl}$ according to the mechanism of Figure 3.8.1-B. Here, the ratios of $\mathrm{HCl}$ adsorbed to the overall oxygen content, $[\mathrm{HCl}] /[\mathrm{O}]$, were of the order 1 . Carbons with lower oxygen content had $[\mathrm{HCl}] /[\mathrm{O}]>>2$, which suggested that the basal-plane protonation mechanism of Figure 3.8.1-C was dominant. The enhanced adsorption of $\mathrm{HCl}$ in our heat-treated $\mathrm{F} 400$ carbons (as opposed to the oxidized forms) appear to be consistent with this mechanism as well. 
References for Chapter 3

Barrett, E.P.; Joyner, L.G.; Halenda, P.P. Journal of the American Chemical Society, 1951, 73, 373-380.

Brunauer, S. The Adsorption of Gases and Vapors, Vol. I, Princeton University Press: Princeton, New Jersey, 1945.

Gomez-Serrano, V.; Acedo-Ramos, M.; Lopez-Peinado, A.J.; Valenzuela-Calahorro, C. Fuel, 1994, 3, 387-395.

Greenberg, A.E.; Trussell, R.R.; Clesceri, L.S., Eds. Standard Methods for the Examination of Water and Wastewater, $16^{\text {th }}$ Edition, 1985, A.P.H.A.: Washington D.C.

Kilduff, J.E.; King, C.J. Ind. Eng. Chem. Res., 1997, 36, 1603-1613.

Kinoshita, K. Carbon Electrochemical Physicochemical Properties, John Wiley and Sons Inc., 1988.

Leon y Leon, C.A.; Solar, J.M.; Calemma, V.; Radovic, L.R. Carbon, 1992, 30, 5, 797-811.

Munson, C.L. Separation of Polar Organics from Dilute Aqueous Solutions by the Methods of Liquid Extraction and Solid Adsorption onto Activated Carbons. Ph.D. Dissertation, University of California, Berkeley, CA, 1985.

Noh, J.S.; Schwarz, J.A. Carbon, 1990, 28, 5, 675-682.

Otake, Y.; Jenkins, R.G. Carbon, 1993, 31, 1, 109-121.

Rohm and Haas, Co., Technical Notes, Ambersorb Carbonaceous Adsorbents, Philadelphia, PA, 1992.

Starsinic, M.; Taylor, R.L.; Walker, Jr., P.L.; Painter, P.C. Carbon, 1983, 21, 1, 69-74.

Vinke, P.; Van der Eijk, M.; Verbree, M.; Voskamp, A.F.; Van Bekkum, H. Carbon, $1994,32,4,675-686$.

You, J.H.; Chiang, H.L.; Chiang, P.C. Environmental Progress, 1994, 13(1), 31-36. 


\section{Chapter 4. Adsorption Equilibria}

\subsection{Overview}

This chapter presents equilibrium data in the form of isotherms for a number of related multi $-\mathrm{OH}$ compounds adsorbing from water. The effects of solution-phase chemistry, temperature, and carbon-surface oxidation on the uptake capacity are explored. The research presented in this chapter is therefore a first step for rational selection and/or design of carbons with optimum affinity and capacity for multi $-\mathrm{OH}$ compounds.

To provide the reader with a starting point, Figure 4.1-1 presents measured composite isotherms for several multi $-\mathrm{OH}$ compounds adsorbing from water onto heat-treated $\mathrm{F} 400$ carbon at $25^{\circ} \mathrm{C}$. F400 is a bituminous coal-based carbon, and serves as the standard adsorbent for most of our work. The data show that active carbons have a substantial capacity for adsorbing a wide variety of sugars and glycols. At an equilibrium mass fraction of $5 \mathrm{wt} . \%$, the composite uptake ranges from 100 to $250 \mathrm{mg} / \mathrm{g}$. This means that an additional $10-25 \%$ of the carbon dry weight consists of adsorbed solute. All of the isotherm data presented in this chapter are tabulated in Appendix E.

Throughout the remainder of this chapter, composite isotherms are usually plotted as $\mathrm{q}(\mathrm{mmol} / \mathrm{g})$ vs. $X_{f}(\mathrm{~mol} / \mathrm{mol})$ for thermodynamic analysis and/or comparison of different molecular species. Also, $\mathrm{q}\left(\mathrm{mmol} / 1000 \mathrm{~m}^{2}\right)$ will often be used to account for differences in surface area among various adsorbents. The various lines drawn through the isotherm data represent empirical curve fits, and are shown primarily for clarity. Discussion of the 

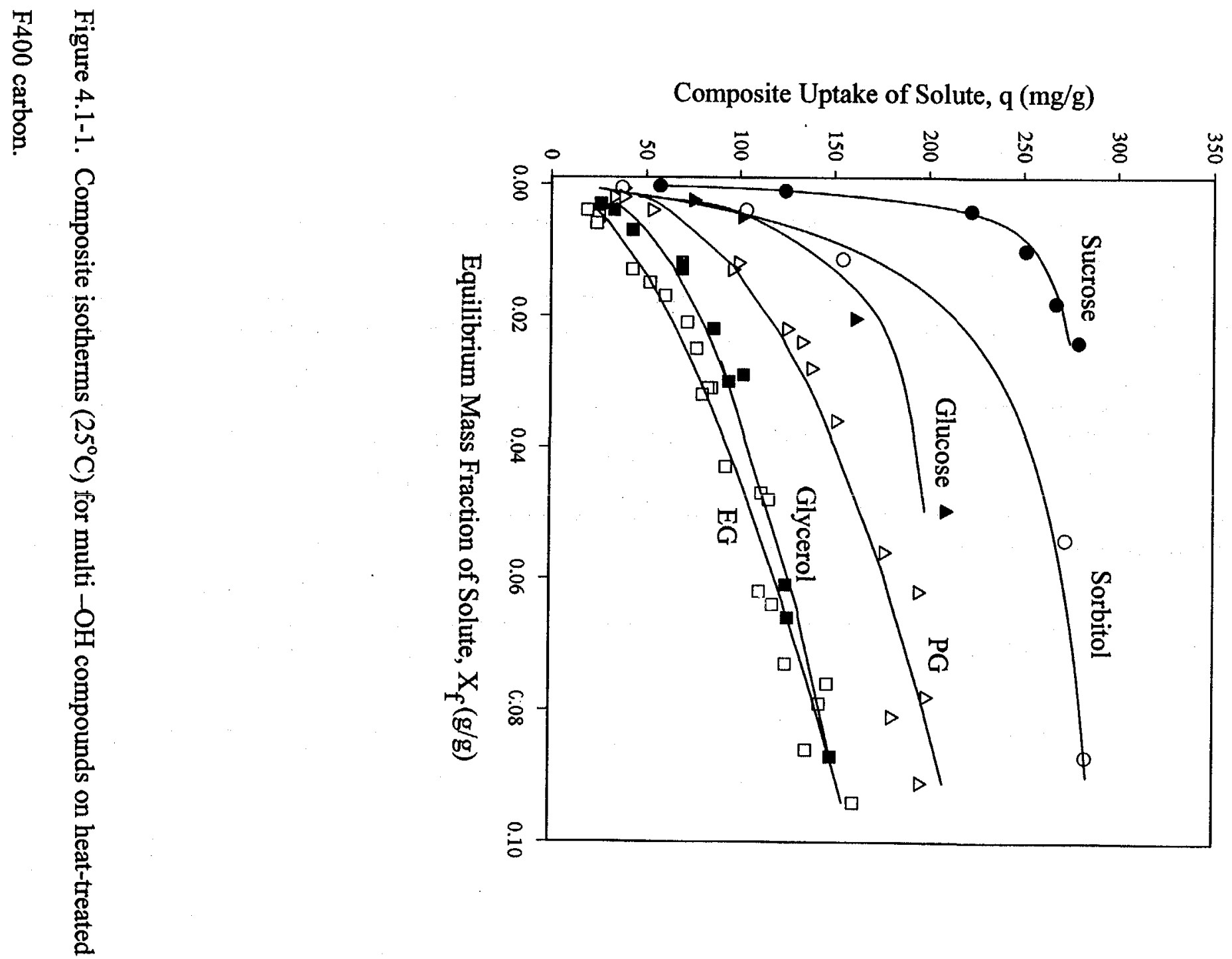
error bars associated with the experimental data, along with specific parameters for the correlations, are presented in Appendices B and C respectively.

\subsection{Effects of Solution Chemistry on Adsorption}

\subsubsection{The Gibbs Adsorption Equation}

Adsorption is often attributed to the intrinsic affinity of the solute for the solid surface. However, a large driving force for adsorption stems from the solution-phase interactions between solute and solvent. A classical method for predicting adsorption in the absence of the adsorbent (i.e. adsorption onto a vapor-liquid interface), exists in the form of the Gibbs Adsorption Equation (Adamson, 1967):

$$
\Gamma_{2,1}=-\frac{\mathrm{d} \sigma}{\operatorname{RTd} \ln \left(\gamma_{2} \mathrm{x}_{2}\right)}
$$

where $\Gamma_{2,1}$ is the surface excess $\left(\mathrm{mol} / \mathrm{m}^{2}\right)$ of the solute (component 2) relative to zero adsorption of the solvent (component 1$), R$ is the gas constant $\left(8.314 \mathrm{~J} / \mathrm{mol}^{*} \mathrm{~K}\right), \mathrm{T}$ is absolute temperature $(\mathrm{K}), \mathrm{x}_{2}$ is the equilibrium solute mole fraction, $\gamma_{2}$ is the solute activity coefficient in solution ( $\gamma=1$ for pure component), and $\sigma$ is the interfacial tension of the solution $(\mathrm{N} / \mathrm{m})$.

Eq. (4.2-1) is based on fundamental thermodynamic principles, and states that adsorption of a solute from a binary solution onto a vapor-liquid interface is driven by changes in surface tension with solute activity. Consequently, in order for a solute to be "positively" 
adsorbed at the surface, it must lower the interfacial tension. Precise surface tension and activity coefficient data are obviously required for use of eq. (4.2-1). In applying the Gibbs Adsorption Equation, we postulate no preferential interactions of the solute with the vapor phase. Similarly, for adsorption onto a solid surface, we assume no preferential interactions of the solute with the solid surface.

\subsubsection{Solution-Phase Activity Coefficients}

Nearly all of the multi $-\mathrm{OH}$ solutes tested in our work exhibit negative deviations from solution-phase ideality. This means that there are interactions between the solute and solvent (water) that are preferential over both solute-solute and solvent-solvent interactions. By contrast, the solvents used in our solvent-regeneration experiments (acetone and methanol), exhibit strong positive deviations from ideality in aqueous solution.

In our work, activity coefficients are correlated using the three-suffix Margules equations:

$$
\begin{aligned}
& \ln \left(\gamma_{1}\right)=\left[\mathrm{A}_{12}+2\left(\mathrm{~A}_{21}-\mathrm{A}_{12}\right) \mathrm{x}_{1}\right] \mathrm{x}_{2}{ }^{2} \\
& \ln \left(\gamma_{2}\right)=\left[\mathrm{A}_{21}+2\left(\mathrm{~A}_{12}-\mathrm{A}_{21}\right) \mathrm{x}_{2}\right] \mathrm{x}_{1}^{2}
\end{aligned}
$$

where $A_{12}$ and $A_{21}$ are temperature-dependent fitting parameters. Vapor-liquid equilibrium data for solutes fully miscible with water were obtained from Gmehling et al. 
(1988). Data for aqueous sugar solutions at $25^{\circ} \mathrm{C}$ were reported by Miyajima et al.

(1982), using the asymmetric convention $(\gamma=1$ at infinite dilution). Sugars also exhibit negative deviations from ideality; however, the effects are noticeable only at extremely high concentrations. We therefore assumed ideal solutions using the symmetric convention $(\gamma=1)$ for sugar solutions in our calculations with eq. (4.2-1). The Margules parameters and infinite dilution activity coefficients for several chemicals used in our work are listed in Table 4.2-1.

TABLE 4.2-1

Activity Coefficient Data $\left(25^{\circ} \mathrm{C}\right)$ for Solutes in Aqueous Solution

\begin{tabular}{|c|c|c|c|c|}
\hline SOLUTE & $\mathrm{A}_{12}$ & $\mathrm{~A}_{21}$ & $\gamma_{1}{ }^{\infty}$ & $\gamma_{2}{ }^{\infty}$ \\
\hline Ethylene Glycol $^{*}$ & -0.170 & -0.2269 & 0.844 & 0.797 \\
\hline Propylene Glycol & -0.0396 & -0.0562 & 0.961 & 0.945 \\
\hline Glycerol & -0.2207 & -0.6499 & 0.802 & 0.522 \\
\hline Acetone & 3.663 & 3.0174 & 38.98 & 20.44 \\
\hline Methanol & 0.5533 & 0.4339 & 1.74 & 1.54 \\
\hline Ethanol & 1.4941 & 0.9851 & 4.46 & 2.68 \\
\hline 1-Propanol & 2.6640 & 1.2128 & 14.35 & 3.36 \\
\hline 2-Propanol & 2.2157 & 1.1593 & 9.18 & 3.19 \\
\hline
\end{tabular}

*Results were extrapolated from data at $50^{\circ} \mathrm{C}, 60^{\circ} \mathrm{C}, 70^{\circ} \mathrm{C}$, and $90.3^{\circ} \mathrm{C}$ with an equation of the form, $\ln \left(\gamma_{2}\right)=\mathrm{c}+\mathrm{d} / \mathrm{T}$ (Prausnitz et al., 1986).

Ethanol and the two isomers of propanol were included in our study because they are analogs of ethylene and propylene glycol, respectively.

\subsubsection{Surface Tension Data for Aqueous Solutions}

Most of the experimental surface tension data obtained from the literature were correlated to an equation of the form: 


$$
\sigma=\sigma_{1}-\left[1+\frac{\mathrm{bx}_{1}}{1-\mathrm{ax}_{1}}\right] \mathrm{x}_{2}\left(\sigma_{1}-\sigma_{2}\right)
$$

where the subscripts 1 and 2 denote solvent and solute respectively (with $\sigma_{1}=72.8$ $\mathrm{mN} / \mathrm{m}$ ), and " $\mathrm{a}$ " and " $\mathrm{b}$ " refer to temperature-dependent fitting parameters. This equation has a theoretical basis (Connors and Wright, 1989), and is convenient for estimating surface tensions over the full concentration range. Data for the systems of interest at $25^{\circ} \mathrm{C}$ are summarized in Table 4.2-2.

TABLE 4.2-2

Surface Tension Data $\left(25^{\circ} \mathrm{C}\right)$ for Aqueous Systems

\begin{tabular}{||c|c|c|c|c||}
\hline SOLUTE & $\mathrm{a}$ & $\mathrm{b}$ & $\sigma_{2}(\mathrm{mN} / \mathrm{m})$ & REFERENCE \\
\hline Ethylene Glycol & 0.870 & 0.781 & $48.4^{*}$ & Hoke and Chen (1991) \\
\hline Propylene Glycol & 0.951 & 0.792 & $36^{*}$ & Hoke and Patton (1992) \\
\hline Glycerol & 0.958 & 0.448 & $63.4^{*}$ & Connors and Wright (1989) \\
\hline Acetone & 0.978 & 0.842 & $23.46^{* *}$ & Connors and Wright (1989) \\
\hline Methanol & 0.899 & 0.777 & $22.07^{* *}$ & Connors and Wright (1989) \\
\hline Ethanol & 0.963 & 0.897 & $21.97^{* *}$ & Connors and Wright (1989) \\
\hline 1-Propanol & 0.990 & 0.999 & $23.32^{* *}$ & Connors and Wright (1989) \\
\hline 2-Propanol & 0.984 & 0.970 & $20.93^{* *}$ & Connors and Wright (1989) \\
\hline
\end{tabular}

*Values from Forker et al (c1991-1998), Martin et al. (c1991-1998), and Morrison (c1991-1998) **Value from CRC Handbook of Chemistry and Physics (1996-1997)

At a given temperature, the surface tension of an aqueous solution will normally decrease with increasing amount of organic solute added. Among nonelectrolytes, one notable exception is the sucrose-water system, as reported by Supran et al. (1971): 


$$
\sigma=73.636+0.099 \mathrm{C}-0.096 \mathrm{~T}
$$

where $\mathrm{C}$ is the weight percent $(\%)$ of sucrose $(1-10 \mathrm{wt} . \%), \mathrm{T}$ is temperature in ${ }^{\circ} \mathrm{C}(20$ $50^{\circ} \mathrm{C}$ ), and $\sigma$ is the surface tension in $\mathrm{mN} / \mathrm{m}$. As shown in eq. (4.2-5), adding sucrose will increase the surface tension of a solution. According to the Gibbs Adsorption Equation, there will be a negative uptake onto the vapor-liquid interface for sucrose, which means that water is preferentially adsorbed.

\subsubsection{Calculated Results}

The uptakes for the various compounds (multi $-\mathrm{OH}$ solutes, alcohols, regenerants) onto the air-liquid interface at $25^{\circ} \mathrm{C}$, as predicted by the Gibbs Adsorption Equation, are plotted in Figure 4.2-1. The mole fraction range reported ( 0 to 0.06$)$ corresponds to a weight fraction range of 0 to $0.10 \mathrm{~g} / \mathrm{g}$. Surface excesses are reported in mmol/1000 $\mathrm{m}^{2}$. In accord with eq. (4.2-1), compounds with greater positive deviations from solution ideality show greater uptake from aqueous solution over the full range of mole fractions. Also, compounds with low surface tensions (alcohols and regenerants) relative to water exhibit high uptakes. This result is not surprising, since a low surface tension suggests that it is thermodynamically easier for a liquid to form interfacial area (i.e. to spread). The order of uptakes for the multi $-\mathrm{OH}$ solutes, whose surface tensions are intermediate between water and the alcohols/regenerants, also follows the order of infinite dilution activity coefficients in descending order. 


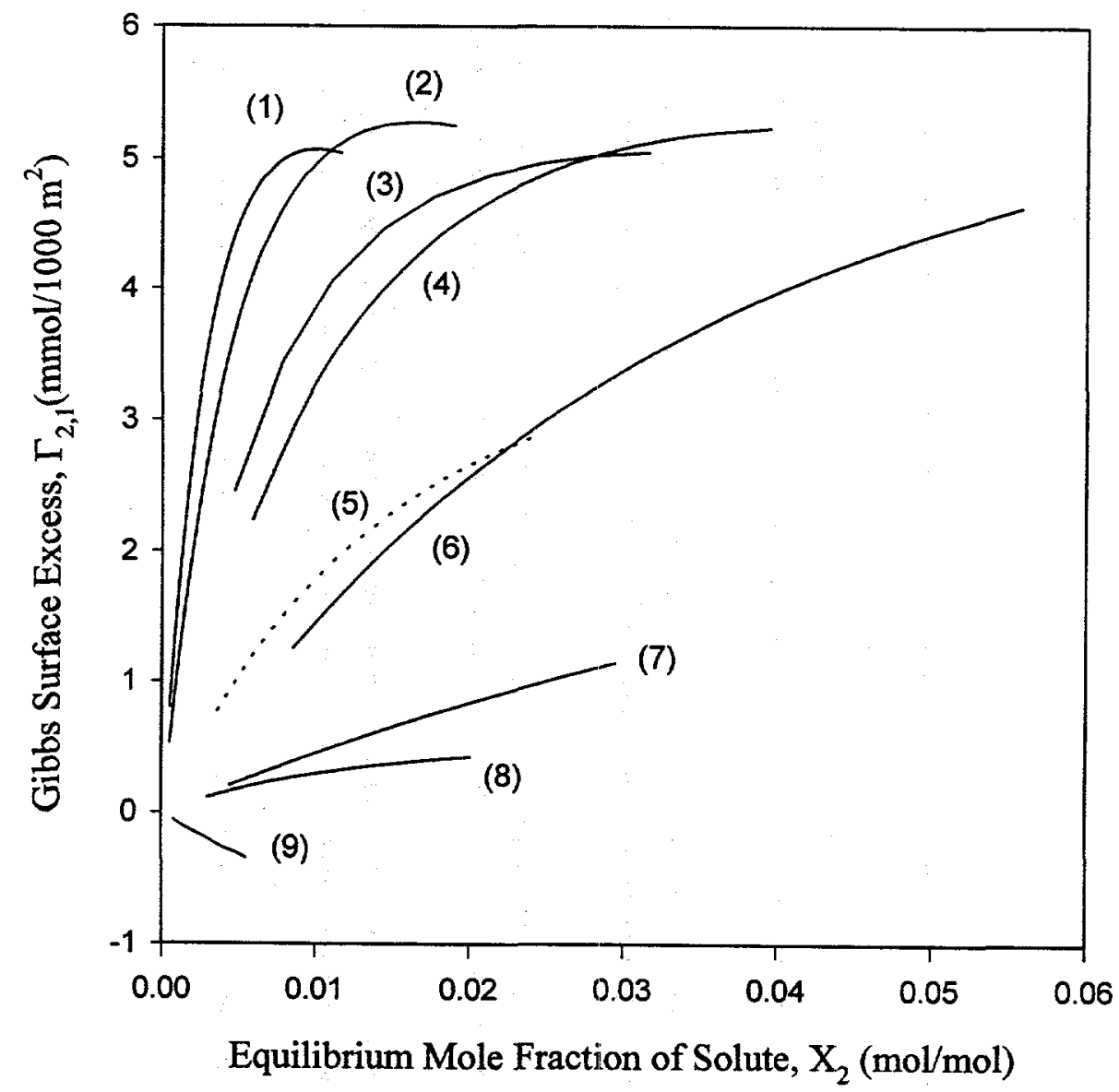

Figure 4.2-1. Surface excesses of multi-OH solutes, alcohols, and regenerants onto the liquid-vapor interface $\left(25^{\circ} \mathrm{C}\right)$, as predicted by the Gibbs Adsorption Equation.
(1) $1-\mathrm{PrOH}, \gamma^{\infty}=3.36$
(2) $2-\mathrm{PrOH}, \gamma^{\infty}=3.18$
(3) Acetone, $\gamma^{\infty}=20.4$
(4) Ethanol, $\gamma^{\infty}=2.5$
(5) $\mathrm{PG}, \gamma^{\infty}=0.945$
(6) Methanol, $\gamma^{\infty}=1.54$
(7) $\mathrm{EG}, \gamma^{\infty}=0.797$
(8) Glycerol, $\gamma^{\infty}=0.522$
(9) Sucrose, $\gamma^{\infty} \sim 1$ 


\subsubsection{Surface vs. Solution Interactions for Adsorption}

A rough comparison between the amounts of solute adsorbed onto activated carbon and at a vapor-liquid interface is now in order. This will give a preliminary assessment of the contribution of surface interactions to adsorption. Table 4.2-3 tallies results for adsorption of glycols and glycerol on heat-treated F400 carbon, at two different equilibrium solute weight fractions.

TABLE 4.2-3

Relative Contributions of Surface Interactions to Adsorption $\left(25^{\circ} \mathrm{C}\right)$

\begin{tabular}{|c|c|c|c|c|}
\hline SOLUTE & $\mathrm{X}_{\mathrm{f}}(\mathrm{g} / \mathrm{g})$ & $\begin{array}{c}\text { Uptake from } \\
\text { Gibbs eq. } \\
\left(\mathrm{mmol} / \mathrm{m}^{2}\right)\end{array}$ & $\begin{array}{c}\text { Uptake on } \\
\mathrm{F} 400 / \mathrm{HT} \\
\left(\mathrm{mmol} / \mathrm{m}^{2}\right)\end{array}$ & $\begin{array}{c}\text { Contribution } \\
\text { from surface } \\
(\%)\end{array}$ \\
\hline Glycerol & 0.02 & 0.111 & 0.85 & 87 \\
\hline Ethylene Glycol & 0.02 & 0.2 & 1.0 & 80 \\
\hline Propylene Glycol & 0.02 & 0.77 & 1.5 & 49 \\
\hline Glycerol & 0.10 & 0.422 & 1.7 & 75 \\
\hline Ethylene Glycol & 0.10 & 1.15 & 2.6 & 56 \\
\hline Propylene Glycol & 0.10 & 2.88 & 2.8 & $\sim 0$ \\
\hline
\end{tabular}

The contribution of surface interactions is considered to be the uptake beyond the Gibbs uptake. As is seen in Table 4.2-3, the contributions from surface interactions to the overall adsorption onto activated carbons are more prominent at lower equilibrium concentrations. At low loadings, the solute molecules will first preferentially adsorb onto the high-energy (high-affinity) sites of the solid adsorbent. The uptake of solute onto carbons will therefore be several times higher than predicted by the Gibbs Equation, where solution chemistry is the sole driving force for adsorption. At progressively higher 
loadings more of these sites become occupied, and this results in a lower contribution from the surface and a greater contribution from solution chemistry.

Figure 4.2-2 shows several composite isotherms of several multi-OH compounds and their alcohol analogs adsorbing from water onto heat-treated $\mathrm{F} 400$ at $25^{\circ} \mathrm{C}$. Also shown are data for lactic acid (2-hydroxypropanoic acid), a compound of substantial industrial importance. The infinite-dilution activity coefficient of 3.6 for lactic acid was estimated by Husson (1997). The trends observed in Figure 4.2-2 mirror those of Figure 4.2-1 to a remarkable degree. That is, the solution-phase activity coefficient of the solute appears to have a dominating influence on its degree of uptake and its affinity for the (carbonliquid) interface. The highest equilibrium capacities were observed for the alcohols and lactic acid, followed by the multi-OH solutes: propylene glycol, ethylene glycol, and glycerol.

\subsubsection{Effects of Solution Chemistry - Summary}

The relative degrees of adsorption of multi $-\mathrm{OH}$ compounds onto both an (inert) airliquid interface and an activated carbon-liquid interface appears to be largely influenced by solution-pinase nonidealities. At both types of interfaces, the uptake of the multi $-\mathrm{OH}$ solutes are lower than that of the analogous alcohols, which bear a single - $\mathrm{OH}$ group and possess a higher infinite-dilution activity coefficient (i.e. stronger positive deviations from ideality). The next goal is to characterize the nature of the interactions between the carbon surface and and the multi-OH/alcohol adsorbates. 


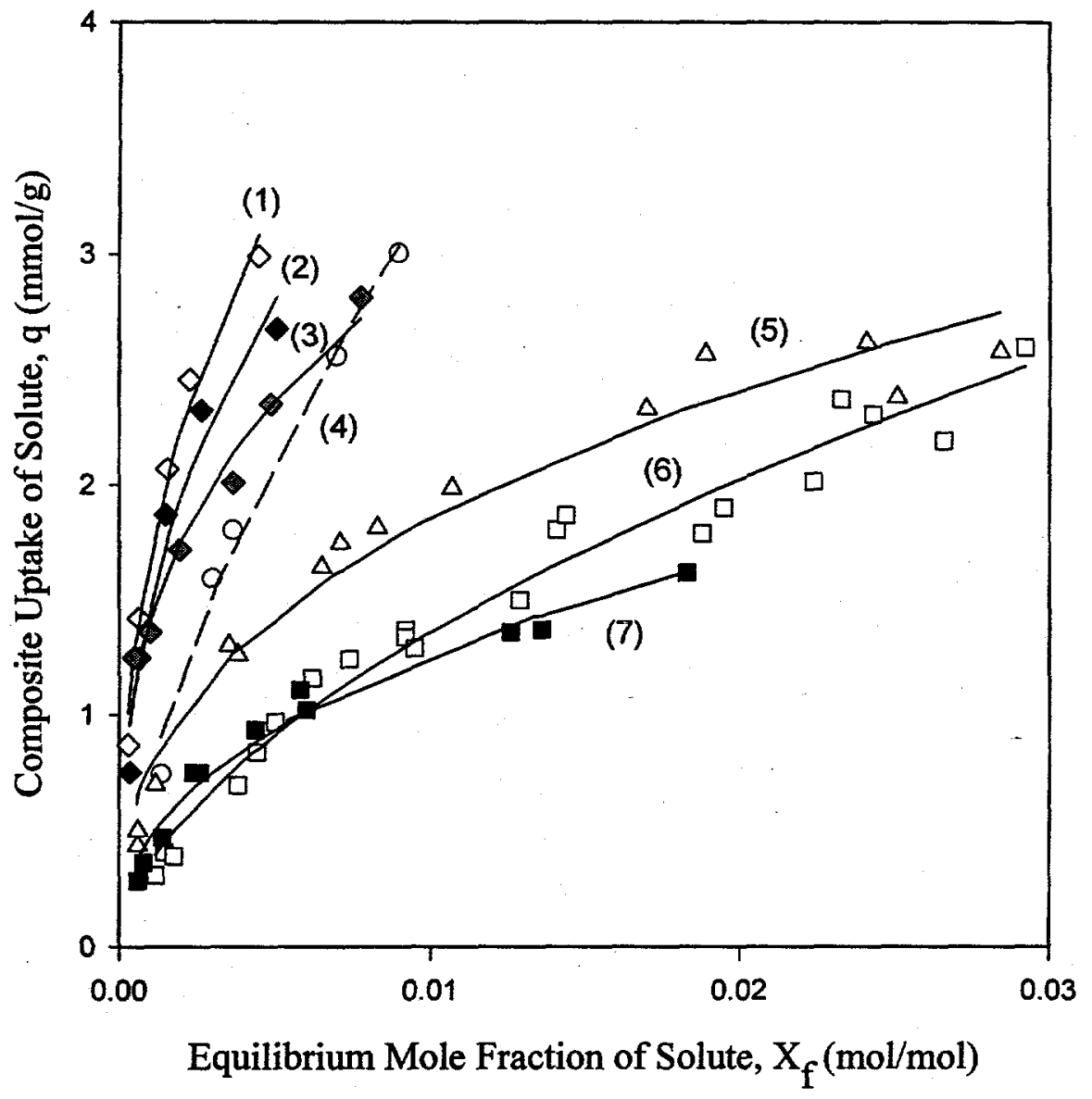

Figure 4.2-2. Composite uptakes $\left(25^{\circ} \mathrm{C}\right)$ of alcohols and multi-OH solutes on $\mathrm{F} 400$ carbon. (1) $1-\mathrm{PrOH}, \gamma^{\infty}=3.36$ (2) $2-\mathrm{PrOH}, \gamma^{\infty}=3.18$ (3) Lactic Acid, $\gamma^{\infty}=3.6$
(4) Ethanol, $\gamma^{\infty}=2.5$
(5) $\mathrm{PG}, \gamma^{\infty}=0.945$
(6) $\mathrm{EG}, \gamma^{\infty}=0.797$
(7) Glycerol, $\gamma^{\infty}=0.522$ 


\subsection{Effects of Temperature on Adsorption}

\subsubsection{Adsorption Isotherms at Several Temperatures}

Batch adsorption experiments were carried out for aqueous multi $-\mathrm{OH}$ and single $-\mathrm{OH}$ solutes on $\mathrm{F} 400$ carbon from $25^{\circ} \mathrm{C}$ to $65^{\circ} \mathrm{C}$ to study the effects of temperature. There were two reasons for conducting these experiments. First, it was important to determine whether a temperature-swing process is suitable for recovery of these compounds bound on carbons. Secondly, the experiments provided a measure of the heat of adsorption, and therefore an indirect method for distinguishing physical adsorption from chemisorption.

Figure 4.3-1 depicts the composite isotherms for sucrose on untreated F400 carbon at three temperatures. The mole fraction range $\left(0\right.$ to $\left.2.5 \times 10^{-4}\right)$ corresponds to a weight fraction range of 0 to $4.7 \times 10^{-3} \mathrm{~g} / \mathrm{g}$. Since the percent depletion of the sucrose from solution is quite large throughout this concentration range, error bars for the composite uptakes are considered negligible. Overall, the capacities for sucrose are all noticeably lower at higher temperatures. This means that the overall enthalpy of adsorption is exothermic, which is consistent with the idea that the entropy loss upon solute adsorption must be overcome for the entire process to be thermodynamically favorable.

Figure 4.3-2 depicts similar sets of isotherms for ethylene glycol (EG) and propylene glycol (PG) at $25^{\circ} \mathrm{C}$ and $65^{\circ} \mathrm{C}$. The mole fraction range $\left(0\right.$ to $\left.7 \times 10^{-3}\right)$ corresponds to a weight fraction range of 0 to about $0.03 \mathrm{~g} / \mathrm{g}$. The equilibrium capacities of F400 for both solutes are also lower at elevated temperatures, with the effect somewhat more pronounced for PG than EG, but weaker than in the case of sucrose. These results 


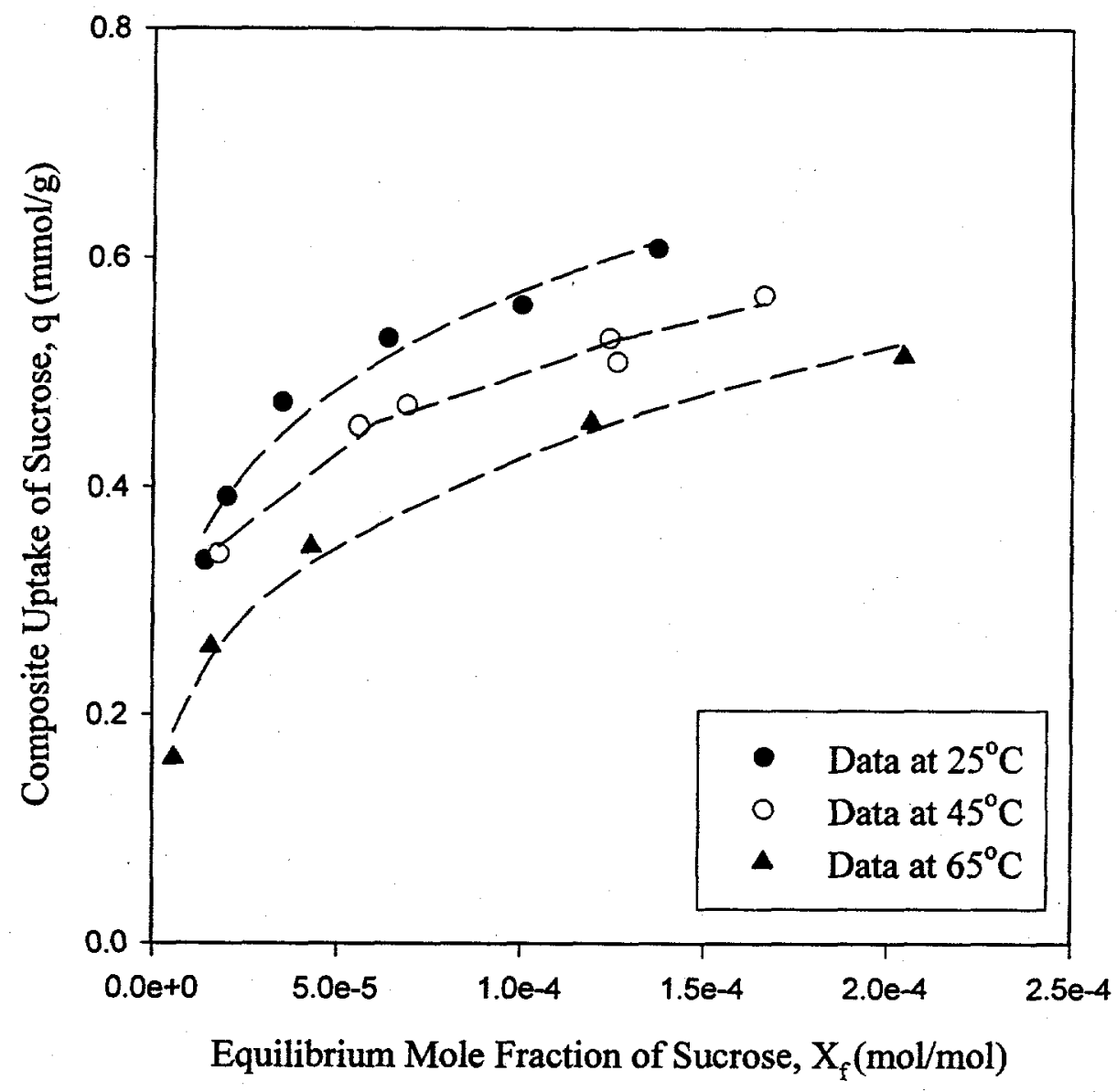

Figure 4.3-1. Composite isotherms of sucrose on F400 carbon for several temperatures. 


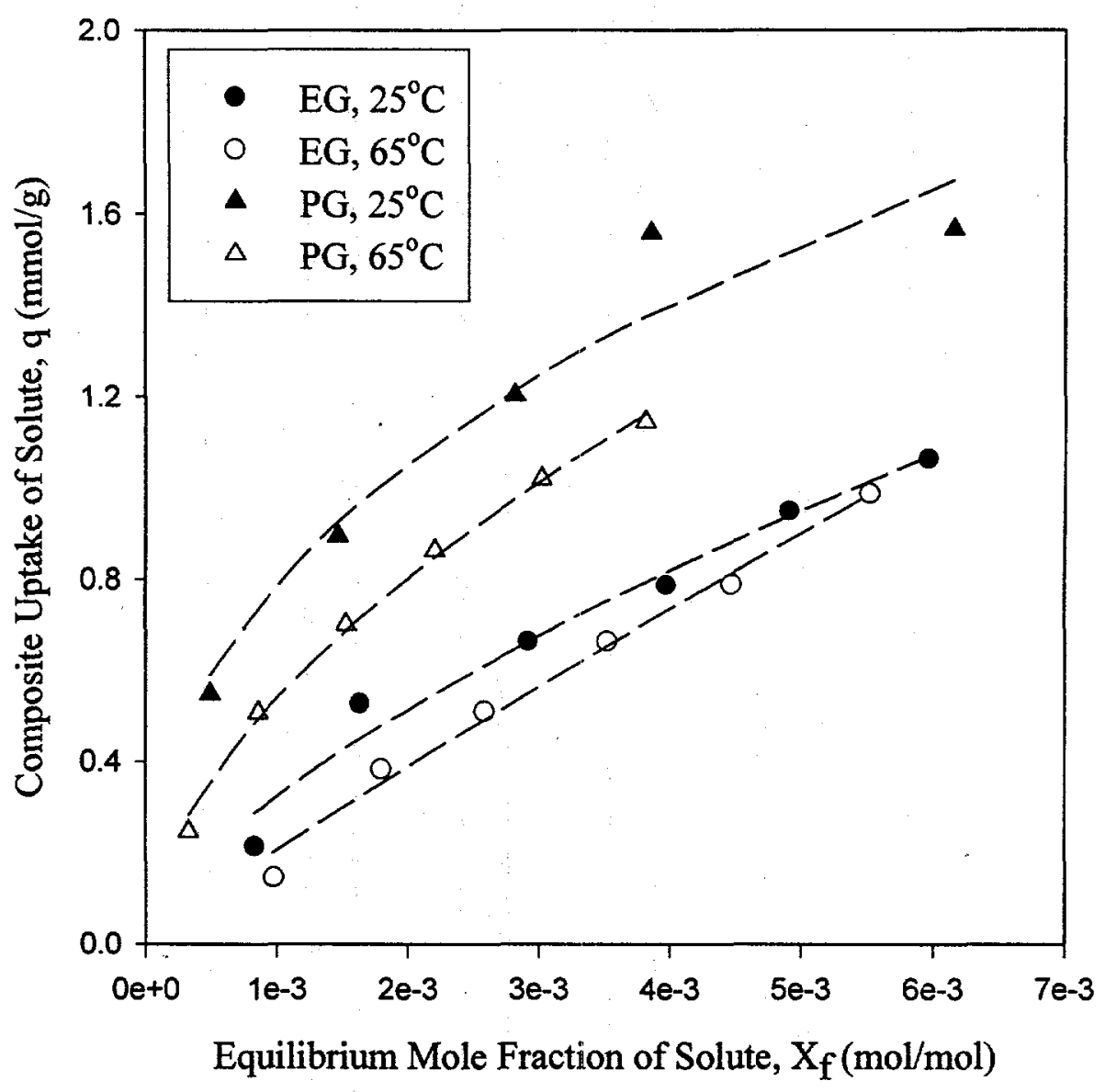

Figure 4.3-2. Composite isotherms of ethylene glycol (EG) and propylene glycol (PG) on F400 carbon for several temperatures. 
contrast with the findings of Broekhuis (1995), where there was a minimal effect of temperature upon PG uptake onto XAD-761 (Rohm and Haas) and Reillex-425 (Reilly, Inc.) synthetic polymeric adsorbents.

\subsubsection{Heats of Adsorption from the Isosteric Method}

\subsubsection{Background}

Enthalpies of adsorption were estimated using the isosteric method, which is based on observing the shift of adsorption isotherms with temperature. This method was originally used for gas-phase (single component) adsorption, but has been developed for the more complicated scenario of adsorption from solutions (Denoyel et al., 1990). The net enthalpy of adsorption ( $\Delta \mathrm{H}, \mathrm{kJ} / \mathrm{mol})$, which includes the enthalpy effect from the removal of previously bound water upon adsorption, is given as:

$$
\Delta \mathrm{H}=\frac{\mathrm{R}}{\Phi_{1}}\left(\frac{\partial \ln \mathrm{a}_{2}}{\partial 1 / \mathrm{T}}\right)_{\mathrm{q}_{2}}
$$

where $a_{2}$ is the solution activity ( $\mathrm{mol} / \mathrm{mol}$ ) of the solute in equilibrium with the surface loading $\mathrm{q}_{2}(\mathrm{mmol} / \mathrm{g})$ at temperature $\mathrm{T}(\mathrm{K}), \mathrm{R}$ is the gas constant $\left(8.314 \times 10^{-3} \mathrm{~kJ} / \mathrm{mol}^{*} \mathrm{~K}\right)$, and $\Phi_{1}$ is a term to account for the volumetric displacement of water:

$$
\Phi_{1}=\frac{\mathrm{x}_{1}}{\mathrm{x}_{1}+\mathrm{r} \mathrm{x}_{2}}
$$


where $\mathrm{x}_{1}$ and $\mathrm{x}_{2}$ refer to the mole fractions of solvent and solute respectively, and $\mathrm{r}$ is the ratio of molar volumes of solute to solvent. The $\Phi_{1}$ term did not vary significantly from unity throughout our experiments; it becomes important only in cases of large solutes and/or high loadings $(>1 \mathrm{mmol} / \mathrm{g})$, where a typical value of $\Phi_{1}$ is about 0.94 .

The isosteric method provides a quick, but rough estimate of the enthalpy of adsorption as a function of coverage. Although it was derived rigorously from thermodynamics, there are several points that limit its reliability compared to direct calorimetry (Denoyel et al., 1990):

(1) Knowledge of liquid-phase activity coefficients is necessary.

(2) The number of adsorption sites is temperature-independent.

(3) The composition of the adsorbed phase is the same at different temperatures when the excess amount $\left(q_{2}\right)$ is the same.

(4) The heat of adsorption is constant over the temperature range used in its calculation.

This method, nevertheless, is useful for comparing the adsorption of multi $-\mathrm{OH}$ solutes and their analogous alcohols from water onto a given adsorbent. Despite the above limitations, Johnson et al. (1990) have reported reasonable agreement between the isosteric method and both immersion and displacement calorimetry for a graphonheptane-heptanol system. 


\subsubsection{Calculated Results}

Calculations using eq. (4.3-1) were made using data from isotherms at two or three different temperatures. Since concentration is relatively low and narrow, infinite-dilution activity coefficients were used in the calculations. Table 4.3-1 lists some of the parameters used for the calculations:

TABLE 4.3-1

Parameters for Calculating Heats of Adsorption

\begin{tabular}{|c|c|c|}
\hline SOLUTE & $\mathrm{r}\left(\mathrm{V}_{2} / \mathrm{V}_{1}\right)$ & $\begin{array}{c}\text { Infinite Dilution } \\
\text { Activity Coefficients* }\end{array}$ \\
\hline Glucose & 6.39 & Assumed Ideal \\
\hline Sucrose & 11.94 & Assumed Ideal \\
\hline Ethylene Glycol & 3.11 & $\left(25^{\circ} \mathrm{C}\right) 0.797 ;\left(65^{\circ} \mathrm{C}\right) 0.82$ \\
\hline Propylene Glycol & 4.11 & $\begin{array}{c}\left(25^{\circ} \mathrm{C}\right) 0.945 ;\left(45^{\circ} \mathrm{C}\right) 1.12^{* *} \\
\left(65^{\circ} \mathrm{C}\right) 1.20^{* *}\end{array}$ \\
\hline Glycerol & 4.06 & $0.522^{* * *}$ \\
\hline Ethanol & 3.22 & $\left(25^{\circ} \mathrm{C}\right) 2.51 ;\left(50^{\circ} \mathrm{C}\right) 2.00$ \\
\hline 1-Propanol & 4.17 & $\left(25^{\circ} \mathrm{C}\right) 3.98 ;\left(50^{\circ} \mathrm{C}\right) 3.82$ \\
\hline 2-Propanol & 4.22 & $\left(25^{\circ} \mathrm{C}\right) 3.68 ;\left(50^{\circ} \mathrm{C}\right) 3.31$ \\
\hline
\end{tabular}

*All values from Gmehling et al. (1988), unless otherwise stated **Value from Suleiman and Eckert (1994)

*** Value used for all temperatures due to lack of reliable data

From Table 4.3-1, aqueous solutions of single $-\mathrm{OH}$ and multi $-\mathrm{OH}$ compounds all tends toward ideality $\left(\gamma^{\infty}=1\right)$ at higher temperatures. A likely reason is that molecular interactions become less important from the increased motion of molecules associated with the elevated temperatures. Propylene glycol and other diols have been observed to shift from having negative deviations at low temperatures to having modest positive deviations at higher temperatures (Suleiman and Eckert, 1994). The authors suggested 
that the effect is caused by association (e.g., intramolecular hydrogen bonding) and nonspecific forces among the glycols.

Figure 4.3-3 shows the calculated heats of adsorption for the various multi $-\mathrm{OH}$ compounds adsorbing from water onto F400 carbon, as a function of surface loading. Several trends are immediately apparent from the data. First, as expected, all of the enthalpies of adsorption are indeed exothermic for reasons discussed in section 4.3-1. The values are well below the characteristic bond energies of covalently bound molecules $(200-400 \mathrm{~kJ} / \mathrm{mol})$, but within the range of most hydrogen-bond energies $(8-40 \mathrm{~kJ} / \mathrm{mol})$ mentioned by Prausnitz et al., 1986. Second, the fact that more exothermic values are observed at low loadings is probably due to the heterogeneity of the surface. Highenergy sites are preferentially taken up first by the adsorbate, and therefore solute-surface interactions are strongest at low surface coverage.

From Figure 4.3-3, it appears that there are two competing effects that influence the magnitude of the heat of adsorption: (1) the molecular weight of the solute, and (2) the presence of the $-\mathrm{OH}$ group(s) on the solute. A high molecular weight leads to stronger dispersion interactions with the carbon surface, so it is not surprising that the heat of adsorption is highest for sucrose and lowest for ethylene glycol (EG). However, another competing factor is that the presence of the $-\mathrm{OH}$ group(s) appears to result in lower heats of adsorption. Glycerol and propylene glycol (PG), both three-carbon compounds, have substantially different heats of adsorption. Presumably, the additional $-\mathrm{OH}$ group of glycerol renders it more attractive to water than $\mathrm{PG}$, and 


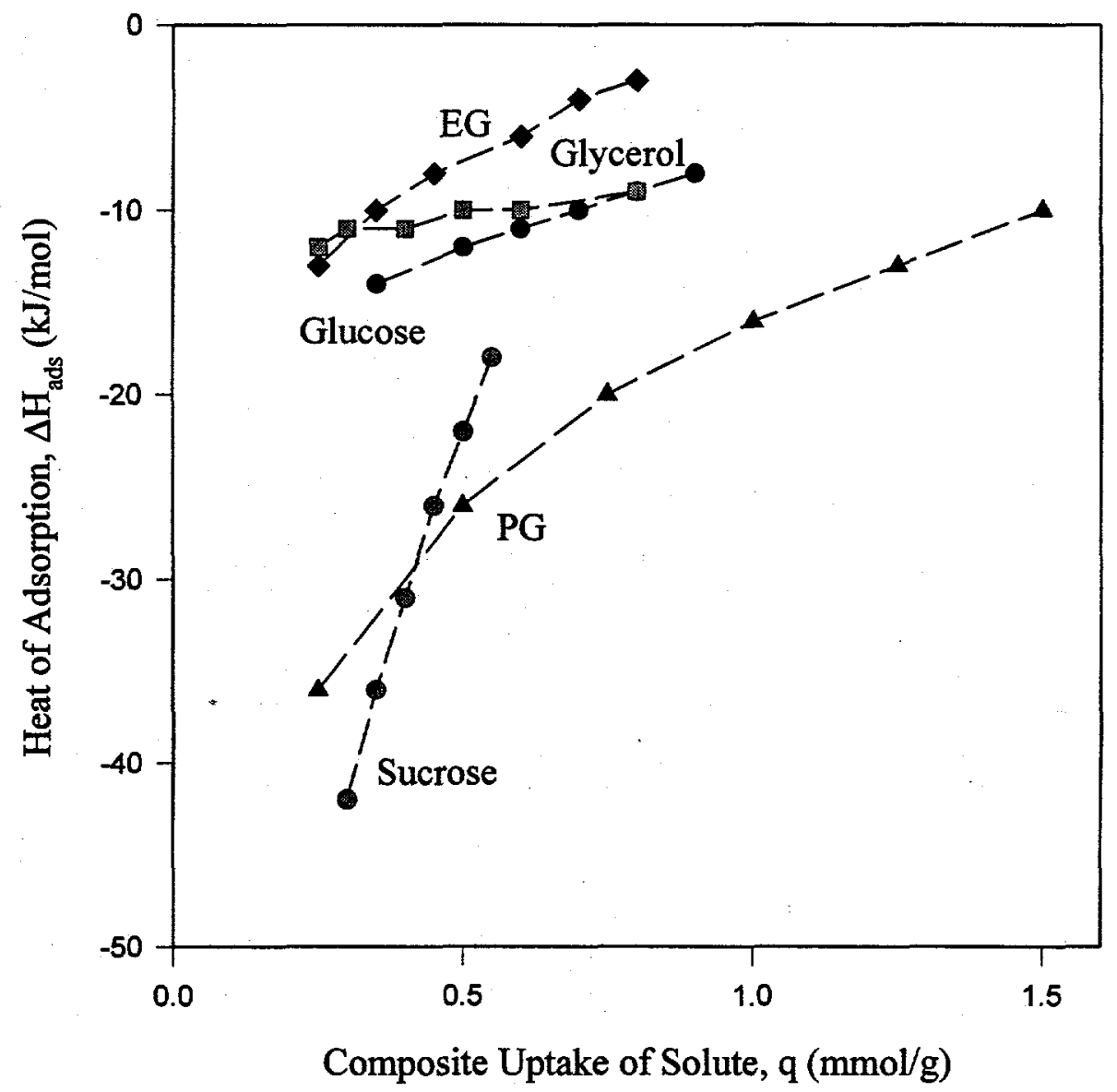

Figure 4.3-3. Isosteric heat of adsorption of multi - $\mathrm{OH}$ compounds on $\mathrm{F} 400$ carbon as a function of loading. 
consequently its interaction with the carbon surface is weaker. This may be because the interaction with water keeps the extra $-\mathrm{OH}$ group of glycerol oriented into the solution. All of these factors help explain why glucose, which is a compound saturated with $-\mathrm{OH}$ groups of intermediate molecular weight (180), has a heat of adsorption between EG and sucrose.

Figure 4.3-4 shows the calculated heats of adsorption for the analogous alcohols adsorbing from water onto F400 carbon, as a function of surface loading. Since the carbons have substantially higher capacities for alcohols over the multi $-\mathrm{OH}$ solutes, direct comparison with the results of Figure 4.3-3 are more difficult. As all three alcohols have just a single $-\mathrm{OH}$ group, the magnitude and ordering of the heat of adsorption (ethanol < 2-propanol < 1-propanol) are governed by the size of the molecule and the solution-phase activity coefficient. The heats of adsorption of the two propanol isomers are comparable to that of PG over at loadings above $1 \mathrm{mmol} / \mathrm{g}$, while the same could be said of ethanol and EG from 0.25 to $0.75 \mathrm{mmol} / \mathrm{g}$.

\subsubsection{Effects of Temperature on Adsorption - Summary}

Based on the results of Figures 4.3-3 and 4.3-4, it appears that dispersion interactions and aqueous-phase nonidealities attributed to the $-\mathrm{OH}$ group(s) are the main factors that govern adsorption of multi - $\mathrm{OH}$ compounds onto activated carbons. Larger heats of adsorption are observed with compounds that have large molecular weights and more positive deviations from solution ideality. The trends observed in Figure 4.2-2 are also reflected in the heat of adsorption calculations; namely, the presence of the $-\mathrm{OH}$ groups 


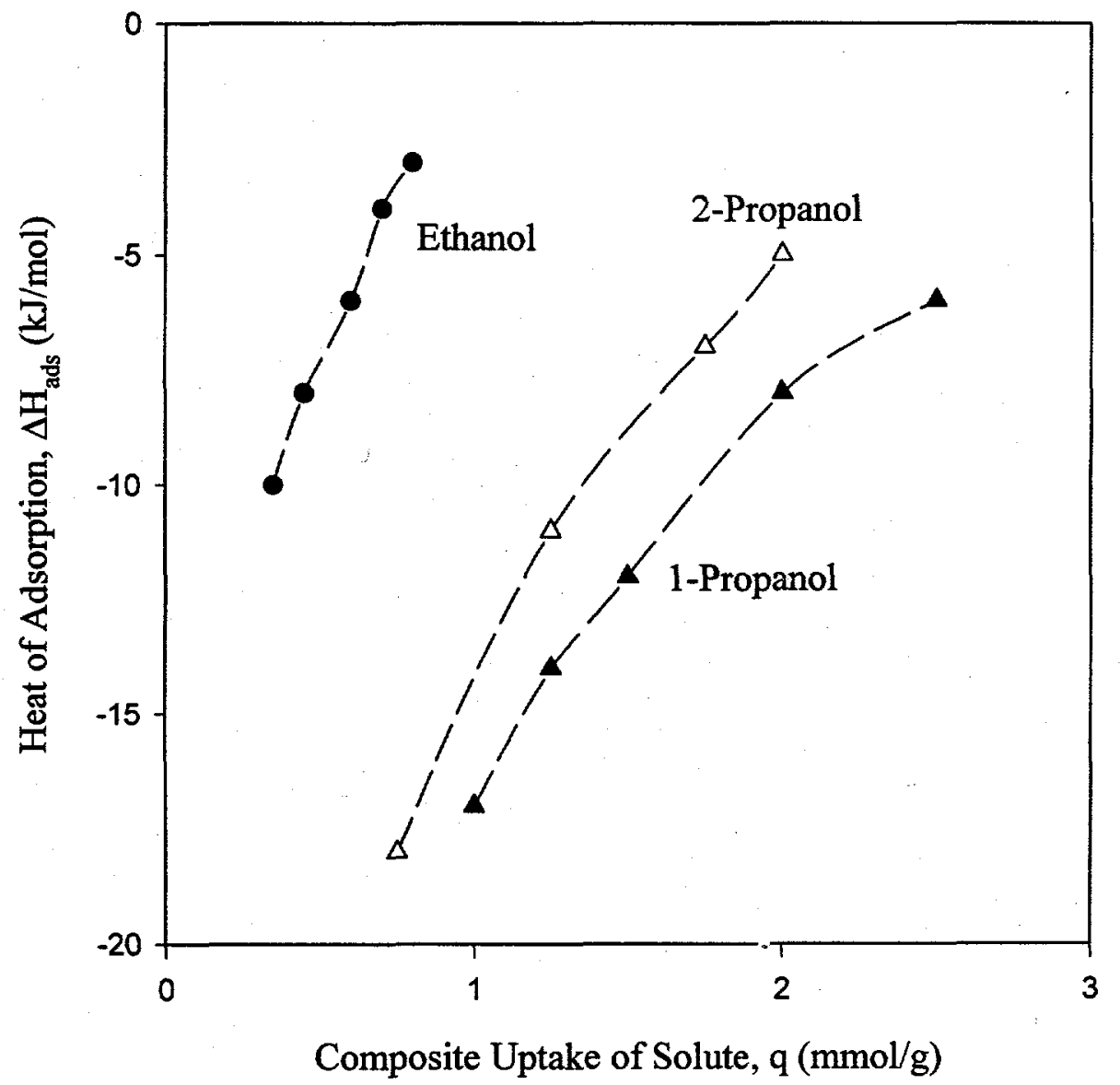

Figure 4.3-4. Isosteric heat of adsorption of alcohols on F400 carbon as a function of loading. 
appears to result in weaker, rather than stronger, interactions with the surface. The heats of adsorption are exothermic and are in the characteristic range of physical adsorption, but are likely too low for temperature swing to be a practical recovery process.

\subsection{Effects of Surface Chemistry on Adsorption}

In this section, we present the measured composite isotherms $\left(25^{\circ} \mathrm{C}\right)$ for aqueous multi $\mathrm{OH}$ compounds adsorbing onto a variety of activated carbons, and we examine the effects of both the source material and surface chemistry of the carbons on uptake capacity. As was mentioned in Chapter 3, the most frequently studied surface-chemical properties of active carbons are the nature and density of oxygen-bearing functional groups. We therefore seek to rationalize the adsorption behavior of a wide range of multi $-\mathrm{OH}$ compounds in terms of surface acidity and basicity. Also, it is of interest to see whether hydrophilic surfaces lead to enhanced capacity for multi - $\mathrm{OH}$ compounds, presumably through secondary hydrogen-bonding interactions with the solutes.

\subsubsection{Data for Surface-Treated Carbons (Variable Surface Acidity)}

Almost all of the data presented in this section are for adsorption onto heat-treated and acid-oxidized (to various degrees) F400 carbon. Performing experiments on a particular carbon allows us to isolate the surface-treatment properties that affect adsorption. Heattreated F400 was chosen as the standard carbon for our work; its adsorption capacity and physical properties do not differ significantly from the as-received F400. 


\subsubsection{Data for Glycols (EG, PG) and Glycerol}

Figures 4.4-1, 4.4-2, and 4.4-3 show the composite isotherms $\left(25^{\circ} \mathrm{C}\right)$ of $\mathrm{EG}, \mathrm{PG}$, and glycerol, respectively, on heat-treated and acid-oxidized F400 carbons. All of the isotherms appear to be of the Freundlich type (see Appendix C) where the uptake increases monotonically, unlike reaching the clear plateau characteristic of Langmuirtype isotherms. The data show that an increasing degree of surface oxidation (surface acidity) results in lower capacities of the carbon for all three solutes. These results, along with the data in Figure 3.6-1, suggest that the hydrophilic surfaces probably attract water, rather than encouraging hydrogen-bonding interactions with the solute.

The differences between the two oxidized carbons $\left(50^{\circ} \mathrm{C} / 2 \mathrm{hrs}\right.$. and $70^{\circ} \mathrm{C} / 2 \mathrm{hrs}$.) appear to be greater in the case of EG than in glycerol and PG. Since glycerol is a larger molecule than ethylene glycol, it may be able to displace more water molecules upon adsorption. Hence, the competitive adsorption of water encouraged by the oxidized surfaces may be less important in the case of larger solutes. The isotherms for PG are interesting, since there is significant scatter between the two oxidized carbons; in fact, they can be correlated to a single curve. From the previous section, we observed that the heat of adsorption of $\mathrm{PG}$ is much higher than most multi $-\mathrm{OH}$ solutes (except sucrose). The dispersion interactions with the unoxidized portion of the surface may remain strong enough so that the increase in surface acidity from $50^{\circ} \mathrm{C} / 2 \mathrm{hrs}$. to $70^{\circ} \mathrm{C} / 2 \mathrm{hrs}$. has little effect on the overall uptake. 


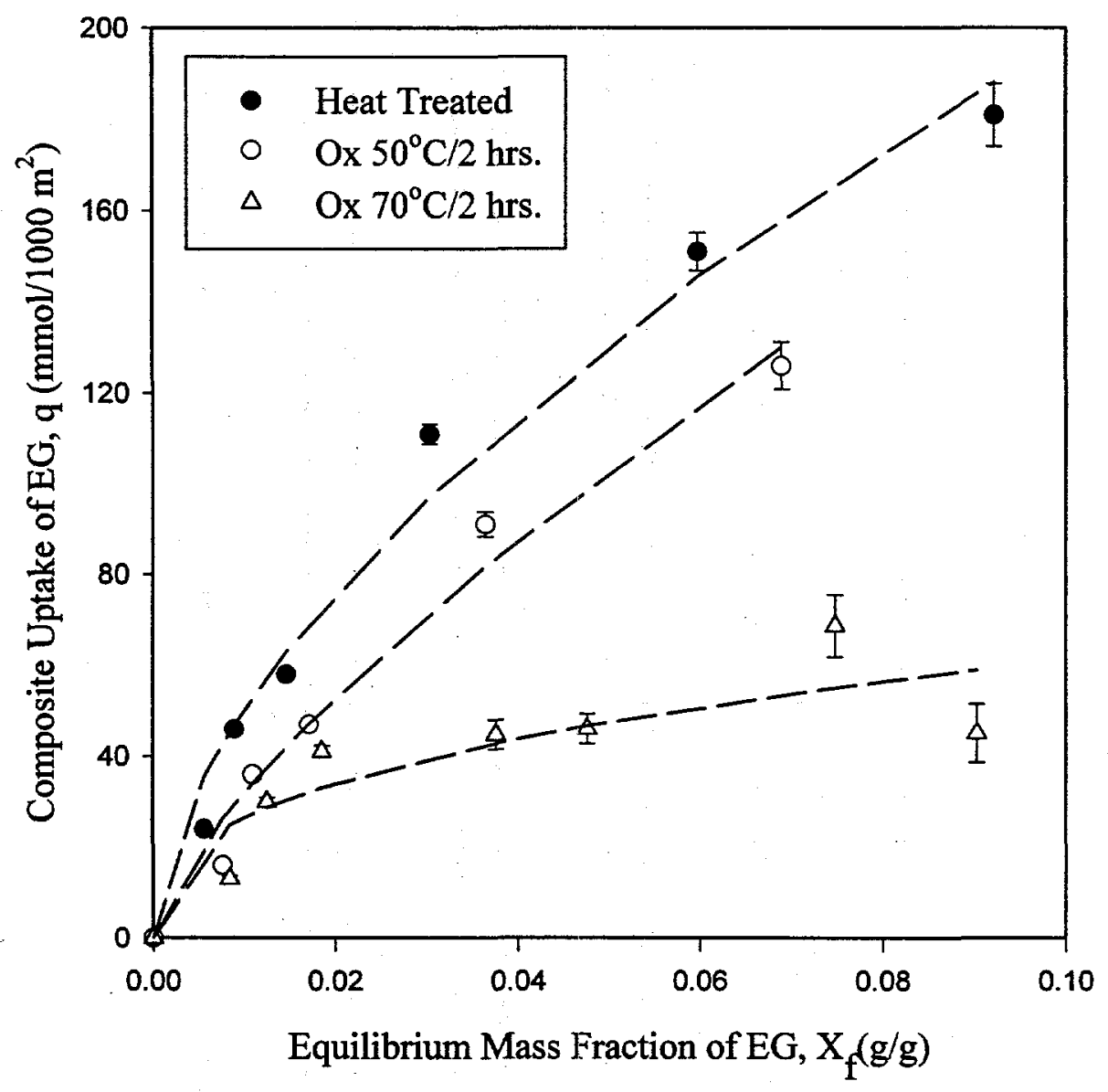

Figure 4.4-1. Composite isotherms $\left(25^{\circ} \mathrm{C}\right)$ for ethylene glycol (EG) adsorbing onto $\mathrm{F} 400$ carbons with various surface treatments. 


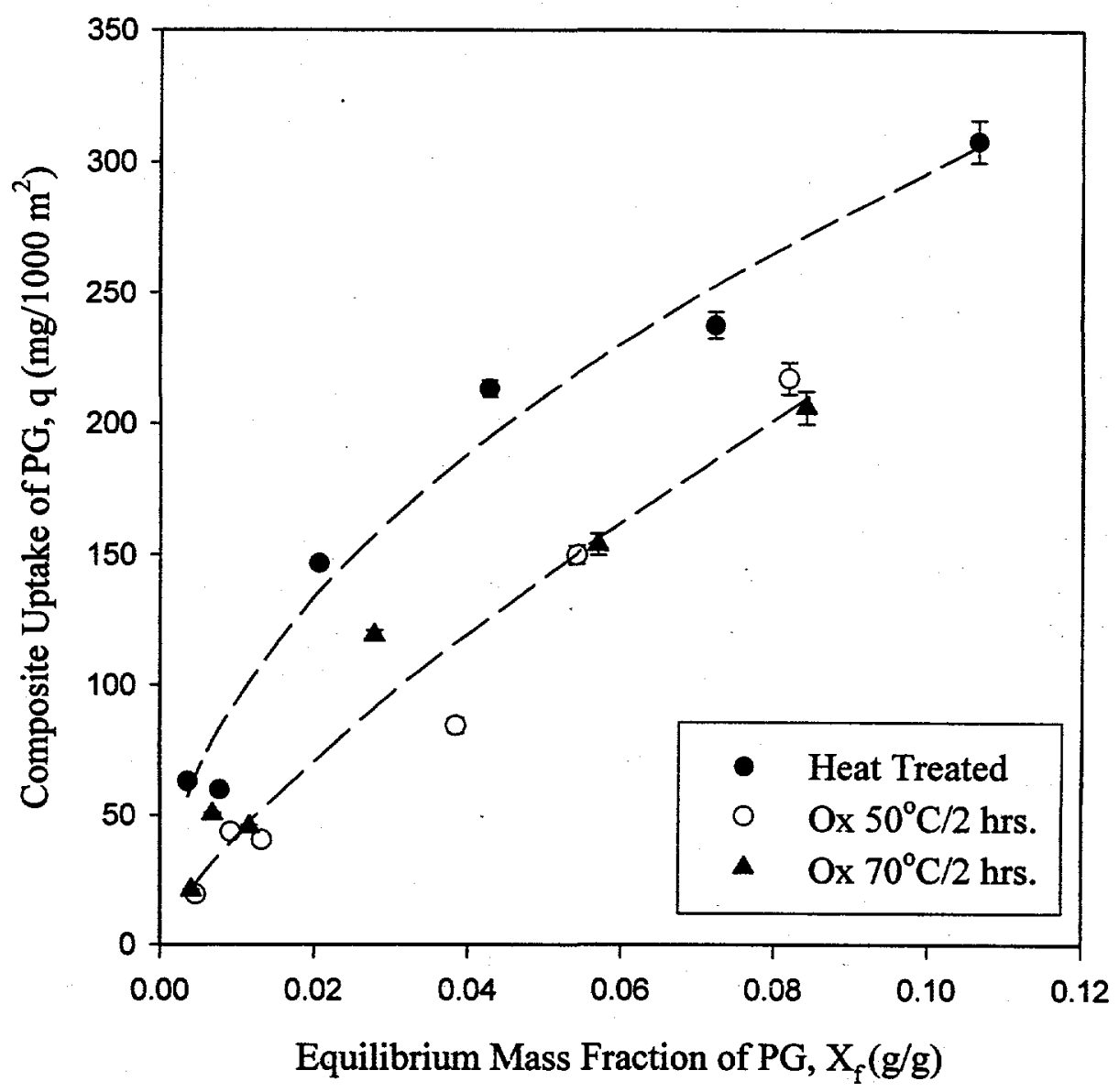

Figure 4.4-2. Composite isotherms $\left(25^{\circ} \mathrm{C}\right)$ for propylene glycol (PG) adsorbing onto F400 carbons with various surface treatments. 


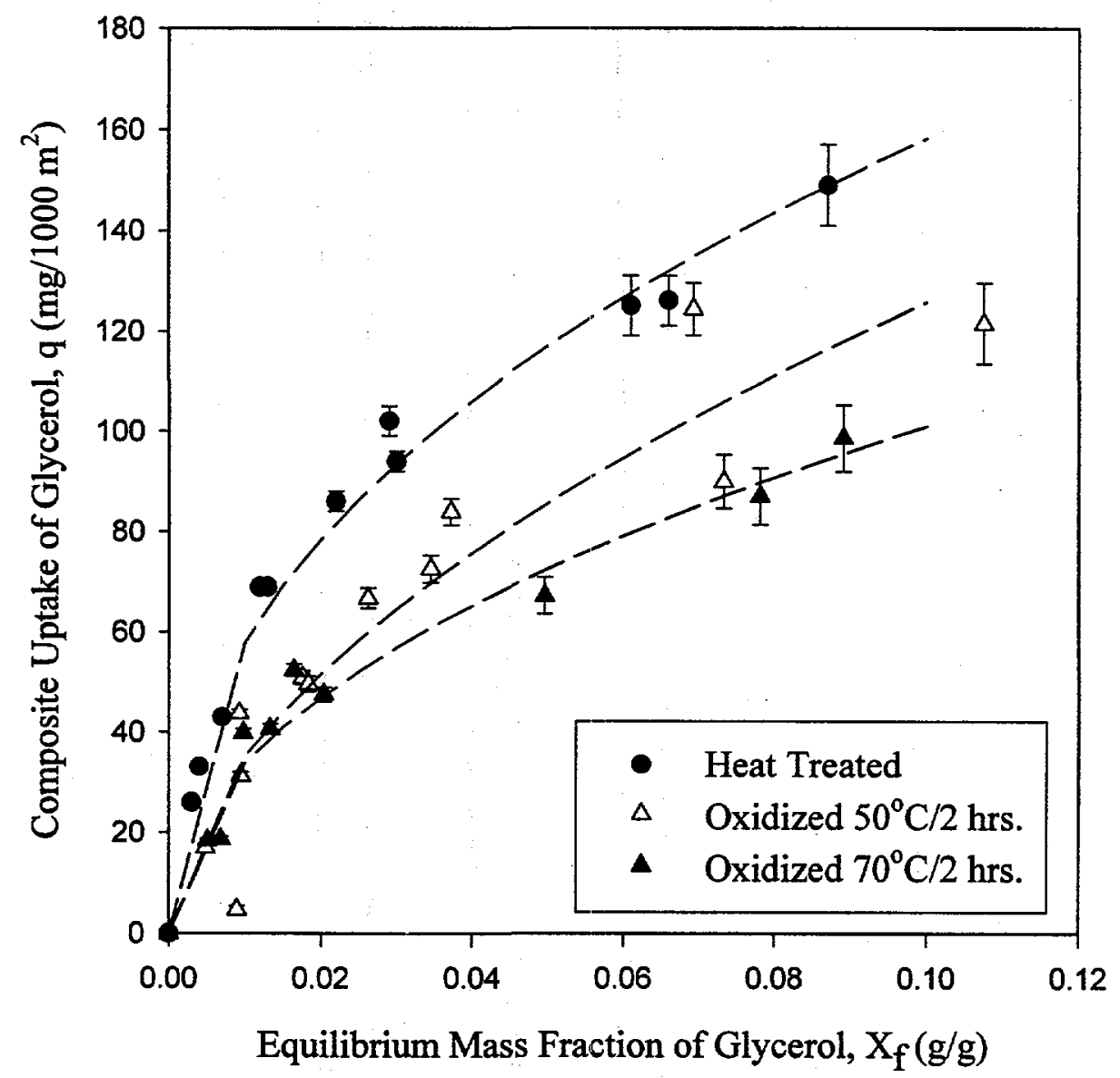

Figure 4.4-3. Composite isotherms $\left(25^{\circ} \mathrm{C}\right)$ for glycerol adsorbing onto $\mathrm{F} 400$ carbons with various surface treatments. 


\subsubsection{Data for Glucose}

Figure 4.4-4 shows the composite isotherms of glucose on heat-treated and oxidized F400 carbons. The shapes of the isotherms differ from those of the glycols/glycerol; namely, the data seems to correlate with a Langmuir-type isotherm (see Appendix C). The data show that both the initial slope and loading plateau of the glucose isotherms are progressively reduced upon surface oxidation. This suggests that the increased number of acidic groups lowers both the overall affinity and total number of adsorption sites of the carbon for glucose. Both effects could be explained from the increased competitive adsorption of water for the oxidized carbons.

\subsubsection{Data for (Monomeric) Lactic Acid}

It was of interest to see whether the observed trends in adsorption onto heat-treated and acid-oxidized carbons persist for other polar, hydroxyl-bearing solutes. Although not studied to any greater extent in our work, lactic acid (2-hydroxypropanoic acid) is also of substantial industrial importance. Figure 4.4-5 shows composite isotherms for lactic acid onto heat-treated and oxidized F400 carbons. The trends observed for the sugars, glycols, and glycerol are also observed in the lactic-acid isotherms, which are of the Freundlich type. In addition to the strong nature of dispersion interactions with the carbon surface (see Fig. 4.2-2), acid-base interactions may be significant in the adsorption of lactic acid.

In Chapter 3, we showed an example where the basal planes of a (bare) heat-treated carbon could act as a basic site. 


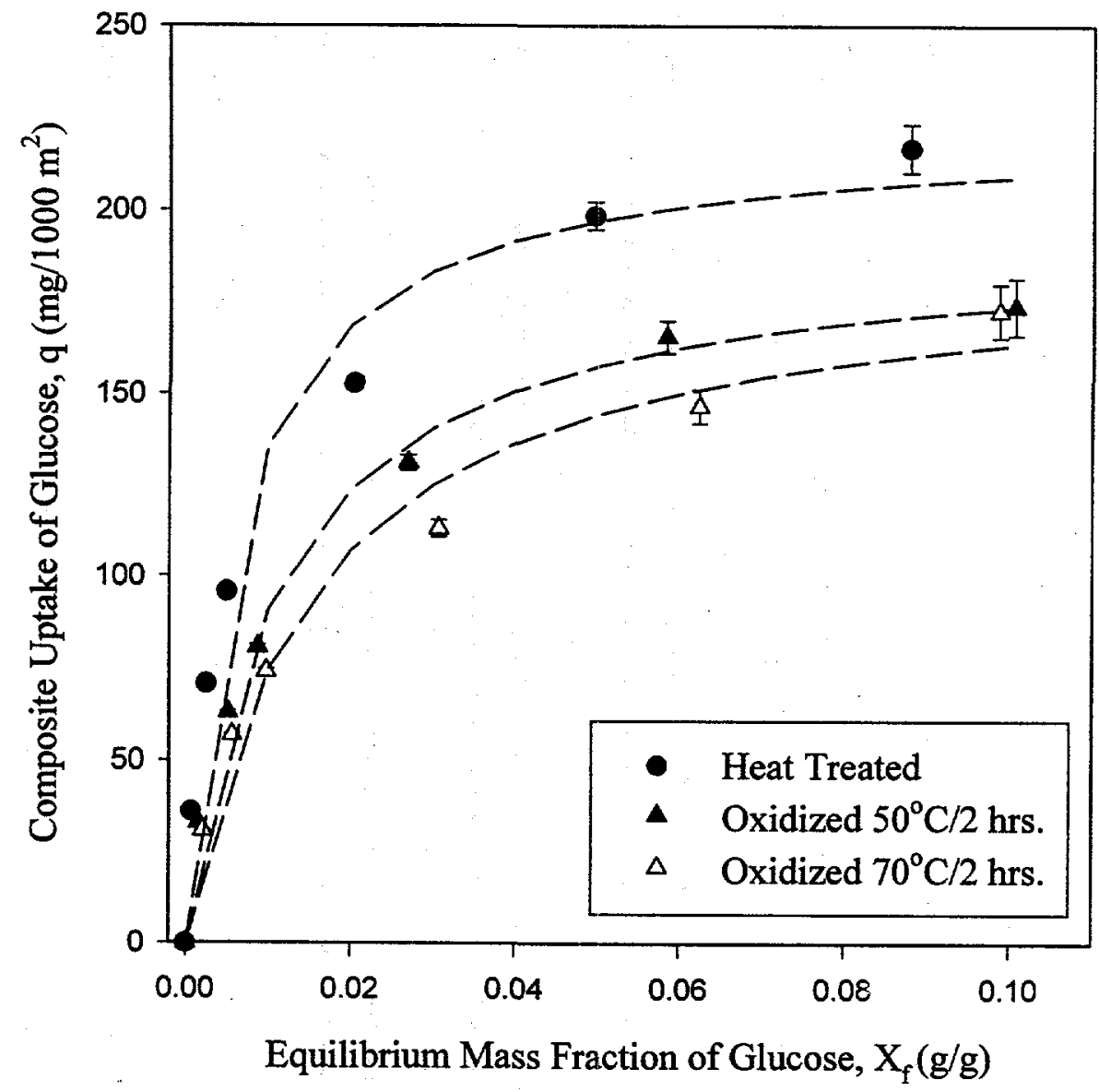

Figure 4.4-4. Composite isotherms $\left(25^{\circ} \mathrm{C}\right)$ for glucose adsorbing onto $\mathrm{F} 400$ carbons with various surface treatments. 


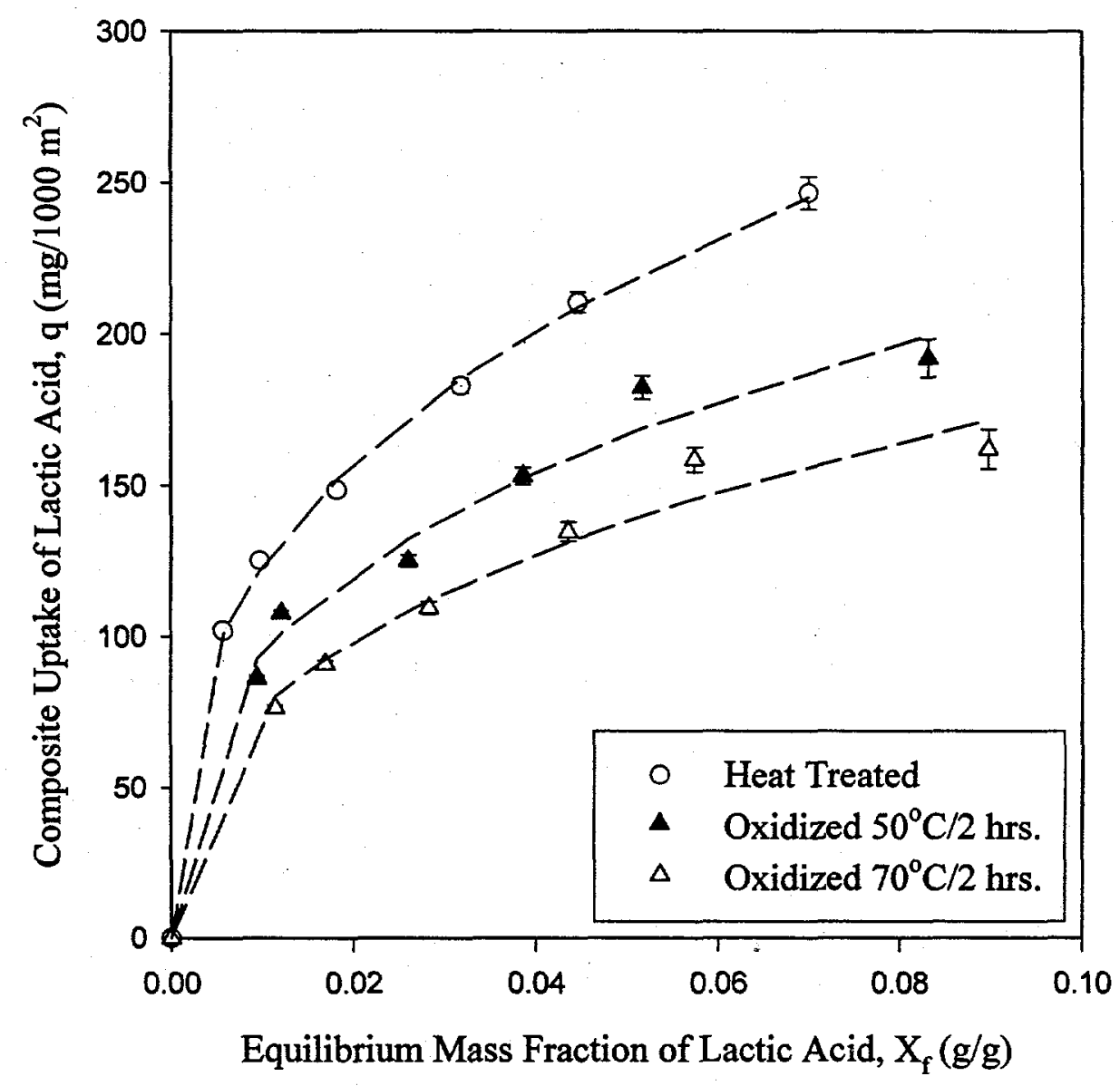

Figure 4.4-5. Composite isotherms $\left(25^{\circ} \mathrm{C}\right)$ for (monomeric) lactic acid adsorbing onto F400 carbons with various surface treatments. 


\subsubsection{Data for As-Received Carbons (Variable Source Material)}

In the previous section, we demonstrated that the capacity of a carbon for aqueous multi $\mathrm{OH}$ solutes becomes progressively lower with increasing degrees of surface oxidation. The greater number of oxygen-bearing acidic groups associated with such surfaces appear to attract water, rather than encourage hydrogen-bonding interactions with the solute. These findings may prove useful when comparing carbons of various source material, especially if the key differences are in the oxygen content, rather than in other physical properties (surface area, pore-size distribution, etc.).

Figure 4.4-6 shows the composite isotherms of EG on as-received carbonaceous adsorbents derived from wood (WVB), extruded peat (RO 0.8), bituminous coal (F400), and pyrolyzed polymer (A572). Among the active carbons, WVB has the lowest uptake of EG on both per-surface-area and per-carbon-mass bases. This result is not surprising, considering the fact that WVB has the highest bulk oxygen content and number of acid sites among all adsorbents in our work. The uptake capacity of EG on A572 well exceeds that of all the as-received carbons on both per-surface-area and per-carbon-mass bases. Although the surface properties of A572 have not been characterized, its surface area and bulk elemental composition are comparable to those of heat-treated F400 (Chapter 3). Manufactured from pyrolyzed polymer, A572 is likely to behave as an activated carbon wiih a more homogeneous surface, with possibly a greater density of high-energy sites. 


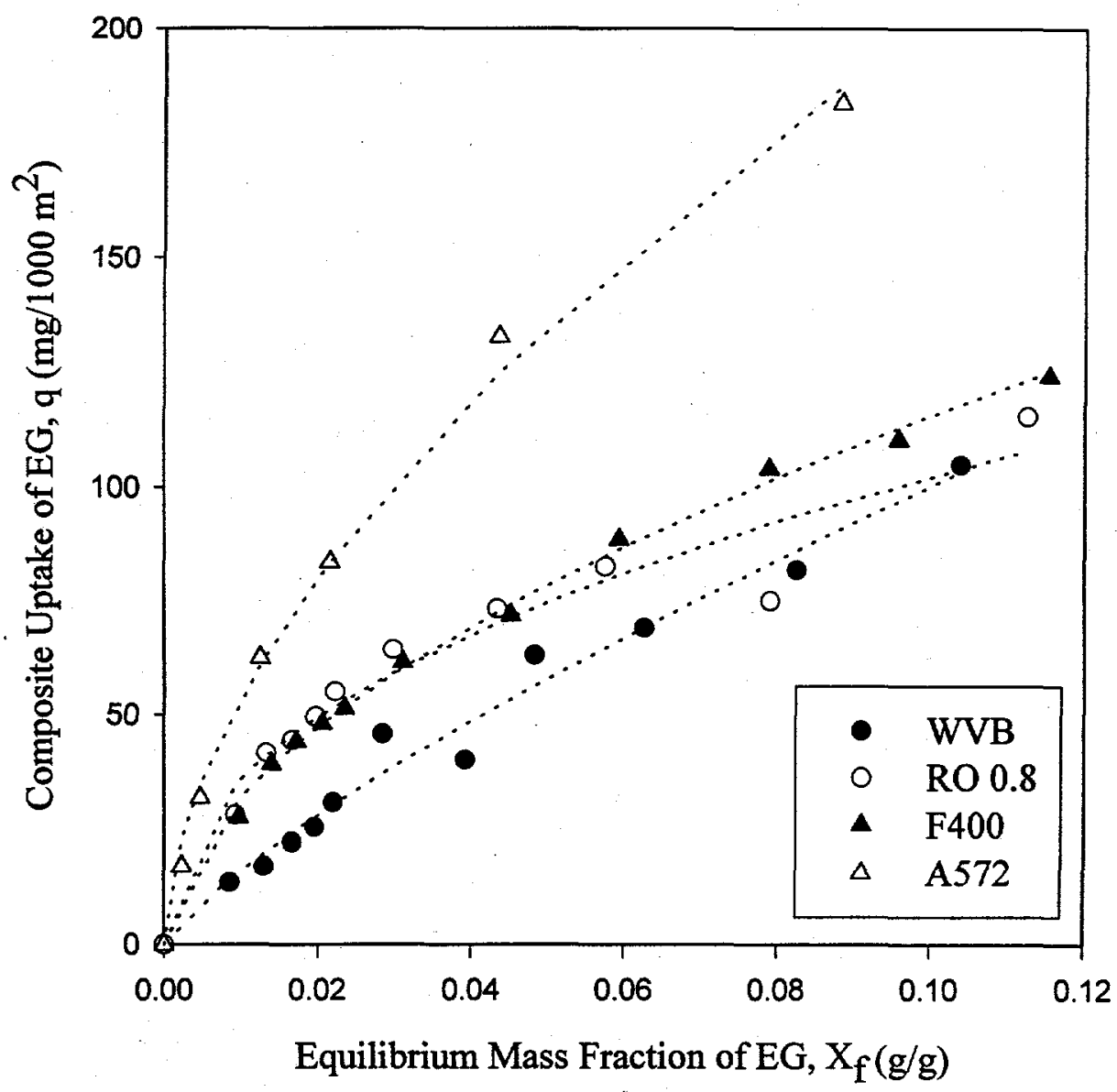

Figure 4.4-6. Composite isotherms $\left(25^{\circ} \mathrm{C}\right)$ for ethylene glycol (EG) adsorbing onto wood (WVB), extruded peat (RO 0.8), bituminous coal (F400), and pyrolyzed polymer (A572) based carbons. 
Similar results for glucose are shown in Figure 4.4-7 on all adsorbents except A572. Langmuir-type isotherms are observed, where there is a sharp rise in the early portion of the curve followed by a plateau in loading. The lower glucose capacity on the WVB carbon is further evidence that adsorption of aqueous multi $-\mathrm{OH}$ solutes is unfavorable on highly oxidized surfaces. The fact that the initial isotherm slopes for RO 0.8 and F400 are much sharper than for WVB also shows that the affinity for glucose is reduced from the presence of more acidic-surface groups.

Figure 4.4-8 compares the results for the adsorption of glucose onto an as-received batch of WVB with those onto a batch of WVB that has been heat treated. The results show that the heat-treated sample, which has lower oxygen content and density of acidic sites, exhibits a higher uptake of glucose. Besides having a lower degree of competitive water adsorption, heat treatment may have widened the pores in WVB, which results in a greater amount of accessible surface area for the adsorption of a large solute such as glucose.

\subsubsection{Roles of Carbon-Surface Oxides on Adsorption - Discussion}

In the last few decades, researchers have postulated several modes of interaction between surface oxide groups and adsorbates. Experiments have supported each of these mechanisms separately. Nevertheless, there is no set of overall concepts of adsorption that hold universally for all systems. The majority of the work in this area was done with phenols and other aromatic compounds, but we will relate the key findings to non- 


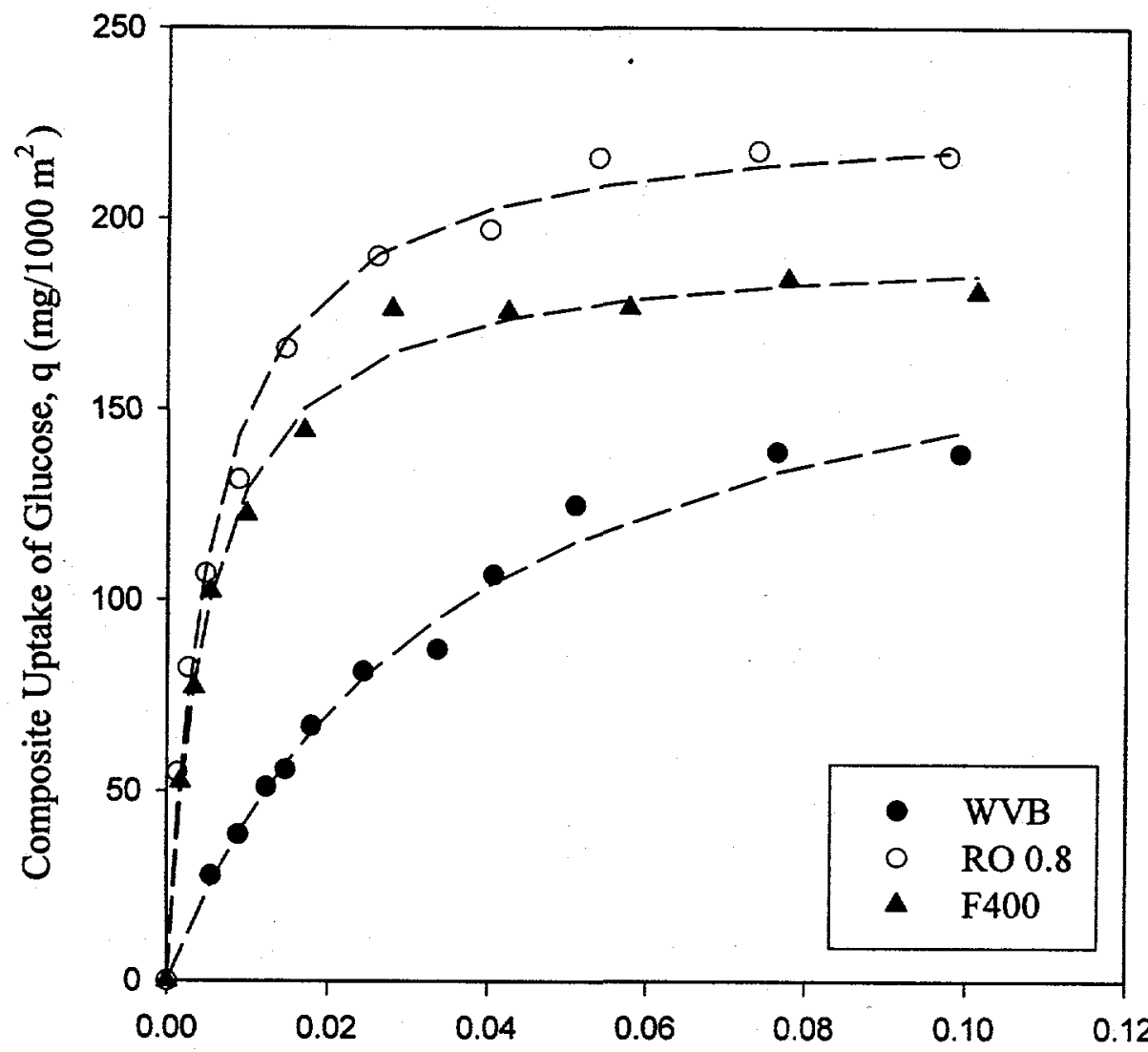

Equilibrium Mass Fraction of Glucose, $X_{f}(g / g)$

Figure 4.4-7. Composite isotherms $\left(25^{\circ} \mathrm{C}\right)$ for glucose adsorbing onto wood (WVB), extruded peat (RO 0.8), and bituminous coal (F400) based carbons. 


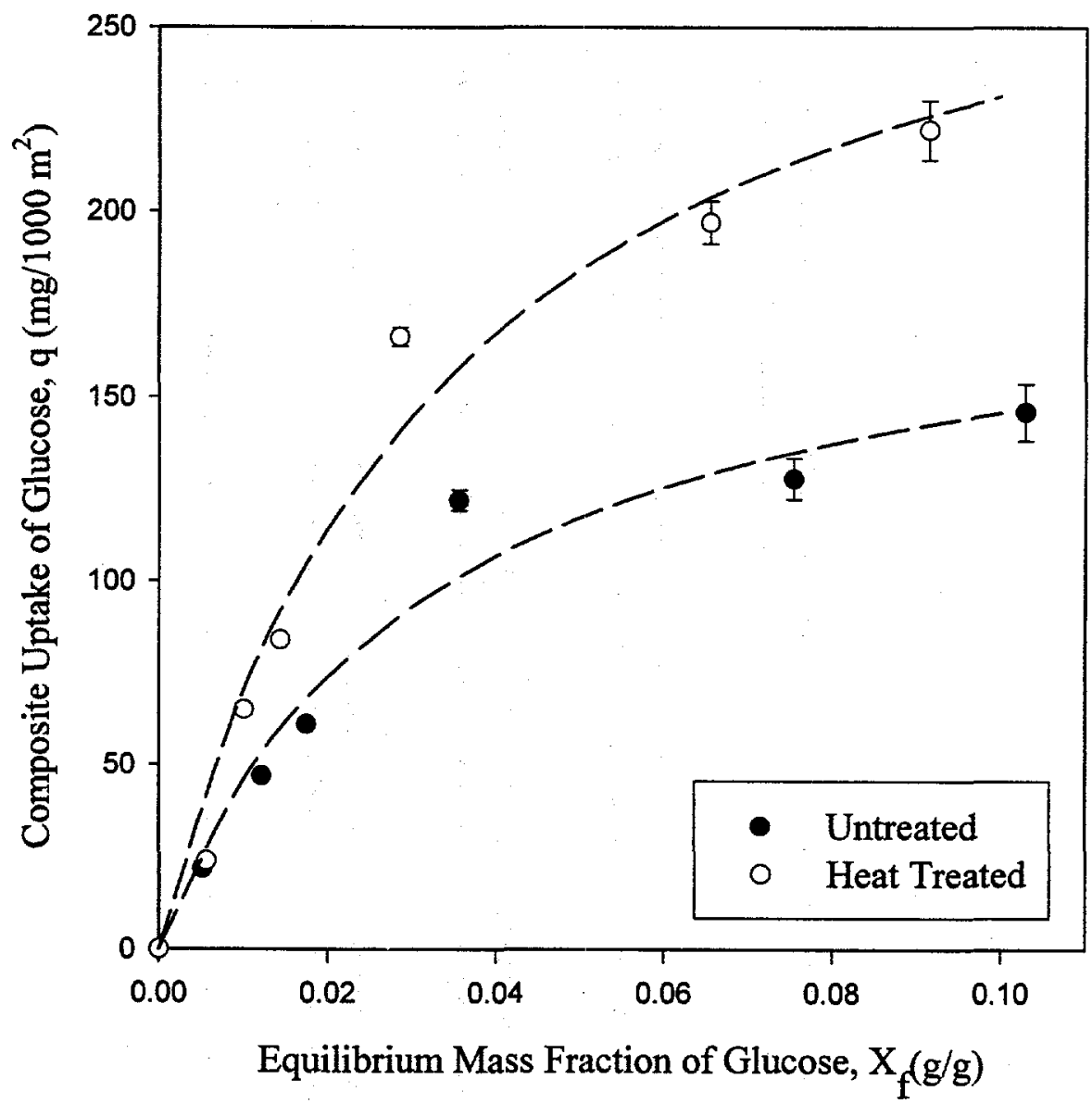

Figure 4.4-8. Composite isotherms $\left(25^{\circ} \mathrm{C}\right)$ for glucose adsorbing onto untreated and heattreated WVB carbon. 
aromatic, multi-OH compounds in the present work.

\subsubsection{Evidence for Polar Interactions}

There are several cases where the presence of surface oxide groups has been shown to affect the selectivity of a carbon for adsorption. Puri et al. (1972) showed that carbons with a preponderance of acidic surface oxides $\left(\mathrm{CO}_{2}\right.$-evolving groups, see Chapter 3) preferentially adsorbed methanol (up to methanol mole fractions of 0.5 to 0.7 ) from two nonpolar solvents, benzene and carbon tetrachloride. Removal of the acidic, $\mathrm{CO}_{2-}$ evolving groups by heat treatment $\left(700\right.$ to $\left.1000^{\circ} \mathrm{C}\right)$ reversed the selectivity of the carbon. Benzene was then positively adsorbed throughout the entire methanol concentration range. Jankowska et al. (1983) did similar work with ethanol-benzene mixtures, and showed that the acid-oxidized carbon had a larger capacity and selectivity for ethanol than the as-received and heat-treated carbons.

In both the cases cited above, it appears that hydrogen bonding occurred between the surface acidic groups and the polar alcohol adsorbate. Removal of the surface acidic groups shifted the selectivity to the nonpolar component, resulting in a different mode of adsorption such as dispersive or electron donor-acceptor interactions. In these studies, the nature of the solvent played a paramount role. When both the solute and the solvent (water) are polar, as in our work, hydrogen bonding does not appear to be the dominating interaction at any solute concentration. This is observed in our adsorption isotherms, with the uptakes of all solutes (sugars, glycols, glycerol, lactic acid) decreasing with 
progressive acid oxidation. An alternative type of interaction, namely preferential affinity for water, appears more likely in our systems.

One experiment where acid oxidation of the carbon actually improved the uptake of solute from an aqueous system was reported by Mahajan et al. (1978). Presenting both batch and fixed-bed adsorption data, the authors showed that carbons strongly oxidized by $\mathrm{HNO}_{3}$ had greater uptakes for ammonia (as $\mathrm{NH}_{4} \mathrm{OH}$ ) than as-received carbons and carbons weakly oxidized by $\mathrm{H}_{2} \mathrm{O}_{2}$ or air. These results are not too surprising, considering that $\mathrm{NH}_{4} \mathrm{OH}$ itself is a base and is prone to interact with acidic sites. Such interactions could arise with the anionic surface oxides (ionic forces), or through donor-acceptor complexes (hydrogen-bonding forces).

\subsubsection{Evidence for Dispersive Interactions with Basal Plane}

Several researchers have reported that acid oxidation of carbons lowers uptakes of phenol from aqueous solution (Coughlin and Ezra, 1968; Mahajan et al., 1980; Kilduff and King, 1997). Coughlin and Ezra (1968) postulated that phenol adsorption is mainly attributable to dispersive interactions between the $\pi$-electrons of the phenol and the $\pi$ electrons of the carbon basal plane. The presence of surface oxides thereby serves to deplete electrons from the carbon surface, which results in a lower affinity for phenol. The importance of the $\pi$ electrons on the surface was demonstrated in a separate experiment by Mahajan et $a l$. (1980). A polycrystalline graphite doped with $0.79 \%$ boron (thereby having less $\pi$ electrons) had a substantially lower phenol capacity than the as-received material. 
Although the multi $-\mathrm{OH}$ solutes in our work are not aromatic compounds, evidence for dispersive interactions is seen in the isotherms. Among all carbons tested, the heattreated samples had the highest uptake for all solutes relative to the acid-oxidized samples. The fact that activated carbons are able to adsorb such a wide variety of aqueous multi $-\mathrm{OH}$ compounds suggests that the solute-surface interactions are of a nonspecific nature. Also, our heat of adsorption calculations for single and multi $-\mathrm{OH}$ solutes demonstrated that the $-\mathrm{OH}$ group does not appear to interact directly with the carbon surface, but rather favorably with the solvent. Finally, the extraordinary capacity of A572 (styrene-divinylbenzene backbone) for glycol might be due to it being a more homogeneous surface, with a greater density of surface $\pi$ electrons.

\subsubsection{Evidence for Electron Donor-Acceptor Interactions}

On the basis of infrared internal reflection (IRS) spectroscopy of loaded carbons, Mattson et al. (1969) argued that the adsorption of phenol and its (nitro-) derivatives was due to electron donor-acceptor complexes with the carbon surface. The functional groups (-OH, $-\mathrm{NO}_{2}$ ) on the phenol did not participate in any specific interaction with the carbon, since the corresponding bands in the IR spectra did not change significantly after adsorption. The authors suggested that the carbonyl groups on the carbons served as the donor while the phenol (through the $\pi$ electrons) was the acceptor. To support the observations of Coughlin and Ezra (1968), the authors proposed that the lower phenol uptakes from acid treatment of the carbon were attributable to the irreversible oxidation of carbonyl groups into carboxylic acid groups. 
Evidence for a donor-acceptor mechanism with surface carbonyl groups in a nonaqueous system was found in work by Puri et al. (1972). Carbons relatively free of acidic, $\mathrm{CO}_{2}$-evolving groups but retaining $\mathrm{CO}$-evolving groups were found to adsorb benzene preferentially from a methanol-benzene mixture. A carbon that solely contained CO-evolving groups had a surprisingly larger benzene capacity than a carbon completely devoid of oxygen. Puri et al. (1972) suggested that the CO-evolving groups were quinones (see Figure 3.5.1-A). The partial positive charge of the surface carbonyl carbon could interact with the electron-rich aromatic ring of benzene. When both $\mathrm{CO}_{2}$ and $\mathrm{CO}-$ evolving complexes were present on the carbon, the selectivity was dominated by the acidic groups; hence, methanol was selectively adsorbed.

For an aqueous system, Kilduff and King (1997) showed that removal of acidic surface groups from a heavily oxidized F400 carbon resulted in aqueous-phenol capacities that exceeded those of the as-received carbon. These results again support the notion that acidic oxides hindered adsorption, while donor-acceptor complexes are possible with phenol and non-acidic oxygen surface groups. However, there have been virtually no studies reported by the literature on the effect of the CO-evolving surface groups on the adsorption of non-aromatic compounds on carbons.

The multi $-\mathrm{OH}$ compounds in this work all lack the $\pi$ electrons characteristic of aromatic compounds, consequently donor-acceptor interactions with the surface are not likely to be as significant as for phenol. Although the $-\mathrm{OH}$ group has donor-acceptor and hydrogenbonding properties, our data thus far show that it does not interact favorably with the 
carbon surface in competition with water. With regards to adsorption of aqueous multi $-\mathrm{OH}$ solutes, it is highly probable that the $\mathrm{CO}$-evolving groups may attract water preferentially.

\subsubsection{Evidence for Preferential Affinity for Water}

In aqueous systems, a possible role of surface oxide groups is to bond water molecules selectively. Dubinin (1966) suggested that water adsorbed to the oxygen groups provide secondary adsorption centers that bind other water molecules through hydrogen bonding. These water complexes may prevent adsorbate molecules from accessing certain active sites. Work by Kilduff and King (1997) showed that carbons progressively oxidized with acid were shown to be more hydrophilic (see Figure 3.6-1).

Among the acid-oxidized carbons, preferential affinity of the surface oxides for water may well explain the capacity losses observed in all of the solutes in our work. The effect seems to be less severe with larger solutes (such as glucose) than for smaller solutes (such as ethylene glycol). One possible explanation is that the larger solutes are capable of displacing more adsorbed water than the smaller solutes; consequently, having more acidic sites would have a lesser effect on adsorption.

\subsubsection{Adsorption Equilibria - Summary}

Based on the results presented in this chapter, the adsorption mechanisms of aqueous multiple $-\mathrm{OH}$ solutes onto activated carbons appear to be largely influenced by dispersion interactions (favored by high molecular weight) and solution-phase 
nonidealities (arising from the presence of the $-\mathrm{OH}$ groups). Both effects are supported by comparisons with isotherm data for alcohols and heat of adsorption measurements on F400. Oxygen-bearing acidic groups present on the carbon surface serve to reduce the uptake capacity and affinity for multi $-\mathrm{OH}$ solutes, presumably through preferential interactions with water. Similar trends were observed in as-received carbons with substantial natural oxygen content (wood-based WVB carbon), as opposed to highly carbonaceous adsorbents (F400, RO 0.8, A572). 


\section{References for Chapter 4}

Adamson, A.W. Physical Chemistry of Surfaces, $2^{\text {nd }}$ edition. Interscience-John Wiley and Sons, Inc.: New York, 1961.

Broekhuis, R.R. Recovery of Propylene Glycol from Dilute Aqueous Solutions by Reversible Chemical Complexation with Organoboronates and via Reversible Reaction with Aldehydes. Ph.D. Dissertation, Department of Chemical Engineering, University of California, Berkeley, 1995.

Connors, K.A.; Wright, J.L. Anal. Chem. 1989, 61, 194-198.

Coughlin, R.W.; Ezra, F.S. Environmental Science and Technology, 1968, 2(4), 291-297.

Denoyel, R.; Rouquerol, F.; Rouquerol, J. Journal of Colloid and Interface Science, 1990, 136(2), 375-384.

Dubinin, M.M. Chemistry and Physics of Carbon, P.L. Walker, Jr., Ed., Marcel-Dekker: New York, 1966, Vol. 2, 51.

Forkner, M.W.; Robson, J.H.; Snellings, W.M. "Glycol (Ethylene Glycol and Oligomers)." In Kirk-Othmer Encyclopedia of Chemical Technology, $4^{\text {th }}$ edition; Kroshwitz, J.I.; Howe-Grant, M., Eds., John Wiley and Sons: New York, c1991, Vol. 12, 695-713.

Gmehling, J.; Onken, U.; Rarey-Nies, J.R. Vapor-Liquid Equilibrium Data Collection, Dechema: Frankfurt, 1988.

Hoke, B.C.; Chen, J.C. J. Chem. Eng. Data, 1991, 36, 322-326.

Hoke, B.C.; Patton, E.F. J. Chem. Eng. Data, 1992, 37, 331-333.

Huss sn, S.M. Regeneration of Basic Adsorbents in the Recovery of Carboxylic Acids From Dilute Aqueous Solution and Multiple-acid Equilibria in Adsorption of Carboxylic Acids from Dilute Aqueous Solution. Ph.D. Dissertation, Department of Chemical Engineering, University of California, Berkeley, 1998.

Jankowska, H., Swiatkowski, A.; Oscik, J. Carbon, 1983, 21, 117.

Johnson, I.; Denoyel, R.; Rouquerol, J.; Everett, D.H. Colloids and Surfaces, 1990, 49, 133-148.

Kilduff, J.E.; King, C.J. Ind. Eng. Chem. Res., 1997, 36, 1603-1613. 
Lide, D.R.; Frederikse, H.P.R., Eds., CRC Handbook of Chemistry and Physics, $77^{\text {th }}$ edition, CRC Press, Inc.: Boca Raton, 1996-1997.

Mahajan, O.P.; Moreno-Castilla, C.; Walker, Jr., P.L. Separation Science and Technology, 1980, 15(10), 1733-1752.

Mahajan, O.P.; Youssef, A.; Walker, Jr., P.L. Separation Science and Technology, 1978, 13(6), 487-499.

Martin, A.E.; Murphy, F.H. "Glycols (Propylene)." In Kirk-Othmer Encyclopedia of Chemical Technology, $4^{\text {th }}$ edition; Kroshwitz, J.I.; Howe-Grant, M., Eds., John Wiley and Sons: New York, c1991, Vol. 12, 715-725.

Mattson, J.S.; Mark, Jr., H.B. Activated Carbon, Surface Chemistry and Adsorption from Solution, Marcel Dekker, Inc.: New York, 1971.

Mattson, J.S.; Mark, Jr., H.B.; Malbin, M.D.; Weber, Jr., W.J.; Crittenden, J.C. Journal of Colloid and Interface Science, 1969, 31(1), 116-130.

Miyajima, K.; Sawada, M.; Nakagaki, M. Bull. Chem. So. Japan, 1983, 56, 1620-1623.

Morrison, L.R. "Glycerol." In Kirk-Othmer Encyclopedia of Chemical Technology, $4^{\text {th }}$ edition; Kroshwitz, J.I.; Howe-Grant, M., Eds., John Wiley and Sons: New York, c1991, Vol. 12, 681-694.

Prausnitz, J.M.; Lichtenthaler, R.N.; de Azevedo, E.G. Molecular Thermodynamics of Fluid-Phase Equilibria, $2^{\text {nd }}$ edition. P T R Prentice-Hall, Inc.: New Jersey, 1986.

Puri, B.R.; Singh, D.D.; Kaistha, B.C. Carbon, 1972, 10, 481-486.

Supran, M.K.; Acton, J.C.; Howell, A.J.; Saffle, R.L. J. Milk Food Technol., 1971, 34, 584-585.

Suleiman, D.; Eckert, C.A. J. Chem. Eng. Data, 1994, 39, 692-696. 


\section{Chapter 5. Solvent Regeneration of Activated Carbons}

\subsection{Overview}

Whereas the preceding chapter dealt with understanding the factors governing adsorption of multi - $\mathrm{OH}$ compounds from aqueous solution, this chapter and the next one explore desorption of solute from the carbon surface. Our chosen regeneration method involves leaching of loaded carbons by organic solvents, but we will briefly discuss other avenues for regeneration as well. This chapter is largely geared toward understanding the desorption equilibria, with the specific goals of assessing the completeness of desorption and rationalizing reasons for any incompleteness.

\subsection{Current Regeneration Methods}

One need for developing an effective regeneration method stems from the usually prohibitive cost of using activated carbons on a throwaway basis (Himmelstein et al., 1973; Cooney et al., 1983; Martin and Ng, 1987; McLaughlin, 1995). Besides the issue of carbon reusability, choosing the appropriate regeneration process is important for recovering the adsorbed compound(s). Often, substances removed from aqueous waste streams are valuable products and/or raw materials for other processes (Himmelstein et al., 1973). Carbon regeneration methods can be grouped into three categories: thermal, reversible reaction, and solvent desorption. 


\subsubsection{Thermal Regeneration}

In practice, the most common regeneration method is to heat the spent carbon in multiple-hearth furnaces at temperatures of $300-800^{\circ} \mathrm{C}$ (Cooney et al., 1983; Martin and $\mathrm{Ng}, 1987 ;$ McLaughlin, 1995). Under these conditions, the adsorbates volatilize and/or decompose into gaseous $\left(\mathrm{CO}, \mathrm{CO}_{2}, \mathrm{H}_{2} \mathrm{O}, \mathrm{NO}_{\mathrm{X}}\right.$, etc.) residues, without significant deterioration of the carbon structure (McLaughlin, 1995). Though simple and effective, direct heating has several disadvantages: destruction of the adsorbate, loss of carbon (5$10 \%$ ), and lowering of carbon capacity for subsequent cycles (Chang and Savage, 1981; Cooney et al., 1983). Direct heating is also among the most expensive regeneration processes, in the range of a dollar per pound of carbon regenerated (McLaughlin, 1995).

Stripping with steam or hot, inert gas is a thermal method of regenerating loaded carbons that is usually nondestructive to the adsorbate (McLaughlin, 1995). In the case of steam stripping, the vapor stream can be condensed to a liquid and distilled. In the case of stripping by inert gases, the vapor stream can be cooled to allow condensation of the adsorbed components. Although the cost for steam regeneration is several cents per pound of regenerated carbons, its application is usually restricted to volatile compounds with normal boiling points up to $120^{\circ} \mathrm{C}$ (McLaughlin, 1995). Clearly, regeneration by stripping does not appear feasible for the nonvolatile sugars and other high-boiling $\left(\mathrm{T}_{\mathrm{nbp}}\right.$ of $200-300^{\circ} \mathrm{C}$ ) multi $-\mathrm{OH}$ compounds in our work. 


\subsubsection{Regeneration by Reversible Reaction}

Another nondestructive alternative to direct heating is to react the adsorbed compounds into products that desorb more easily. One classic example is to change the $\mathrm{pH}$ in the proximity of the carbon surface. The adsorption equilibrium between the surface and the ionized form of the adsorbate therefore become unfavorable (McLaughlin, 1995).

Carbon regeneration processes based on $\mathrm{pH}$-swing were designed for phenol $\left(\mathrm{pK}_{\mathrm{a}}=9.89\right.$; McMurry, 1990) recovery, where adsorbed phenol is converted to the phenoxide form using dilute sodium hydroxide (Himmelstein et al., 1973). A similar method applied for recovery of non-aromatic multi - $\mathrm{OH}$ compounds would be much more difficult, since the $\mathrm{pK}_{\mathrm{a}}$ of the hydroxyl groups on glycols and sugars are between 12 and 14 (Chapter 1).

\subsubsection{Regeneration by Solvents}

In solvent regeneration, the spent carbon is equilibrated with an organic solvent which has a greater affinity for the surface than do the adsorbed compounds. The adsorbates are displaced from the surface and dissolved by the solvent. Product recovery from the organic phase can be effected by conventional distillation, whereas residual solvent must be rinsed or stripped from the carbon. Solvent regeneration offers several advantages over conventional thermal regeneration (Cooney et al., 1983):

(1) Regeneration can be done in situ, minimizing adsorber downtime and eliminating transportation and repacking of carbons.

(2) There is no carbon degradation from repetitive pyrolysis, allowing longer service. 

(3) Well-chosen solvents can be easily removed from the carbon and subsequently recovered (e.g. by distillation).

Lastly, costs associated with carbon regeneration by solvents are about one-tenth as great as for thermal regeneration (McLaughlin, 1995).

\subsection{Solvent Regeneration - Fundamental Concepts}

\subsubsection{Equilibrium Standpoint}

Figure 5.3-1 shows composite isotherms $\left(25^{\circ} \mathrm{C}\right)$ for ethylene glycol and glycerol adsorbing onto heat-treated F400 carbon from two different organic solvents, as well as from water. To account for solution-phase nonidealities, the equilibrium mole fractions are multiplied by the solute activity coefficients. Table 4.2-1 lists activity-coefficient (three-suffix Margules) parameters for aqueous systems while similar data for nonaqueous systems are shown in Table 5.3-1 below.

TABLE 5.3-1

Activity Coefficient Data for Solutes in Nonaqueous Systems

\begin{tabular}{|c|c|c|c|c|c|}
\hline SYSTEM & $\mathrm{T}\left({ }^{\circ} \mathrm{C}\right)$ & $\mathrm{A}_{12}$ & $\mathrm{~A}_{21}$ & $\gamma_{1}{ }^{\infty}$ & $\gamma_{2}{ }^{\infty}$ \\
\hline (1) Acetone (2) EG & 50 & 1.5291 & 1.8354 & 4.61 & 6.27 \\
\hline (1)MeOH (2) Glycerol & 25 & 0.0624 & 1.0325 & 1.06 & 2.81 \\
\hline
\end{tabular}

As Figure 5.3-1 shows, the degree of solute adsorption onto the carbon surface from an aqueous solution is substantially greater than from an organic solution (acetone or methanol). Solvent regeneration can therefore be thought of as a process where there is 


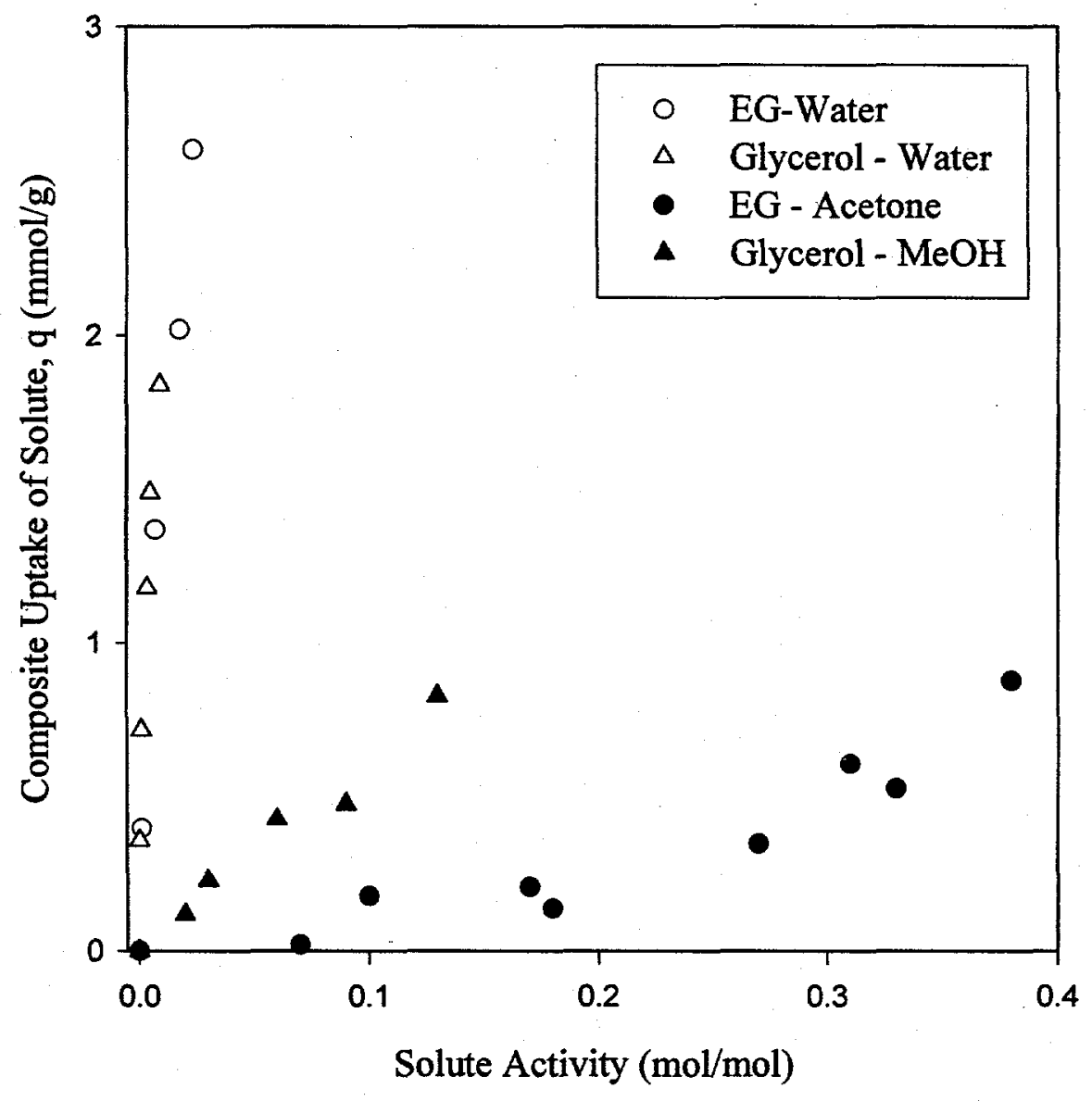

Figure 5.3-1. Composite isotherms $\left(25^{\circ} \mathrm{C}\right)$ for $\mathrm{EG}$ and glycerol on $\mathrm{F} 400 / \mathrm{HT}$ carbon, from two different solvents. Note: activity coefficient data at $50^{\circ} \mathrm{C}$ were used for the EGacetone isotherm. 
a large swing in the adsorption equilibrium, caused by the transition from an aqueous to an organic environment.

The results of Figure 5.3-1 also pose the important question of whether water entrained within the carbon has any effect on the adsorption/desorption equilibrium. In our work, a gram of carbon will have $0.5-0.7 \mathrm{~g}$ of water taken up nonselectively during loading. The isssue of whether effective solvent regeneration requires preliminary drying of the carbons therefore must be addressed. In Section 5.5, two types of batch experiments will be discussed: wet regeneration and dry regeneration. "Wet" means that the loaded carbons are regenerated by solvents immediately after the centrifugation stage (see Section 2.4.2). "Dry" means that after the centrifugation process, the loaded carbons are dried under vacuum $(0.3 \mathrm{~atm})$ at $65^{\circ} \mathrm{C}$. In using these mild conditions, our goal was to evaporate all of the water with minimal solute losses.

\subsubsection{Individual Uptakes of Solute}

As was noted in Section 2.4.3, a quantitative assessment of regenerability requires the actual (individual), rather than excess (composite) uptake of solute onto carbons. Figures 5.3-2, 5.3-3, and 5.3-4 show the individual uptakes $\left(25^{\circ} \mathrm{C}\right)$, respectively, of $E G, P G$, and glycerol on heat-treated F400 carbon. In each figure, the composite uptake of solute is

also shown for reference. The origin of the error bars are discussed in Appendix B. Two methods were used in estimating the individual uptakes: "wet" individual uptakes were calculated from eq. (2.4.3-6), while "dry" individual uptakes were determined from weighing after the vacuum-drying step: 


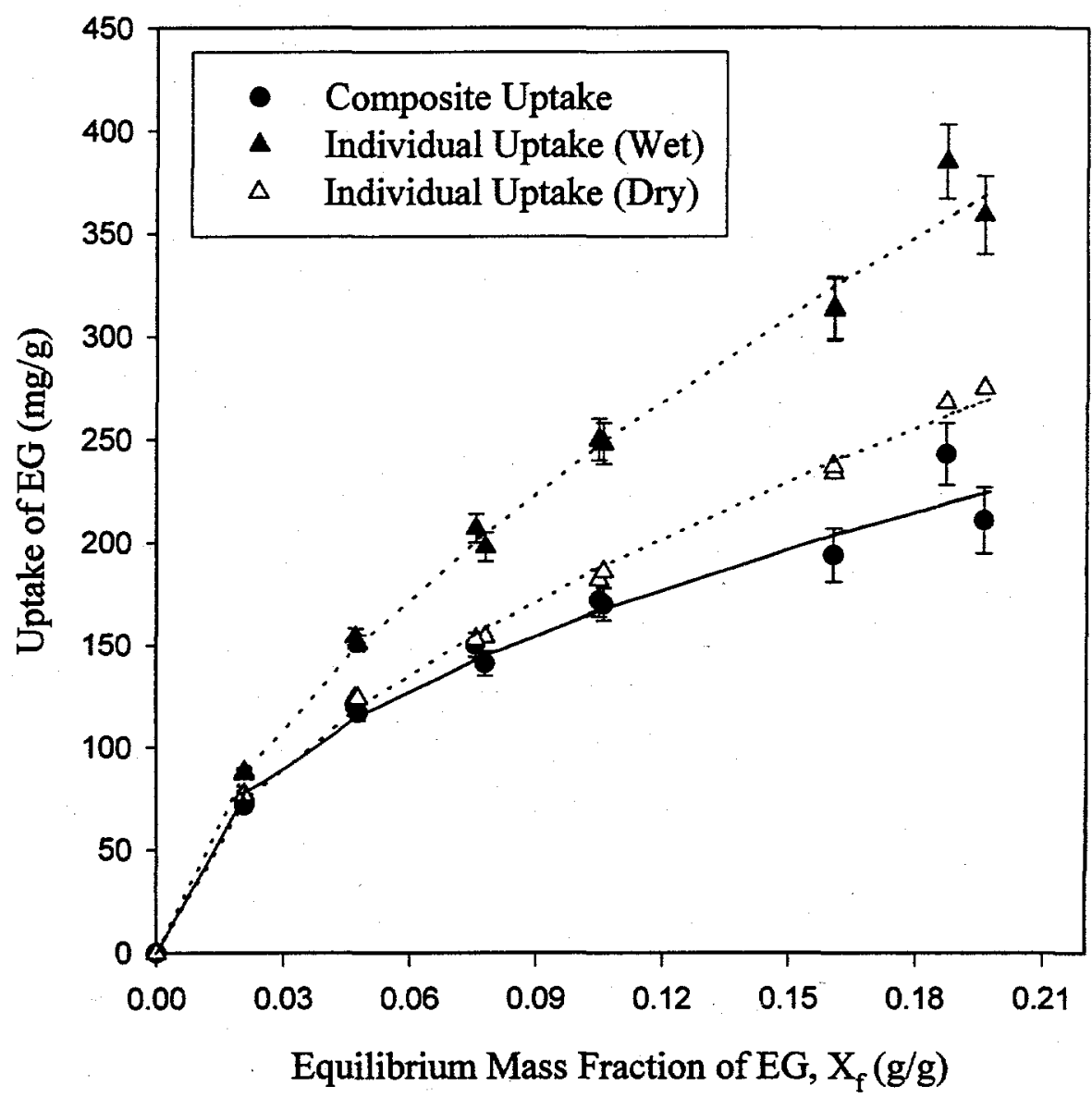

Figure 5.3-2. Composite and individual isotherms $\left(25^{\circ} \mathrm{C}\right)$ for $\mathrm{EG}$ on $\mathrm{F} 400 / \mathrm{HT}$ carbon. "Wet" individual uptakes were calculated from eq. (2.4.3-6), and "Dry" individual uptakes were determined from eq. (5.3-1). 


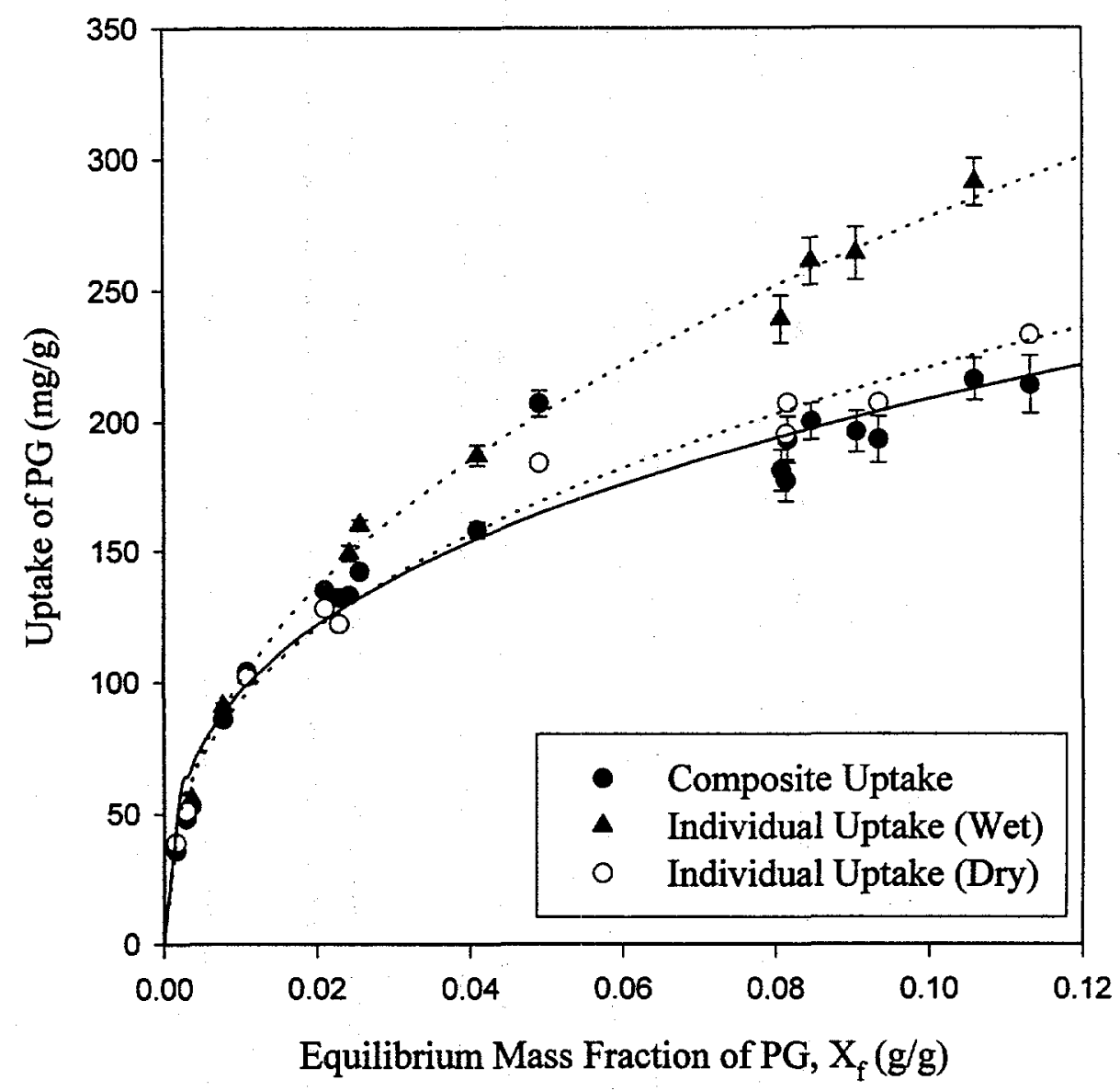

Figure 5.3-3. Composite and individual isotherms $\left(25^{\circ} \mathrm{C}\right)$ for $\mathrm{PG}$ on $\mathrm{F} 400 / \mathrm{HT}$ carbon. "Wet" individual uptakes were calculated from eq. (2.4.3-6), and "Dry" individual uptakes were determined from eq. (5.3-1). 


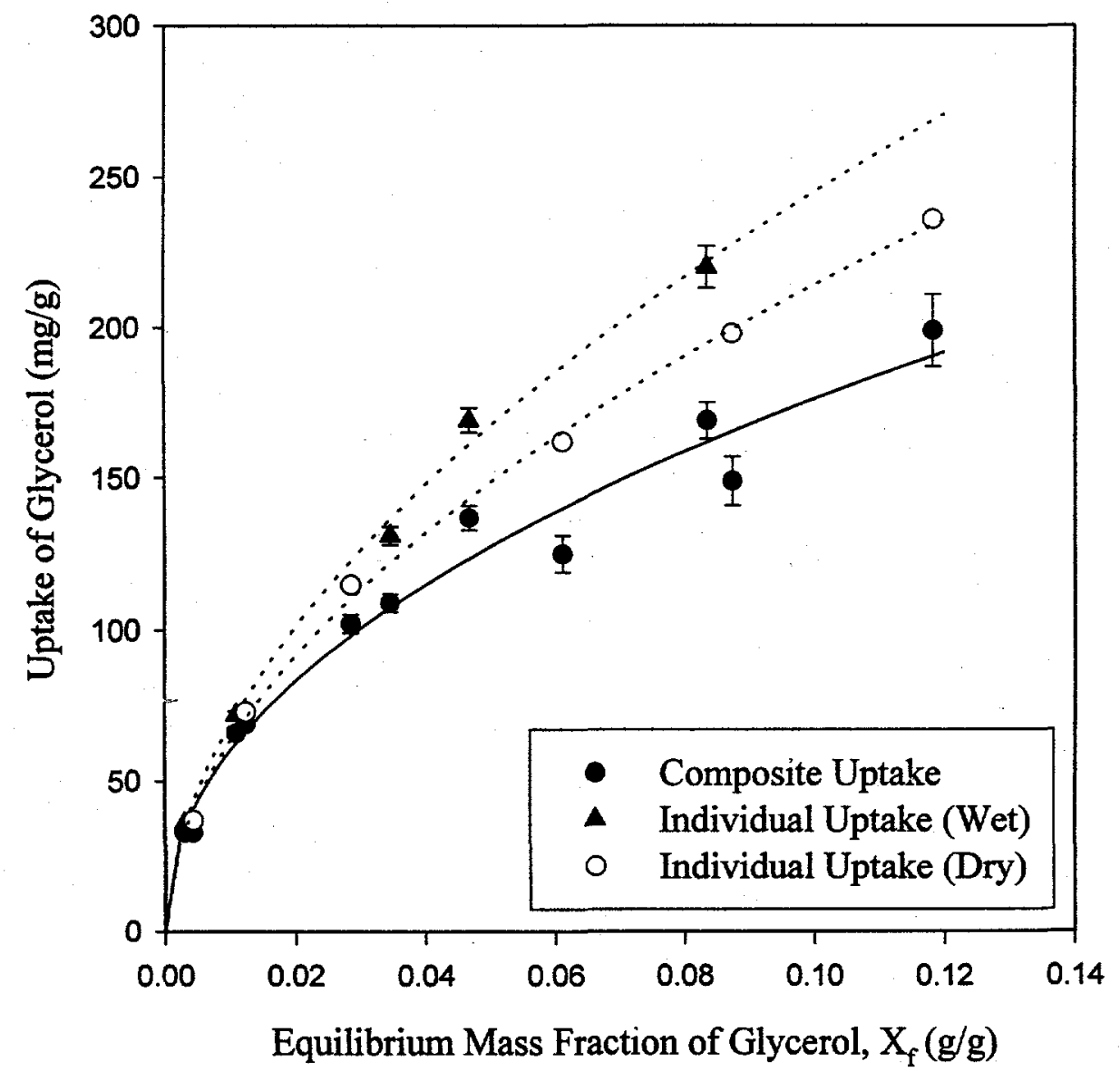

Figure 5.3-4. Composite and individual isotherms $\left(25^{\circ} \mathrm{C}\right)$ for glycerol on $\mathrm{F} 400 / \mathrm{HT}$ carbon. "Wet" individual uptakes were calculated from eq. (2.4.3-6), and "Dry" individual uptakes were determined from eq. (5.3-1). 


$$
\mathrm{Q}^{*}=1000 \frac{\mathrm{m}^{*}-\mathrm{m}}{\mathrm{m}}
$$

where $\mathrm{m}$ is the dry carbon mass $(\mathrm{g}), \mathrm{m}^{*}$ is the carbon mass $(\mathrm{g})$ determined after the loading, centrifugation, and vacuum-drying steps, and Q* is the "dry" individual uptake of solute $(\mathrm{mg} / \mathrm{g})$. Note that eq. (5.3-1) assumes that all of the water is removed from the carbon.

Figures 5.3-2 through 5.3-4 show that at sufficiently high solute concentrations, the individual solute uptake is much greater than the composite uptake. At an equilibrium solute mass fraction of $0.06 \mathrm{~g} / \mathrm{g}$, the "wet" individual uptake is 30 to $50 \%$ higher than the composite uptake. The difference between the "wet" and "dry" individual uptakes is likely due to the solute losses in the vacuum-drying stage. PG, the most volatile of the multi - OH solutes, has a "dry" individual uptake that is rather close to the composite uptake. This suggests that most of the nonselectively held solute in the pores is coevaporated with the water. The differences between "wt " and "dry" individual uptakes are smallest for glycerol, the least volatile multi $-\mathrm{OH}$ co pound.

Figure 5.3-5 shows the composite and "wet" individua! takes $\left(25^{\circ} \mathrm{C}\right)$ for sucrose on untreated F400 carbon. Unlike the previous three solutes, the composite isotherm is of the Langmuir type (Appendix C). The composite isotherm reaches a plateau in sucrose uptake above an equilibrium mass fraction of $0.02 \mathrm{~g} / \mathrm{g}$ sucrose. Due to the extraordinary affinity and capacity for sucrose, the individual and composite uptakes are much closer 


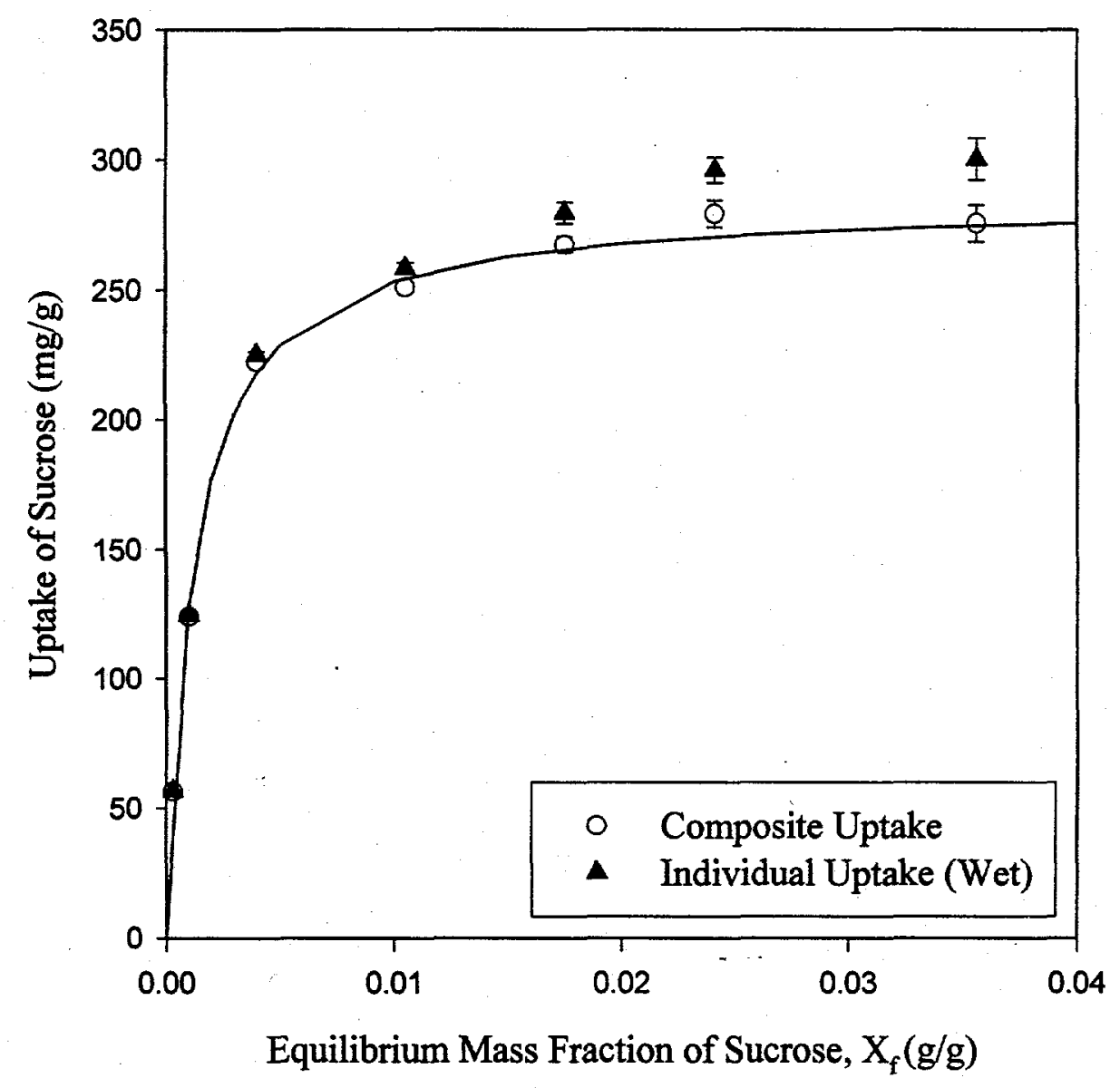

Figure 5.3-5. Composite and individual isotherms $\left(25^{\circ} \mathrm{C}\right)$ for sucrose on $\mathrm{F} 400 / \mathrm{HT}$ carbon. "Wet" individual uptakes were calculated from eq. (2.4.3-6). 
than for other multi $-\mathrm{OH}$ solutes that exhibit Freundlich-type isothems. At a mass

fraction of $0.04 \mathrm{~g} / \mathrm{g}$, the individual and composite uptakes differ by only about $10 \%$. The reader will note that a distinction between "wet" and "dry" is not made in Figure 5.3-5.

The reason is that for sucrose, a nonvolatile solute, the two are likely to be the same. Also, as is discussed in the following section, recovery of sucrose from carbons was exclusively done by "wet" solvent regeneration. This was necessitated by the relative insolubility of sucrose in nearly all solvents except water.

\subsection{Selection of Regenerants}

The solvent chosen for regeneration should be one that: (1) is completely miscible with the solute and water, and (2) has a sufficiently greater affinity for the carbon surface than the solute. Both properties result in the large swings in adsorption equilibria shown in Figure 5.3-1. Also, the regenerant should be volatile for ease in subsequent separation from the solute and/or carbon. Lastly, the solvents should be inexpensive, as losses occur invariably during operation. Table 5.4-1 summarizes the properties of several candidate regenerants that meet most or all of these criteria.

TABLE 5.4-1

Candidate Solvents for Regeneration of Carbons

\begin{tabular}{||c|c|c|c||}
\hline \hline COMPOUND & $\mathrm{MW}$ & $\mathrm{T}_{\text {nbp }}\left({ }^{\circ} \mathrm{C}\right)$ & Cost $(\$ / \mathrm{lb})^{*}$ \\
\hline Acetone & 58 & 56 & 0.39 \\
\hline Ethanol & 46 & 79 & 0.16 \\
\hline Ethyl Acetate & 88 & 77 & 0.59 \\
\hline Methyl Acetate & 74 & 57 & $\mathrm{NL}$ \\
\hline Methanol & 32 & 65 & 0.05 \\
\hline 2-Propanol & 60 & 82 & 0.34 \\
\hline
\end{tabular}

*Value from Deyrup (1998). NL means not listed. 
From Tables 1.5-1 and 5.4-1, it appears that acetone and methanol are logical

regenerants for $\mathrm{EG}$ and $\mathrm{PG}$, while methanol is the likely choice for glycerol recovery.

Results for these fully miscible solutes are shown in Section 5.5.

The choice of regenerant for glucose, sorbitol, and sucrose is complicated by the limited solubility of the solute. In these cases, the regenerant cannot be a pure solvent; but rather an aqueous solution of one of the compounds listed in Table 5.4-1. The regenerant should be concentrated enough to allow for full displacement of the adsorbed solute, yet not so concentrated such that there the solubility limit of the solute is exceeded.

Using sucrose as the standard adsorbate, batch regeneration experiments $\left(25^{\circ} \mathrm{C}\right)$ were conducted on loaded ( $q=250 \mathrm{mg} / \mathrm{g}$ ) F400 carbons. To screen for the best displacer, regenerant solutions of up to 2 wt. $\%$ acetone, 2 wt. $\%$ ethanol, 2 wt. $\%$ ethyl acetate, and 6 wt. \% methyl acetate in water were prepared. All experiments employed a solution to carbon mass ratio of 10:1. After equilibrating the regenerant solution with the sucroseloaded carbon, the percent regenerability (\%RE) may be determined using eqs. (2.4.3-7) through (2.4.3-10). The results are summarized in Figure 5.4-1.

In Figure 5.4-1 the \%RE of sucrose from F400 carbon is plotted as a function of the initial displacer concentration for the regenerants mentioned above. Each data point corresponds to a separate experiment. A single data point using pure water (zero displacer) as the regenerant is shown for reference. Several things can be inferred from 


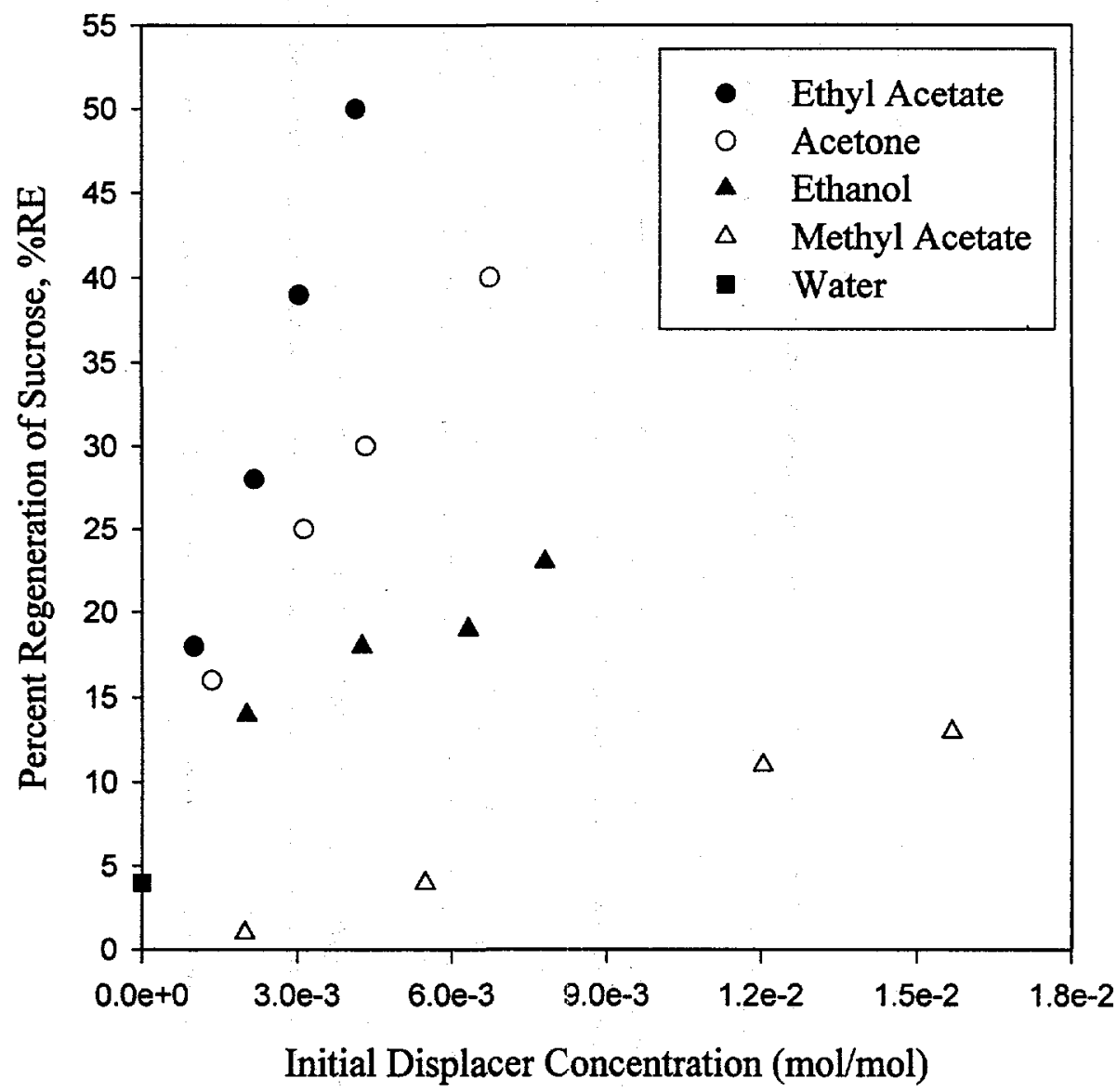

Figure 5.4-1. $\% \mathrm{RE}\left(25^{\circ} \mathrm{C}\right)$ for sucrose-loaded $\mathrm{F} 400$ carbons as a function of initial displacer concentration. Initial sucrose loading for all runs was $\mathrm{q}=250 \mathrm{mg} / \mathrm{g}$. 
Figure 5.4-1. First, it appears that even dilute regenerant solutions $(<2 \mathrm{~mol} \%)$ are capable of displacing a substantial portion of the adsorbed sucrose. Ethyl acetate and acetone are the best displacers, being able to recover between 40 to $50 \%$ of the adsorbed sucrose under the experimental conditions. Methyl acetate, which was shown by Kamlet et al. (1985) to have an affinity for carbon comparable to that of acetone, performed rather poorly as a displacer.

As for the glycols, it appears that acetone would be a suitable displacer for partially miscible multi-OH solutes (glucose, sorbitol, sucrose). Acetone is less expensive and more volatile than ethyl acetate, and has the additional advantage that it is fully miscible with water. Ethyl acetate, however, is soluble at $25^{\circ} \mathrm{C}$ to $9 \mathrm{wt} . \%$ in water (Windholz et al., 1983). Sucrose also happens to be highly soluble $\left(25^{\circ} \mathrm{C}\right)$ even in solutions containing substantial proportions of acetone in water, as shown in Table 5.4-2 below:

TABLE 5.4-2

Sucrose Solubility $\left(25^{\circ} \mathrm{C}\right)$ in Acetone-Water Mixtures

\begin{tabular}{|c|c|}
\hline $\begin{array}{c}\text { Weight Fraction Acetone } \\
\text { in Water }(\mathrm{g} / \mathrm{g})\end{array}$ & $\begin{array}{c}\text { Sucrose Solubility } \\
\text { in Water }(\mathrm{g} / \mathrm{g})^{*}\end{array}$ \\
\hline 0 & 0.675 \\
\hline 0.165 & 0.599 \\
\hline 0.252 & 0.577 \\
\hline 0.344 & 0.494 \\
\hline 0.392 & 0.452 \\
\hline 0.600 & $\sim 0.3$ \\
\hline 0.853 & $\sim 0.1$ \\
\hline
\end{tabular}

*Data from Stephen and Stephen (1964) 
A separate experiment was performed where a series of F400 carbons loaded with sucrose $(q=250 \mathrm{mg} / \mathrm{g})$ was regenerated by solutions of up to $14 \mathrm{wt} . \%$ acetone $(10 \mathrm{~g}$ regenerant/g carbon) in water. The results are summarized in Figure 5.4-2, where plotted simultaneously are: (1) the composite uptake of acetone onto the sucrose-loaded carbon, and (2) the residual (or irreversible) uptake of sucrose, as a function of equilibrium mole fraction of acetone. From the data, it appears that between 8 to 11 moles of acetone need to be adsorbed for the displacement of 1 mole of adsorbed sucrose.

The results so far have not demonstrated whether full recovery of sucrose from carbons is possible. From Table 5.4-2, it appears that even more concentrated regenerants could be employed. Although no further batch-regeneration experiments were performed, several experiments were performed where sucrose and sorbitol were recovered from a fixedbed, using concentrated $(>70 \mathrm{wt} . \%)$ regenerants. These results are shown in Chapter 7 .

\subsection{Completeness of Regeneration: Glycols and Glycerol}

\subsubsection{Wet vs. Dry Regeneration}

Our initial batch-regeneration experiments $\left(25^{\circ} \mathrm{C}\right)$ consisted of equilibrating $10-20 \mathrm{~mL}$ of pure solvent (acetone or methanol) with 1 gram of heat-treated F400 carbons that were loaded with EG, PG, or glycerol to various degrees. To test whether entrained water affected the desorption equibria, both "wet" and "dry" regeneration were performed. All experimental results are plotted as reversible composite uptake, as defined by eq. (2.4.39), versus composite uptake. The ratio between the two uptakes is defined as percent regenerability, \%RE. Figures 5.5-1 and 5.5-2 show results for EG recovery from 


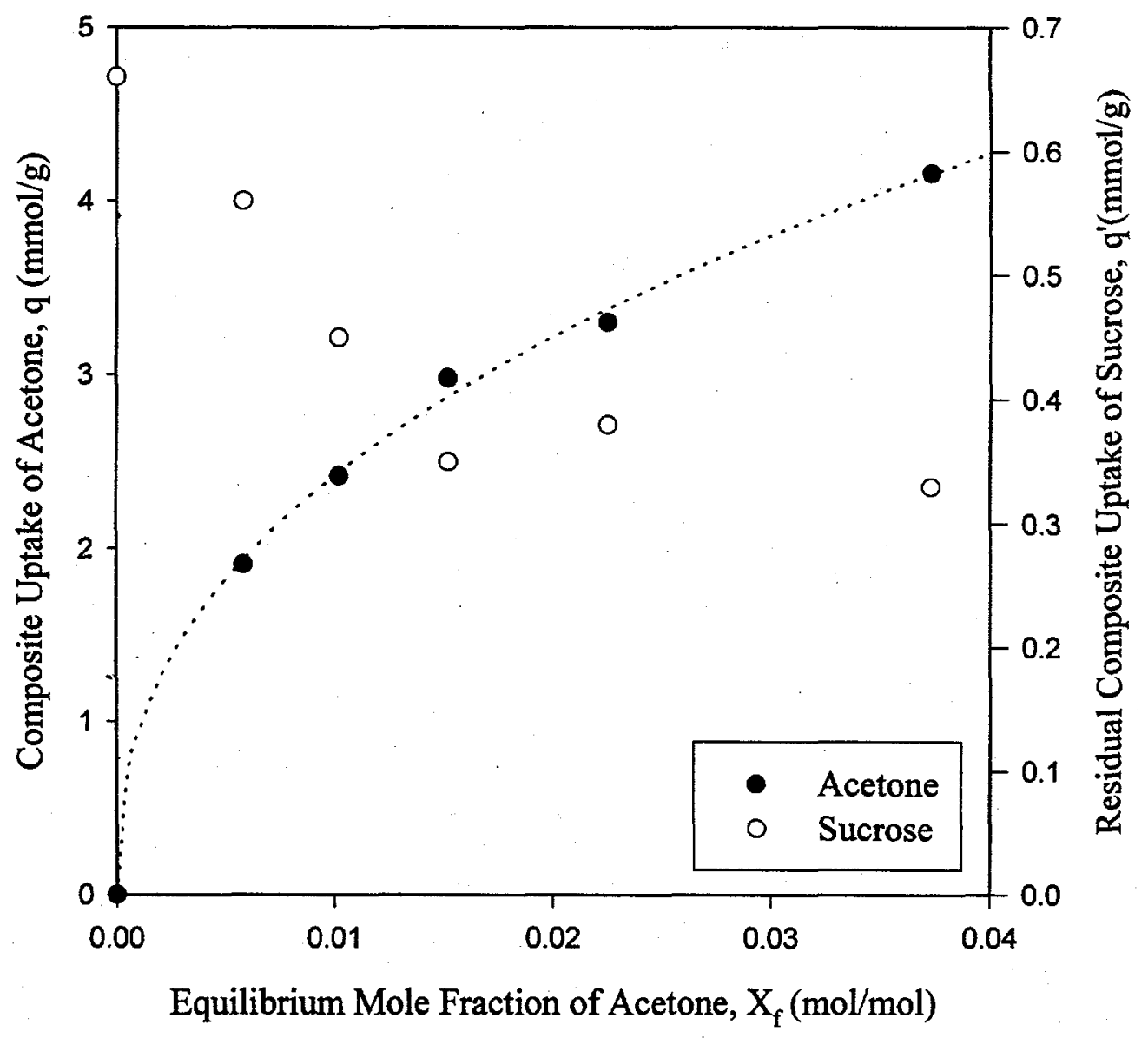

Figure 5.4-2. Acetone uptake $\left(25^{\circ} \mathrm{C}\right)$ onto sucrose-loaded $\mathrm{F} 400$ carbons as a function of equilibrium displacer concentration. Also shown simultaneously is the irreversible uptake of sucrose. 


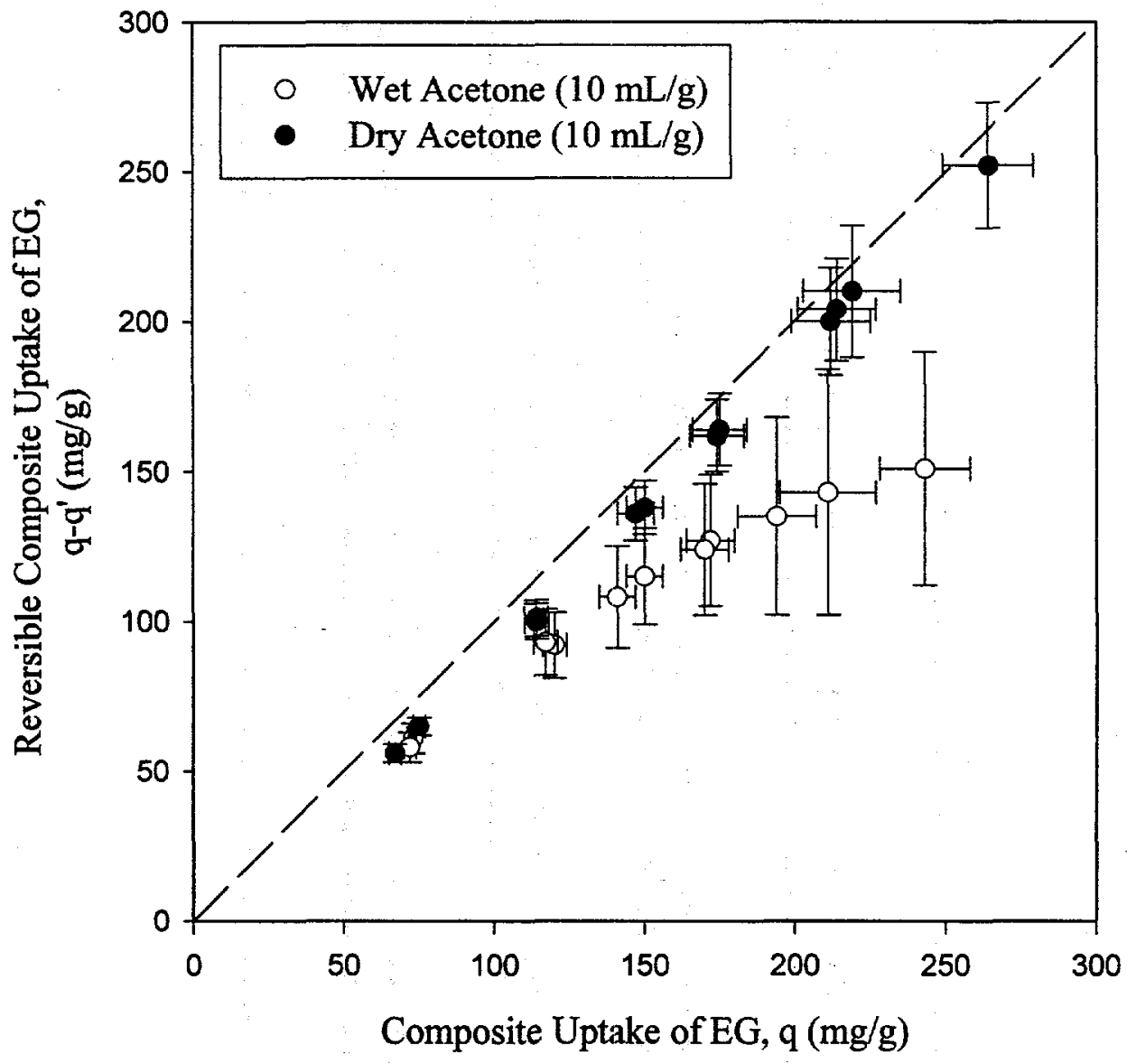

Figure 5.5-1. Reversible vs. composite uptake $\left(25^{\circ} \mathrm{C}\right)$ for acetone regeneration of EGloaded F400/HT carbons. Line $y=x$ denotes $100 \%$ regeneration. 


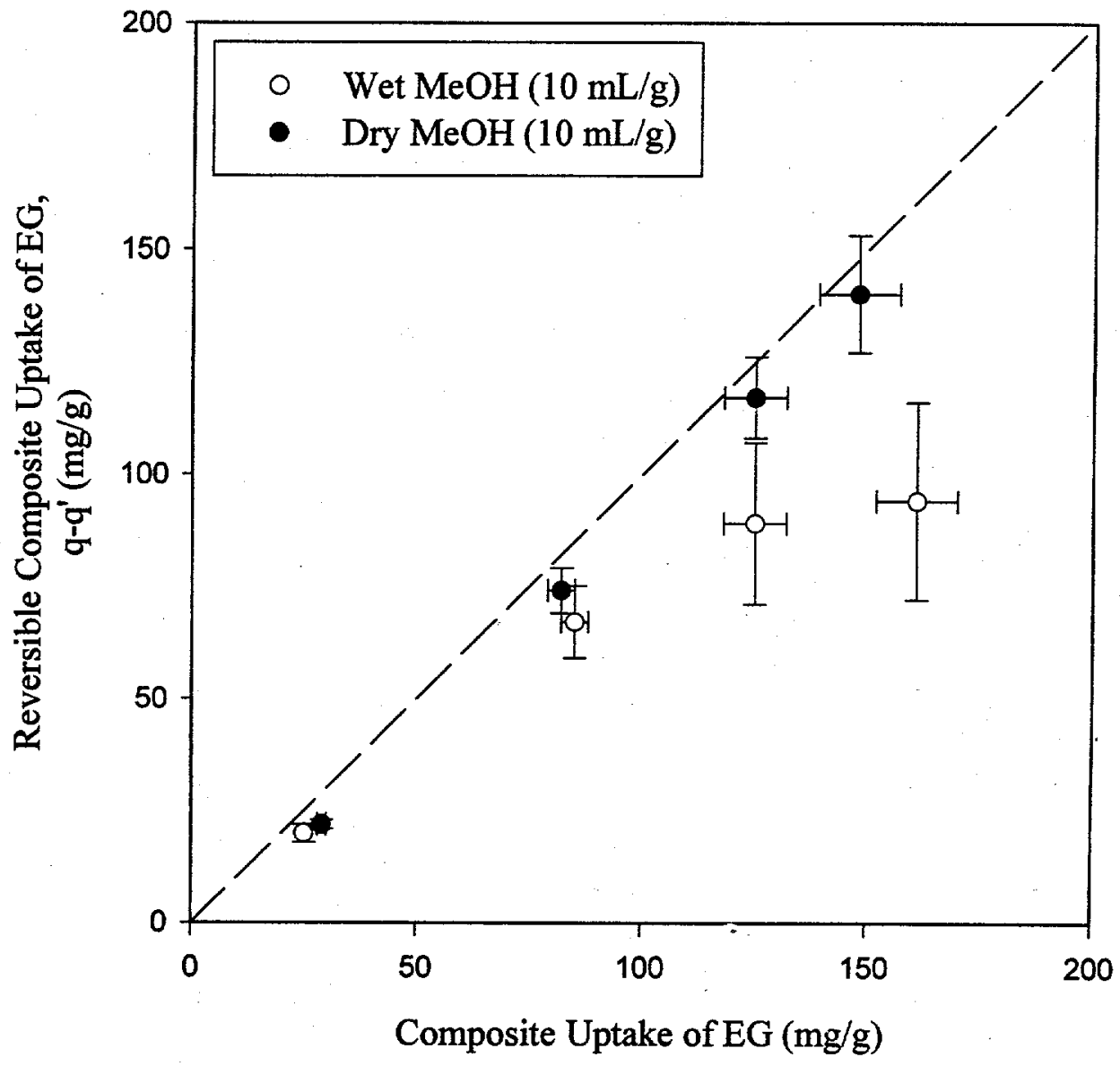

Figure 5.5-2. Reversible vs. composite uptake $\left(25^{\circ} \mathrm{C}\right)$ for methanol regeneration of EGloaded $\mathrm{F} 400 / \mathrm{HT}$ carbons. Line $\mathrm{y}=\mathrm{x}$ denotes $100 \%$ regeneration. 
F400/HT carbon by acetone and methanol, respectively. Figures 5.5-3 and 5.5-4 show similar results for PG using acetone and methanol as well. Lastly, Figure 5.5-5 shows results for glycerol recovery by methanol.

Several trends are evident in all of the figures. It appears that solvent regeneration is nearly complete under "dry" conditions for all loadings. The reversible uptakes under "wet" regeneration conditions appear to match those under "dry" conditions at low loadings ( $\mathrm{q}<125 \mathrm{mg} / \mathrm{g}$ ); however, at higher loadings the deviation becomes significant. The experimental error bars also become substantial at higher loadings for "wet" regeneration, as they are compounded by uncertainties in both q and q' (See Appendix C).

There are several conceivable rationalizations for why "dry" regeneration appears more effective than "wet" regeneration. The entrained water within the carbon may have an inhibitory effect on the desorption equilibria, resulting in an isotherm that is intermediate between the solute-water and solute-regenerant isotherms such as in Figure 5.3-1. An irreversible, water-catalyzed reaction between the solute and the carbon surface is also a potential cause in concept; however, the low isosteric heats of adsorption (Chapter 4) of glycols/glycerol on carbons does not support this idea. The differences between "wet" and "dry" regeneration may not even be related to the presence of water, but rather the difference in how the individual uptakes are determined for each case. For "wet" regeneration, calculations of individual uptakes using eq. (2.4.3-6) may not be valid at 


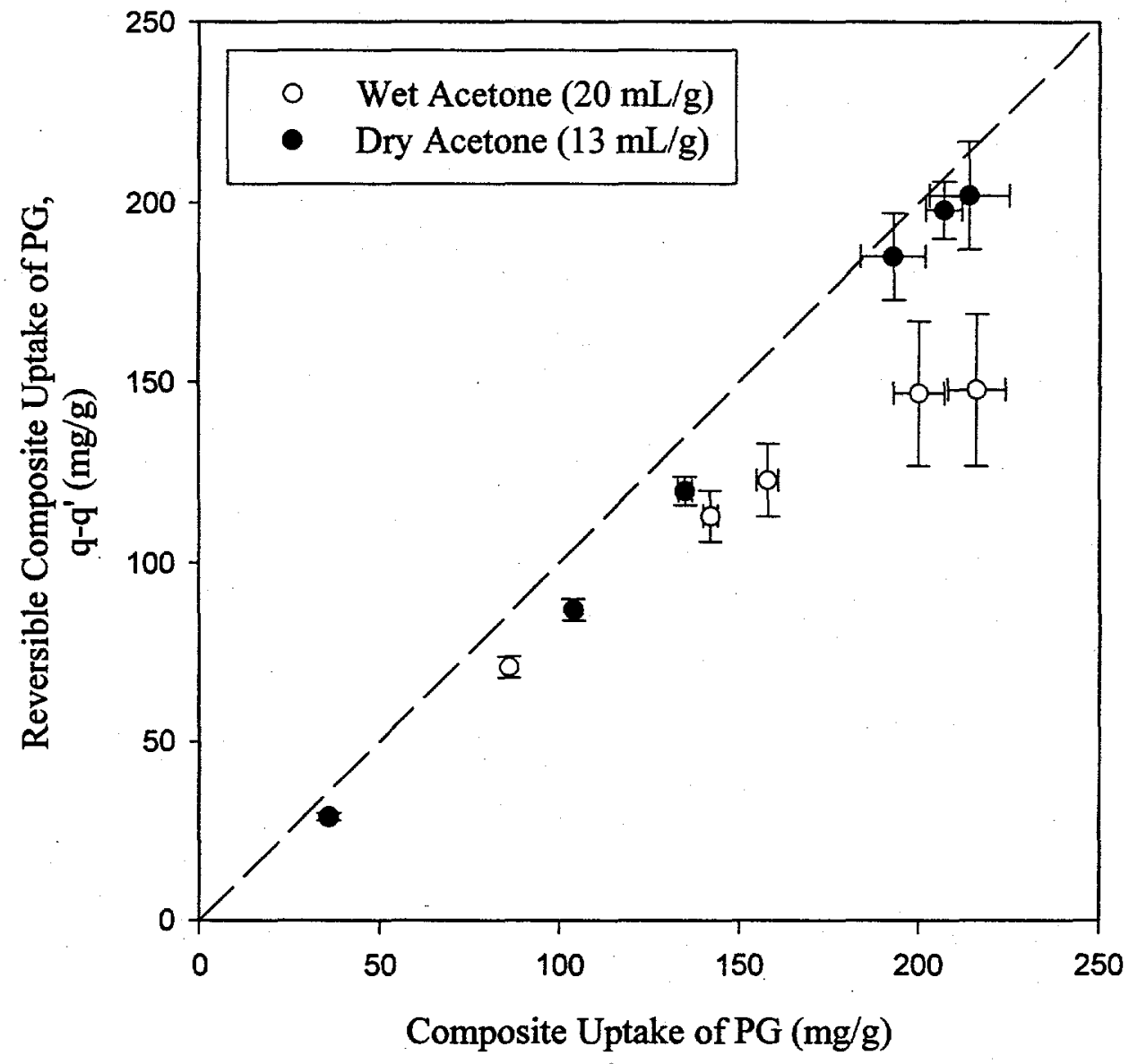

Figure 5.5-3. Reversible vs. composite uptake $\left(25^{\circ} \mathrm{C}\right)$ for acetone regeneration of PGloaded $\mathrm{F} 400 / \mathrm{HT}$ carbons. Line $\mathrm{y}=\mathrm{x}$ denotes $100 \%$ regeneration. 


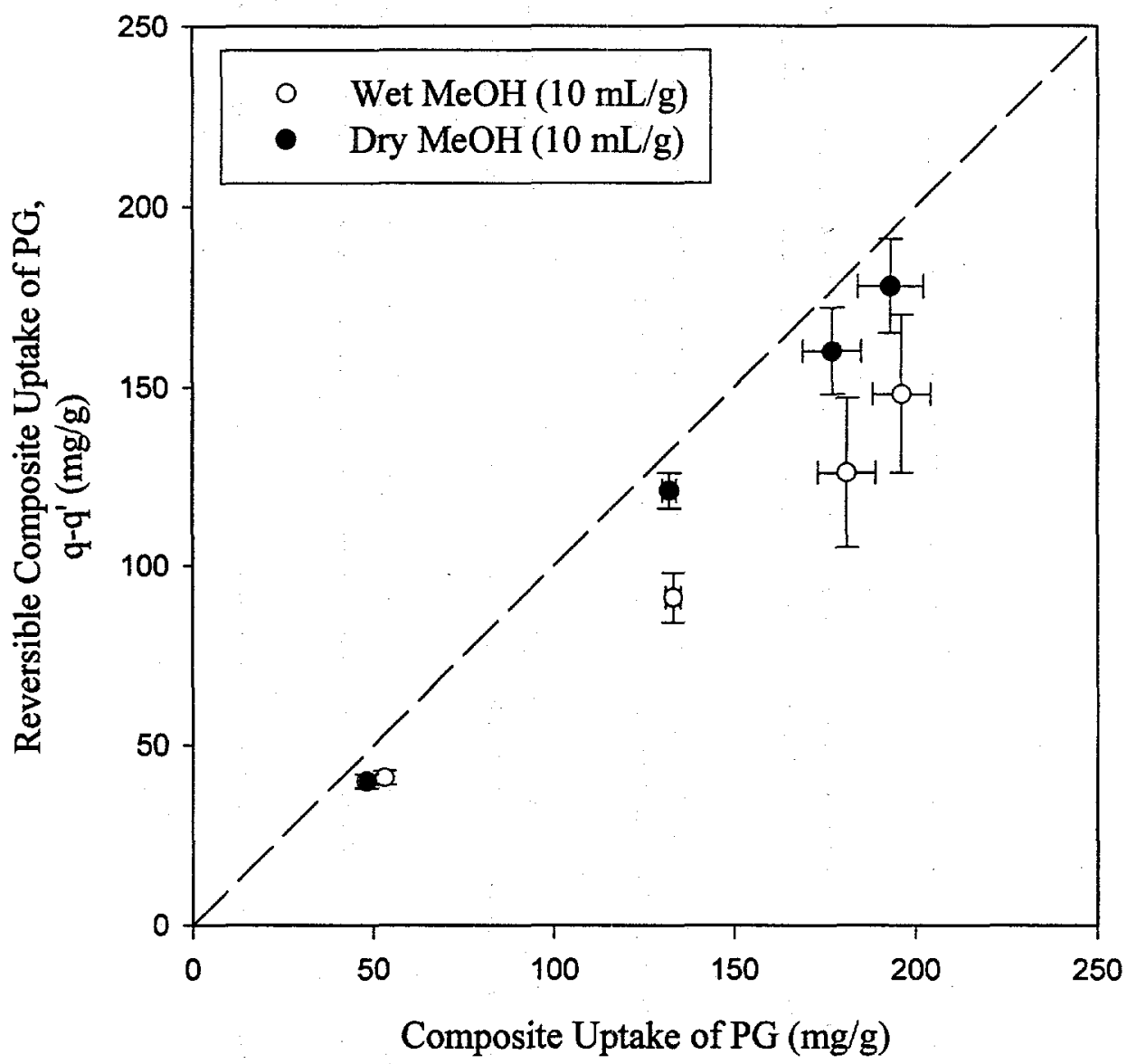

Figure 5.5-4. Reversible vs. composite uptake $\left(25^{\circ} \mathrm{C}\right)$ for methanol regeneration of PGloaded F400/HT carbons. Line $y=x$ denotes $100 \%$ regeneration. 


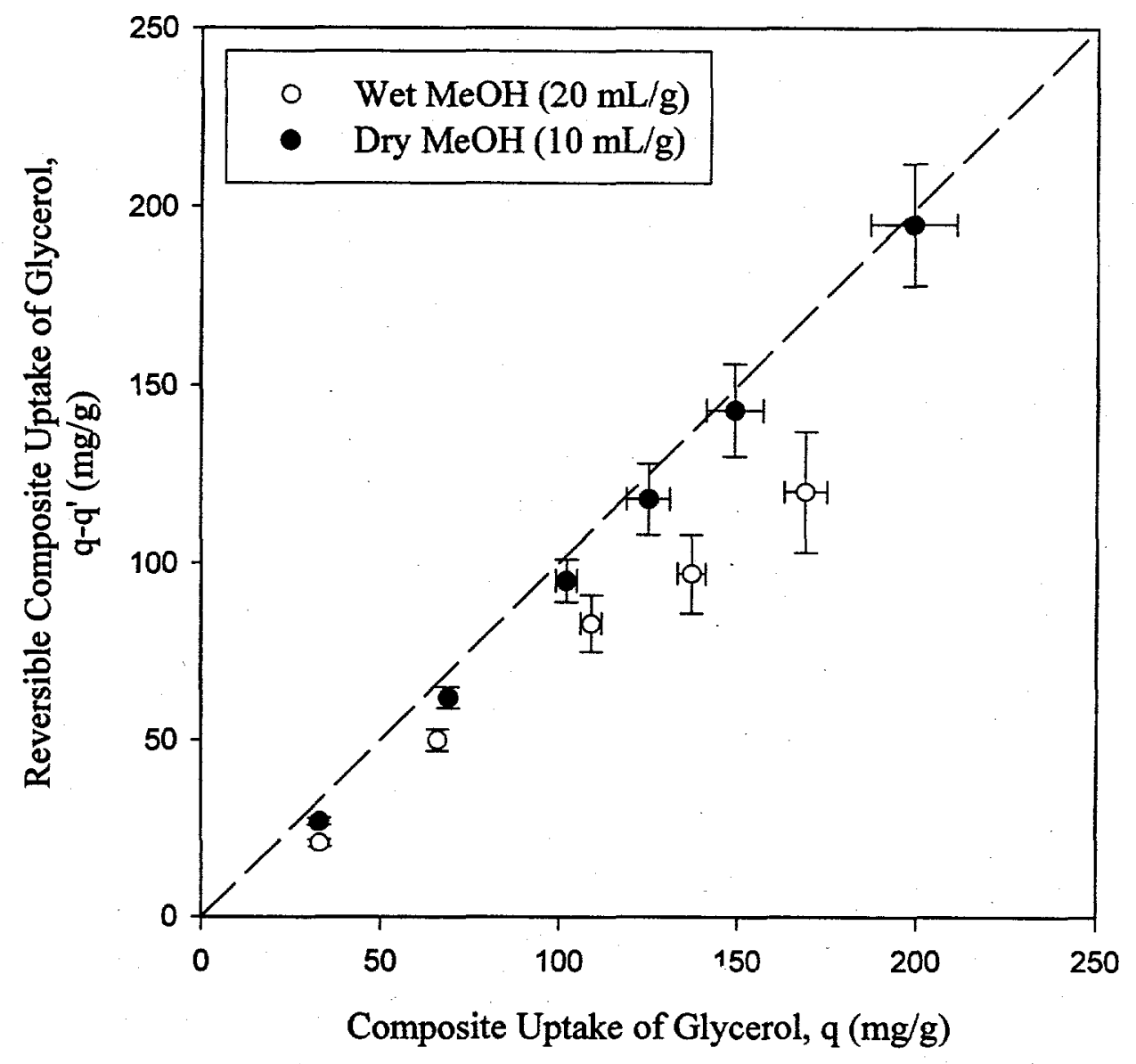

Figure 5.5-5. Reversible vs. composite uptake $\left(25^{\circ} \mathrm{C}\right)$ for methanol regeneration of glycerol-loaded $\mathrm{F} 400 / \mathrm{HT}$ carbons. Line $\mathrm{y}=\mathrm{x}$ denotes $100 \%$ regeneration. 
high solute concentrations. There exists the possibility that some or all of the fluid held in the pores has solute concentrations lower than that of the bulk solution at equilibrium. Finally, the large error bars suggest that experimental uncertainty itself may be the cause. A separate, independent method of assessing the composition of the adsorbed phase (for "wet" regeneration) was therefore sought. That method was thermogravimetric analysis (TGA), described in Chapter 6.

\subsubsection{Adsorption Equilibria from Water-Organic Mixtures}

In an effort to obtain a better understanding of the effect of water on the soluteregenerant-carbon equilibrium, batch adsorption experiments were performed where EG was adsorbed onto $\mathrm{F} 400 / \mathrm{HT}\left(25^{\circ} \mathrm{C}\right)$ from acetone-water mixtures. All experiments were conducted using a solution to carbon mass ratio of $4: 1$. Equilibrium concentrations of EG ranged from 0.01 to $0.14 \mathrm{~g} / \mathrm{g}$, while the solvents used ranged from $10 \mathrm{wt}$. $\%$ acetone in water to pure acetone. All results are plotted in Figure 5.5-6.

In view of the results shown in Figure 5.3-1, the trends seen in Figure 5.5-6 are somewhat unexpected. The addition of water in acetone does not result in composite EG-isotherms between the binary EG-water and EG-acetone isotherms. Rather EG uptakes onto the carbon surface were lowest from 52 and 75 wt. \% acetone, highest in pure acetone, and intermediate at 10 and 90 wt. \% acetone. At low concentrations, the uptakes of EG were sometimes negative, which suggests preferential uptake of either acetone or water. However, the data must be regarded with caution as the uptakes themselves are much lower than for EG adsorption from water. 


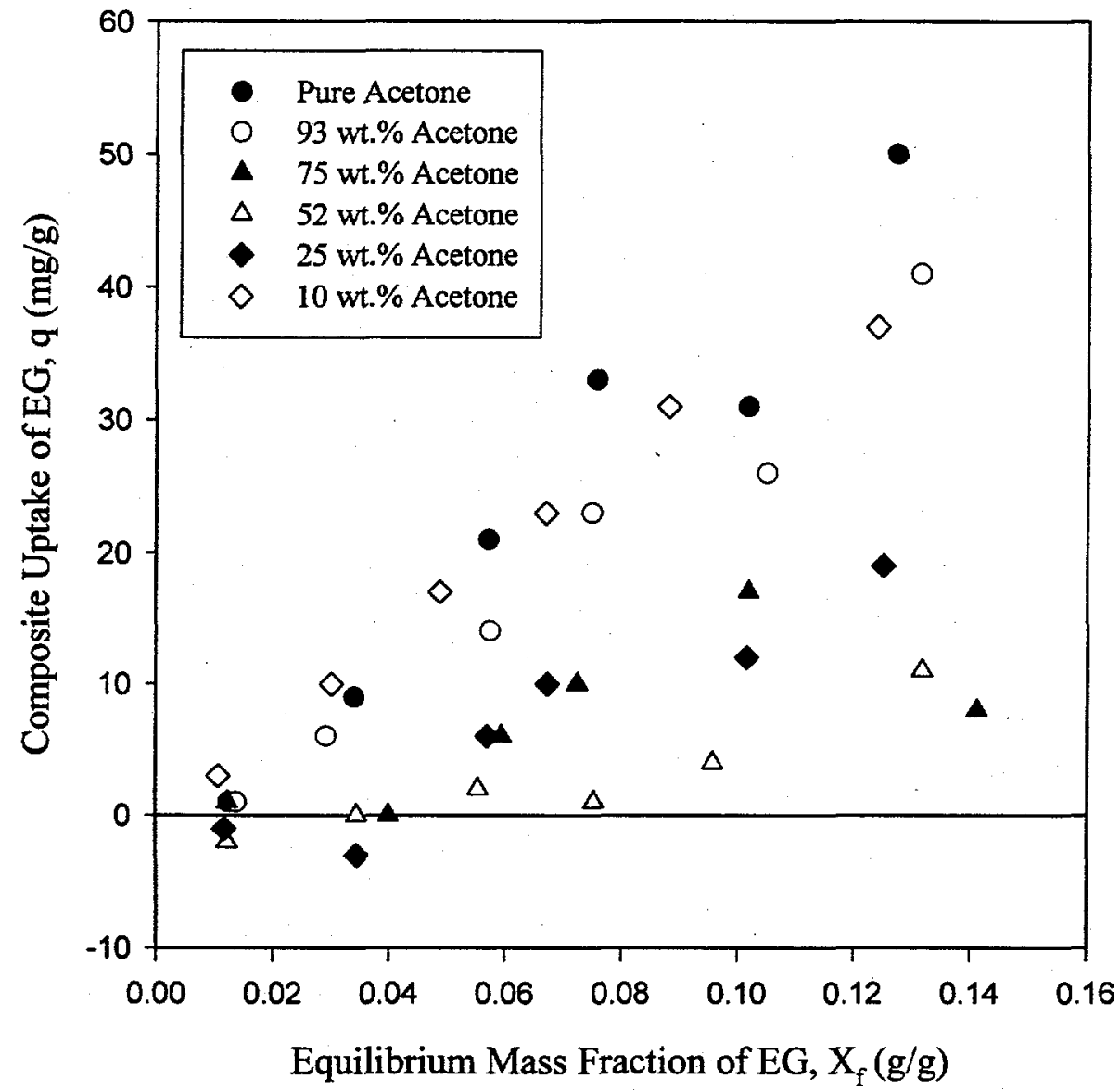

Figure 5.5-6. Composite isotherms $\left(25^{\circ} \mathrm{C}\right)$ for $\mathrm{EG}$ on $\mathrm{F} 400 / \mathrm{HT}$ carbons, with varying acetone content in the solvent phase. 


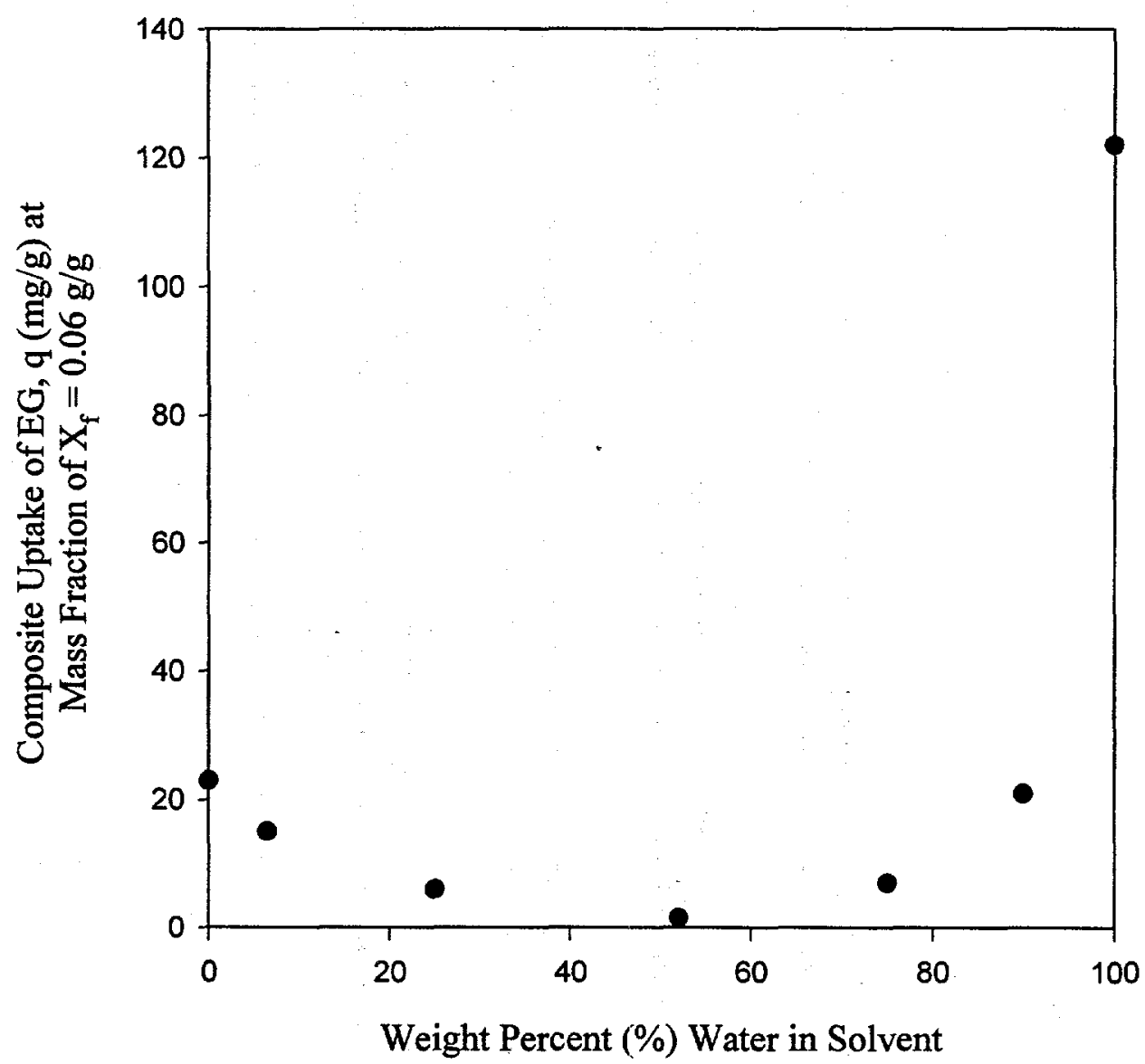

Figure 5.5-7. Composite uptake $\left(25^{\circ} \mathrm{C}\right)$ for $\mathrm{EG}$ on $\mathrm{F} 400 / \mathrm{HT}$ carbons at $\mathrm{X}_{\mathrm{f}}=0.06 \mathrm{~g} / \mathrm{g}$, plotted as a function of water content in the solvent phase. 
Another way of looking at the data is shown in Figure 5.5-7. Here, a single point (q at $\mathrm{X}_{\mathrm{f}}=0.06 \mathrm{~g} \mathrm{EG} / \mathrm{g}$ solution) was taken from each isotherm and plotted against the weight percent of water in the solvent. The result is a "U-shaped" curve with the endpoints corresponding to EG adsorption from the binary (water or acetone) systems. As expected, uptakes are largest from water due to the simultaneous effects of: (1) hydrophobic exclusion of water from the carbon surface and (2) attractive dispersion interactions between the solute and surface. In pure acetone, competitive adsorption of acetone occurs and therefore causes the EG capacity to be much lower. This is despite EG having a much more positive activity coefficient in acetone than in water. The most interesting trend occurs at intermediate water content, where the EG uptake reaches a minimum near $50 \mathrm{wt}$ \% water. One possible explanation for this behavior is that the activity coefficient of EG might be lower in the ternary system (water-acetone-EG) than in either binary system. As an example of the "water-enhanced solvation" mechanism, the liquid-phase activity coefficient of $P G$ in methylcyclohexanone is reduced by a factor of 1.6 when the water content in the solvent is raised from 0 to 3 wt. \% (Lee et al., 1994).

The results seen in Figures 5.5-6 and 5.5-7 are contrary to the idea that water greatly hinders the desorption equilibria of EG-acetone-carbon. In fact, the lower uptakes of EG observed from mixed-solvents seems to suggest that acetone-water mixtures are superior (from an equilibrium standpoint) to pure acetone as a regenerant. To test out these ideas, EG-loaded F400/HT carbons were "wet" and "dry" regenerated by mixtures of acetonewater at various phase ratios. 


\subsubsection{Effect of Displacer Concentration and Phase Ratio on Regeneration}

The results for "wet regeneration" presented in Section 5.5-1 imply that solute recovery using pure acetone at phase ratios of $10-20 \mathrm{~mL} / \mathrm{g}$ carbon is incomplete. An experiment was conducted to see whether changing the phase ratio affected regenerability. Also, in view of the results shown in the previous section, different proportions of acetone and water were used to formulate the regenerants.

A series of heat-treated F400 carbons were loaded from a 16 wt. $\%$ EG solution ( $q=176$ $\pm 12 \mathrm{mg} / \mathrm{g}$ ). The carbons were to be "wet" or "dry" regenerated, using various phase ratios of $25 \mathrm{wt} . \%, 57 \mathrm{wt}$ \%, or $85 \mathrm{wt}$ \% acetone in water. Figure $5.5-8$ plots the $\%$ RE of EG against phase ratio for "wet" regeneration, while Figure 5.5-9 shows similar results for. "dry" regeneration.

Figure 5.5-8 shows, within the experimental error bars, that neither acetone concentration nor phase ratio appears to affect \%RE significantly. In fact, a mean value of $\% \mathrm{RE}=80$ could be calculated by averaging all the data. Some scatter is observed in Figure 5.5-9, although a majority of the points have $\% \mathrm{RE}>95$. Here too, there is no discernable effect of acetone concentration or phase ratio on regenerability. The results from both figures suggest that the incompleteness of regeneration is not likely due to thermodynamic, or equilibrium-type factors. 


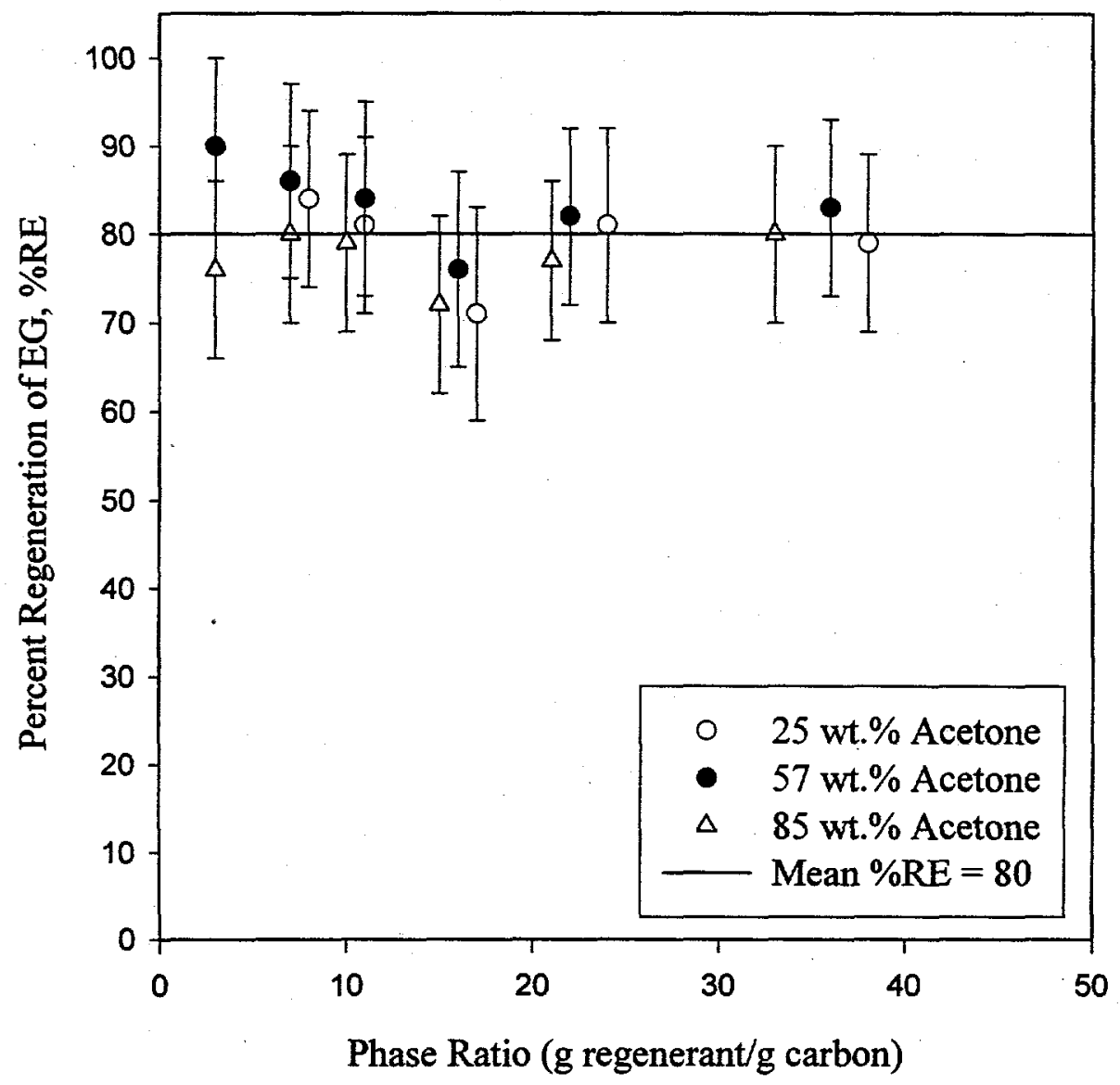

Figure 5.5-8. $\% \mathrm{RE}\left(25^{\circ} \mathrm{C}\right)$ for $\mathrm{EG}$ on $\mathrm{F} 400 / \mathrm{HT}$ carbon, "wet" regenerated by acetonewater solutions, plotted as a function of phase ratio. 


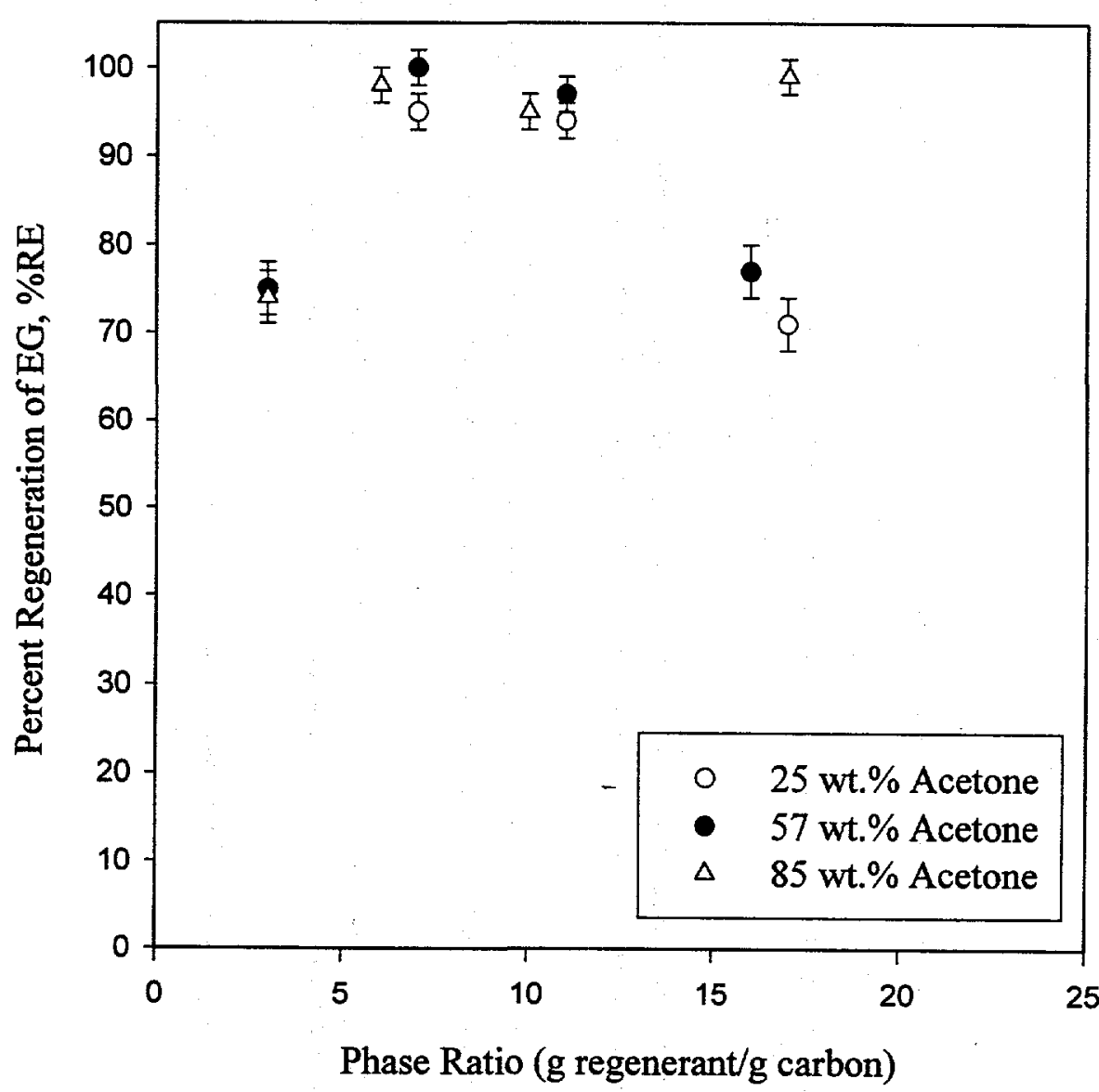

Figure 5.5-9. \%RE $\left(25^{\circ} \mathrm{C}\right)$ for EG on F400/HT carbon, "dry" regenerated by acetonewater solutions, plotted as a function of phase ratio. 


\subsection{Solvent Regeneration - Summary}

In this chapter, solvent regeneration was explored as a viable method of recovering adsorbed multi $-\mathrm{OH}$ compounds from carbons. Acetone and methanol were identified as technically (and economically) feasible regenerants. The results show that regeneration appears to be incomplete $(\% \mathrm{RE}=60-80)$ in the presence of entrained water within the carbon, but nearly complete $(\% \mathrm{RE}>90)$ in the absence in water. Adsorption experiments suggest that $50 \mathrm{wt} . \%$ acetone in water may be the best regenerant; however, returning the solute to an aqueous solution is not in accord with our process goals. Experiments were conducted and show that the apparent incompleteness of "wet" regeneration was probably not attributable to thermodynamic effects. An independent procedure of measuring individual uptakes will be useful to differentiate better between "wet" and "dry" regeneration. 


\section{References for Chapter 5}

Chang, C.H.; Savage, D.W. Environmental Science and Technology, 1981, 15(2), 201-206.

Cooney, D.O.; Nagerl, A.; Hines, A.L. Water Res., 1983, 17(4), 403-410.

Deyrup, C. Chemical Prices. Chemical Marketing Reporter, 1998, 254(13).

Himmelstein, K.J.; Fox, R.D.; Winter, T.H. Chemical Engineering Progress, 1973, 69(11), 65-69.

Kamlet, M.J.; Doherty, R.M.; Abraham, M.H.; Taft, R.W. Carbon, 1985, 23(5), 549-554.

Lee, J.H.; Van Brunt, V.; King, C.J. Ind. Eng. Chem. Res., 1994, 33, 1373-1379.

Martin, R.J.; Ng., W.J. Water Res., 1987, 21(8), 961-965.

McLaughlin, H.S. Chemical Engineering Progress, July 1995, 45-53.

McMurry, J. Fundamentals of Organic Chemistry, $2^{\text {nd }}$ edition; Brooks/Colt: Belmont, California, 1990.

Stephen, H.H.; Stephen, T., Eds., Solubilities of Inorganic and Organic Compounds, Pergamon Press: New York, 1964, Vol. 2(part II).

Windholz, M.; Budavari, S.; Blumetti, R.F.; Otterbein, E.S., Eds., Merck Index, $10^{\text {th }}$ edition; Merck and Co., Inc.: New Jersey, 1983. 


\section{Chapter 6. Thermogravimetric Analysis (TGA) of Active Carbons}

\subsection{Overview}

In this chapter, Thermogravimetric Analysis (TGA) is introduced as a powerful analytical method for direct characterization of the adsorbed phase. TGA enables a more precise method of quantifying the completeness of carbon regeneration by solvent leaching, a calculation that was performed in the previous chapter. Previously, the results seemed to indicate an inhibitory effect of residual water upon solvent regeneration. Through experiments with different solutes, carbons, and heating rates, TGA provides further understanding of the kinetics and energetics of desorption.

\subsubsection{Sample TGA Data}

Figure 6.1-1 is an example of a TGA weight-change "thermogram" for heat-treated F400 carbon loaded with aqueous ethylene glycol $(q=161 \mathrm{mg} / \mathrm{g})$. The sample was taken directly from a batch adsorption experiment, after the centrifugation step (Chapter 2). Heating in nitrogen was done at $10^{\circ} \mathrm{C} / \mathrm{min}$ from room temperature to about $650^{\circ} \mathrm{C}$. Desorptions of water and glycol are distinguishable from the two inflection points on the gaph, one at about $110^{\circ} \mathrm{C}$ and the other near $200^{\circ} \mathrm{C}$. When all of the material fully desorbs from the surface, the sample weight(\%) levels off to an essentially constant value. The weight-change thermogram for a bare carbon is also shown for reference, with the minute weight decrease attributable to the evaporation of water adsorbed from the atmosphere during handling. A clearer and more useful method of presenting TGA results is through a derivative plot, such as the one in Figure 6.1-2. Throughout this 


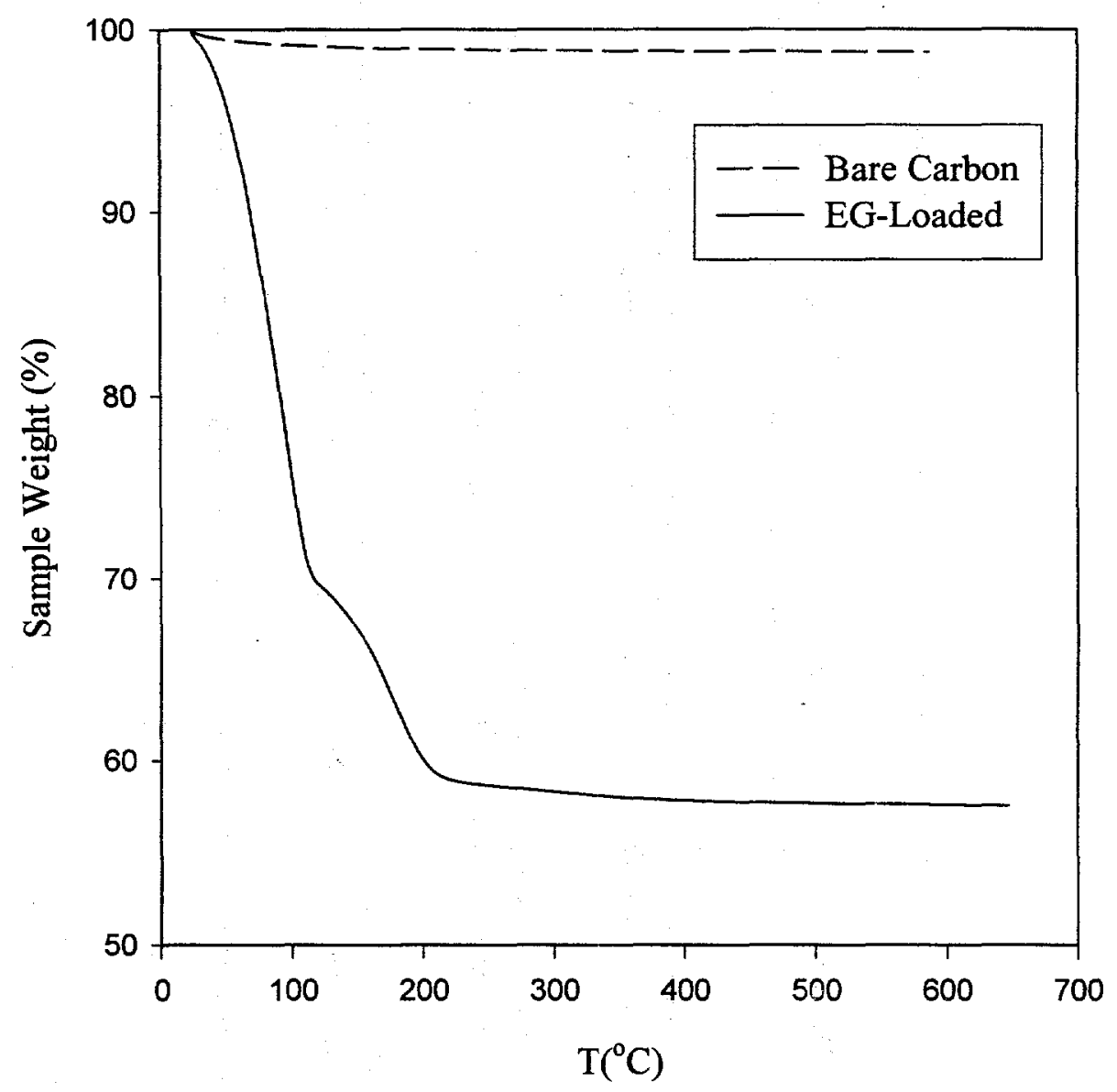

Figure 6.1-1. TGA weight-change thermogram for F400/HT carbon, loaded with EG $\left(\mathrm{q}=161 \mathrm{mg} / \mathrm{g}\right.$ ). Heating rate: $10^{\circ} \mathrm{C} / \mathrm{min}$. 


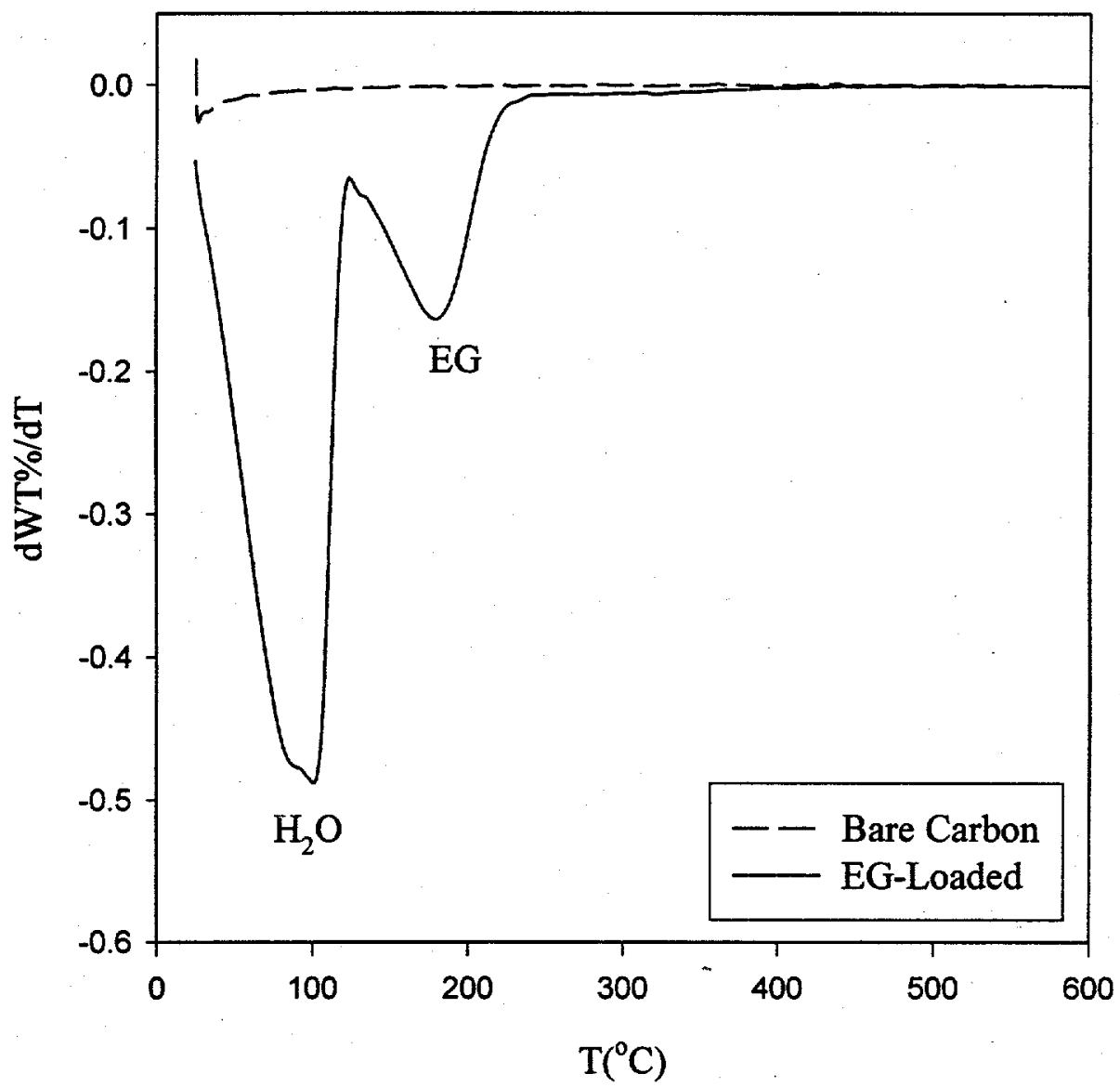

Figure 6.1-2. TGA derivative plot for F400/HT carbon, loaded with EG ( $\mathrm{q}=161 \mathrm{mg} / \mathrm{g})$, with bare carbon reference. Heating rate: $10^{\circ} \mathrm{C} / \mathrm{min}$. 
chapter, all of the TGA data will be shown exclusively through derivative plots, which reveal detailed structure not as evident in the weight-change thermograms.

Figure 6.1-2 results from numerical differentiation of the data in Figure 6.1-1. The desorbed water and glycol are thereby represented as separate peaks, similar to those on a chromatogram. The peaks appear centered near the normal boiling points of water and $\mathrm{EG}$ at $100^{\circ} \mathrm{C}$ and $198^{\circ} \mathrm{C}$, respectively. This is not always the case; as will be seen, the location of the peak maximum, relative to the boiling point, may change depending on the type of solute and heating rate. Also, the shift of the peak maximum with heating rate forms the basis for obtaining first-order kinetic parameters associated with thermal desorption. TGA thus provides precise information regarding the composition and thermal stability of the adsorbed phase.

\subsubsection{Background on Thermal Desorption of Carbons}

Some of the earliest TGA experiments conducted on loaded activated carbons were carried out by Suzuki et al. (1978). The authors tested n-alkanes $\left(C_{5}-C_{12}\right)$, alkanols $\left(C_{4^{-}}\right.$ $\mathrm{C}_{8}$ ), and aromatics (phenols). The aromatic solutes were loaded from aqueous solution onto the carbon, while the alkanes and alkanols were loaded onto the carbon by immersion into the pure liquid. The weight-change thermograms were classified by shape according to the nature of the organic solute. "Type I" curves have a shape that is concave toward the right of the theninogram, and were characteristic of most volatile solutes with normal boiling points below $220^{\circ} \mathrm{C}$. "Type II" curves are rarer and are convex to the right of the thermogram. They are observed for high-molecular-weight 
species such as surfactants and polyethylene glycol. "Type III" thermograms show a gradual change of sample weight versus temperature, with substantial material remaining on the surface as residue at $800^{\circ} \mathrm{C}$. These types of TGA plots are common for most aromatic and/or nonvolatile (phenols, humic acid) compounds. Derivative plots were not developed from the data, but the authors did propose simple models to estimate isosteric heats of adsorption.

More recent work on thermal desorption from carbons (Ferro-Garcia et al., 1993; FerroGarcia et al., 1995; Rivera-Utrilla et al., 1995; Moreno-Castilla et al., 1995) combined TGA with mass spectrometry, so as to distinguish physical and chemical adsorption of phenolic adsorbates. The solutes tested included aqueous aminophenol, chlorophenol, cresol, gallic acid, nitrophenol, and phenol. TGA derivative plots for phenols typically exhibited two or more peaks for the desorbing solute: the initial, low-temperature peak corresponds to vaporization of the solute, while the high-temperature peak(s) represent degradation products from the pyrolysis of chemisorbed solute. Mass spectrometry was capable of detecting $\mathrm{H}_{2} \mathrm{O}, \mathrm{CO}, \mathrm{CO}_{2}$, and $\mathrm{H}_{2}$ among the degradation products for these high-temperature peaks, but nothing in the low-temperature peak. All of these researchers also varied the heating rates to obtain first-order kinetic parameters associated with thermal desorption.

The literature also describes thermal-desorption methods other than TGA that have been used to characterize the adsorbed phase. Senf and Frank (1990) desorbed benzene, $n$ alkanes $\left(\mathrm{C}_{5}-\mathrm{C}_{11}\right)$, and n-alkanols $\left(\mathrm{C}_{2}-\mathrm{C}_{4}\right)$ from active carbons, using a carbon-packed 
heating tube equipped with a flame-ionization detector. Analysis of the vapor effluent yielded peaks for the desorbing species, not unlike those of Figure 6.1-2. The authors found a linear correlation between the normal boiling point of the solute and the peak desorption temperature. They suggested similar mechanisms of interaction in the liquid and adsorbed states, caused by non-specific dispersion forces between the surface and hydrocarbon chain. Bandu et al. (1993) characterized desorption of water, alcohols, and aromatics from carbons using differential scanning calorimetry (DSC). DSC is related to TGA except that the heat flux needed into or out of the sample, rather than sample weight, is measured continuously during a constant rate of temperature increase. The authors were able to measure enthalpies of desorption directly, and to correlate them with properties of the adsorbate: molecular weight, dipolar moment, and molar refraction.

\subsubsection{TGA for Studying Desorption of Multi - OH Compounds}

TGA was originally chosen as a more reliable technique of closing the mass balances presented in Chapter 5, which yielded inconsistencies in assessing the degree of regenerabilty by solvent leaching. Applying TGA to the study of aqueous multi -OH adsorbates on carbons also yielded broader understanding of the adsorption mechanisms. As seen from the brief literature survey above, nearly all previous TGA or related work on carbons dealt with alkanes, alcohols, and aromatic compounds. These results from previous researchers, combined with the present work, provide new insights on how the additional $-\mathrm{OH}$ group(s) on the solutes affect their uptake onto carbons. 


\subsection{Regenerability of Carbons}

\subsubsection{TGA Results for Pure Solvents on Carbons}

Figure 6.2-1 shows TGA derivative plots for three different solvents (acetone, methanol, and water) loaded onto heat-treated F400. The acetone sample was prepared by immersion into the pure liquid, the methanol sample was taken from a batch regeneration experiment using methanol as solvent, and the water sample was taken from a batch adsorption experiment. All three samples were centrifuged to remove interstitial fluid, prior to TGA. For clarity, the solute peaks from the methanol and water samples were excluded from Figure $6.2-1$. For a heating rate of $10^{\circ} \mathrm{C} / \mathrm{min}$, the data show that both water and methanol have maximum desorption rates close to their normal boiling points $\left(65^{\circ} \mathrm{C}\right.$ and $100^{\circ} \mathrm{C}$, respectively). Hence, both of these compounds exhibit similar behavior in the adsorbed and bulk-liquid state. Acetone shows a desorption maximum close to its boiling point $\left(57^{\circ} \mathrm{C}\right)$ as well, but surprisingly remains on the carbon up to $200^{\circ} \mathrm{C}$. It appears that a substantial fraction of acetone is very strongly adsorbed onto the surface. Although acetone is a strong displacer, its low volatility when on the surface may pose problems in practice. It would take substantially more energy to remove the excess acetone between adsorption and regeneration cycles if the carbons are to be reused. Also, as it may be difficult to remove all of the acetone completely, substantial loss of carbon capacity could be expected. A solvent such as methanol, whose volatility when adsorbed is not much different than that of water, is probably a better choice of regenerant. Since the acetone desorption profile extends into the temperature range of glycol desorption, all carbons regenerated by acetone were first centrifuged and then 


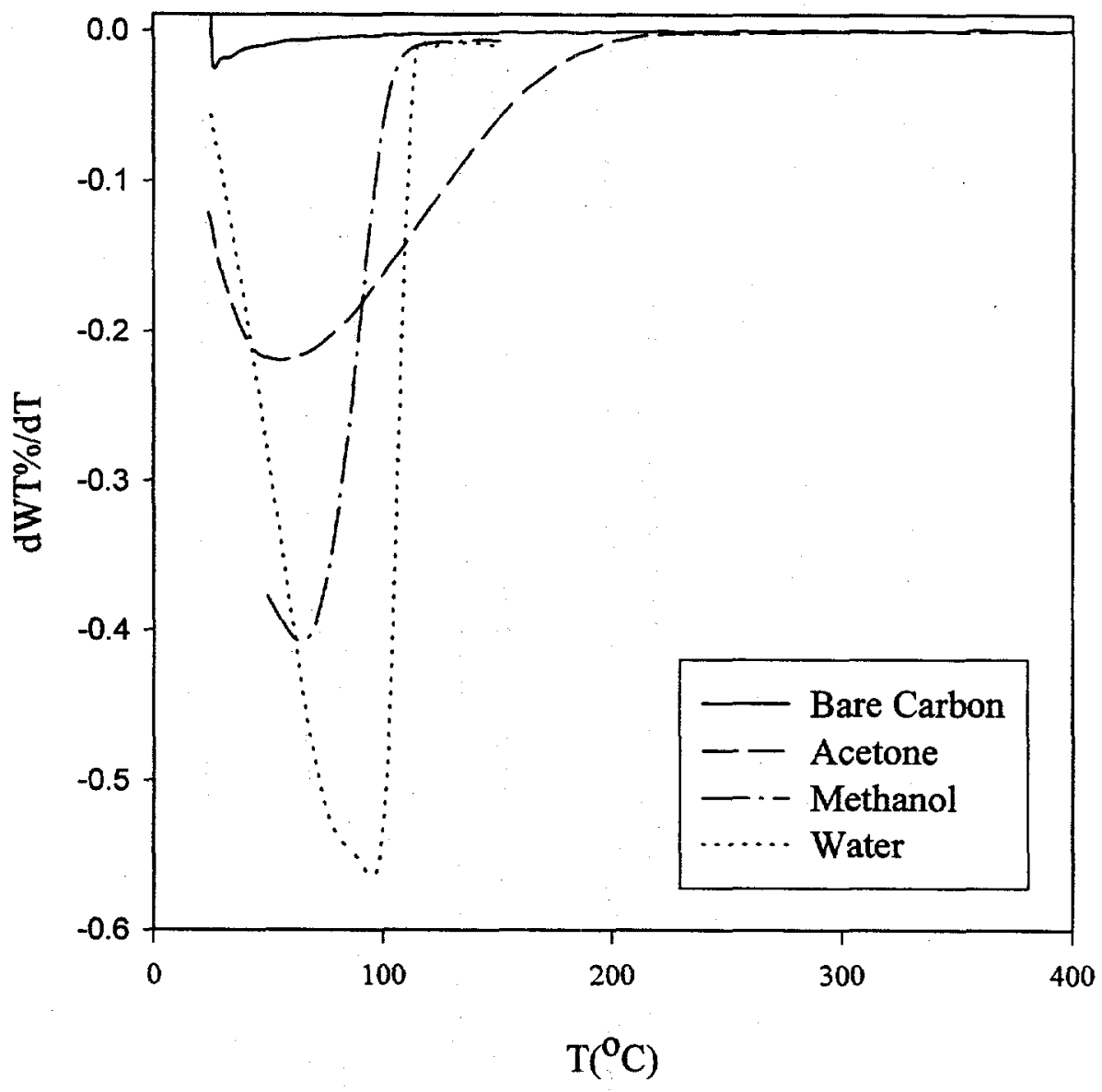

Figure 6.2-1. TGA derivative plots for F400/HT carbon loaded with acetone, methanol, and water, with bare carbon reference. Heating rate: $10^{\circ} \mathrm{C} / \mathrm{min}$. 
vacuum-dried at $0.3 \mathrm{~atm}$. and $65^{\circ} \mathrm{C}$ for several hours prior to TGA work, so as to remove acetone before the TGA measurement.

\subsubsection{Sample Data for Batch Regeneration}

To demonstrate how TGA could be used to assess regenerability, Figure 6.2-2 shows superimposed derivative plots corresponding to loaded and regenerated carbons. Heattreated F400 was loaded with ethylene glycol $(\mathrm{q}=23 \mathrm{mg} / \mathrm{g})$, centrifuged, and then vacuum dried to remove water. Part of the carbon was analyzed by TGA, while the rest was batchwise regenerated by methanol $(10 \mathrm{~mL} / \mathrm{g}$ carbon). Calculations using the methods of Section 2.4 .3 yielded a regenerability of $89 \%$, based on the composite uptake. Prior to TGA, the regenerated carbons were first vacuum dried to remove methanol. The TGA heating rate for both samples was $10^{\circ} \mathrm{C} / \mathrm{min}$.

The desorption profiles in Figure 6.2-2 exhibit interesting characteristics. There appears to be a substantial fraction of EG that was not amenable to methanol regeneration. The EG from the regenerated sample has a peak desorption temperature $\left(T_{\max }\right)$ of $200^{\circ} \mathrm{C}$, while that of the loaded sample was at $180^{\circ} \mathrm{C}$. Furthermore, the portions of the curves for $\mathrm{bc}$ th the loaded and regenerated samples nearly coincide above $200^{\circ} \mathrm{C}$. This strongly suggests that the fraction of EG remaining on the carbon surface after regeneration resides on high-energy sites. By using the derivative plots in conjunction with the weight-change thermogram, one may calculate the individual uptake of solute: 


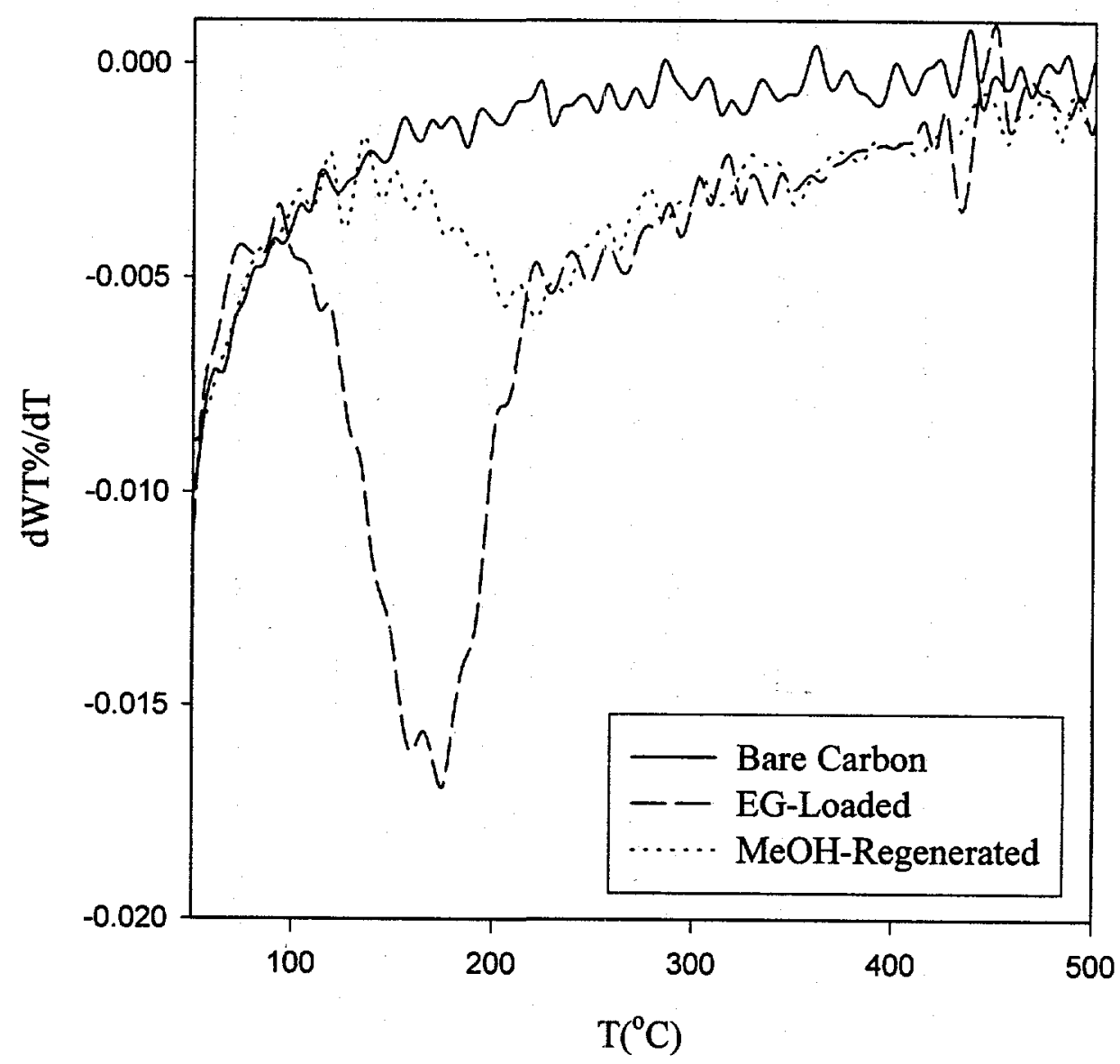

Figure 6.2-2. TGA derivative plots for (1) EG-loaded ( $\mathrm{q}=23 \mathrm{mg} / \mathrm{g}$ ) F400/HT carbon, (2) Dry MeOH-regenerated F400/HT carbon, and (3) bare carbon reference. Heating rate: $10^{\circ} \mathrm{C} / \mathrm{min}$. 


$$
\mathrm{Q}_{\mathrm{TGA}}=1000\left[\frac{(\mathrm{WT} \%)_{\mathrm{i}}-(\mathrm{WT} \%)_{\mathrm{f}}}{(\mathrm{WT} \%)_{\mathrm{f}}}\right]
$$

where QTGA is the individual uptake of solute $(\mathrm{mg} / \mathrm{g})$ as determined from TGA, $(\mathrm{WT} \%)_{\mathrm{i}}$ is the weight percent solute on the sample at the onset of desorption, and (WT\%) $\mathrm{f}$ is the weight percent solute on the sample at the end of desorption. For most of our experiments, $(\mathrm{WT} \%)_{\mathrm{i}}$ is the value taken around $100^{\circ} \mathrm{C}$, where nearly all of the solvent is removed. $(\mathrm{WT} \%)_{\mathrm{f}}$ is taken at $500^{\circ} \mathrm{C}$, where the solute desorption profile usually matches that of the bare carbon profile. From eq. (6.2-1), values of $\mathrm{Q}_{\mathrm{TGA}}$ for the loaded and regenerated carbons are 21 and $11 \mathrm{mg} / \mathrm{g}$, respectively. The loading value is lower than that determined from the adsorption equilibrium experiment, probably because some of the glycol is lost during the drying stages. Despite there being a large difference in volatility, some glycol is no doubt co-evaporated with the relatively large amount of water.

TGA also allows an alternative method of defining regenerability (\% $\left.\mathrm{RE}_{\mathrm{TGA}}\right)$, one that is based on actual (individual uptake) rather than excess (composite uptake) loadings:

$$
{ }^{2} \mathrm{RE}_{\mathrm{TGA}}=100\left[1-\frac{\mathrm{Q}_{\mathrm{TGA}, \mathrm{R}}}{\mathrm{Q}_{\mathrm{TGA}, \mathrm{L}}}\right]
$$


where the subscripts " $R$ " and " $L$ " refer to the regenerated and loaded samples, respectively. In applying eq. (6.2-2) to Figure $6.2-2$, we find $\% \mathrm{RE}_{\mathrm{TGA}}$ to be 48 , which is much lower than the value of $89 \%$ determined from mass-balance calculations. If the carbons have a relatively constant density of high-energy sites, then one would expect $\% \mathrm{RE}_{\mathrm{TGA}}$ to increase with loading. After the high-energy sites are occupied, all subsequent solute molecules adsorbing onto the remaining low-energy sites should be amenable to solvent regeneration. The value of $\% \mathrm{RE}=89$ as determined by calculations, therefore appears to be imprecise and inconsistent with the TGA results.

\subsubsection{Wet versus Dry Regeneration}

With TGA as a more precise characterization tool for the adsorbed phase, we are now in a better position to address the effect of entrained water on the regenerability of loaded carbons by solvents. Previously, in Chapter $\underline{5}$, it appeared that batch regeneration in the absence of water was nearly complete $(>90 \%)$ while regeneration in the presence of water was always incomplete (50-70\%). The data presented in this section are for regeneration of heat-treated F400 with a fairly high loading $(q=100-200 \mathrm{mg} / \mathrm{g})$ of ethylene or propylene glycol. A constant phase ratio of acetone or methanol, equal to 10 $\mathrm{mL} / \mathrm{g}$ carbon, was used in the regeneration experiments. All TGA experiments were conducted with a $10^{\circ} \mathrm{C} / \mathrm{min}$ heating rate. For clarity, we only show the desorption profiles of the regenerated carbons (rather than the originally loaded carbons) in the following derivative plots. 
Figure 6.2-3 shows derivative plots of heat-treated F400 initially loaded with aqueous EG $(q=113 \mathrm{mg} / \mathrm{g})$ and then regenerated separately by wet and dry acetone. Figure $6.2-4$ shows similar results for another batch of EG-loaded $(\mathrm{q}=155 \mathrm{mg} / \mathrm{g})$ carbon, with wet or dry methanol as the regenerant. Both sets of data show that there is a noticeable amount of solute desorbing between $150^{\circ}$ and $180^{\circ} \mathrm{C}$, which is not the case for the results for low loadings ( $\mathrm{q}=23 \mathrm{mg} / \mathrm{g}$ ), shown previously in Figure 6.2-2. This result is consistent with the notion that with higher surface loadings, a larger proportion of the solute occupies the low-energy sites, which desorb from the surface at a lower temperature. The fixed ratio of regenerant to carbon $(10 \mathrm{~mL} / \mathrm{g})$ used was also probably insufficient for desorbing all of the glycol from the low-energy sites in the more heavily-loaded carbon sample.

Figure 6.2-5 shows derivative plots of heat-treated F400 initially loaded with aqueous PG $(q=163 \mathrm{mg} / \mathrm{g}$ ) and then regenerated separately by wet and dry acetone. Figure 6.2-6 shows similar results for another batch of PG-loaded ( $q=195 \mathrm{mg} / \mathrm{g}$ ) carbon, with wet and dry methanol as the regenerants. Because of the relatively high loadings, the results obtained are similar to those observed for EG in that residual solute is present throughout the entire temperature range.

All four sets of data show that the glycol-desorption profiles of the regenerated carbons are not substantially affected by the presence of entrained water within the carbon. Table 6.2-1 compares the $\mathrm{Q}_{\mathrm{TGA}, \mathrm{R}}$ and $\% \mathrm{RE}_{\mathrm{TGA}}$ values for wet versus dry regeneration. 


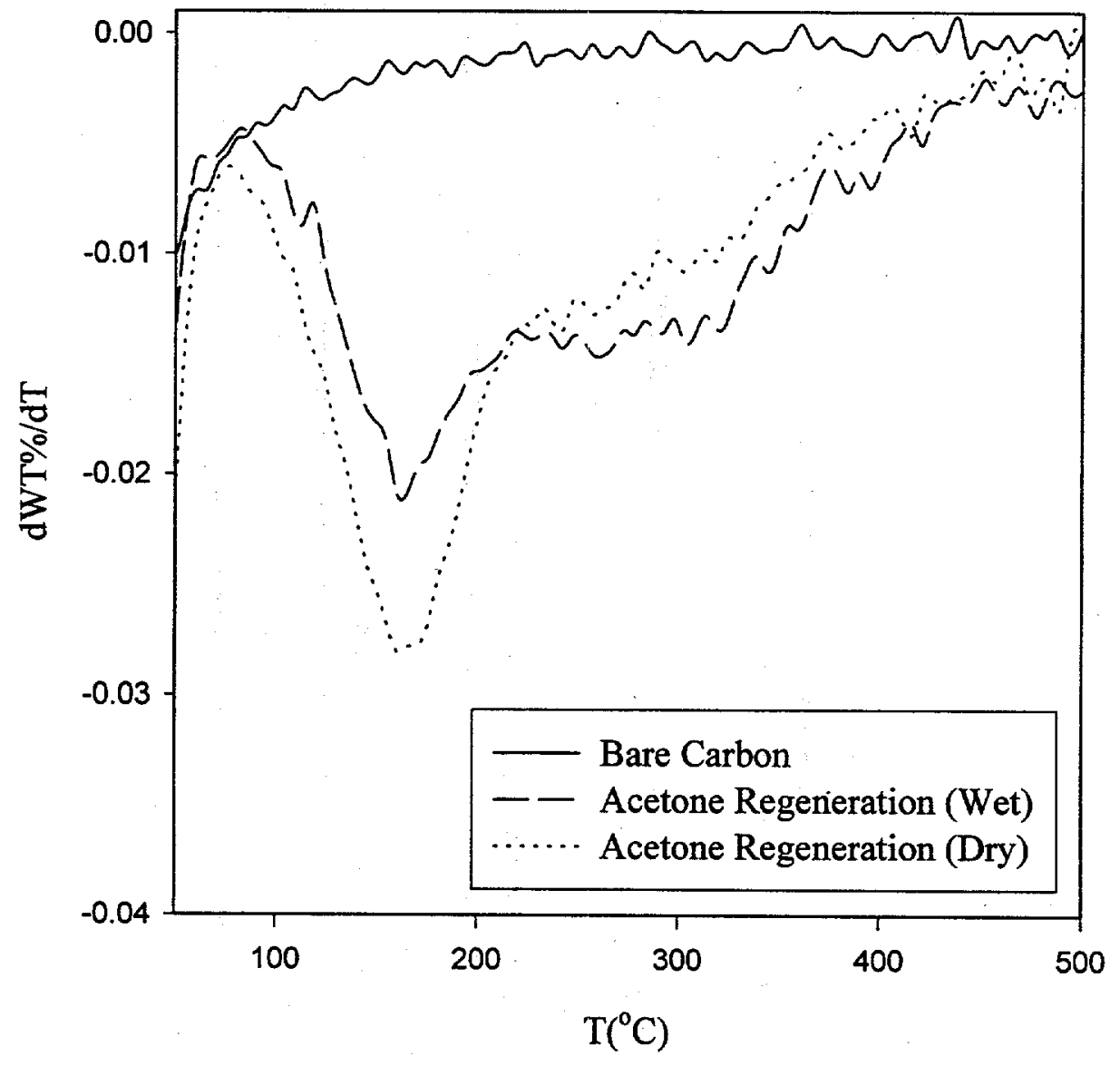

Figure 6.2-3. TGA derivative plots shown for (1) Wet acetone-regenerated F400/HT carbon, (2) Dry acetone-regenerated F400/HT carbon, and (3) bare carbon reference. Heating rate: $10^{\circ} \mathrm{C} / \mathrm{min}$. Original sample was EG-loaded ( $\mathrm{q}=113 \mathrm{mg} / \mathrm{g}$ ) F400/HT carbon. 


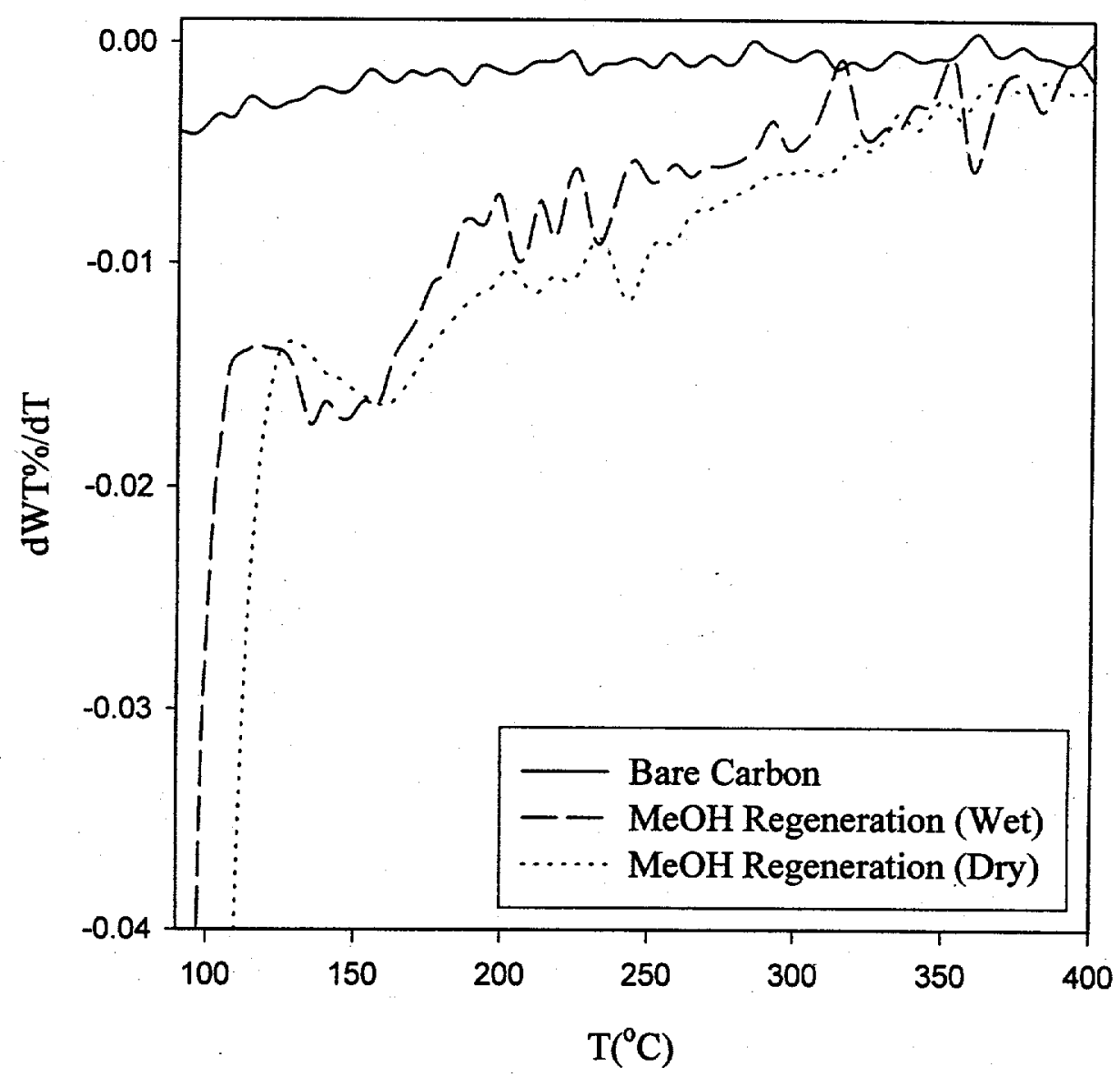

Figure 6.2-4. TGA derivative plots shown for (1) Wet MeOH-regenerated F400/HT carbon, (2) Dry MeOH-regenerated F400/HT carbon, and (3) bare carbon reference. Heating rate: $10^{\circ} \mathrm{C} / \mathrm{min}$. Original sample was EG-loaded ( $\mathrm{q}=155 \mathrm{mg} / \mathrm{g}$ ) F400/HT carbon. 


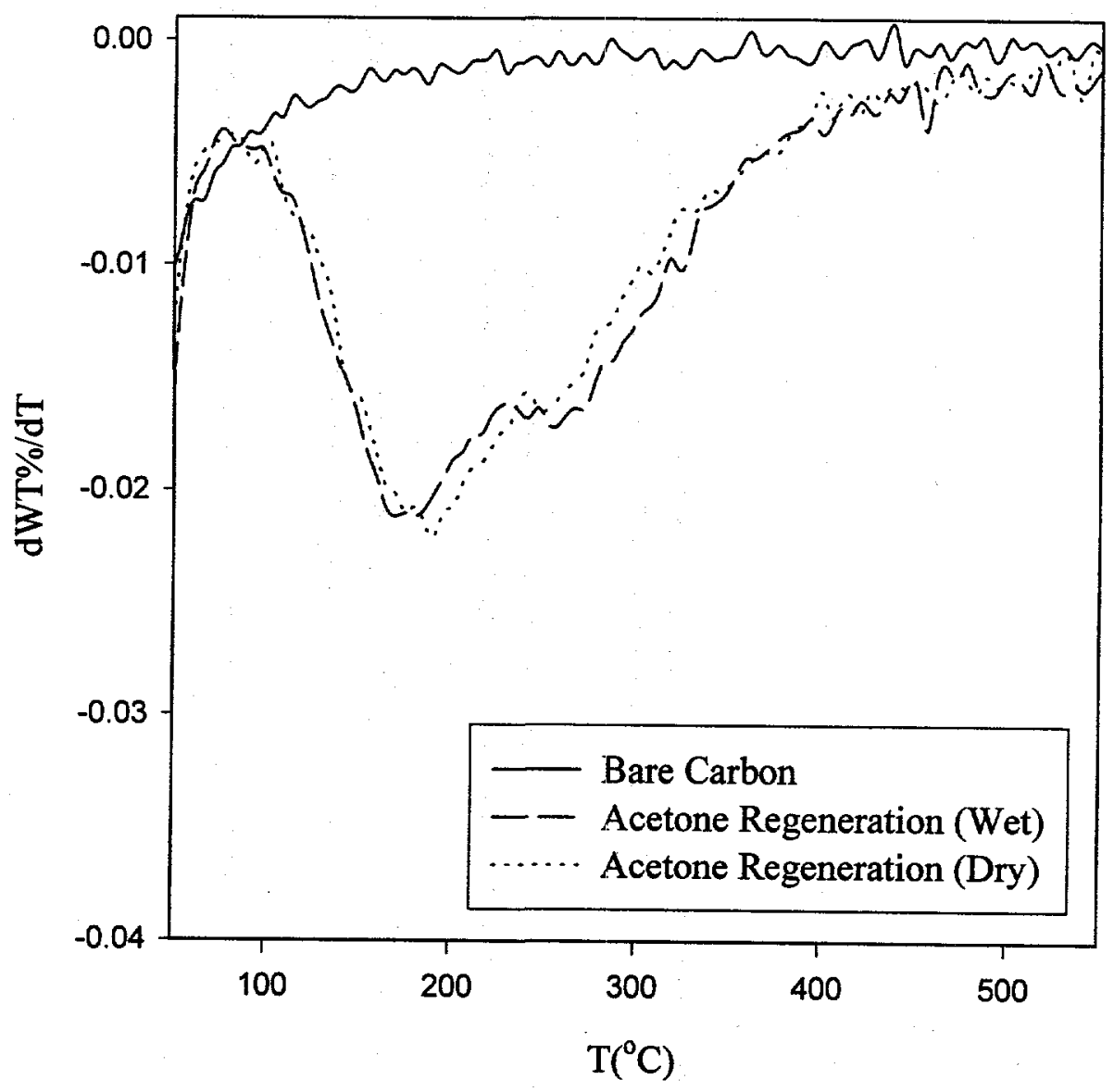

Figure 6.2-5. TGA derivative plots shown for (1) Wet acetone-regenerated F400/HT carbon, (2) Dry acetone-regenerated F400/HT carbon, and (3) bare carbon reference. Heating rate: $10^{\circ} \mathrm{C} / \mathrm{min}$. Original sample was PG-loaded ( $\mathrm{q}=163 \mathrm{mg} / \mathrm{g}$ ) F400/HT carbon. 


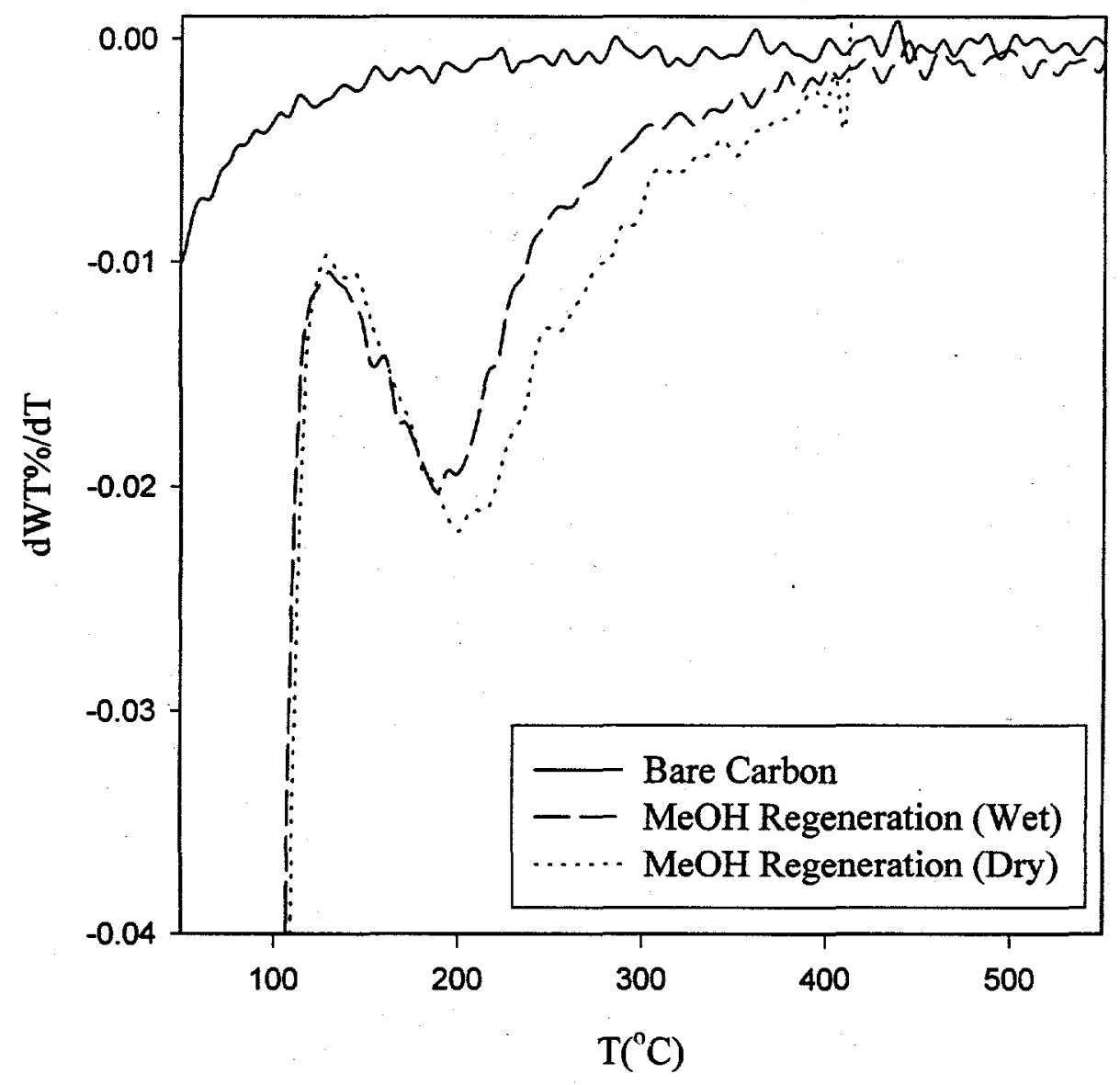

Figure 6.2-6. TGA derivative plots shown for (1) Wet MeOH-regenerated F400/HT carbon, (2) Dry MeOH-regenerated F400/HT carbon, and (3) bare carbon reference. Heating rate: $10^{\circ} \mathrm{C} / \mathrm{min}$. Original sample was PG-loaded ( $\mathrm{q}=195 \mathrm{mg} / \mathrm{g}$ ) F400/HT carbon. 
TABLE 6.2-1

TGA of Wet versus Dry Regeneration of Glycol-Loaded F400/HT

\begin{tabular}{|c|c|c|c|c|}
\hline SOLUTE & $\mathrm{Q}_{\mathrm{TGA}, \mathrm{L}}(\mathrm{mg} / \mathrm{g})$ & REGENERANT & $\mathrm{Q}_{\mathrm{TGA}, \mathrm{R}}(\mathrm{mg} / \mathrm{g})$ & $\% \mathrm{RE}_{\mathrm{TGA}}$ \\
\hline \multirow[t]{4}{*}{$\mathrm{EG}$} & $\mathrm{ND}^{*}[148]$ & Acetone (Wet) & 46 & 69 \\
\hline & $\mathrm{ND}^{*}[158]$ & Acetone (Dry) & 48 & 70 \\
\hline & 205 & Methanol (Wet) & 33 & 84 \\
\hline & ND*[219] & Methanol (Dry) & 33 & 85 \\
\hline \multirow[t]{4}{*}{$\mathrm{PG}$} & 192 & Acetone (Wet) & 44 & 77 \\
\hline & 192 & Acetone (Dry) & 42 & 78 \\
\hline & 222 & Methanol (Wet) & 34 & 85 \\
\hline & $\mathrm{ND} *[261]$ & Methanol (Dry) & 38 & 85 \\
\hline
\end{tabular}

*ND means a separate TGA was not done for the loaded sample. The value in brackets was determined by adsorption equilibrium experiments, and is used in calculating $\% \mathrm{RE}_{\mathrm{TGA}}$.

Several trends are apparent from the data in Table 6.2-1. First, the values of $Q_{T G A, R}$ and $\% \mathrm{RE}_{\mathrm{TGA}}$ for wet regeneration are virtually identical with that for dry regeneration. This suggests that for the regenerant-carbon phase ratio used $(10 \mathrm{~mL} / \mathrm{g})$, entrained water within the carbon does not affect the desorption equilibrium for solvent regeneration. This means that after the carbons are loaded from aqueous solution, they may be regenerated by solvents in-situ without the need for a drying step. The apparent effect of entrained water on regenerabilty as seen in Chapter 5 , is therefore not physico-chemical in nature, but rather caused by imprecise mass-balance calculations and experimental propagation of error.

Another trend seen in Table 6.2-1 (see also data in Section 6.2.2) is that $\% \mathrm{RE}_{\mathrm{TGA}}$ appears to increase with $\mathrm{Q}_{\mathrm{TGA}, \mathrm{L}}$ for both ethylene and propylene glycol. This is consistent with the notion of surface heterogeneity. A given carbon has a finite amount of high-energy sites, which are preferentially occupied by a given amount of solute. At high loadings, all 
additional solute resides at the lower-energy sites, which may be characterized by TGA as the fraction desorbing at a lower temperature. A given amount of regenerant (wet or dry) displaces solute preferentially from the low-energy sites; hence, when more of these sites are occupied the $\% \mathrm{RE}_{\mathrm{TGA}}$ always appears to increase with loading.

It appears that regenerability is slightly greater with methanol rather than with acetone. Whether this trend is caused by individual differences in $\mathrm{Q}_{\mathrm{TGA}, \mathrm{L}}$ or differences in intrinsic displacing powers is not immediately clear from the data. Some authors argue that lowmolecular-weight regenerants are superior since they can more easily penetrate into the micropores of the carbon (Martin and Ng, 1985). On the other hand, our TGA results (Figure 6.2-1) show that interactions between the carbon and acetone $(M W=58)$ are much stronger than those with methanol $(\mathrm{MW}=32)$, a result which indicates that there are other factors at play.

\subsubsection{Batch Reloading Experiments}

In order to explore carbon regenerability and surface heterogeneity further, experiments were conducted where the carbuns were reloaded (at two different loadings) with ethylene glycol or glycerol after being regenerated by methanol. After the initial batchloading stage, the carbons were centrifuged and then regenerated by (wet) methanol (10 $\mathrm{mL} / \mathrm{g})$. After regeneration, the carbons were centrifuged and then vacuum-dried ( 0.3 atm., $65^{\circ} \mathrm{C}$ ) for a hour to remove excess methanol. The dried carbons were then reequilibrated with the solution used in the initial adsorption stage, and finally centrifuged. 
In each stage of loading, regeneration, and reloading, a small aliquot of carbon was sampled for TGA. All TGA experiments were conducted at a heating rate of $15^{\circ} \mathrm{C} / \mathrm{min}$.

Figure 6.2-7 shows four TGA derivative plots for each type of heat-treated F400 carbon: bare, loaded, regenerated, and reloaded. An aqueous solution of EG of $0.82 \mathrm{wt} . \%$ was used during the loading and reloading stages. Figure 6.2-8 shows similar plots, differing only in that an $11 \mathrm{wt} . \%$ aqueous solution of EG was used for loading and reloading. As with the data seen in previous sections, both figures exhibit a noticeable EG peak centered at $180^{\circ} \mathrm{C}$, followed by a high-temperature tail that extends up to $500^{\circ} \mathrm{C}$.

Figure 6.2-9 shows similar TGA results for heat-treated F400 loaded and reloaded with an aqueous solution of $0.89 \mathrm{wt} . \%$ glycerol. For this data set, it is remarkable that the derivative curves for the loaded and reloaded carbons are virtually identical. Figure 6.210 shows the results when a $7.2 \mathrm{wt} . \%$ glycerol solution was used for loading and reloading. A peak for glycerol is seen at about $250^{\circ} \mathrm{C}$, followed by a high-temperature tail that extends up to $500^{\circ} \mathrm{C}$.

For both aqueous EG and glycerol, all four reloading experiments exhibit similar behavior. After regeneration by methanol, most of the solute that originally desorbed at $180^{\circ} \mathrm{C}$ for $\mathrm{EG}$ and $250^{\circ} \mathrm{C}$ for glycerol has vanished. The fraction not regenerated by methanol remains on high-energy sites, which are manifested by the higher temperature ranges for desorption (i.e., the tailing region in the derivative plots). When the carbon is reloaded, all of the additional solute appears exclusively in the regions near $180^{\circ} \mathrm{C}$ for EG 


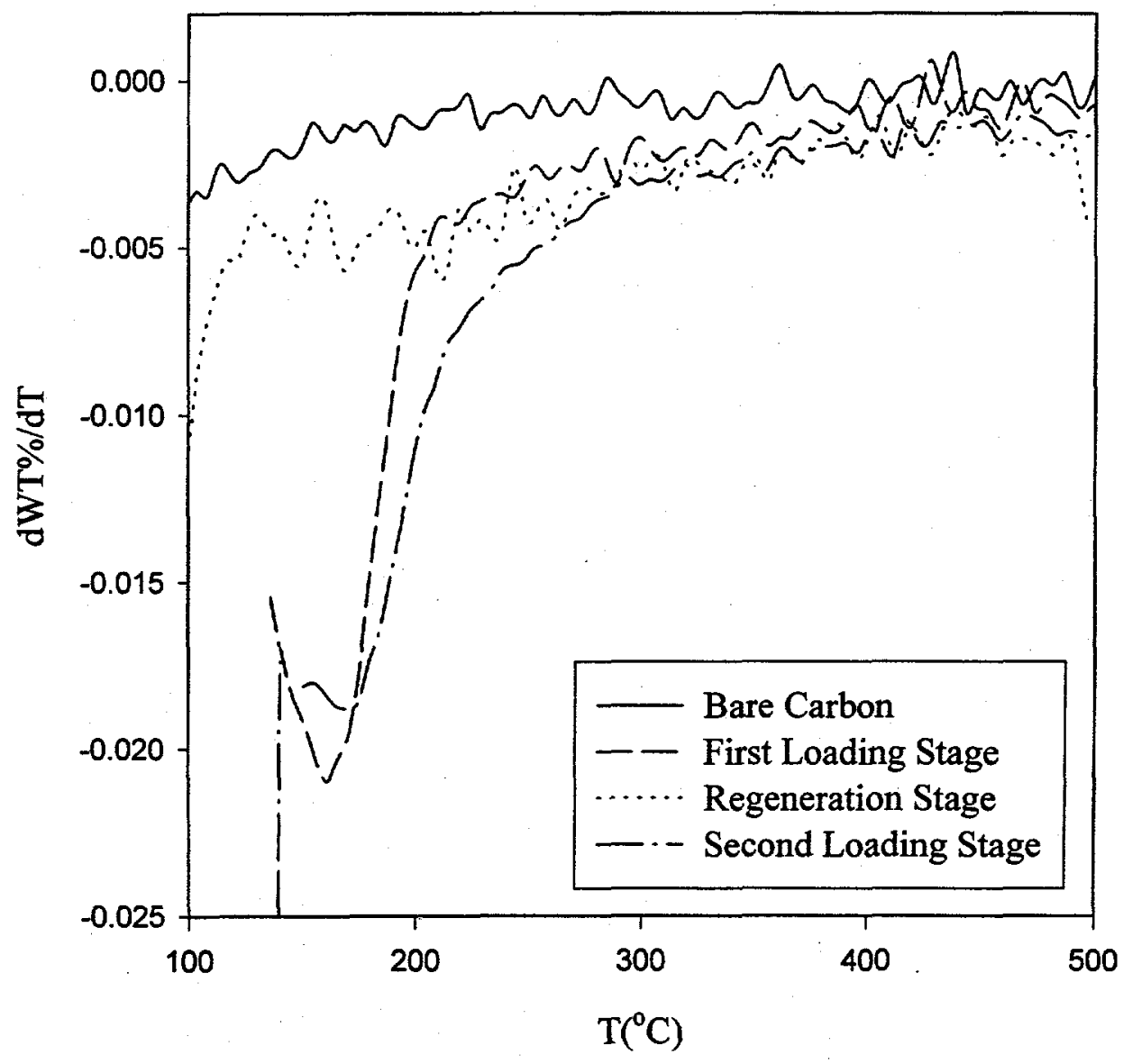

Figure 6.2-7. TGA derivative plots shown for (1) Loaded (from $0.82 \mathrm{wt} \%$ EG) F400/HT carbon, (2) Wet MeOH-regenerated F400/HT carbon, (3) Reloaded (from 0.82 wt.\% EG), and (4) bare carbon reference. Heating rate: $15^{\circ} \mathrm{C} / \mathrm{min}$. 


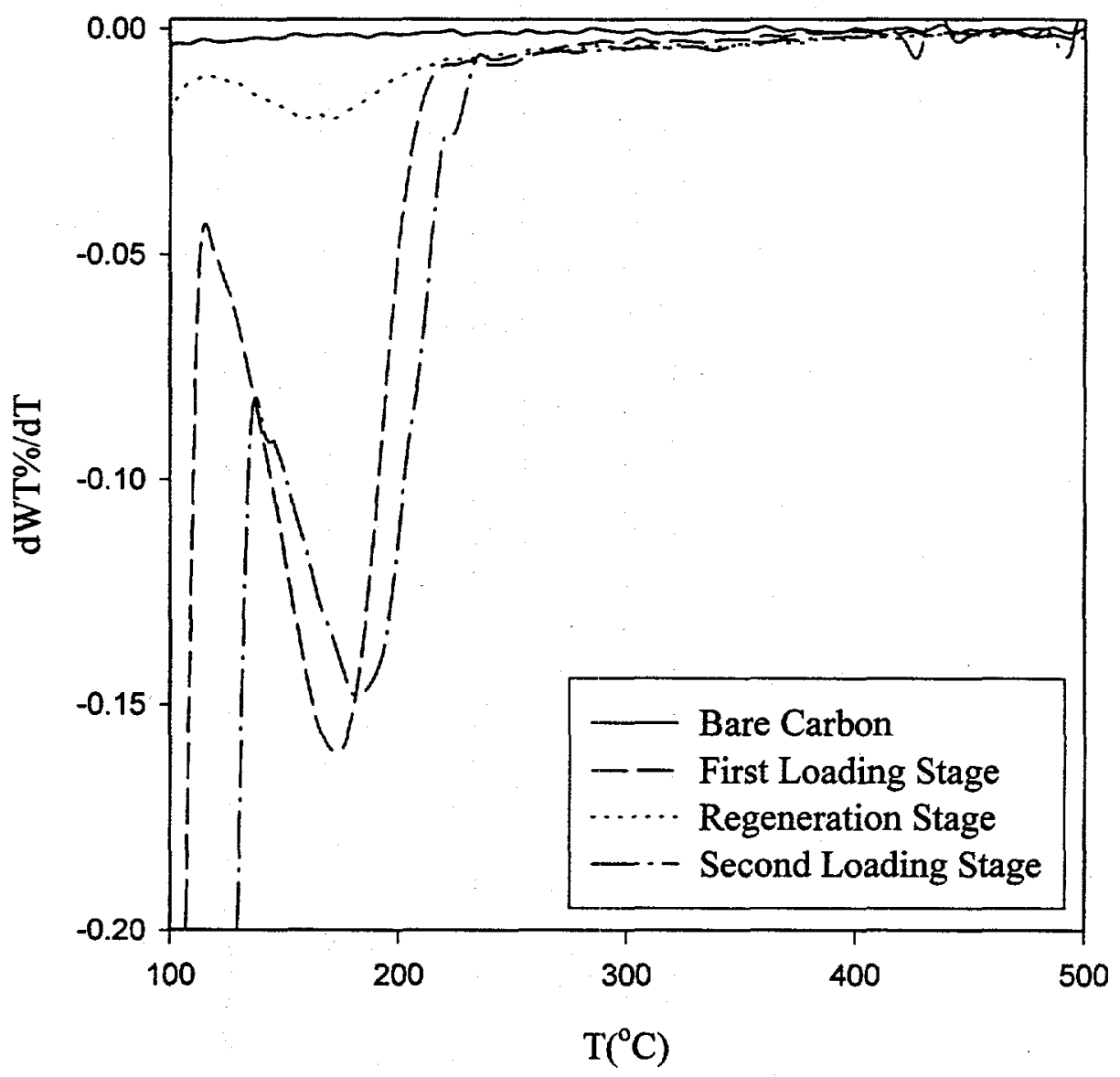

Figure 6.2-8. TGA derivative plots shown for (1) Loaded (from 11 wt.\% EG) F400/HT carbon, (2) Wet MeOH-regenerated F400/HT carbon, (3) Reloaded (from 11 wt.\% EG), and (4) bare carbon reference. Heating rate: $15^{\circ} \mathrm{C} / \mathrm{min}$. 


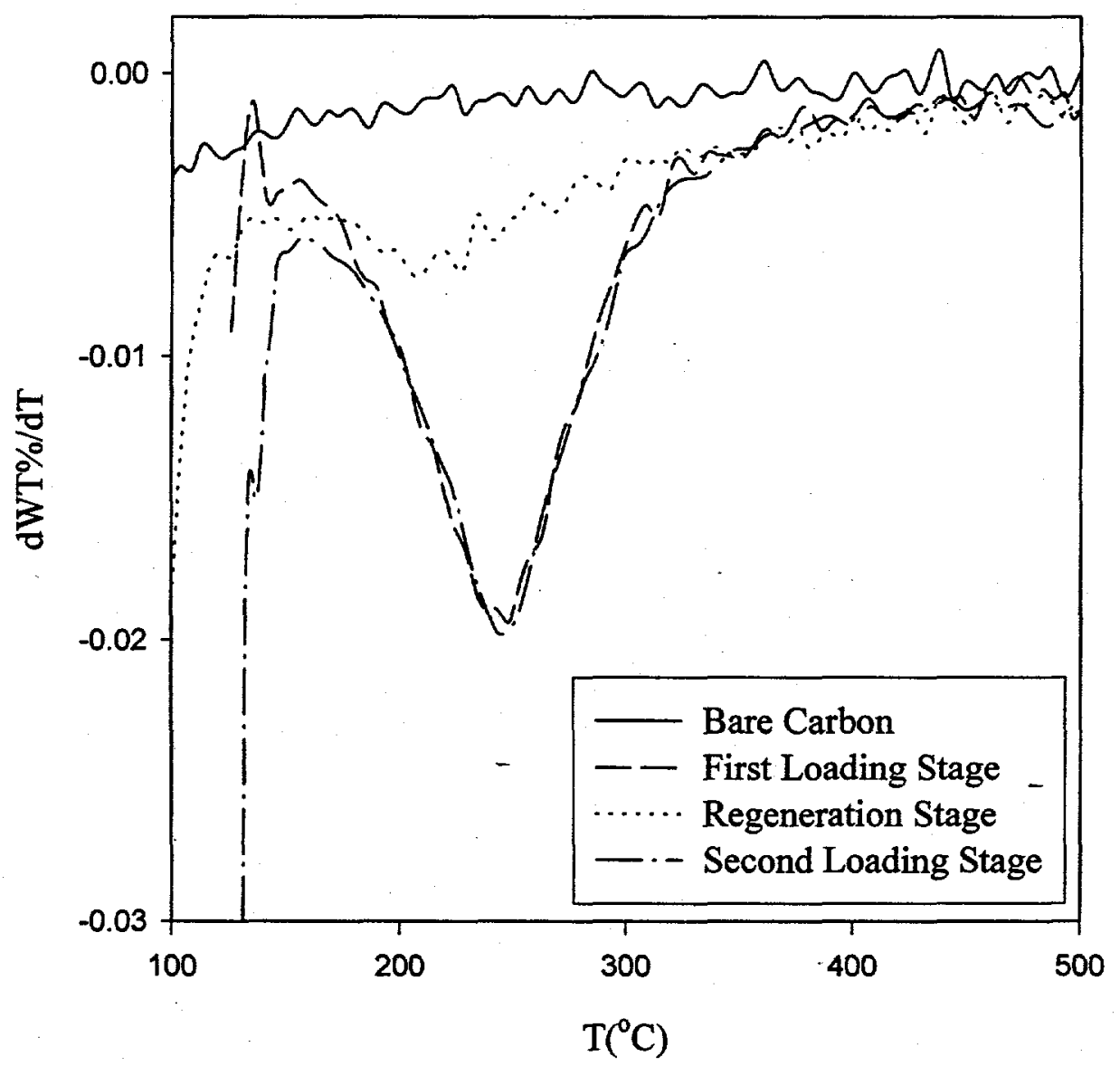

Figure 6.2-9. TGA derivative plots shown for (1) Loaded (from $0.89 \mathrm{wt} \%$ glycerol) F400/HT carbon, (2) Wet MeOH-regenerated F400/HT carbon, (3) Reloaded (from 0.89 wt. $\%$ glycerol), and (4) bare carbon reference. Heating rate: $15^{\circ} \mathrm{C} / \mathrm{min}$. 


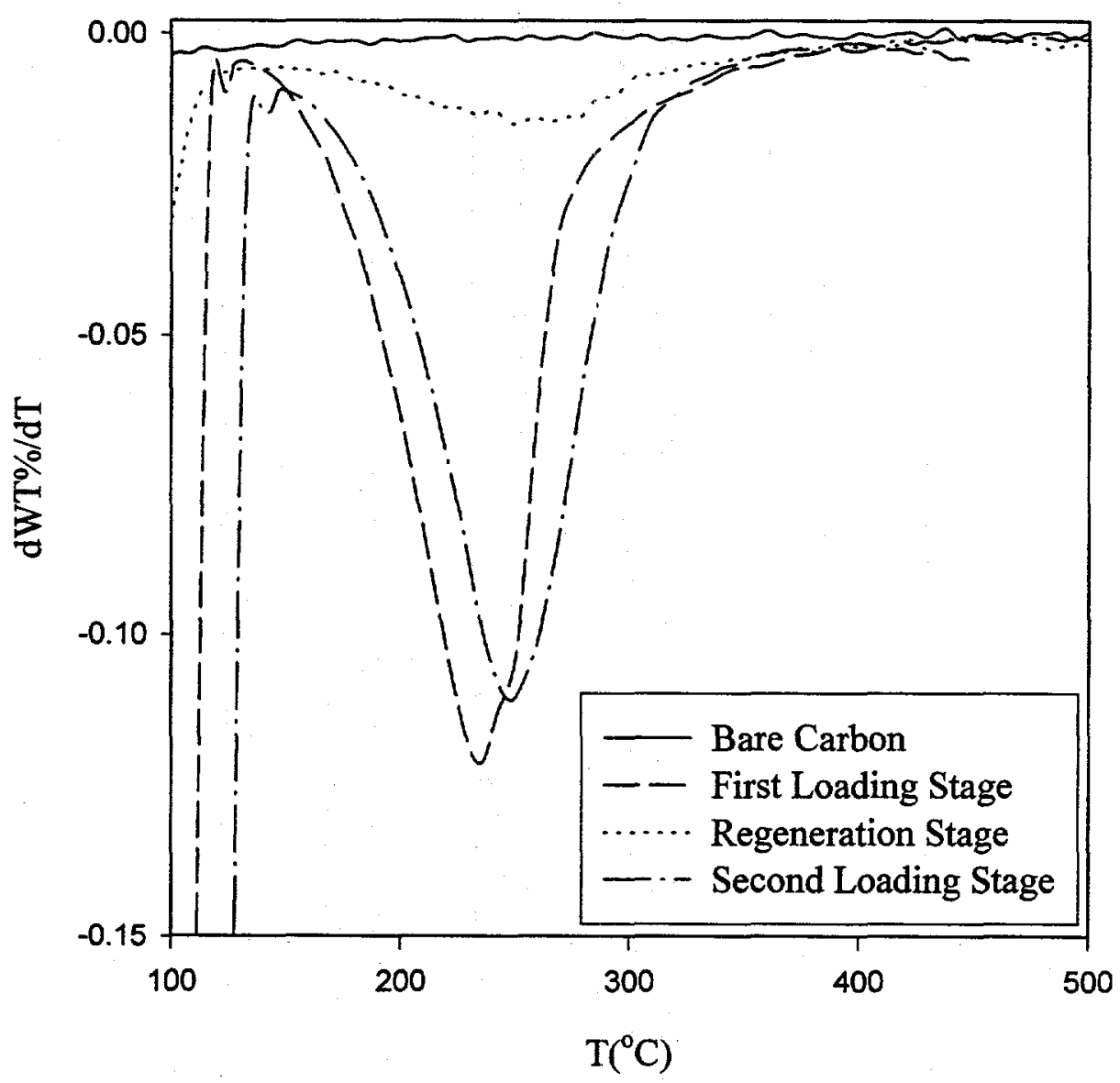

Figure 6.2-10. TGA derivative plots shown for (1) Loaded (from $7.2 \mathrm{wt} . \%$ glycerol) F400/HT carbon, (2) Wet MeOH-regenerated F400/HT carbon, (3) Reloaded (from 7.2 wt. \% glycerol), and (4) bare carbon reference. Heating rate: $15^{\circ} \mathrm{C} / \mathrm{min}$. 
and $250^{\circ} \mathrm{C}$ for glycerol. The derivative values in the tailing regions have not changed significantly, suggesting that nearly all of the high-energy sites were already occupied. Table 6.2-2 presents the actual calculations for all four data sets.

TABLE 6.2-2

TGA for Reloading of EG and Glycerol on F400/HT

\begin{tabular}{||c|c|c|c|c|c|}
\hline SOLUTE & FIGURE & Q $_{\text {TGA,L1 }}(\mathrm{mg} / \mathrm{g})$ & $\mathrm{Q}_{\mathrm{TGA}, \mathrm{R} 1}(\mathrm{mg} / \mathrm{g})$ & \%RE $_{\mathrm{TGA}}$ & $\mathrm{Q}_{\mathrm{TGA}, \mathrm{L} 2}(\mathrm{mg} / \mathrm{g})$ \\
\hline EG & $6.2-7$ & 27 & 12 & 56 & 30 \\
\hline & $6.2-8$ & 170 & 25 & 85 & 176 \\
\hline Glycerol & $6.2-9$ & 32 & 14 & 56 & 34 \\
\hline & $6.2-10$ & 162 & 26 & 84 & 166 \\
\hline
\end{tabular}

The close agreement of $\mathrm{Q}_{\mathrm{TGA}, \mathrm{L} 1}$ and $\mathrm{Q}_{\mathrm{TGA}, \mathrm{L} 2}$ suggests that essentially the same equilibrium loading was reached during both loading and reloading. The now familiar effect of loading on $\% \mathrm{RE}_{\mathrm{TGA}}$ is again clearly seen from the data, this time for glycerol as well.

\subsubsection{Carbon Regenerability - Summary}

TGA has provided two key findings with regards to carbon regenerability by solvent leaching. First, the water entrained within the carbon has no effect on the regenerability in that similar results were obtained from wet and dry regeneration by acetone and methanol for both EG and PG-loaded F400/HT. Second, the surface heterogenity of carbons has a profound effect on regenerability. In all of the data seen (EG, PG, glycerol) it appears that a fixed portion of solute remains on high-energy sites, and is not easily displaced by a regenerant. Solvents appear to be successful in displacing most of 
the aqueous solutes desorbing from the low-temperature regions, but not from the high-temperature tail. We have also confirmed, with precision, that carbons may be reloaded with minimal capacity loss. These findings play a key role in designing processes based on continuous/semi-continuous adsorption and regeneration, the focal point of Chapter 7.

\subsection{Volatility of Adsorbed Phase and Desorption Kinetics}

\subsubsection{Temperature of Maximum Desorption, $T_{\max }$}

The TGA data presented in Section 6.2 have demonstrated that adsorbates have a maximum rate of desorption at some characteristic temperature, $T_{\max }$. In this section, it is of interest to see how the degree of loading and the type of carbon affect $T_{\max }$. We also compare values of $\mathrm{T}_{\max }$ among different solutes, from both the present research and studies in the literature. A simple method for assessing the volatility of an adsorbed compound (relative to the pure liquid state) is to compare $T_{\max }$ with its normal boiling point. Discussion of the effect of heating rate on $T_{\max }$ is deferred until Section 6.3.2, where we estimate the first-order kinetic parameters for desorption.

\subsubsection{Effect of Surface Loading on $T_{\max }$}

Figure 6.3-1 shows TGA derivative plots for heat-treated F400 carbons with varying degrees of aqueous EG loading. A heating rate of $40^{\circ} \mathrm{C} / \mathrm{min}$ was used for all experiments. Although greater loadings led to larger desorption peaks, Figure 6.3-1 shows that $T_{\max }$ remained essentially constant. $T_{\max }$ is $197^{\circ} \mathrm{C}$ at the lowest loading of $\mathrm{Q}_{\mathrm{TGA}, \mathrm{L}}=18 \mathrm{mg} / \mathrm{g}$, while a seven-fold increase in loading results in an $10^{\circ} \mathrm{C}$ increase in 


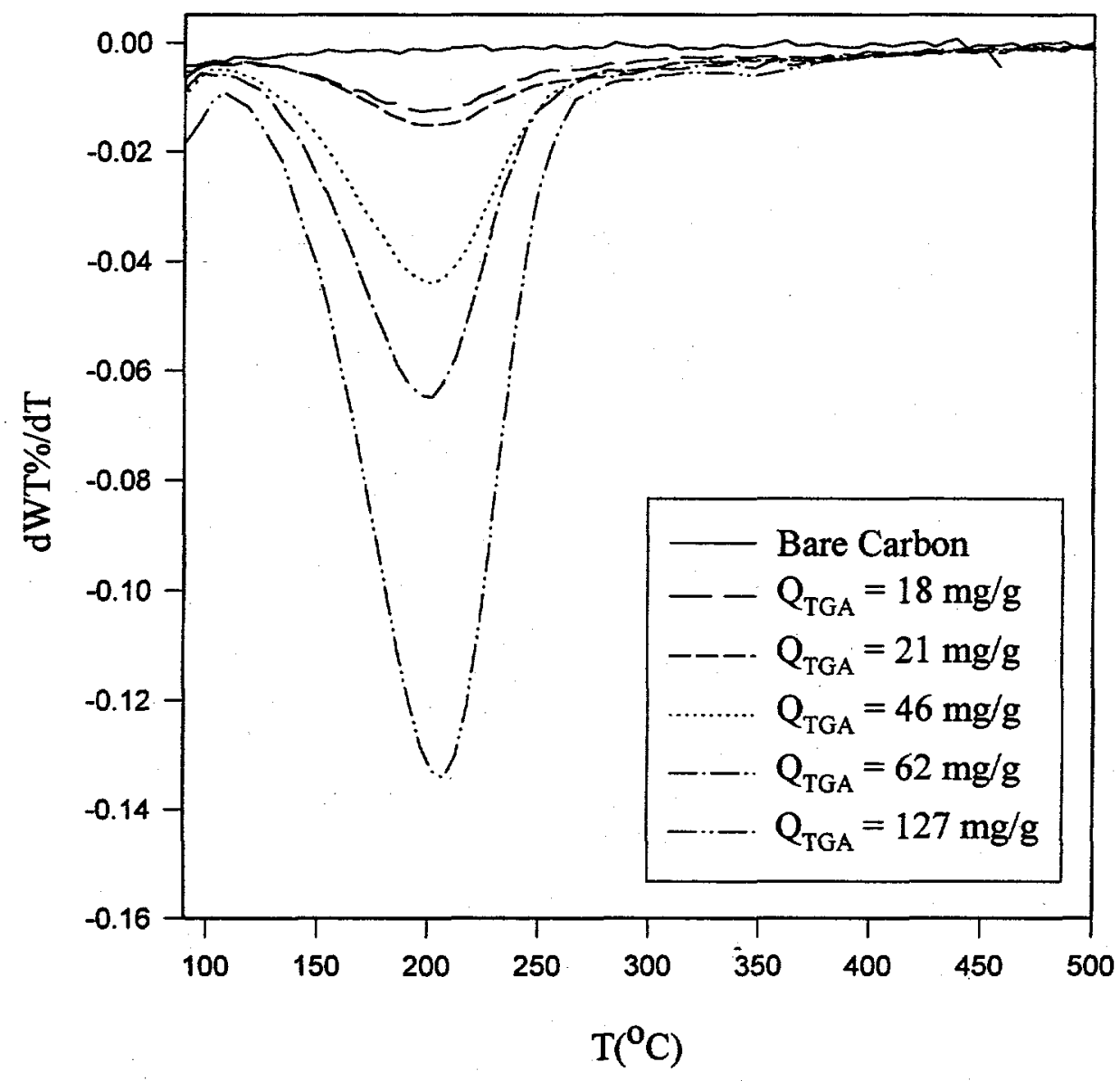

Figure 6.3-1. TGA derivative plots shown for F400/HT carbon with varying degrees of EG loading, with bare carbon reference. Heating rate: $40^{\circ} \mathrm{C} / \mathrm{min}$. 
$\mathrm{T}_{\max }$ to $207^{\circ} \mathrm{C}$. As was observed previously for the reload experiments of Section 6.2.4, the derivatives did not increase appreciably, with increasing initial loading, in the high-temperature tailing region. Rather, all of the additional glycol molecules from the higher loadings desorb near $T_{\max }$.

\subsubsection{Effect of Carbon Type on $T_{\max }$}

All of the results so far this chapter were obtained for heat-treated F400 carbon, which was designated as the standard activated carbon. It was of interest to see whether $T_{\max }$ for a given solute varies greatly for other carbons. Figure 6.3-2 shows TGA derivatives for EG loaded from aqueous solution onto heat-treated F400 ( $\mathrm{q}=23 \mathrm{mg} / \mathrm{g})$, untreated WVB $(\mathrm{q}=40 \mathrm{mg} / \mathrm{g})$, and untreated $\mathrm{RO} 0.8(\mathrm{q}=53 \mathrm{mg} / \mathrm{g})$. The heating rate for all cases was $10^{\circ} \mathrm{C} / \mathrm{min}$. The data show that $\mathrm{T}_{\max }$ for $\mathrm{EG}$ varied no more than $1^{\circ} \mathrm{C}$ among the carbons; the values being about $175^{\circ} \mathrm{C}$ for all three carbons. Although the carbons vary in surface area, pore structure, and oxygen content, the similar values of $T_{\max }$ for $E G$ might suggest that the majority of surface-solute interactions are also similar. In Chapter 4, we discussed how the adsorption mechanisms appear to be dominated by solution-phase nonidealities and dispersion forces. The results of Figure 6.3-2 provide further support to the interpretation that the solute interacts primarily with the unoxidized portions of the carbon surface. From Figure 6.3-3, different results arise when the above TGA experiments are done at a heating rate of $40^{\circ} \mathrm{C} / \mathrm{min}$. The $T_{\max }$ values for aqueous $E G$ on F400/HT, RO 0.8 , and WVB are now $199.82^{\circ} \mathrm{C}, 211.88^{\circ} \mathrm{C}$, and $202.52^{\circ} \mathrm{C}$, respectively. At higher heating rates, it is likely that kinetic limitations begin to play a more important role in determining $T_{\max }$. 


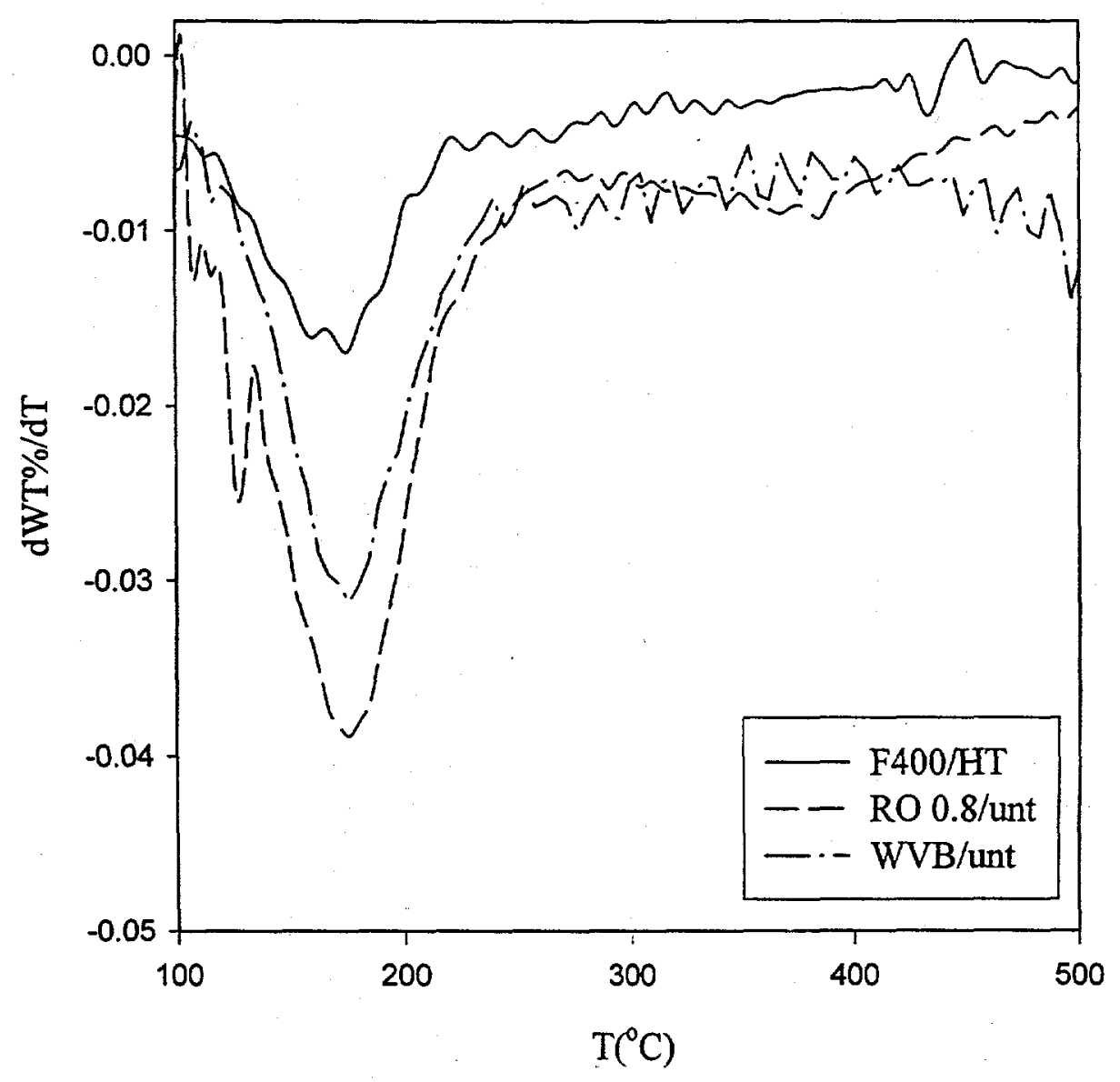

Figure 6.3-2. TGA derivative plots of EG loaded on F400/HT carbon ( $q=23 \mathrm{mg} / \mathrm{g}$ ), WVB carbon ( $\mathrm{q}=40 \mathrm{mg} / \mathrm{g}$ ), and $\mathrm{RO} 0.8$ carbon $\left(\mathrm{q}=53 \mathrm{mg} / \mathrm{g}\right.$ ). Heating rate: $10^{\circ} \mathrm{C} / \mathrm{min}$. 


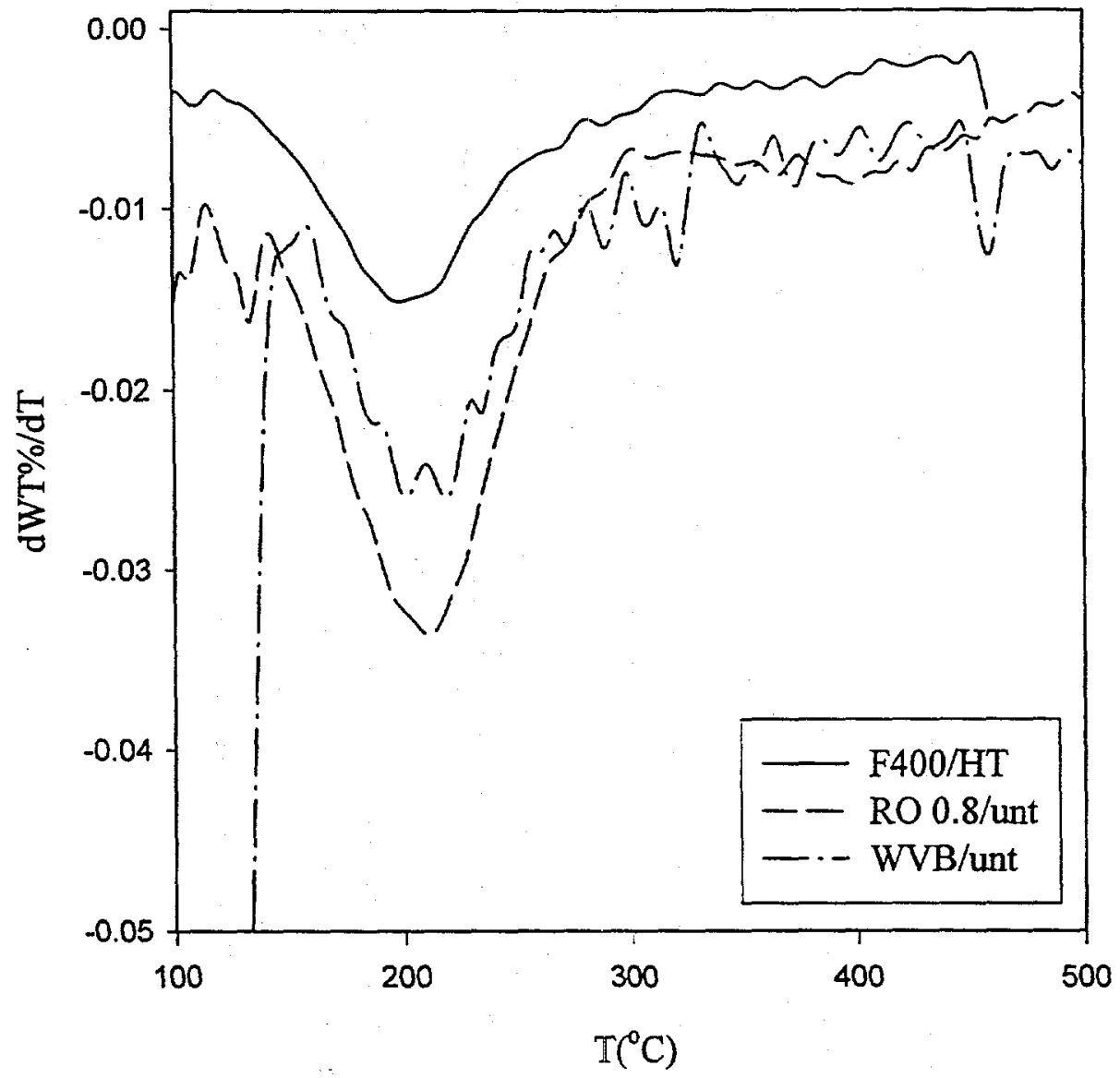

Figure 6.3-3. TGA derivative plots of EG loaded on F400/HT carbon $(\mathrm{q}=23 \mathrm{mg} / \mathrm{g})$, WVB carbon $(\mathrm{q}=40 \mathrm{mg} / \mathrm{g})$, and $\mathrm{RO} 0.8$ carbon $(\mathrm{q}=53 \mathrm{mg} / \mathrm{g})$. Heating rate: $40^{\circ} \mathrm{C} / \mathrm{min}$. 
Figure 6.3-4 shows TGA derivatives for EG loaded from aqueous solution onto A563 $(\mathrm{q}=31 \mathrm{mg} / \mathrm{g}), \operatorname{A} 572(\mathrm{q}=52 \mathrm{mg} / \mathrm{g})$, and A575 $(\mathrm{q}=43 \mathrm{mg} / \mathrm{g})$. The heating rate for all cases was $10^{\circ} \mathrm{C} / \mathrm{min}$. The EG-desorption profiles for the Ambersorbs are similar to those of Figure $6.3-2$, except that there appears to be a small but noticeable peak near $250^{\circ} \mathrm{C}$. This peak may represent glycol desorbing from high-energy sites, which may be more uniform on an Ambersorb than on a carbon due to the greater surface homogeneity of the former. The peak desorption temperatures of $\mathrm{A} 563\left(\mathrm{~T}_{\max }=174.87^{\circ} \mathrm{C}\right)$ and $\mathrm{A} 572\left(\mathrm{~T}_{\max }=\right.$ $\left.179.68^{\circ} \mathrm{C}\right)$ are comparable to those for carbons. However, $\mathrm{A} 575\left(\mathrm{~T}_{\max }=189.29^{\circ} \mathrm{C}\right)$ appears to be significantly different. These results suggest that for the most part, interactions between EG and the Ambersorb surfaces do not differ much from the interactions with carbon surfaces. Figure 6.3-5 shows the TGA results when the experiments with the EG-loaded Ambersorbs are done using a heating rate of $40^{\circ} \mathrm{C} / \mathrm{min}$. As in the case of the carbons, kinetic limitations begin to have greater influence on $T_{\max }$. From Figure 6.3-5, the $\mathrm{T}_{\max }$ values for $\mathrm{EG}$ on $\mathrm{A} 563, \mathrm{~A} 572$, and $\mathrm{A} 575$ are $194.98^{\circ} \mathrm{C}$, $205.48^{\circ} \mathrm{C}$, and $221.46^{\circ} \mathrm{C}$, respectively.

\subsubsection{3 $T_{\max }$ for Various Solutes}

So far we have evidence that, with the heating rate fixed, the nature of the carbon and degree of loading have little influence on $\mathrm{T}_{\max }$ for a given solute. In order to examine a broader range of compounds, we include some of the data from Suzuki et al. (1977) for comparison. The TGA work by Suzuki et al. (1977) was performed on bituminous coalbased carbons, with the loading done by immersion into pure liquids or batch 


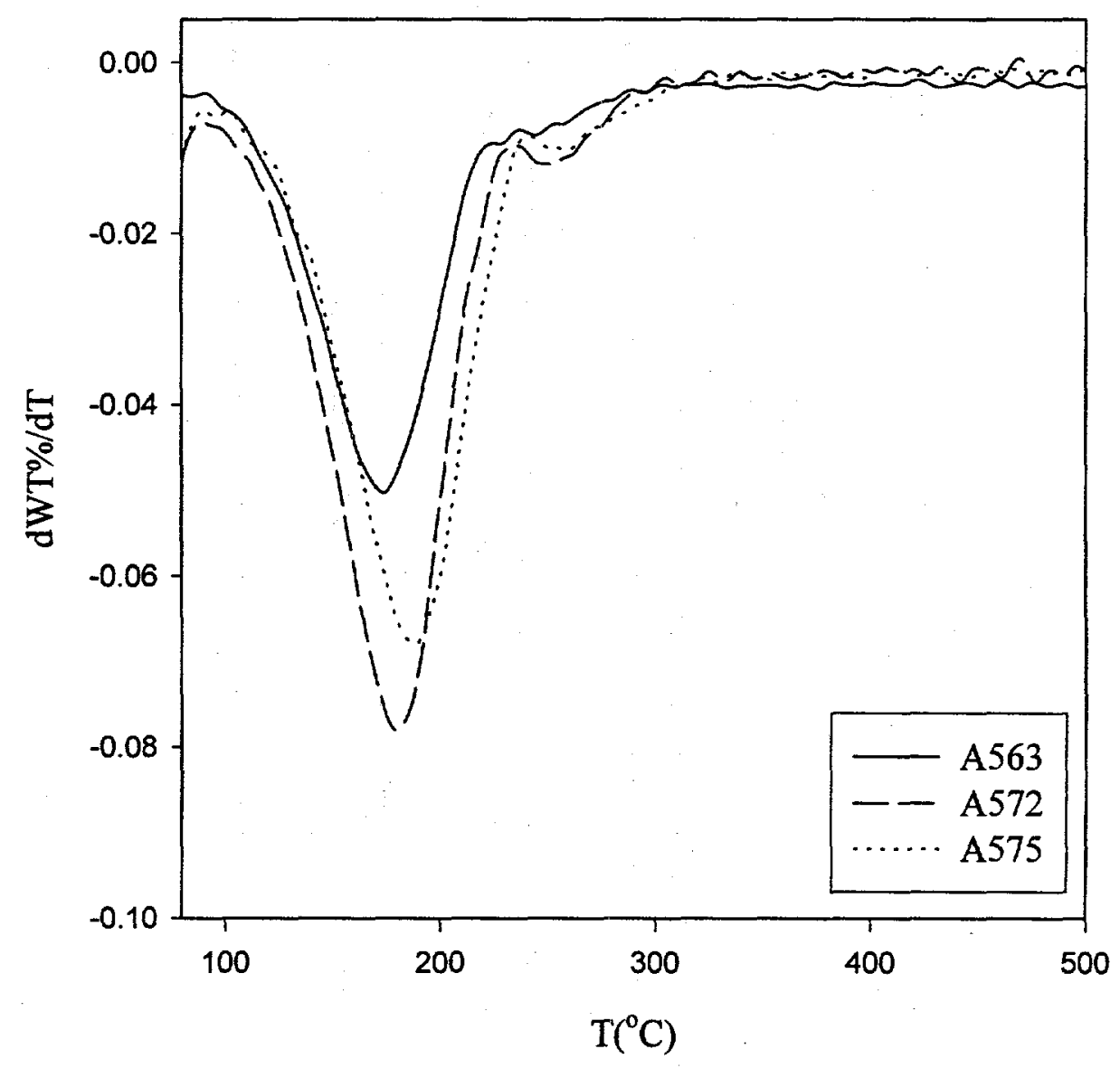

Figure 6.3-4. TGA derivative plots of EG loaded on A563 ( $\mathrm{q}=31 \mathrm{mg} / \mathrm{g})$, A572 ( $\mathrm{q}=52$ $\mathrm{mg} / \mathrm{g})$, and A575 (q=43 mg/g). Heating rate: $10^{\circ} \mathrm{C} / \mathrm{min}$. 


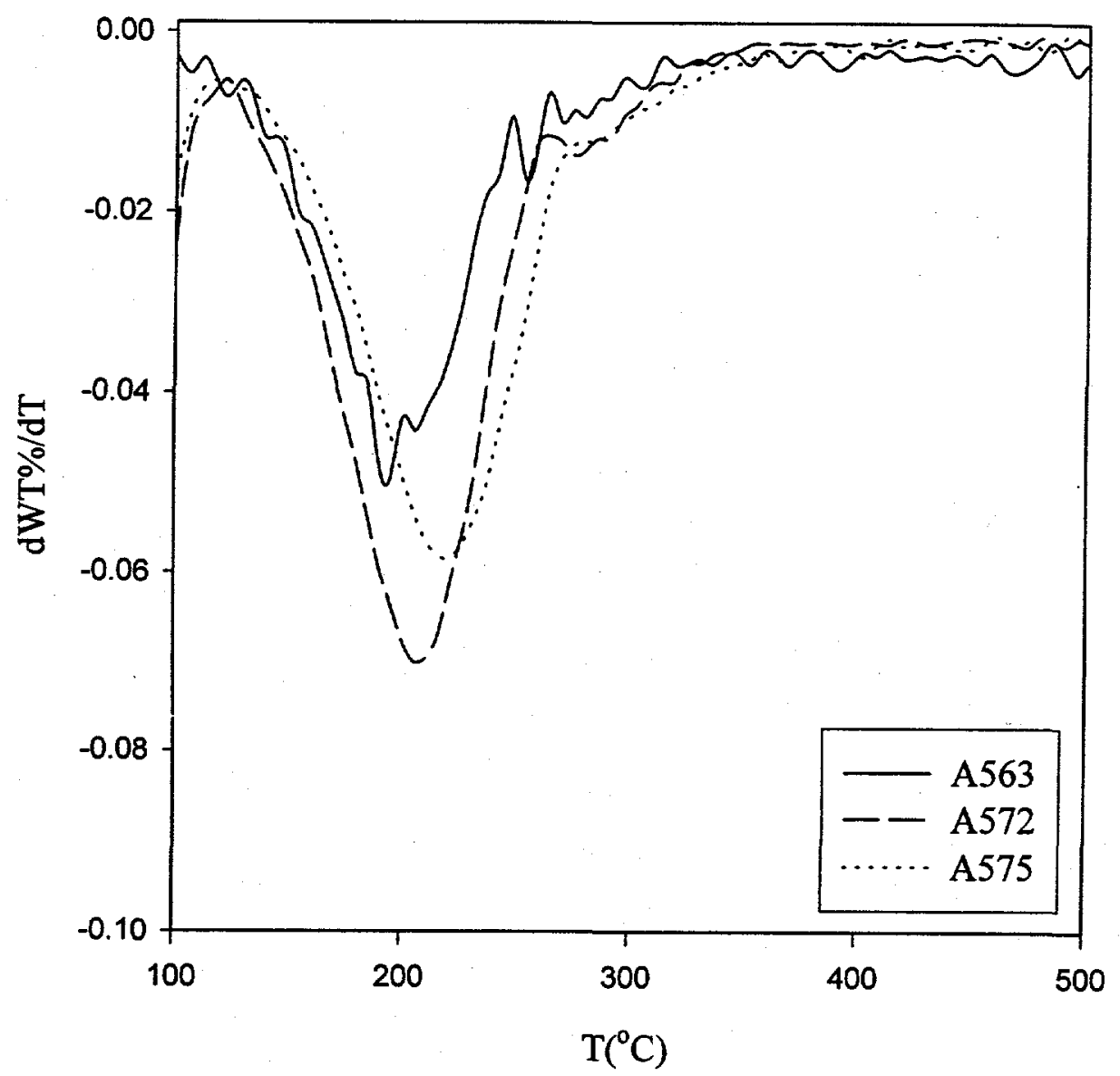

Figure 6.3-5. TGA derivative plots of EG loaded on A563 ( $\mathrm{q}=31 \mathrm{mg} / \mathrm{g}$ ), A572 ( $\mathrm{q}=52$ $\mathrm{mg} / \mathrm{g}$ ), and $\mathrm{A} 575(\mathrm{q}=43 \mathrm{mg} / \mathrm{g})$. Heating rate: $40^{\circ} \mathrm{C} / \mathrm{min}$. 
adsorption experiments from solution. Although the authors did not make derivative plots, $\mathrm{T}_{\max }$ could be estimated from the steepest region of the weight-change curve.

Figure 6.3-6 shows a plot correlating $\mathrm{T}_{\max }$ for various adsorbed solutes (alkanes, alkanols, multi $-\mathrm{OH}$ compounds) with the normal boiling point of the pure solute. All of the data presented in Figure 6.3-6 were obtained at heating rates between 6 and $10^{\circ} \mathrm{C} / \mathrm{min}$. The line $y=x$, representing equal solute volatility in the liquid and adsorbed states, is also shown for reference.

We first discuss the results of Suzuki et al. (1977), where the compounds studied included nonpolar and single $-\mathrm{OH}$ compounds. The most apparent feature from the data is that alkanes $\left(\mathrm{C}_{5}-\mathrm{C}_{10}\right)$ and heavy alcohols $\left(\mathrm{C}_{4}-\mathrm{C}_{8}\right)$ have a $\mathrm{T}_{\max }$ substantially higher than their normal boiling point. As all of these compounds have an essentially hydrophobic structure, it appears that the reduced volatility relative to the pure liquid state is due to strong dispersion interactions with the surface. Benzene and toluene are aromatic compounds, and in addition to dispersion forces may have secondary electron acceptordonor interactions with the surface oxides, as discussed in Chapter 4. The fact that these compounds have $T_{\max }$ values above their boiling points is therefore lot surprising.

The situation with light alcohols $\left(\mathrm{C}_{2}-\mathrm{C}_{3}\right)$ and multi $-\mathrm{OH}$ solutes (glycols, glycerol, glycol polymers) is different. Whereas the light alcohols exhibit only a marginal increase of $T_{\max }$ relative to the boiling point, the $T_{\max }$ values for EG, $P G$, and glycerol are all noticeably below the respective boiling points. One possible explanation is that the extra 


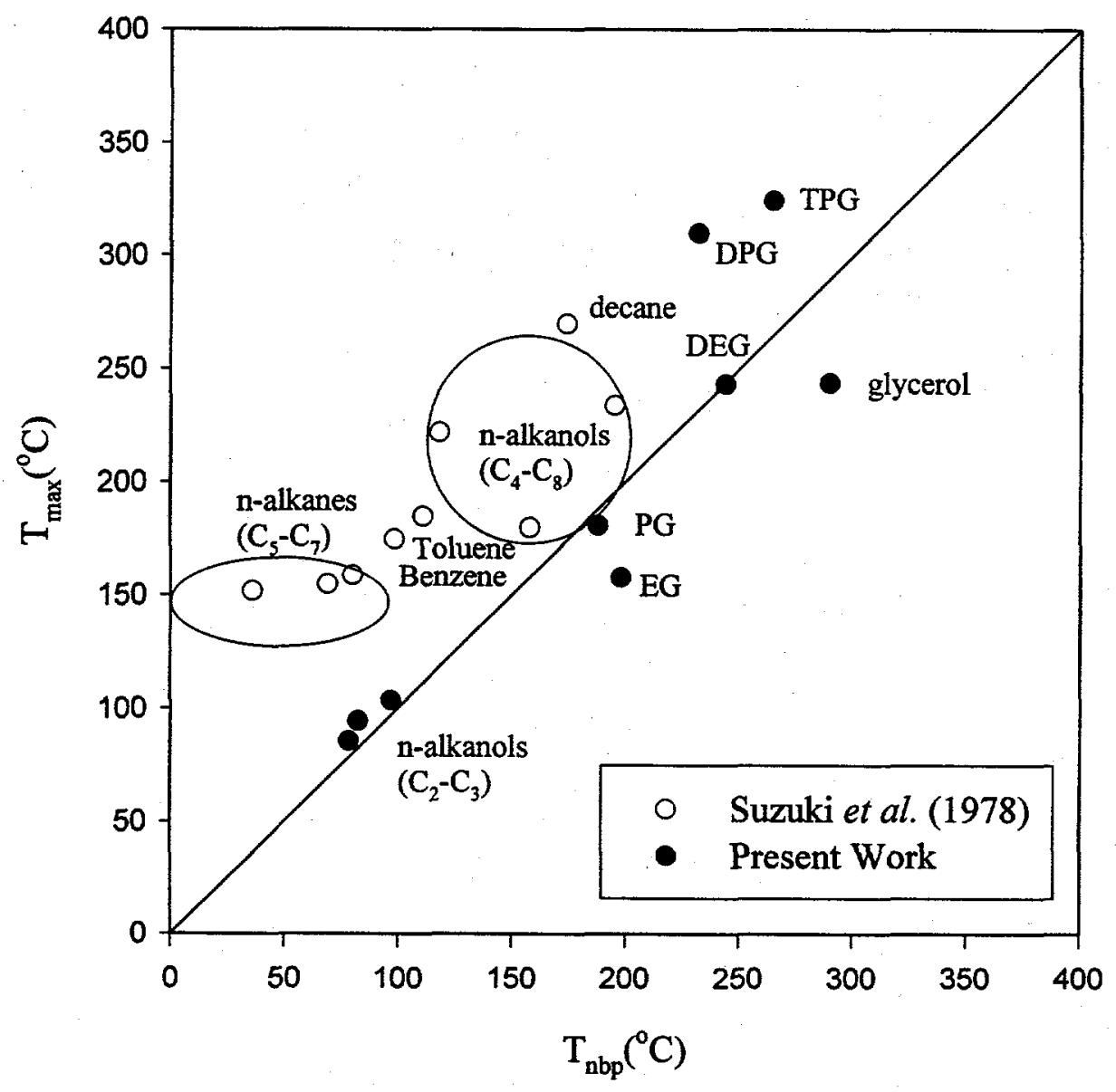

Figure 6.3-6. Plot of $T_{\max }$ vs. normal boiling point $\left(T_{n b p}\right)$ for various adsorbates, with data from Suzuki et al. (1978). Heating rate: $6-10^{\circ} \mathrm{C} / \mathrm{min}$. 
$-\mathrm{OH}$ group(s) somehow limit the number of favorable orientations that the adsorbed solute can assume. Adsorption of multi $-\mathrm{OH}$ solutes on carbons may involve mainly interactions with the hydrocarbon portion of the molecule. This idea not only rationalizes the differences in equilibrium uptakes between multi - $\mathrm{OH}$ solutes and alcohol analogs presented in Chapter 4, but also help explain why an adsorbed glycol has a higher volatility, relative to that of the pure liquid state, than an alkane of similar molecular weight. The glycol polymers: diethylene glycol (DEG), dipropylene glycol (DPG), and triethylene glycol (TEG) show interesting results in that their $T_{\max }$ values match or exceed their respective boiling points. The high molecular weights (100-200) of these compounds may result in sufficiently strong dispersion interactions that compensate for the detrimental effect of the $-\mathrm{OH}$ group on thermal stability. Also, some of the $-\mathrm{OH}$ groups in the glycol polymers have joined, with the release of water, to form much less polar ether linkages.

Figure 6.3-7 shows similar data, only here we include the data of Senf and Frank (1990), with all data taken at a $20^{\circ} \mathrm{C} / \mathrm{min}$ heating rate. Senf and Frank (1990) loaded peat-based carbons with organics statically from the gas phase. Instead of employing traditional TGA, the authors monitored the gaseous effluent (with a flame ionization detector) upon thermal desorption, and defined $\mathrm{T}_{\max }$ as the peak in FID signal of the desorbed solute. Despite these differences in methodology, the trends observed in the data of Senf and Frank (1990) appear to be consistent with the results of Figure 6.3-6. 


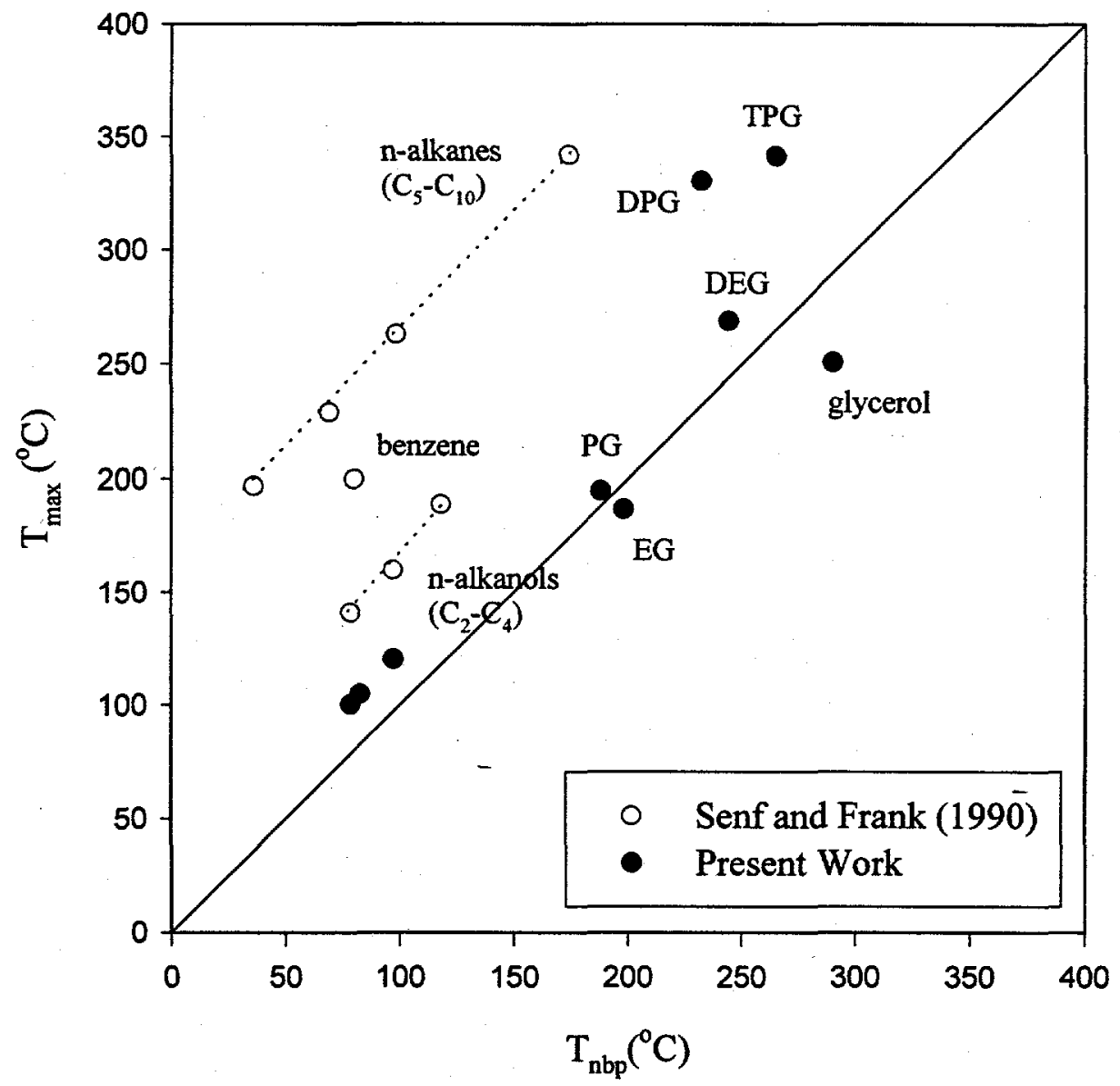

Figure 6.3-7. Plot of $T_{\max }$ vs. normal boiling point $\left(T_{n b p}\right)$ for various adsorbates, with data from Senf and Frank (1990). Heating rate: $20^{\circ} \mathrm{C} / \mathrm{min}$. 
From Figure 6.3-7, we see nearly linear correlations between $T_{\max }$ and the boiling points for alkanes and for alcohols. In the absence of other functional groups, it appears that the volatility of the adsorbed solute decreases in proportion to the molecular weight. These results point to dispersion and/or hydrophobic interactions with the surface as being very characteristic of adsorption onto carbons. As with Figure 6.3-6, the volatility of the adsorbate with respect to that of the pure liquid state is lowest for the alkanes, followed by the alcohols and multi $-\mathrm{OH}$ compounds of intermediate molecular weight $(60-90)$. When a compound has both multiple $-\mathrm{OH}$ groups and a high molecular weight (100-200), it appears that the dispersion interactions again dominate.

Although nearly all of our TGA work was confined to F400/HT as the standard carbon, a few experiments were conducted with other adsorbents: RO 0.8, A572, and A575. Figure 6.3-8 shows the results for TGA experiments done at $10^{\circ} \mathrm{C} / \mathrm{min}$, with $\mathrm{T}_{\max }$ of ethanol, $\mathrm{EG}$, and glycerol plotted versus normal boiling point. Figure 6.3-9 shows the same results, with the heating rate at $20^{\circ} \mathrm{C} / \mathrm{min}$. Even with different adsorbents, the trends seen in these two figures are consistent with the previous results seen in Figures 6.3-6 and 6.3-7. That is, the volatilities of adsorbed alcohols relative to the pure liquid state are nearly always lower than those for adsorbed multi $-\mathrm{OH}$ compounds.

\subsubsection{First-Order Kinetics Model for Thermal Desorption}

\subsubsection{Background and Model Development}

Thermal desorption experiments have been used to obtain kinetic parameters associated with the desorption step: activation energy, pre-exponential factor, and reaction order. 


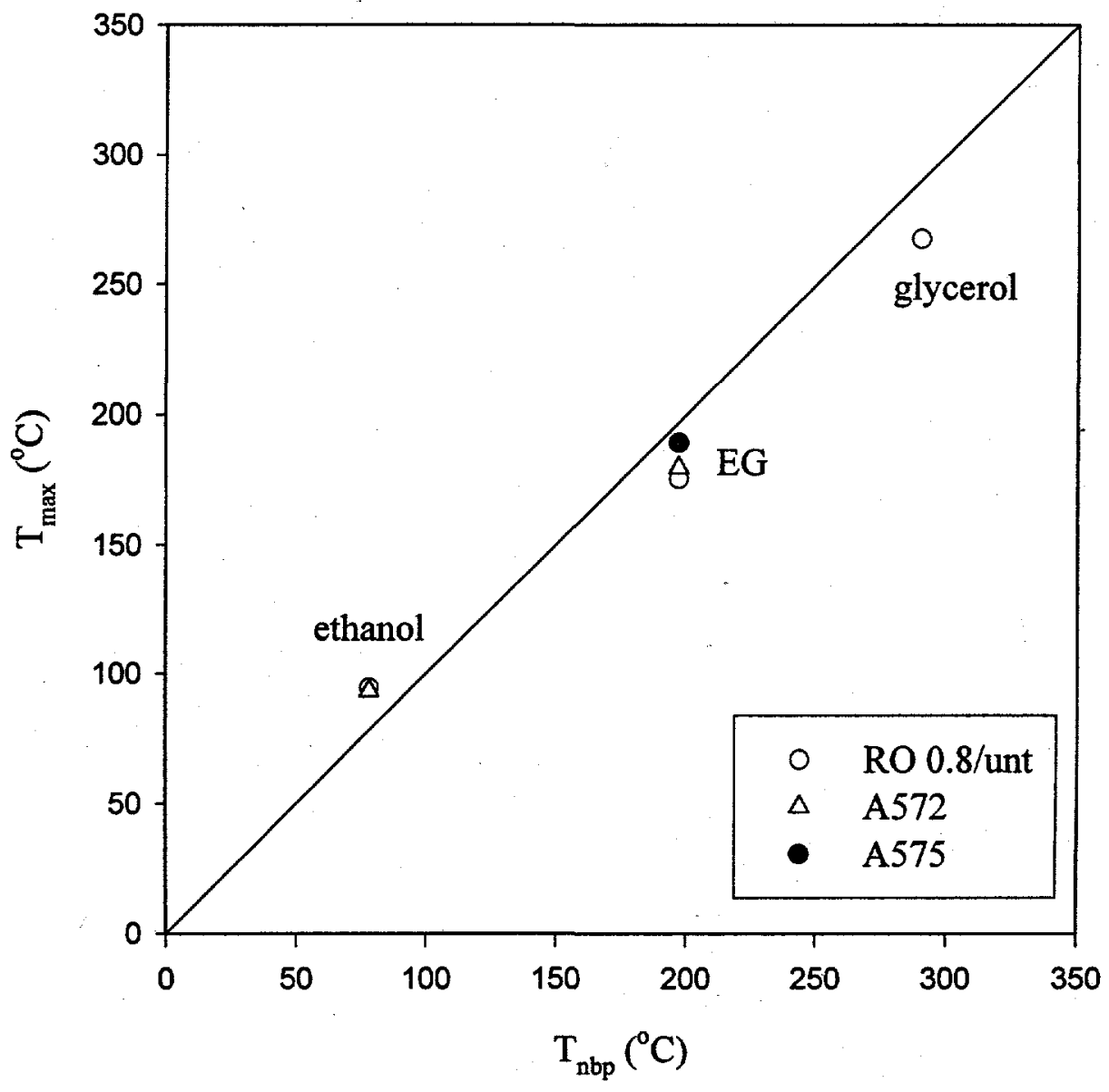

Figure 6.3-8. Plot of $T_{\max }$ vs. normal boiling point $\left(\mathrm{T}_{\mathrm{nbp}}\right)$ for various adsorbates, with different adsorbents. Heating rate: $10^{\circ} \mathrm{C} / \mathrm{min}$. 


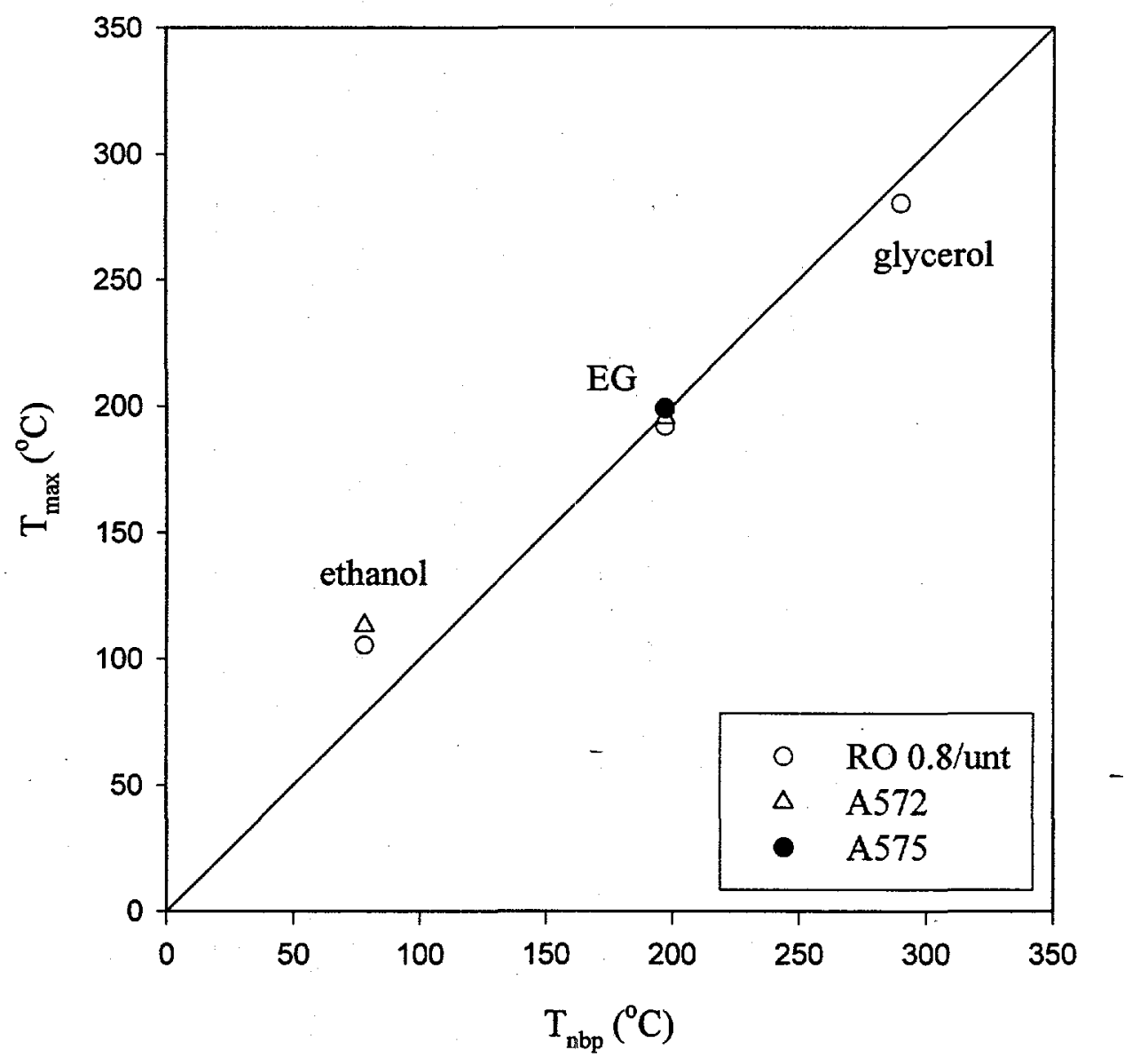

Figure 6.3-9. Plot of $T_{\max }$ vs. normal boiling point $\left(T_{n b p}\right)$ for various adsorbates, with different adsorbents. Heating rate: $20^{\circ} \mathrm{C} / \mathrm{min}$. 
One of the earliest examples was "flash-filament" desorption experiments, where chemisorbed gases were desorbed from refractory metals at high temperature (Redhead, 1962; Carter, 1962). The method consists of analyzing the desorption thermogram of the gases at several controlled heating schedules.

The following derivation is taken from Perrard and Joly (1989). Consider a first-order reaction where solute $\left(\mathrm{S}^{*}\right)$ initially bound on a surface is desorbed as a vapor $(\mathrm{S})$ in a closed system:

$$
\frac{\mathrm{dN}_{\mathrm{S}}}{\mathrm{dt}}=-\frac{\mathrm{dN}_{\mathrm{S}^{*}}}{\mathrm{dt}}=\mathrm{kN}_{\mathrm{S}^{*}}
$$

where $\mathrm{N}_{\mathrm{S}}$ and $\mathrm{N}_{\mathrm{S}^{*}}$ refer to the moles of gaseous and sorbed solute, respectively; $t$ is time ( $\mathrm{min}) ; \mathrm{k}$ is the Arrhenius rate constant $\left(\mathrm{min}^{-1}\right)$ given by:

$$
k=A \exp \left(-\frac{E_{d}}{R T}\right)
$$

where $A$ is the pre-exponential factor $\left(\min ^{-1}\right) ; E_{d}$ is the activation energy of desorption $(\mathrm{kJ} / \mathrm{mol})$; $\mathrm{T}$ is temperature $(\mathrm{K}) ; \mathrm{R}$ is the gas constant, $8.314 \times 10^{-3} \mathrm{~kJ} / \mathrm{mol}{ }^{*} \mathrm{~K}$. We will consider a constant heating rate ( $\alpha=\mathrm{dT} / \mathrm{dt}$ ), and there will be a characteristic temperature (or time) where the desorption rate must reach a maximum. Here, 


$$
\begin{gathered}
\frac{\mathrm{d}^{2} \mathrm{~N}_{\mathrm{S}^{*}}}{\mathrm{dt}^{2}}=0 \\
\frac{\mathrm{d}^{2} \mathrm{~N}_{\mathrm{S}^{*}}}{\mathrm{dt}^{2}}=\mathbf{k} \frac{\mathrm{dN}_{\mathrm{S}^{*}}}{\mathrm{dt}}+\mathrm{N}_{\mathrm{S}^{*}} \frac{\mathrm{dk}}{\mathrm{dt}}=0
\end{gathered}
$$

Next, eq. (6.3-1) is substituted into eq. (6.3-3a), while eliminating $t$ in favor of $T$ :

$$
\frac{\mathrm{d}^{2} \mathrm{~N}_{\mathrm{S}^{*}}}{\mathrm{dt}^{2}}=-\mathrm{k}^{2} \mathrm{~N}_{\mathrm{S}^{*}}+\alpha \mathrm{N}_{\mathrm{S}^{*}} \frac{\mathrm{dk}}{\mathrm{dT}}=0
$$

After simplification, this expression reduces to:

$$
\alpha \frac{\mathrm{d} \ln (\mathrm{k})}{\mathrm{dT}}=\mathbf{k}
$$

The temperature derivative of $\ln (\mathrm{k})$ is straightforward to evaluate:

$$
\frac{\mathrm{d} \ln (\mathrm{k})}{\mathrm{dT}}=\frac{\mathrm{E}_{\mathrm{d}}}{\mathrm{RT}^{2}}
$$


The final step is to substitute eqs. (6.3-2) and (6.3-4) into eq. (6.3-3c). After some rearrangement, we obtain the desired form:

$$
\frac{\alpha}{\mathrm{RT}_{\max } 2}=\frac{\mathrm{A}}{\mathrm{E}_{\mathrm{d}}} \exp \left(-\frac{\mathrm{E}_{\mathrm{d}}}{\mathrm{RT}_{\max }}\right)
$$

Eq. (6.3-5) allows a graphical solution where plotting $\ln \left(\alpha / \mathrm{RT}_{\max }{ }^{2}\right)$ against $1 / \mathrm{RT}_{\max }$ should yield a line with slope $-E_{d}$ and intercept $\ln \left(A / E_{d}\right)$. It is also worth noting that for first-order desorption kinetics, $T_{\max }$ is independent of surface coverage for a given value of $E_{d}$.

The above model is a quick method for estimating kinetic parameters, requiring a minimal amount of experimental effort. It appears especially well-suited for TGA work, and may be useful for comparing a wide range of different adsorbates. The literature also mentions more complicated scenarios: higher-order desorption kinetics (Redhead, 1962), discrete versus continuum energies of binding sites (Carter, 1962), and surface reaction with de:orption of both reactants and products (Perrard and Joly, 1989).

\subsubsection{Sample Data - Effect of Heating Rate on $\mathbf{T}_{\max }$}

Figure 6.3-10 shows TGA derivative plots of heat-treated F400 loaded with aqueous EG $\left(\mathrm{q}=23 \mathrm{mg} / \mathrm{g}\right.$ ), at $10^{\circ} \mathrm{C}, 20^{\circ} \mathrm{C}$, and $40^{\circ} \mathrm{C} / \mathrm{min} . \mathrm{T}_{\max }$ increased with the heating rate, which is expected due to the kinetic limitations associated with desorption. The results, along with a separate experimental run at $5^{\circ} \mathrm{C} / \mathrm{min}$, are summarized in Table 6.3-1 below: 


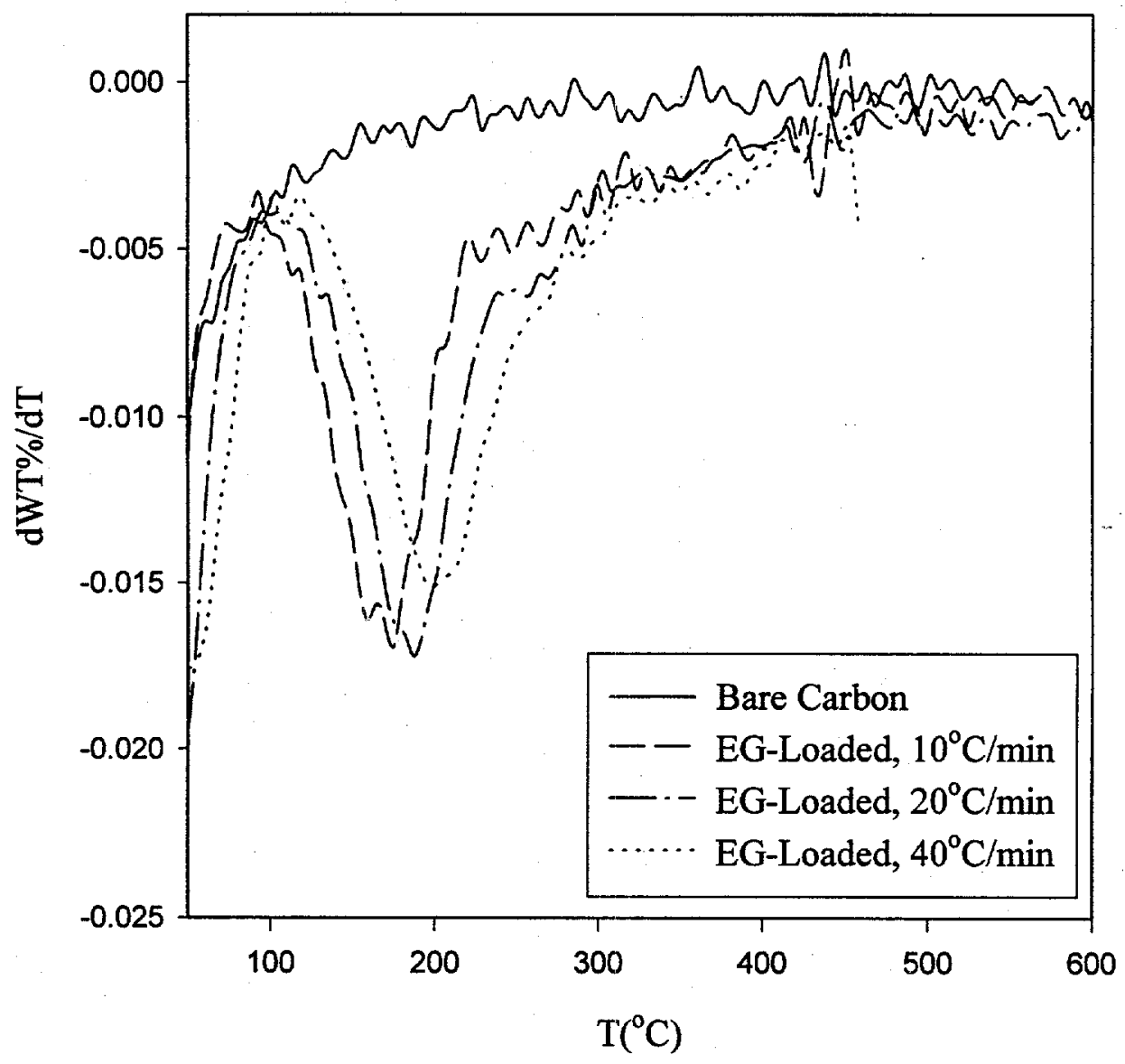

Figure 6.3-10. TGA derivative plots of EG-loaded ( $\mathrm{q}=23 \mathrm{mg} / \mathrm{g}$ ) F400/HT carbon at $10^{\circ} \mathrm{C}, 20^{\circ} \mathrm{C}$, and $40^{\circ} \mathrm{C} / \mathrm{min}$, with bare carbon reference. 
TABLE 6.3-1

Effect of Heating Rate on $\mathrm{T}_{\max }$ of EG-Loaded F400/HT

\begin{tabular}{|c|c|}
\hline$\alpha\left({ }^{\circ} \mathrm{C} / \min \right)$ & $\mathrm{T}_{\max }\left({ }^{\circ} \mathrm{C}\right)$ \\
\hline 5 & $158.22(431.37 \mathrm{~K})$ \\
\hline 10 & $175.30(448.45 \mathrm{~K})$ \\
\hline 20 & $187.31(460.46 \mathrm{~K})$ \\
\hline 40 & $199.82(472.97 \mathrm{~K})$ \\
\hline
\end{tabular}

Figure 6.3-11 shows that the linear regression procedure in accord with eq. (6.3-12). The fit is good, yielding a calculated value for $E_{d}$ of $77( \pm 9 \%) \mathrm{kJ} / \mathrm{mol}$. The fact that $T_{\max }$ is relatively independent of loading (refer to Figure 6.3-1) is further support that the data appear to follow first-order desorption kinetics. The value for the pre-exponential factor (A) is $9 \times 10^{6} \mathrm{~s}^{-1}$; however, it is subject to a much greater uncertainty. A standard error of $11 \%$ in the intercept corresponds to an error of nearly $460 \%$ for the parameter $A$, which means it could vary between $1.6 \times 10^{6}$ to $5.2 \times 10^{7} \mathrm{~s}^{-1}$. Nevertheless this does not take away the utility of the model, as it is the parameter $E_{d}$ which is of greatest interest. Redhead (1962) suggested that for reasonable accuracy, the heating rate should be varied by at least two orders of magnitude. However, in these experiments only one order of magnitude was achievable.

\subsubsection{Results for Alcohols and Multi - OH Solutes}

The desorption parameters for heat-treated F400 loaded with a variety of alcohols and other multi $-\mathrm{OH}$ solutes were obtained using the previously described methods. In all experiments, three different heating rates $\left(10^{\circ} \mathrm{C}, 20^{\circ} \mathrm{C}\right.$, and $\left.40^{\circ} \mathrm{C} / \mathrm{min}\right)$ were used. Table 


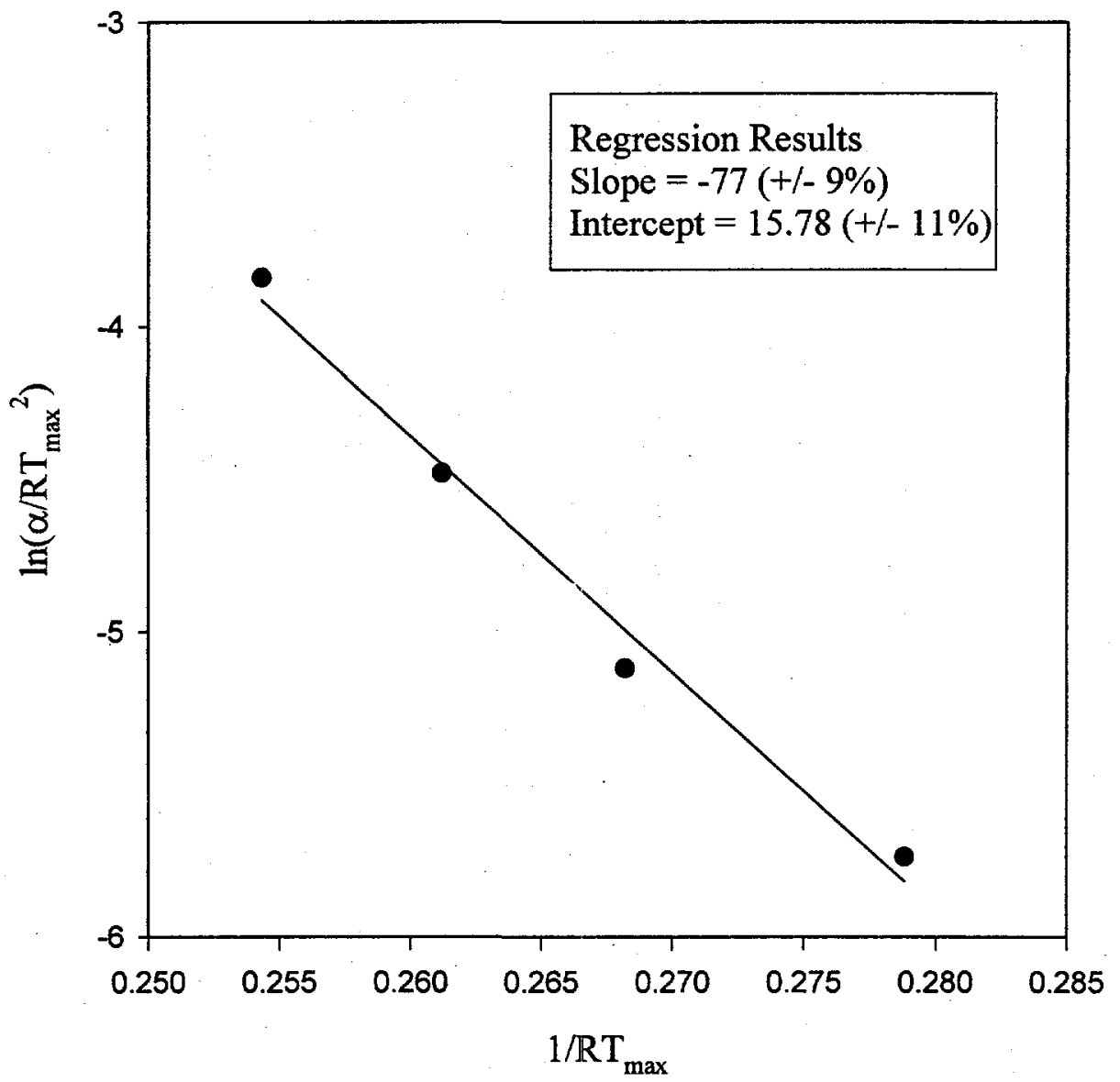

Figure 6.3-11. Linear regression to obtain first-order kinetic parameters for desorption. Data are for EG-loaded ( $\mathrm{q}=23 \mathrm{mg} / \mathrm{g}$ ) F400/HT carbon. 
6.3-2 lists the parameters $E_{d}$ (along with standard error) and the range of $A$ for each solute. Also shown for reference purposes are the molecular weight (MW), normal boiling point $\left(\mathrm{T}_{\mathrm{nbp}}\right)$, and latent heat of vaporization $\left(\Delta \mathrm{H}_{\mathrm{vap}}\right)$ for each solute. $A$ few experiments were also conducted using different adsorbents, most of which had EG as the adsorbate. These results are shown in Table 6.3-3.

TABLE 6.3-2.

Thermal Desorption Parameters of Solutes Loaded on F400/HT

\begin{tabular}{||c|c|c|c|c|c||}
\hline SOLUTE & $\mathrm{MW}$ & $\mathrm{T}_{\mathrm{nbp}}\left({ }^{\circ} \mathrm{C}\right)$ & $\Delta \mathrm{H}_{\mathrm{vap}}(\mathrm{kJ} / \mathrm{mol})$ & $\mathrm{E}_{\mathrm{d}}(\mathrm{kJ} / \mathrm{mol})$ & $\mathrm{A}\left(\mathrm{s}^{-1}\right)$ \\
\hline EtOH & 46 & 78.29 & 38.56 & $37 \pm 12 \%$ & $10^{2}-10^{3}$ \\
\hline 1-PrOH & 60 & 97.20 & 41.44 & $45 \pm 1 \%$ & $10^{3}-10^{4}$ \\
\hline 2-PrOH & 60 & 82.30 & 39.85 & $54 \pm 12 \%$ & $10^{4}-10^{6}$ \\
\hline EG & 62 & 197 & 56.9 & $77 \pm 8 \%$ & $10^{6}-10^{7}$ \\
\hline PG & 76 & 188 & 67 & $65 \pm 12 \%$ & $10^{4}-10^{6}$ \\
\hline Glycerol & 92 & 290 & 76 & $111 \pm 27 \%$ & $10^{6}-10^{11}$ \\
\hline DEG & 106 & 244 & 52.26 & $69 \pm 17 \%$ & $10^{3}-10^{5}$ \\
\hline DPG & 134 & $232-$ & 45.4 & $119 \pm 10 \%$ & $10^{7}-10^{9}$ \\
\hline TPG & 192 & 265 & 35.4 & $123 \pm 4 \%$ & $10^{8}-10^{9}$ \\
\hline
\end{tabular}

TABLE 6.3-3.

Thermal Desorption Parameters of Solutes Loaded on Other Carbons

\begin{tabular}{|c|c|c|c|}
\hline SOLUTE & CARBON & $\mathrm{E}_{\mathrm{d}}(\mathrm{kJ} / \mathrm{mol})$ & $\mathrm{A}\left(\mathrm{s}^{-1}\right)$ \\
\hline EG & RO 0.8 & $61 \pm 3 \%$ & $10^{4}-10^{5}$ \\
\hline EG & WVB & $82 \pm 7 \%$ & $10^{6}-10^{8}$ \\
\hline EG & A563 & $112 \pm 9 \%$ & $10^{9}-10^{12}$ \\
\hline EG & A572 & $87 \pm 16 \%$ & $10^{6}-10^{9}$ \\
\hline EG & A575 & $71 \pm 23 \%$ & $10^{4}-10^{7}$ \\
\hline EtOH & A572 & $37 \pm 5 \%$ & $10^{2}-10^{3}$ \\
\hline EtOH & RO 0.8 & $62 \pm 3 \%$ & $10^{6}-10^{7}$ \\
\hline Glycerol & RO 0.8 & $65 \pm 27 \%$ & $10^{2}-10^{5}$ \\
\hline
\end{tabular}




\subsubsection{Discussion}

As suggested earlier, the large deviation in the pre-exponential factor, A, stems from the standard error of the intercept, which happens to be on a logarithmic scale. An interesting aspect is that for all of the solutes tested, the parameter A is substantially less than the value $10^{13} \mathrm{~s}^{-1}$. This happens to be the theoretical value of the pre-exponential factor for elementary reactions (Ferro-Garcia, et al. 1995). Several authors have suggested that the deviation from theory is due to readsorption of the some of the volatilized solute, made easier by the porous nature of the carbon (Ferro-Garcia et al., 1995; Rivera-Utrilla et al., 1995).

Insights could be gained by comparing the $E_{d}$ for the various solutes. $E_{d}$ represents a characteristic energy barrier that must be exceeded in order for desorption to occur. Two possible components of this energy barrier might be: (1) the energy required to overcome the attractive interactions with the surface, and (2) the intrinsic volatility of the solute, which could also affect the ease of thermal desorption. The fact that many of the solutes have an $E_{d}$ close to, or much greater than the latent heat of vaporization highlights the importance of the first component. The range of $E_{d}$ for all solutes tested $(37-123 \mathrm{~kJ} / \mathrm{mol})$ seems to confirm that bonds between surface and adsorbate are physical, rather than chemical, in nature. In their TGA-MS work with chlorophenols on olive stone carbons, Ferro-Garcia et al. (1995) found an $E_{d}$ value of $67 \mathrm{~kJ} / \mathrm{mol}$ for the physisorbed fraction and a much larger value of $236 \mathrm{~kJ} / \mathrm{mol}$ for the chemisorbed fraction that decomposed into light gases. 
If the primary mechanism of adsorption is dispersion interactions, then we might expect an increase of $E_{d}$ with the molecular weight of the solute. Figure 6.3-12 is a linear $\sim$ correlation of $\mathrm{E}_{\mathrm{d}}$ against molecular weight for all of the solutes listed in Table 6.3-2.

Error bars represent the standard error in $E_{d}$, as determined by the linear-regression procedure. The fit is fair $\left(\mathrm{r}^{2}=0.70\right)$, showing that molecular weight does influence the magnitude of $\mathrm{E}_{\mathrm{d}}$ for alcohols and multi $-\mathrm{OH}$ solutes. The results agree with the findings reported in Figures 6.3-6 and 6.3-7, in that molecular weight, rather than the number of $-\mathrm{OH}$ groups on an adsorbate, has a greater contribution in determining the strength of the solute-surface interactions.

\subsubsection{Thermal Stability of Adsorbed Phase - Summary}

The present TGA work, combined with related findings from the literature, has shown that alkanes and alcohols have lower volatility (relative to that of the bulk liquid state) than multi $-\mathrm{OH}$ solutes when adsorbed onto carbons. These results support some of the key findings from Chapter 4 , in that the main adsorption mechanism appears to be dispersion and/or hydrophobic interactions. The $-\mathrm{OH}$ group appears to result in a greater volatility of the adsorbed solute, relative to the liquid state. The exception is with glycol polymers, which have multiple $-\mathrm{OH}$ groups but sufficiently high molecular weight for strong dispersion interactions. Glycol polymers have fewer $-\mathrm{OH}$ groups in proportion to molecular weight than do the corresponding glycols. Calculated values of the activation energy for desorption $\left(E_{d}\right)$ for various alcohols and multi $-\mathrm{OH}$ compounds also confirm the importance of dispersion interactions for thermal stability. 


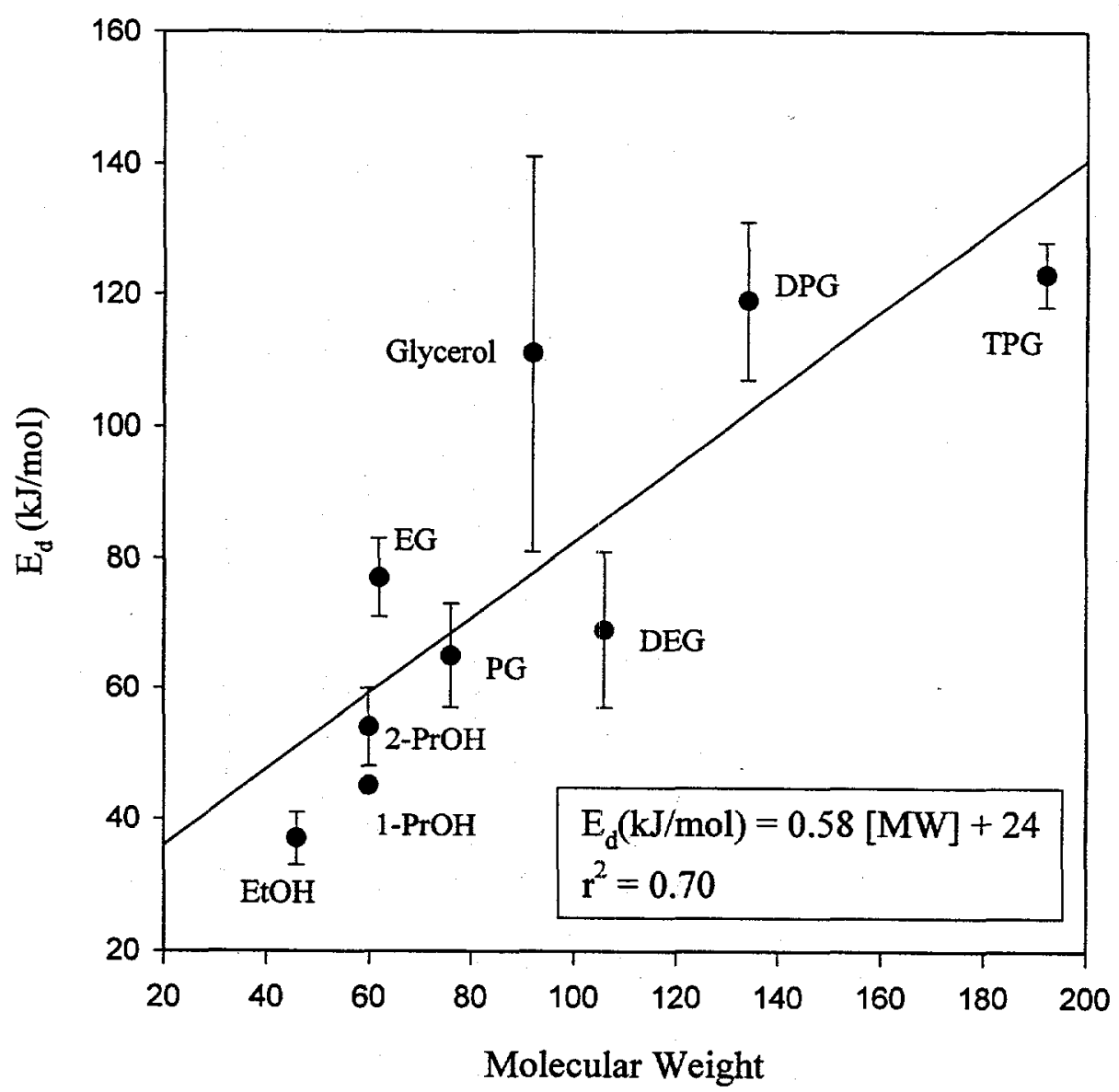

Figure 6.3-12. Linear correlation of $E_{d}(\mathrm{~kJ} / \mathrm{mol})$ and molecular weight for compounds loaded on F400/HT carbon. 


\section{References for Chapter 6}

Bandu, M.; Le Cloirec, P.; Martin, G. Wat. Res., 1993, 27(1), 69-76.

Carter, G. Vacuum, 1962, 12, 245-254.

Ferro-Garcia, M.A.; Utrera-Hildago, E.; Rivera-Ultrilla, J.; Moreno-Castilla, C.; Joly, J.P. Carbon, 1993, 31(6), 857-863.

Ferro-Garcia, M.A.; Utrera-Hildago, E.; Rivera-Ultrilla, J.; Moreno-Castilla, C. Langmuir, 1995, 11, 2648-2651.

Martin, R.J.; Ng, W.J. Water Res., 1985, 12(12), 1527-1535.

Perrard, A.; Joly, J.P. Vacuum, 1989, 39(6), 551-556.

Redhead, P.A. Vacuum, 1962, 12, 203-211.

Rivera-Utrilla, M.; Ferro-Garcia, M.A.; Moreno-Castilla, C.; Bautista-Toledo, I. J. Chem. Soc. Faraday Trans., 1995, 91(18), 3213-3217.

Senf, L.; Frank, H. Journal of Chromatography, 1990, 520, 131-135.

Suzuki, M.; Misic, D.M.; Koyama, O.; Kawazoe, K. Chemical Engineering Science, 1978, 33, 271-279. 


\section{Chapter 7. Fixed-Bed Adsorption and Regeneration}

\subsection{Overview}

This chapter presents fixed-bed experiments for the adsorption of ethylene and propylene glycol, glycerol, sorbitol, and sucrose from dilute aqueous solution onto activated carbon. Once the adsorbent bed was loaded, recovery of the solute was effected by solvent leaching. Several operating parameters were varied in order to attain an optimum recovery: choice of adsorbent and regenerant, volumetric flowrate, and particle-size distribution. We also explored the efficiency of running the fixed-bed over many cycles for the recovery of ethylene glycol. Lastly, we extended the work from single-solute systems to two-solute systems.

The reader is referred to Section 2.6 for description of the apparatus and procedures for running both fixed-bed adsorption and regeneration experiments.

\subsection{Fixed-Bed Loading: Breakthrough Analysis}

\subsubsection{Representative Data}

Figure 7.2-1 shows representative loading curves for aqueous ethylene giycol (EG), propylene glycol (PG), and glycerol, with heat-treated F400 carbon as the adsorbent in all three cases. These curves represent the dynamic response of the effluent concentration following a step input of aqueous-feed solution at "zero" bed volume (see section 2.6). When the adsorbent approaches its equilibrium capacity for the solute, the effluent concentration begins to rise. Over time, the composition the effluent matches that of the 


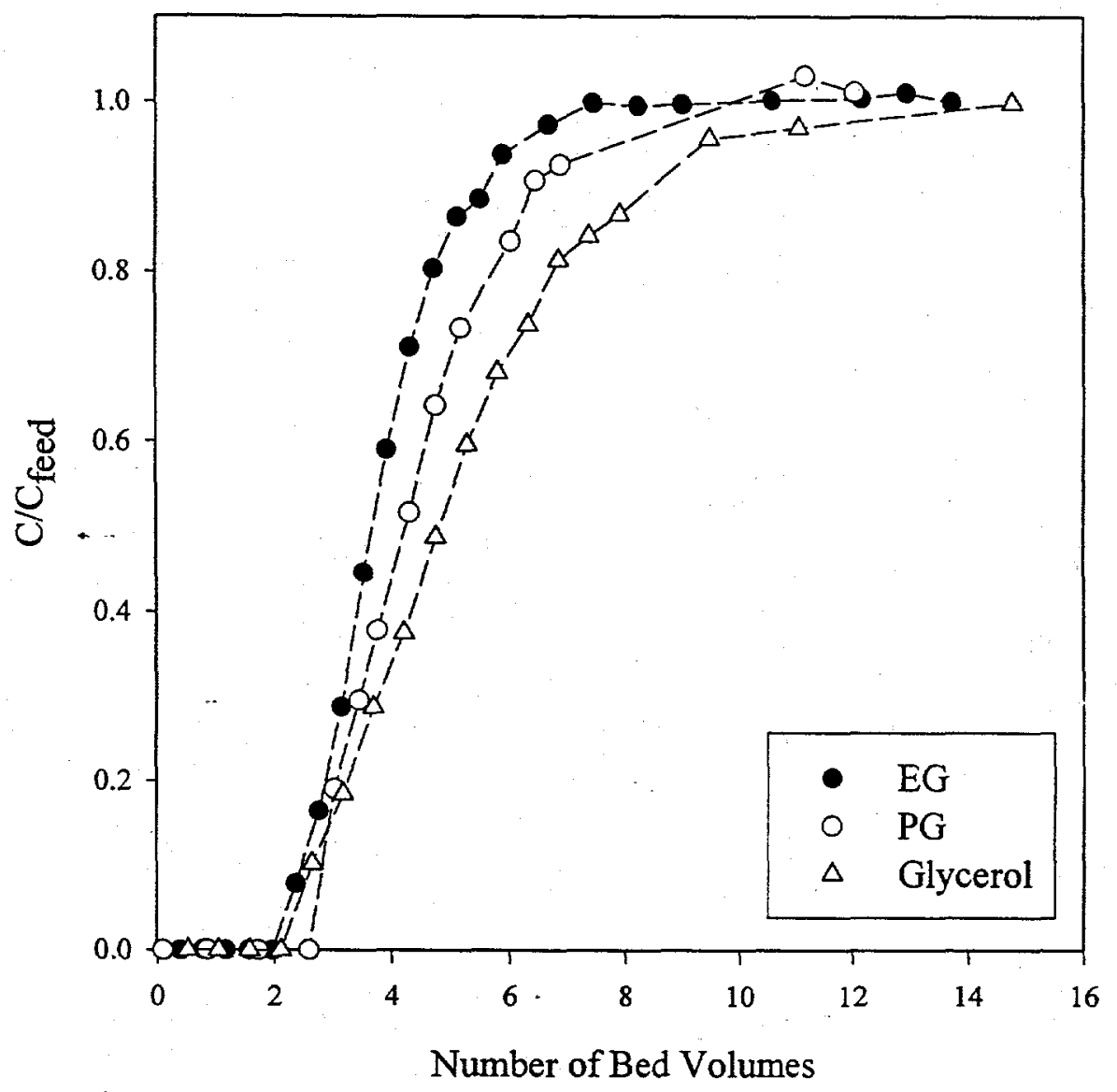

Figure 7.2-1. Three separate experiments showing breakthrough curves for ethylene glycol (EG), propylene glycol (PG), and glycerol on heat-treated F400 carbon. Operating parameters listed in Table 7.2-1. 
aqueous feed, which signifies complete breakthrough of the solute. The actual operating parameters of the data shown in Figure 7.2-1 are summarized below:

TABLE 7.2-1

Fixed-Bed Operating Parameters for Data in Figure 7.2-1

\begin{tabular}{|c|c|c|c||}
\hline SOLUTE & $\begin{array}{c}\text { SIZE OF 1 BED } \\
\text { VOLUME }\left(\mathrm{cm}^{3}\right)\end{array}$ & $\begin{array}{c}\mathrm{C}_{\text {feed }} \\
(\mathrm{g} / \mathrm{mL})\end{array}$ & $\begin{array}{c}\text { FLOWRATE } \\
(\mathrm{mL} / \mathrm{min})\end{array}$ \\
\hline EG & 8.05 & 0.04591 & 1.58 \\
\hline PG & 6.68 & 0.0505 & 1.54 \\
\hline Glycerol & 6.21 & 0.0275 & 1.64 \\
\hline
\end{tabular}

\subsubsection{Shape of the Breakthrough Curves}

Physical insights onto the transport mechanisms can be inferred from the shape of the region of the breakthrough curve where the solute concentration rises to the feed concentration. For the conditions when the adsorption equilibrium is favorable, the shape of the breakthrough curve approaches a step function in the limit of negligible mass transfer resistance and axial dispersion (Sherwood et al., 1975; Wankat, 1990). Conditions are "favorable" when the slope of the adsorption isotherm at the feed concentration is lower than the isotherm slope at the initial fluid concentration in the bed (Sherwood et al., 1975).

In the limiting case where the solid and fluid are locally in equilibrium: (1) mass transfer effects can be ignored, and (2) axial dispersion are negligible (Wankat, 1990). The solute concentration will therefore increase abruptly from zero to that of the feed upon breakthrough. The deviations of the experimental curves from a perfect step-function response are due to several factors. Axial dispersion and (internal and/or external) mass 
transfer limitations of the solute can cause the profiles to spread, resulting in longer times for complete breakthrough. For example, imperfect packing of the bed could cause the fluid velocity across the bed diameter to vary due to the formation of multiple paths. Fluid could therefore move more rapidly by channeling through regions of lower resistance or lag behind when trapped in stagnant areas (Johnson and Stevenson, 1978).

\subsubsection{Theoretical-Plate Concepts from Chromatography}

Further understanding of the dynamics of fixed-bed processes can be gained from the theoretical-plate concepts of chromatography. In chromatography theory the efficiency of a packed column for a given separation is governed by how low the HETP (height of a theoretical plate) is. The HETP is defined as the bed length $(\mathrm{mm})$ divided by the number of theoretical plates. Johnson and Stevenson (1978) give one mathematical form for HETP:

$$
\mathrm{HETP}=\mathrm{H}_{\mathrm{p}}+\mathrm{H}_{\mathrm{d}}+\mathrm{H}_{\mathrm{s}}+\mathrm{H}_{\mathrm{m}}
$$

$H_{p}$ is the contribution from non-uniform paths for flow:

$$
H_{p}=2 \lambda d_{p}
$$

where $d_{p}$ is the particle diameter; $\lambda$ is a constant close to unity that can be reduced with narrower particle-size distributions. 
$H_{d}$ is the contribution from axial dispersion:

$$
\mathrm{H}_{\mathrm{d}}=\frac{2 \gamma \mathrm{D}_{\mathrm{m}}}{\mathrm{v}}
$$

where $D_{m}$ is the diffusivity of the solute in the mobile phase, $v$ is the flow velocity, and $\gamma$ is a tortuosity factor $(>1)$ related to the column packing.

$\mathrm{H}_{\mathrm{s}}$ and $\mathrm{H}_{\mathrm{m}}$ are contributions from mass-transfer rates in the solid and fluid phase, respectively:

$$
\begin{aligned}
& \mathrm{H}_{\mathrm{s}}=\frac{\mathrm{QRD}^{2} \mathrm{v}}{\mathrm{D}_{\mathrm{s}}} \\
& \mathrm{H}_{\mathrm{m}}=\frac{\omega \mathrm{d}_{\mathrm{p}}^{2} \mathrm{v}}{\mathrm{D}_{\mathrm{m}}}
\end{aligned}
$$

where $Q$ is a configuration factor which depends upon the shape of the pool of stationary phase, $\mathrm{R}$ is a constant dependent upon the relative migration rate of solute in the mobile phase, $D$ is the thickness of the stationary phase, $D_{s}$ is the diffusivity of the solute in the stationary phase, and $\omega$ is the column coefficient that decreases when the bed packing is regular and tightly packed. 
To test for the importance of axial dispersion, we conducted breakthrough experiments of a $5 \mathrm{wt}$ \% EG solution for a heat-treated F400 bed at various flowrates (see Figure 7.2-2). In all experiments, a bed length of about $19 \pm 2 \mathrm{~cm}$ was used. As shown in Figure 7.2-2, spreading of the breakthrough curve was largest for the lowest flowrate of 3 bed volumes $/ \mathrm{hr}(0.33 \mathrm{~mL} / \mathrm{min})$. However, the sharpness of the breakthrough curves did not appear to change significantly among the higher flowrates of 6 to 34 bed volumes $/ \mathrm{hr}(0.67-3.64 \mathrm{~mL} / \mathrm{min})$. This suggests that axial dispersion is dominant at extremely low flowrates; however, at higher flowrates both axial dispersion and mass transfer resistance become important.

Figure 7.2-3 shows a result of a parallel experiment where a $5 \mathrm{wt}$ \% EG solution was passed through two separate beds: one packed with heat-treated F400 $(22.4 \mathrm{~cm})$, and the other packed with as-received Ambersorb $572(18 \mathrm{~cm})$. Despite similar volumetric flowrates, the differences between the two breakthrough curves are striking. The bed packed with Ambersorb 572 exhibited a nearly perfect step-function compared to the carbon bed. One possible explanation is that nearly uniform size of the Ambersorb particles allowed for more efficient packing, which reduces the degree of axial dispersion due to multiple paths for fluid flow. As the Ambersorbs were engineered with a more homogeneous surface and porosity, rates of mass transfer might also be faster and more uniform than in activated carbons. 


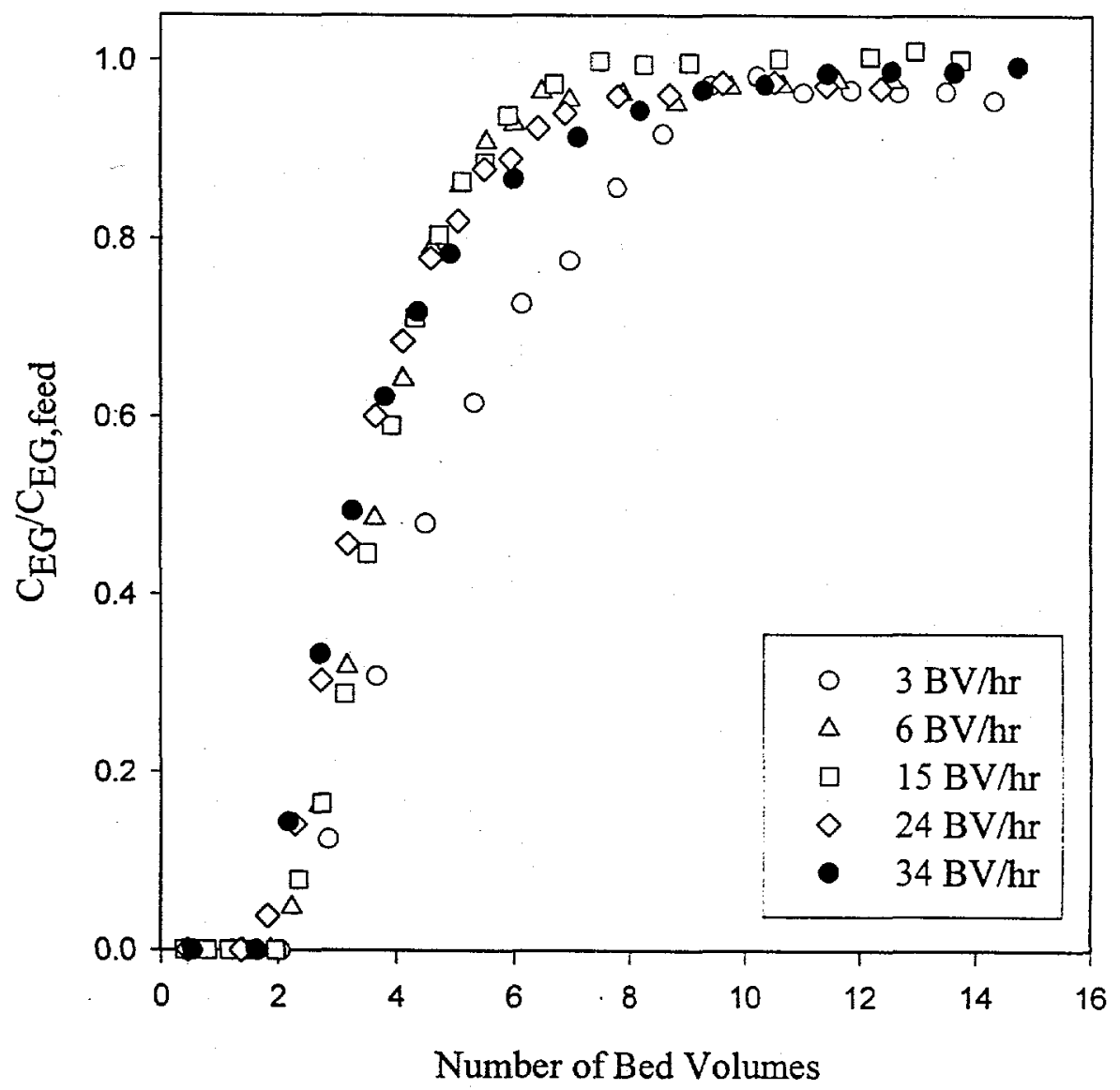

Figure 7.2-2. Effect of volumetric flowrate on the breakthrough curves of $5 \mathrm{wt} . \%$ ethylene glycol (EG) on heat-treated F400 carbon. 


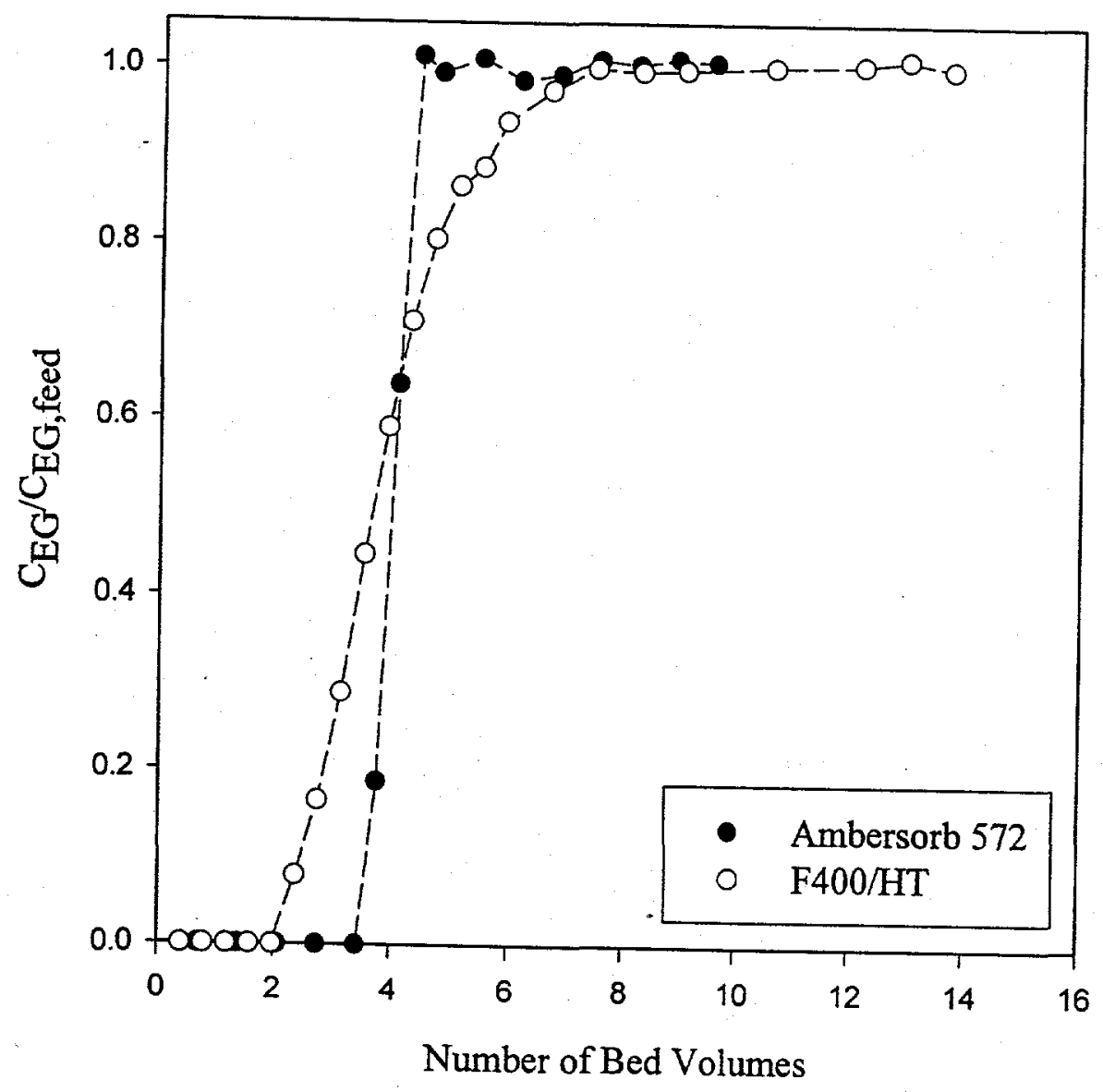

Figure 7.2-3. Comparison of breakthrough curve of 5 wt. \% ethylene glycol (EG) on Ambersorb 572 versus heat-treated F400 carbon. 


\subsection{Fixed-Bed Solvent Regeneration: Elution Analysis}

\subsubsection{Representative Data - Focusing Effect}

Figure 7.3-1 shows representative elution curves for aqueous ethylene glycol (EG), propylene glycol (PG), and glycerol, with heat-treated F400 carbon as the adsorbent in all three cases. These curves represent the dynamic response of the effluent concentration upon a step input of regenerant to a bed previously loaded from the breakthrough experiment. The data in Figure 7.3-1 were obtained using the loaded beds shown in Figure 7.2-1. For all three experiments shown, the volumetric flowrate was not changed between the loading and regeneration stages. Acetone was used for desorbing EG and PG, while methanol was used for the glycerol-loaded bed.

The elution profiles are of a peculiar shape. The first bed volume of fluid eluted corresponds to the displacement of the aqueous feed solution (for which $\mathrm{C} / \mathrm{C}_{\text {feed }}=1$ ) from the earlier breakthrough experiment. Afterwards, the solute concentration rises sharply to about three times the original aqueous-feed concentration. This effect is called "focusing," (Wankat, 1990) and is due to the large shift in adsorption equilibrium upon replacement of the original water with an organic solvent. The conditions in the presence of the solute now favor desorption of the solute, which becomes trapped vetween the regenerant front entering and the aqueous front leaving. With time, the solute accumulates ahead of the regenerant front, which results in the large concentration peaks seen in Figure 7.3-1. When nearly all of the solute is finally removed from the bed, the effluent concentration profile gradually falls to zero. The results in Figure 7.3-1 show that between 3-4 bed volumes are required for reducing the solute concentration to zero. 


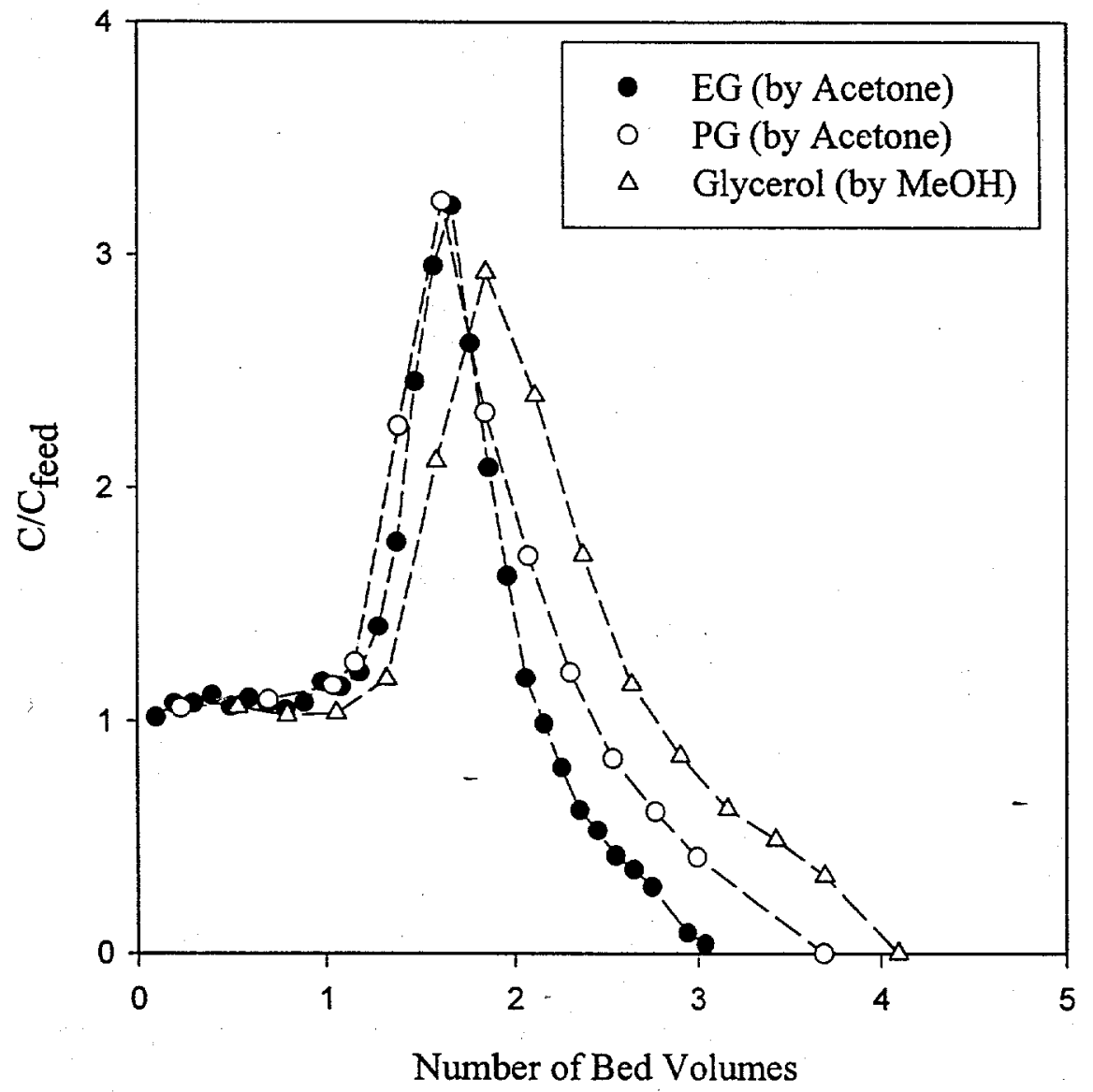

Figure 7.3-1. Three separate experiments showing elution curves, during solvent regeneration, for ethylene glycol (EG), propylene glycol (PG), and glycerol on heattreated F400 carbon. 
Experimental work on other aqueous solutes (e.g. sucrose and sorbitol) also revealed sharp focusing effects with the appropriate choice and concentration of regenerant. An experiment where a heat-treated $\mathrm{F} 400$ bed loaded with aqueous sucrose was regenerated by 5 wt. \% ethyl acetate showed no focusing in the elution curve. Instead, a plateau in the concentration profile (probably due to sucrose displacement at the level of its solubility by the displacer) was observed, followed by a gradual descent to zero. In order to achieve a focusing effect, the organic displacer in the regeneration solvent must have a high enough capacity to insure complete desorption of solute upon each incremental bed volume.

Figures 7.3-2 and 7.3-3 show focusing effects for regeneration of heat-treated F400 beds loaded with aqueous sucrose and sorbitol, respectively. A regenerant composed of about $85 \mathrm{wt} . \%$ acetone in water was used to elute sucrose, whereas $75 \mathrm{wt} . \%$ methanol in water solution was chosen for sorbitol recovery. Also shown in both figures is the breakthrough of the organic displacer, which appears to begin when the solute concentration is maximum. The degrees of focusing are comparable to the results of Figure 7.3-1, although the effect appears greater for sucrose, where the peak concentration is four times the original feed concentration. However, unlike the EG, PG, and glycerol elution profiles, complete removal of sucrose or sorbitol requires substantially more bed volumes of regenerant. A small, but finite amount of solute was still detectable after 6 bed volumes. One jossible explanation is the high affinity of carbons for sugars. Recall from Chapter 4, that the isosteric enthalpy of adsorption for sucrose is substantially higher than those for $\mathrm{C}_{2}-\mathrm{C}_{3}$ alcohols and other multi $-\mathrm{OH}$ solutes. 


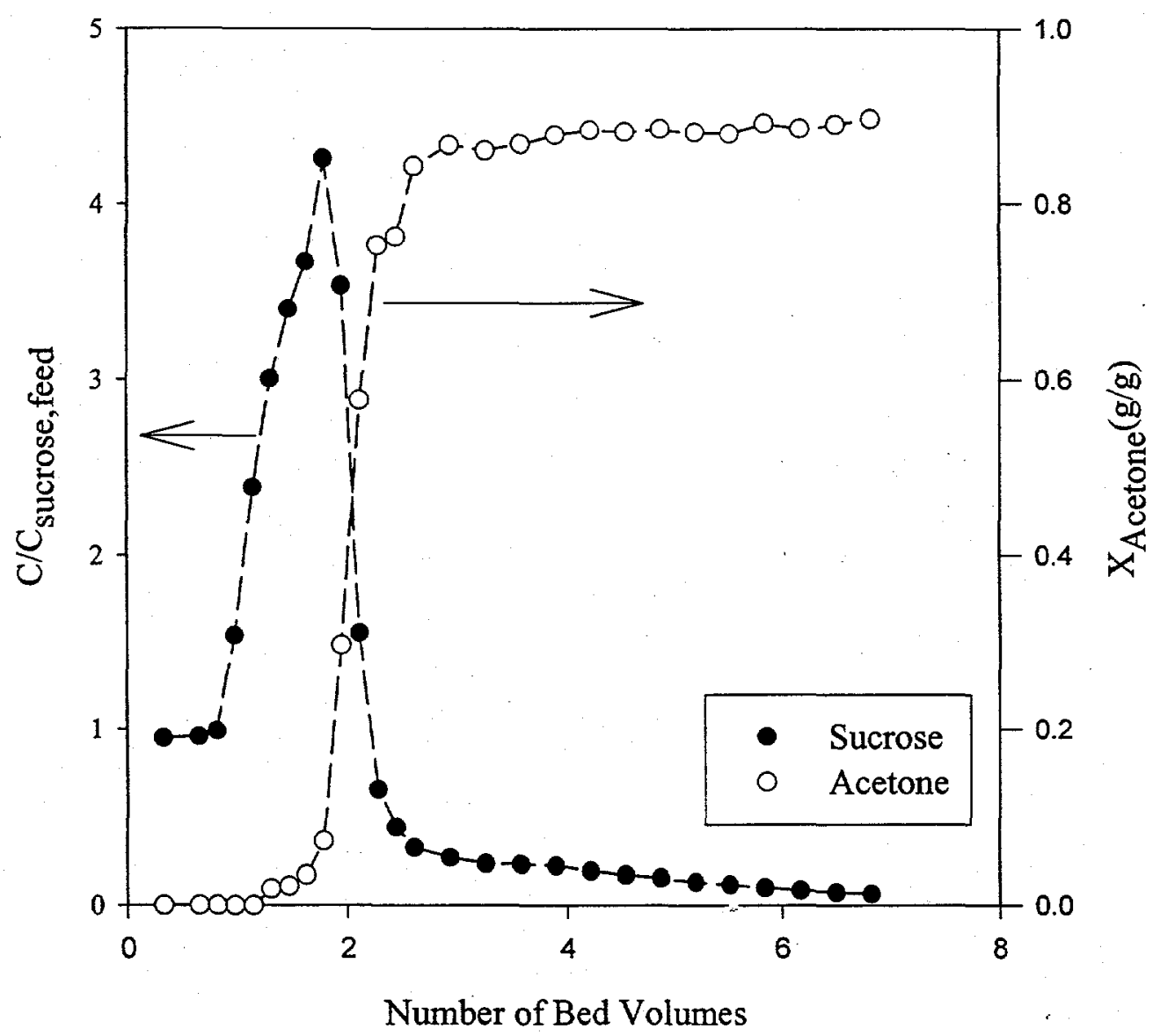

Figure 7.3-2. Fixed-bed solvent regeneration of sucrose from heat-treated F400 carbon, using $85 \mathrm{wt}$. \% acetone in water as the displacer. Also shown is the breakthrough of acetone. 


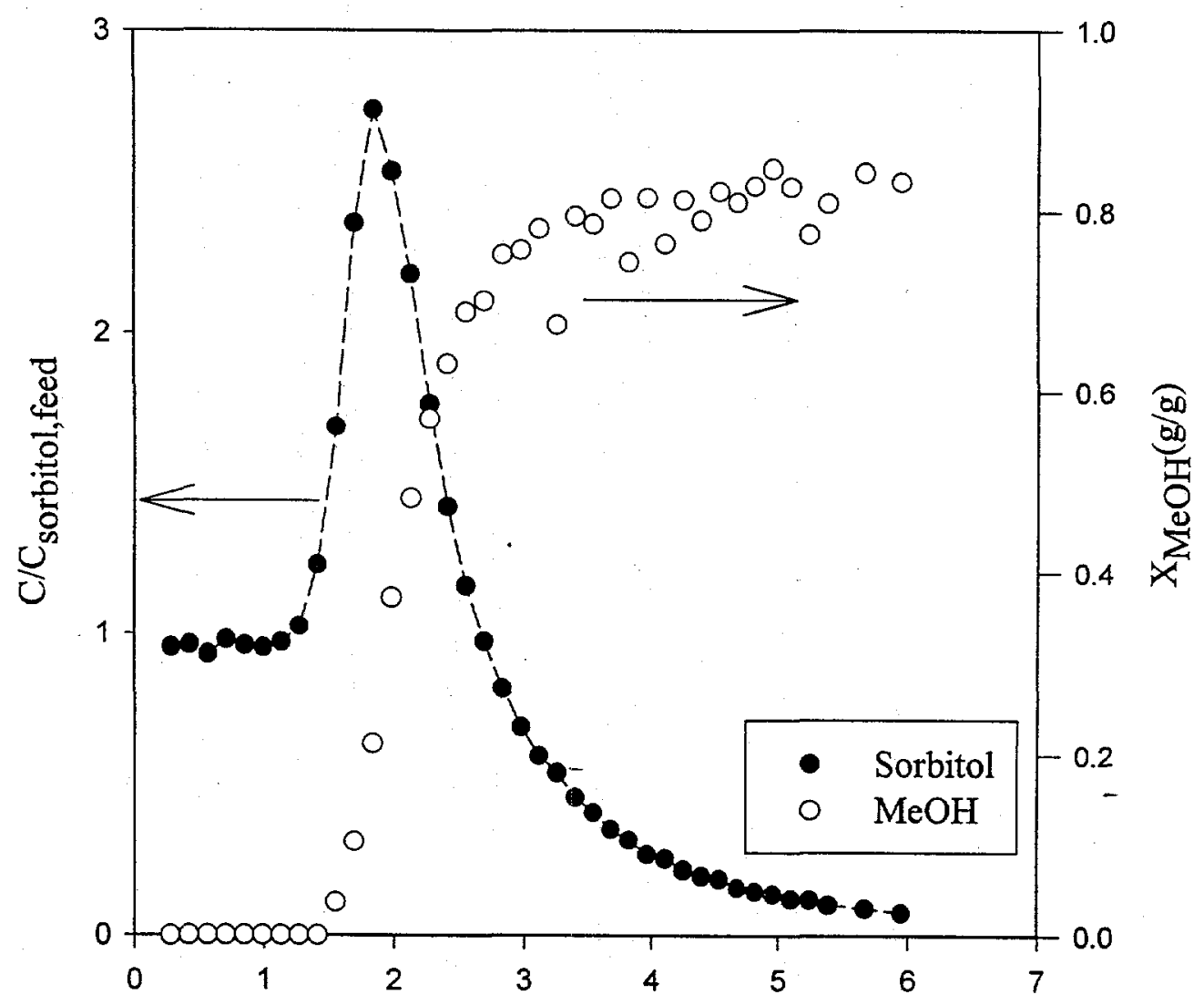

Number of Bed Volumes

Figure 7.3-3. Fixed-bed solvent regeneration of sorbitol from heat-treated F400 carbon, using 75 wt. \% methanol in water as the displacer. Also shown is the breakthrough of methanol. 
A sharper focusing effect might be realized with even more concentrated regeneration solutions.

\subsubsection{Local-Equilibrium Analysis of Focusing Effect}

During solvent regeneration, the concentration profile of the solute can be predicted using local-equilibrium analysis (Wankat, 1990). It is assumed that upon breakthrough of the regenerant, there is an abrupt change from a water-solute-carbon to a organic-solutecarbon adsorption equilibrium. From local-equilibrium analysis, one may predict: (1) the new solute concentration due to the focusing effect, and (2) the degree of tailing in the concentration profile after the focusing concentration is reached. As an example, we study the glycerol-methanol-F400/HT system shown in Figure 7.3-1. The parameters used for the analysis are listed in Table 7.3-1 below.

TABLE 7.3-1

Local Equilibrium Analysis for Glycerol Recovery by Methanol Regeneration: Parameters

\begin{tabular}{||c|c|c||}
\hline PARAMETER & SYMBOL & VALUE \\
\hline Bed Length $(\mathrm{cm})$ & $\mathrm{L}$ & 17.2 \\
\hline Interstitial Porosity & $\mathrm{e}_{\mathrm{e}}$ & 0.46 \\
\hline Intraparticle Porosity & $\mathrm{e}_{\mathrm{p}}$ & $0.57^{*}$ \\
\hline Carbon Skeletal Density $\left(\mathrm{g} / \mathrm{cm}^{3}\right)$ & $\mathrm{p}$ & $1.82^{*}$ \\
\hline Interstitial Velocity $\left(\mathrm{cm} / \mathrm{min}^{3}\right)$ & $\mathrm{v}$ & 4.54 \\
\hline $\begin{array}{c}\text { Feed Glycerol Concentration } \\
\left(\mathrm{g} / \mathrm{cm}^{3}\right)\end{array}$ & $\mathrm{C}_{1}$ & 0.0275 \\
\hline $\begin{array}{c}\text { Glycerol-Water Equilibrium } \\
\mathrm{q}(\mathrm{g} / \mathrm{g}) ; \mathrm{C}\left(\mathrm{g} / \mathrm{cm}^{3}\right)\end{array}$ & $\mathrm{q}_{1}$ & $\mathrm{q}=0.417 \mathrm{C}^{0.441}$ \\
\hline $\begin{array}{c}\text { Glycerol-Methanol Equilibrium } \\
\mathrm{q}(\mathrm{g} / \mathrm{g}) ; \mathrm{C}\left(\mathrm{g} / \mathrm{cm}^{3}\right)\end{array}$ & $\mathrm{q}_{2}$ & $\mathrm{q}=0.475 \mathrm{C}^{0.864}$ \\
\hline \hline
\end{tabular}

*Typical value for coal-based carbons, taken from Wankat (1990) 
The focusing concentration is determined from a mass balance over a differential length $(\Delta \mathrm{z})$ of loaded bed, when in the time interval, $\Delta \mathrm{t}$, the solvent has changed from an aqueous to an organic one. The subscript, " 1 " represents the (initial) conditions for the aqueous system, while " 2 " represents the (final) conditions for the organic system.

$$
\begin{aligned}
& \text { IN - OUT = ACCUMULATION (IN SOLID + FLUID) } \\
& e_{e} v \Delta t\left(C_{2}-C_{1}\right)=\Delta z\left[e_{e}\left(C_{2}-C_{1}\right)+\left(1-e_{e}\right)\left(1-e_{p}\right) p\left(q_{2}-q_{1}\right)\right]
\end{aligned}
$$

The solvent velocity is the same as the interstitial velocity, hence $\Delta z / \Delta t=v$. After some simplification, we obtain:

$$
\left(1-e_{e}\right)\left(1-e_{p}\right) \rho\left(q_{2}-q_{1}\right)+e_{p}\left(1-e_{e}\right)\left(C_{2}-C_{1}\right)=0
$$

The solute concentration at a point in the bed will be $C_{1}$ until methanol passes through, where the concentration then increases to $\mathrm{C}_{2}$. The concentration increase will occur when sufficient time $(\mathrm{L} / \mathrm{v}=3.7$ minutes $)$ has elapsed for methanol to pass through the entire bed. In the glycerol-methanol example, $\mathrm{C}_{2}$ was calculated to be $0.0748 \mathrm{~g} / \mathrm{cm}^{3}$.

Once the concentration $C_{2}$ is reached, the adsorption equilibrium becomes unfavorable, as a solution of higher concentration $\left(\mathrm{C}_{2}\right)$ is displaced from the bed by a solution of lower concentration $(C=0)$. A diffuse wave results where the solute concentration will gradually decay to zero. From local-equilibrium theory, the velocity $\left(\mathrm{u}_{\mathrm{s}}\right)$ of the diffuse wave is concentration-dependent, and has the form (Wankat, 1990): 


$$
u_{s}=\frac{v}{1+\frac{1-e_{e}}{e_{e}} e_{p}+\frac{1-e_{e}}{e_{e}}\left(1-e_{p}\right) \rho \frac{d q_{2}}{d C}}
$$

To determine the concentration profile, one calculates the time, $t=L / u_{s}$ for an arbitrary range of concentrations between 0 and $\mathrm{C}_{2}$.

Figure 7.3-4 compares the experimental elution profile with that predicted from localequilibrium theory for our glycerol-methanol-F400/HT example. There is quantitative agreement between $\mathrm{C}_{2}$ and the actual focusing concentration. However as expected, there is substantial spreading observed at the front and rear of the concentration profiles. The profile shape at either end is likely attributable to axial dispersion, mass-transfer limitations, and the spreading of the solvent-water front. Since it is assumed from localequilibrium theory that the transition in adsorption equilibrium is instantaneous upon breakthrough of the solvent, the diffuse concentration profile calculated from eq. (7.3-3) is much sharper than that observed from experiment.

\subsection{Mass Balances from Fixed-Bed Experiments}

\subsubsection{Mass Balance from Breakthrough Curves}

The total mass of solute loaded onto the fixed-bed is determined by integration of the region bound between the concentration profile and the ordinate ("zero" bed volume) on the breakthrough plot. Since the volumetric flowrate is held constant within a given 


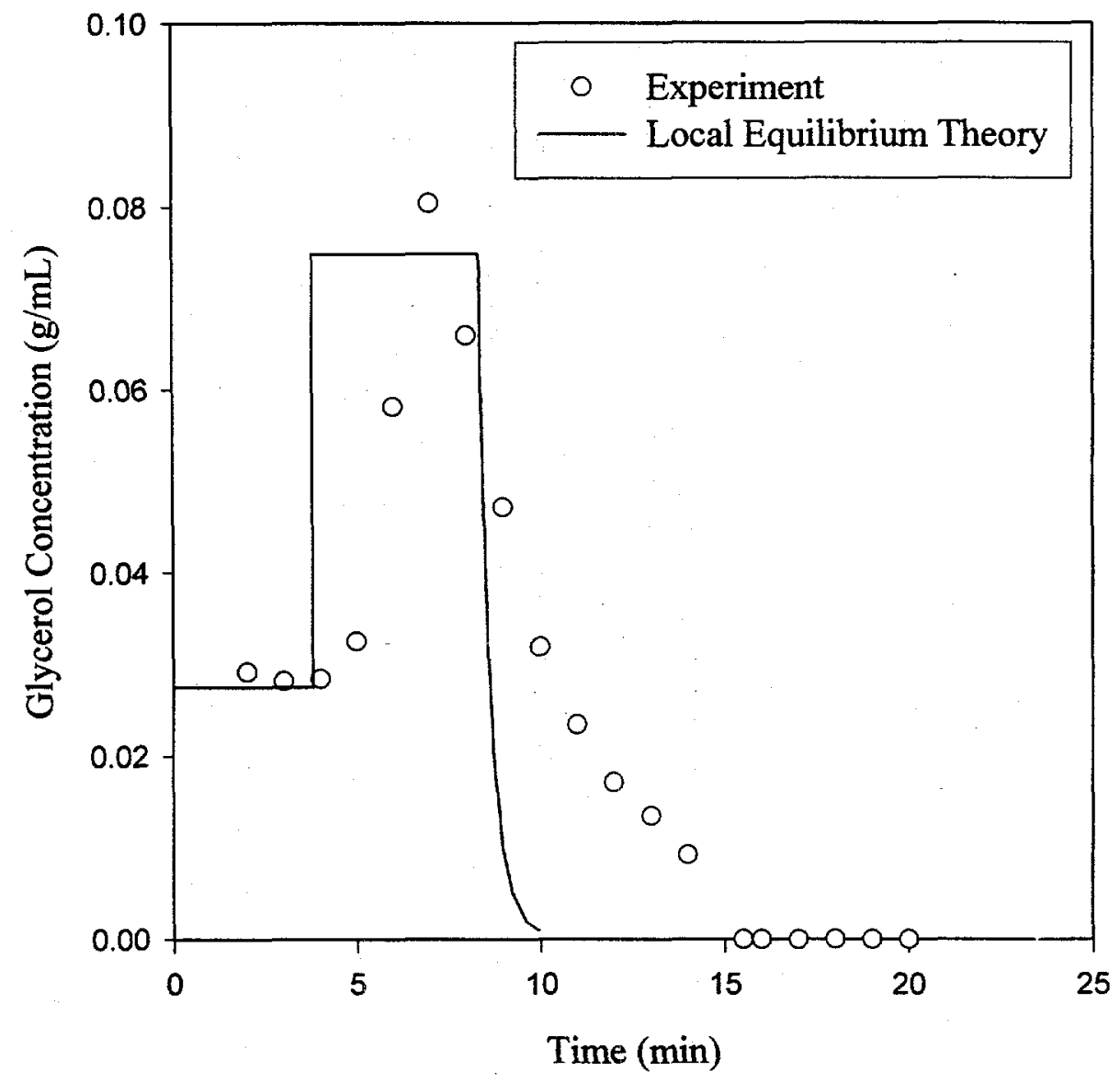

Figure 7.3-4. Local-equilibrium analysis for fixed-bed methanol regeneration of glycerol from $\mathrm{F} 400 / \mathrm{HT}$ carbon. 
experiment, it is appropriate to plot the breakthrough data as $\mathrm{C} / \mathrm{C}_{\text {feed }}$ vs. time ( $\mathrm{t}$ ) for integration:

$$
M_{\text {load }}=C_{\text {feed }} V_{o}\left[t_{F}-\int_{0}^{t_{F}} \frac{C}{C_{\text {feed }}} d t\right]
$$

where $\mathrm{M}_{\text {load }}$ is the total mass $(\mathrm{g})$ of solute distributed between the adsorbent surface, pores, and interstitial space, $\mathrm{C}_{\text {feed }}$ is the solute feed concentration $(\mathrm{g} / \mathrm{mL}), \mathrm{V}_{\mathrm{o}}$ is the volumetric flowrate $(\mathrm{mL} / \mathrm{min})$, and $\mathrm{t}_{\mathrm{F}}$ is the time at the end of the experiment $(\mathrm{min})$, when $C\left(t_{F}\right)=C_{\text {feed }}$

As will be shown in Appendix D, the above integral is easily evaluated using Simpson's rule for numerical integration.

\subsubsection{Mass Balance from Elution Curves}

The total mass of solute removed from the bed is determined by integrating the area under the solute elution curve:

$$
M_{\text {reg }}=V_{o} \int_{0}^{t_{F}} C d t
$$

All symbols are the same as in eq. (7.4-1), except that at $t=t_{F}, C\left(t_{F}\right)=0 . M_{\text {reg }}$ represents the total mass of solute removed, whether it be solute originally adsorbed onto the carbon 
surface, or held within the pores and interstitial spaces. Eq. (7.4-2) is also easily solved with Simpson's Rule (Appendix D). The completeness of the regeneration procedure can therefore be assessed by comparing $M_{\text {load }}$ to $M_{\text {reg. }}$.

\subsubsection{Completeness of Regeneration}

Table 7.4-1 summarizes the calculations using eqs. (7.4-1) and (7.4-2) for several fixedbed results shown thus far.

TABLE 7.4-1

Completeness of Fixed-Bed Regeneration

\begin{tabular}{|c|c|c|c|c|c|}
\hline $\begin{array}{c}\text { SOLUTE/ } \\
\text { REGENERANT }\end{array}$ & FIGURE(S) & $\mathrm{M}_{\text {load }}(\mathrm{g})$ & $\begin{array}{c}m_{\text {bed }}{ }^{*} q_{\text {bed }} \\
(\mathrm{g})\end{array}$ & $\mathrm{M}_{\text {reg }}(\mathrm{g})$ & $\mathrm{M}_{\mathrm{reg}} / \mathrm{M}_{\text {load }}$ \\
\hline EG/Acetone & $7.2-1,7.3-1$ & 1.42 & 0.79 & 1.35 & 0.95 \\
\hline Glycerol/MeOH & $7.2-1,7.3-1$ & 0.89 & 0.52 & 0.83 & 0.93 \\
\hline PG/Acetone & $7.2-1,7.3-1$ & 1.46 & 1.06 & 1.45 & 0.99 \\
\hline EG/Acetone* & $7.2-3$ & 1.49 & 0.92 & 1.47 & 0.99 \\
\hline $\begin{array}{c}\text { Sucrose/ } \\
85 \% \text { Acetone }\end{array}$ & $7.3-2$ & 1.89 & 1.54 & 1.84 & 0.97 \\
\hline $\begin{array}{c}\text { Sorbitol/ } \\
75 \% \mathrm{MeOH}\end{array}$ & $7.3-3$ & 1.55 & 1.35 & 1.52 & 0.98 \\
\hline
\end{tabular}

*For the Ambersorb 572 fixed-bed; all other data are for heat-treated F400 carbon

In addition, $\mathrm{m}_{\text {bed }}{ }^{*} \mathrm{q}_{\mathrm{bed}}$ is defined as the product of the dry carbon mass $(\mathrm{g})$ in the bed and the composite uptake of solute $(\mathrm{mg} / \mathrm{g})$ that is in equilibrium with the aqueous feed solution. The value of $m_{\text {bed }}{ }^{*} q_{\text {bed }}$ for the various solutes range between 55 to $87 \%$ of $\mathrm{M}_{\text {load }}$; hence, most of the overall solute loaded onto the bed is sorbed selectively on the carbon surface. As shown in Table 7.4-1, the mass-balance calculations between the breakthrough and elution experiments are in good agreement. These results also confirm that adsorption of multi $-\mathrm{OH}$ solutes from water onto activated carbons is reversible for 
the most part. Of the total amount of EG (or PG, glycerol, etc.) adsorbed onto carbons, only a small fraction (1-4 wt. \%) does not appear to be amenable to solvent regeneration, as shown by our batch regeneration and TGA experiments.

Figure 7.4-1 shows the TGA derivative plot for an (originally) EG-loaded F400/HT carbon that was regenerated by methanol in a fixed-bed arrangement. The TGA heating rate was $10^{\circ} \mathrm{C} / \mathrm{min}$. Figure 7.4-1 shows that even when a loaded bed is regenerated by an excess amount of regenerant, a small amount of glycol yet remains on the carbon surface. However, in comparison to the total amount of glycol loaded onto this bed $\left(C_{0}=0.0567\right.$ $\left.\mathrm{g} / \mathrm{mL}, \mathrm{M}_{\text {load }}=1.61 \mathrm{~g}, \mathrm{M}_{\text {reg }}=1.53 \mathrm{~g}\right)$, the amount of residual glycol $\left(\mathrm{Q}_{\mathrm{TGA}, \mathrm{R}}=10 \mathrm{mg} / \mathrm{g}\right)$ gives rise to no more than $5 \%$ irreversible adsorption.

\subsubsection{Comparison with Batch Adsorption Data}

Another straightforward method for checking the consistency of the fixed-bed loading data is to compare them with the results predicted from the adsorption isotherms. The individual uptake of solute can be estimated from eq. (2.4.3-6) or from fixed-bed data:

$$
\mathrm{Q}=\frac{\mathrm{M}_{\text {load }}-(\mathrm{BV})\left(\mathrm{C}_{\text {feed }}\right)}{\mathrm{m}_{\text {bed }}}
$$

where BV refers to one bed volume of fluid $\left(\mathrm{cm}^{3}\right)$ and $\mathrm{m}_{\text {bed }}$ is dry mass $(\mathrm{g})$ of carbon used for the bed. The comparisons are shown in Table 7.4-2 below: 


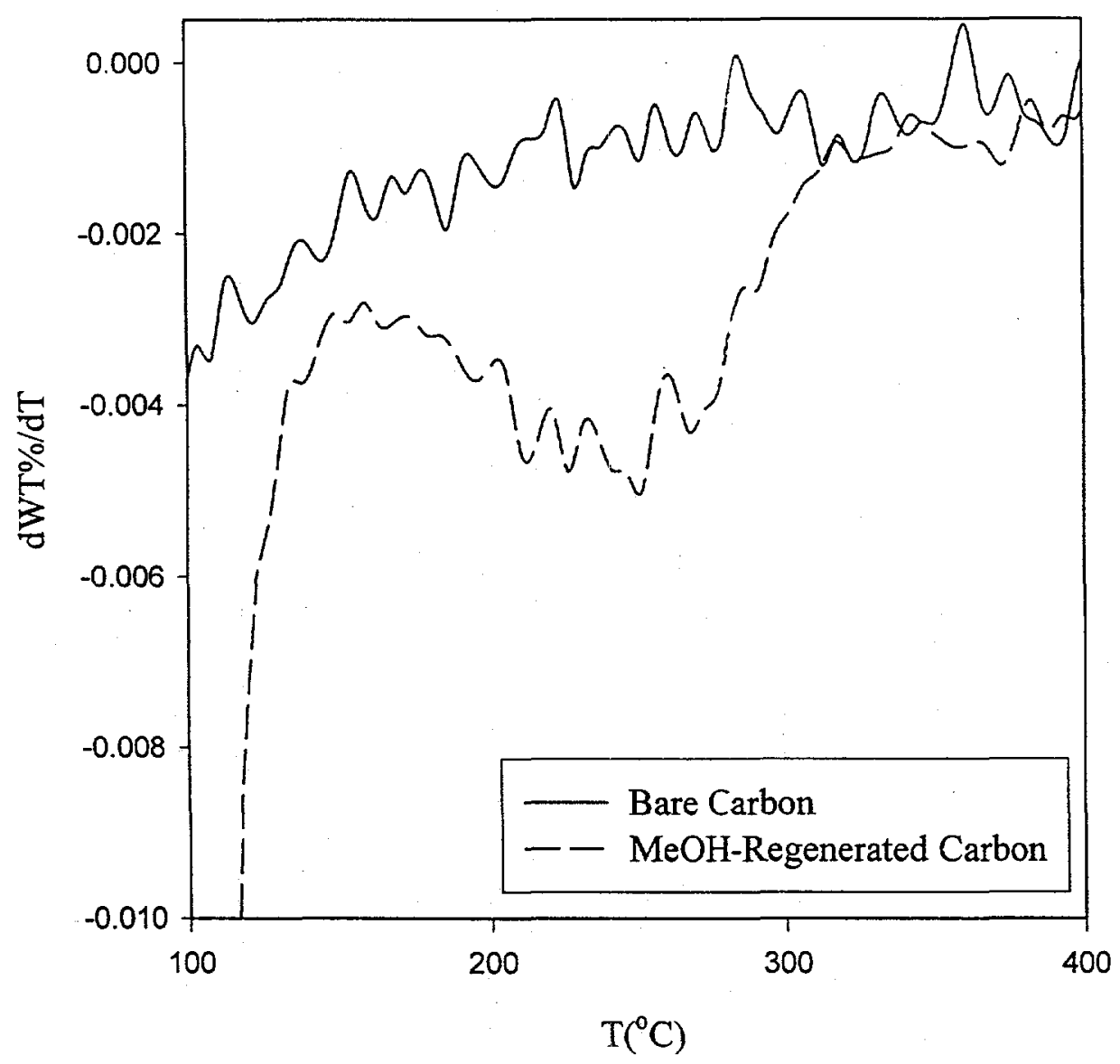

Figure 7.4-1. TGA derivative plot for EG-loaded F400/HT carbon, regenerated by methanol in a fixed-bed. Bare carbon shown for reference. Heating rate: $10^{\circ} \mathrm{C} / \mathrm{min}$. 
TABLE 7.4-2

Comparison between Fixed-Bed and Batch Loading

\begin{tabular}{|c|c|c|c|c||}
\hline $\begin{array}{c}\text { SOLUTE/ } \\
\text { ADSORBENT }\end{array}$ & REFERENCE & $\begin{array}{c}\text { Q(mg/g) } \\
\text { eq. (7.4-3) }\end{array}$ & $\begin{array}{c}\mathrm{Q}(\mathrm{mg} / \mathrm{g}) \\
\text { eq. (2.4.3-6) }\end{array}$ & $\%$ difference \\
\hline EG/F400HT & Fig. 7.2-1 & 136 & 138 & +1.5 \\
\hline Glycerol/F400HT & Fig. 7.2-1 & 125 & 118 & -6 \\
\hline PG/F400HT & Fig. 7.2-1 & 180 & 205 & +14 \\
\hline EG/A572 & Fig. 7.2-3 & 176 & 189 & +7 \\
\hline Sucrose/F400HT & Tab. 7.4-1* & 274 & 266 & -3 \\
\hline Sorbitol/F400HT & Tab. 7.4-1* & 217 & 272 & +25 \\
\hline
\end{tabular}

*Breakthrough curves are not shown, although calculations for $\mathrm{M}_{\text {load }}$ are in Table 7.4-1

The agreement between the fixed-bed and batch-equilibrium loading of multi-OH solutes is reasonable, considering the experimental error, assumptions used in eq. (2.4.36), and possible batch-to-batch variability for activated carbons. The results for sorbitol appear to have a larger deviation than the other solutes, which is likely attributed to uncertainties in the batch experiments rather than a failure of the bed to equilibrate with the feed solution. Differences between fixed-bed and isotherm data of $4 \%$ to $13 \%$ were reported for adsorption of carboxylic acids onto polymeric adsorbents (Rixey, 1987; Husson, 1998).

\subsection{Product Recovery from Solvent Regeneration}

\subsubsection{Width of Product-Stream Cut}

From the elution profiles (see Figures 7.3-1 to 7.3-3 and Figure 7.6-4 to follow), it appears reasonable to recover all of the solute past the point where focusing first begins (i.e. the initial rise of solute concentration in the effluent). Depending on the situation, 
the end of the product "cut" is chosen as a balance between: (1) a higher average product concentration, and (2) a greater cost for recycling, reprocessing, or disposing of the more dilute fraction of the stream. The fluid within the cut contains solute, concentrated to some degree in a highly organic media, that can be sent downstream to a distillation/evaporation unit. The fraction of fluid upstream of the beginning of the cut, which consists of displaced solution from the nominal loading stage, can be recycled back to the original feed. As an example, the calculations in the following section regard the end of the cut as the time when the regeneration experiment is terminated.

The percent solute recovery (\%REC) represents the fraction of the regenerated solute peak recovered (i.e. within the cut), and is defined mathematically as:

$$
\% \text { REC }=100 \frac{M_{\text {cut }}}{M_{\text {reg }}}
$$

where $\mathrm{M}_{\text {cut }}$ is the integrated mass of solute (g) within the "cut," defined exactly as in eq. (7.4-2) except that the lower limit of integration is not zero, but rather the time of incipient focusing of the solute, $t_{\text {cut }},(\mathrm{min})$.

The average concentration of the fluid within the cut, $<\mathrm{C}>,(\mathrm{g} / \mathrm{mL})$ is defined as:

$$
\langle c\rangle=\frac{1}{\left(t_{F}-t_{c u t}\right)} \int_{t_{c u t}}^{t_{F}} c d t
$$


where $t_{F}$ is the time $(\mathrm{min})$ at the end of the cut. Table 7.5-1 shows the calculations for the limiting, non-optimal case where all solute eluted after the first bed volume is recovered.

TABLE 7.5-1

Recovery of Eluted Solute from Fixed-Bed Regeneration

\begin{tabular}{||c|c|c|c|c||}
\hline $\begin{array}{c}\text { SOLUTE/ } \\
\text { REGENERANT }\end{array}$ & REFERENCE & $\% \mathrm{REC}$ & $\begin{array}{c}<\mathrm{C}> \\
\mathrm{g} / \mathrm{mL}\end{array}$ & $<\mathrm{C} / \mathrm{C}_{\text {feed }}>$ \\
\hline EG/Acetone & Fig. 7.3-1 & 65 & 0.0555 & 1.21 \\
\hline Glycerol/MeOH & Fig. 7.3-1 & 72 & 0.0347 & 1.26 \\
\hline PG/Acetone & Fig. 7.3-1 & 80 & 0.0738 & 1.46 \\
\hline EG/Acetone* & Fig. 7.6-4 & 65 & 0.1327 & 2.31 \\
\hline $\begin{array}{c}\text { Sucrose/ } \\
\text { 85 } \% \text { Acetone }\end{array}$ & Fig. 7.3-2 & 89 & 0.0441 & 0.87 \\
\hline
\end{tabular}

*For the Ambersorb 572 fixed bed; all other data are for heat-treated F400 carbon

These calculations show that with the exception of sucrose, the average product concentration in the cut is still significantly higher than in the original aqueous feed, ranging from $21 \%$ to $231 \%$ above the feed concentration. Additional energy savings are, of course, realized from the lower heat of vaporization of the organic solvent. The average concentration of sucrose in the cut is rather low, considering the relatively large focusing effect. This is likely due to the severe tailing of sucrose seen in Figure 7.3-2, which is attributable to the strong affinity of sucrose for the carbon surface. The average product concentration can be made higher, to the extent that more recycle is needed. 


\subsubsection{Energy Requirements}

Assuming an infinite relative volatility of the solvent to the multi-OH solute, the energy required for separation, per unit mass of solute product, is:

$$
\mathrm{Q}_{\text {evap }}=\frac{\mathrm{X}_{1} \Delta \mathrm{H}_{\mathrm{vap}}}{\mathrm{X}_{2}}
$$

where $\mathrm{X}_{1}$ and $\mathrm{X}_{2}$ denote the solvent and solute mass fractions of the feed solution, $\Delta \mathrm{H}_{\text {vap }}$ is the latent heat of vaporization ( $\mathrm{kJ} / \mathrm{g}$ solvent) of the solvent, and $\mathrm{Q}_{\text {evap }}$ is the energy required for separation (kJ/g solute). Calculations using eq. (7.5-3) are shown in Figure $7.5-1$, taking $\Delta \mathrm{H}_{\text {vap }}$ as $2.25 \mathrm{~kJ} / \mathrm{g}$ for water, $1.1 \mathrm{~kJ} / \mathrm{g}$ for methanol, and $0.52 \mathrm{~kJ} / \mathrm{g}$ for acetone (Himmelblau, 1982). The abscissa in Figure 7.5-1 represents a possible range of solute concentrations in the product cut.

As an example, the energy required to recover ethylene glycol from a $5 \mathrm{wt.} \%$ aqueous solution by overhead evaporation of the water is approximately $42 \mathrm{~kJ} / \mathrm{g}$ glycol. When the same aqueous stream is fed through a bed of heat-treated F 400 carbon and subsequently focused, a product cut yields a stream that is about $6 \mathrm{wt}$ \% glycol in acetone. The energy requirement would is now $8 \mathrm{~kJ} / \mathrm{g}$ glycol. Had a bed of A572 adsorbent been used, the product cut would have yielded a stream that is about $12 \mathrm{wt} . \%$ glycol in acetone. The energy requirement here would be reduced even further to about $4 \mathrm{~kJ} / \mathrm{g}$ glycol. 


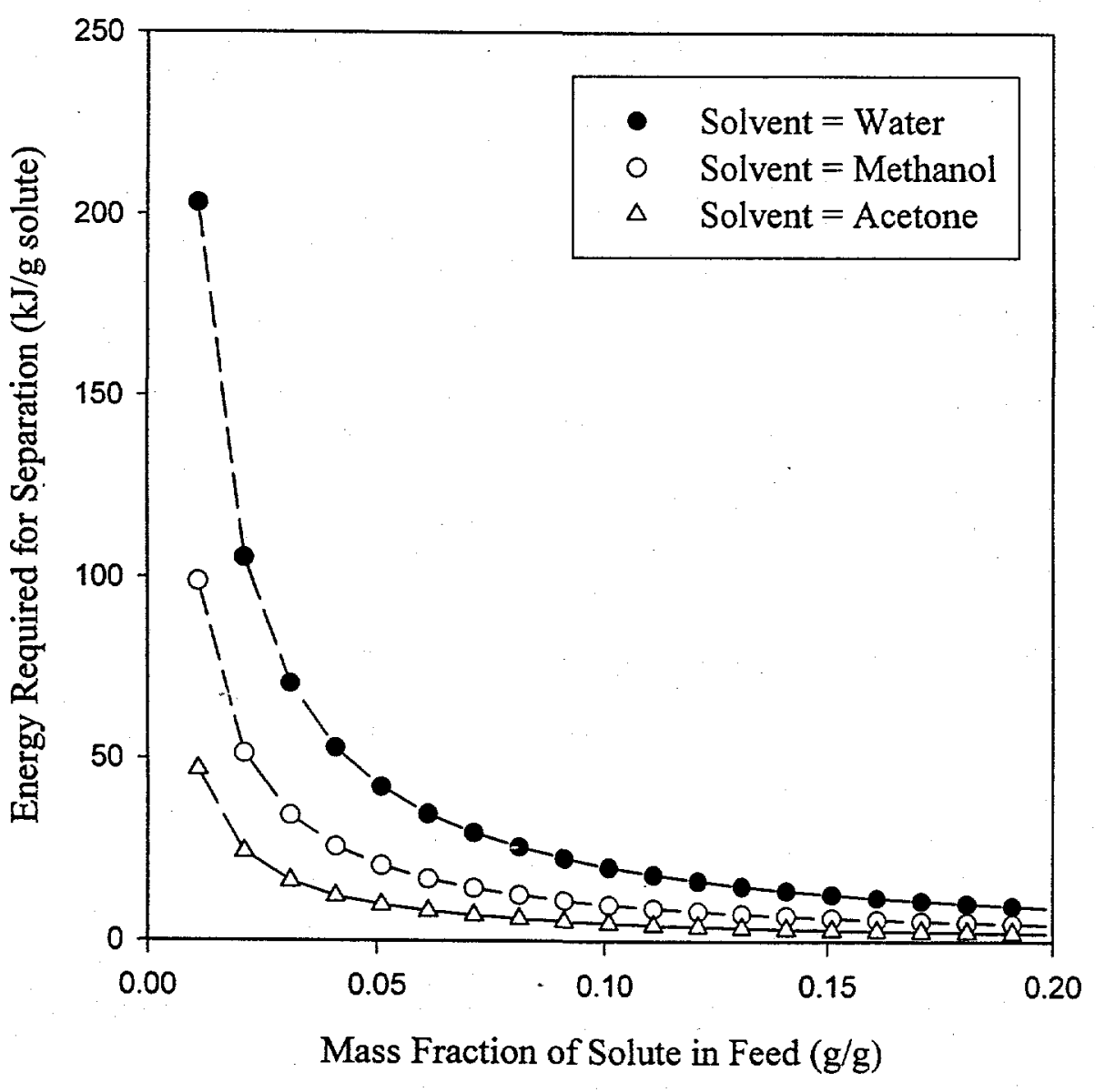

Figure 7.5-1. Calculated energy requirements for separation (kJ/g solute) by complete evaporation of the solvent. 


\subsection{Optimization of the Focusing Effect}

On the basis of the previous discussion, it is clear why it is of great interest to maximize the degree of focusing during solvent regeneration. A sharper focusing effect results in (1) a more concentrated product that lowers the downstream energy requirements for final separation, and (2) a lower number of bed volumes needed for full regeneration, which reduces the amount of recycle needed. Some of the parameters used in our work to optimize focusing were taken from the theoretical-plate concepts of chromatography theory (see section 7.2.3).

Eq. (7.2-1) suggests that a more efficient use of the bed (sharper focusing effect) might be achieved by finding an optimum volumetric flowrate and by using smaller and/or more uniform particle sizes. The effect of these parameters will be explored in sections 7.6.2 and 7.6.3.

\subsubsection{Effect of Carbon Choice}

Our batch-equilibrium and TGA experiments show that organic solvents (acetone, methanol) adsorb to a much greater extent than the multi $-\mathrm{OH}$ solutes, regardless of the type of activated carbon. It is therefore clear that the carbon that leads to a maximum focusing effect during regeneration is likely to be the one with the highest equilibrium capacity. Figure 7.6-1 shows elution profiles for aqueous EG by acetone for several types of $F 400$ carbons. Operating parameters and calculated $\mathrm{M}_{\text {reg }}$ are shown in Table 7.61 below: 


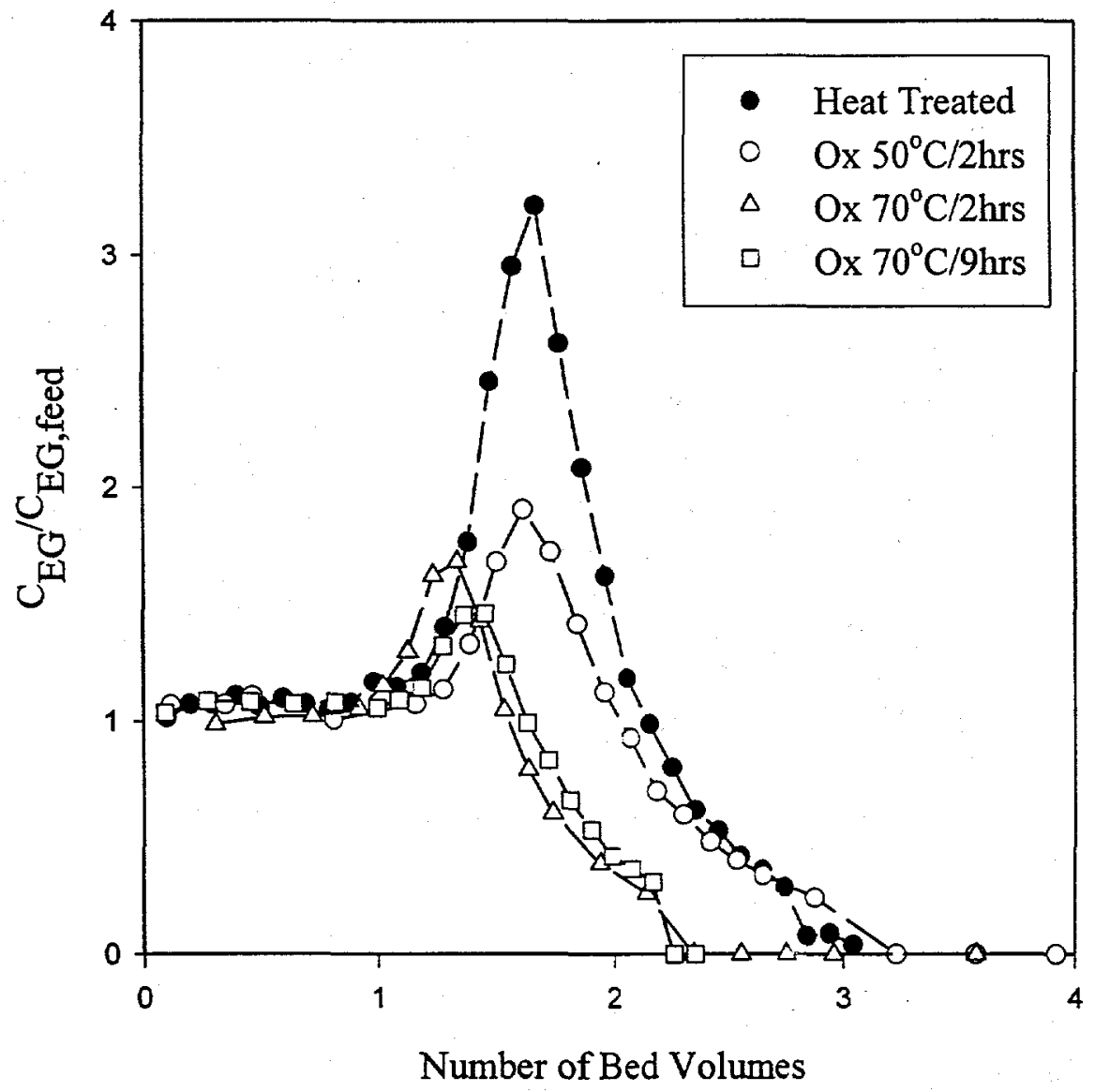

Figure 7.6-1. Comparison of ethylene glycol (EG) focusing by acetone elution for beds packed with heat-treated versus oxidized F400 carbons. 
TABLE 7.6-1

Fixed-Bed Operating Parameters for Data in Figure 7.6-1

\begin{tabular}{|c|c|c|c|c||}
\hline CARBON & $\begin{array}{c}\text { Size of 1 BED } \\
\text { VOLUME }\left(\mathrm{cm}^{3}\right)\end{array}$ & $\begin{array}{c}\mathrm{C}_{\text {feed }} \\
(\mathrm{g} / \mathrm{mL})\end{array}$ & $\begin{array}{c}\text { FLOWRATE } \\
(\mathrm{mL} / \mathrm{min})\end{array}$ & $\mathrm{M}_{\mathrm{reg}}(\mathrm{g})$ \\
\hline HT & 8.05 & 0.04591 & 1.58 & 1.35 \\
\hline OX50/2 & 7.60 & 0.05343 & 1.56 & 1.04 \\
\hline OX70/2 & 6.59 & 0.05343 & 1.51 & 0.97 \\
\hline OX70/9 & 7.61 & 0.04829 & 1.38 & 0.81 \\
\hline
\end{tabular}

The trends observed in Figure 7.6-1 are not too surprising, given the differences in equilibrium capacity among the carbons (discussed in Chapter 4). The greatest degree of focusing is observed with the heat-treated F400, which also has the highest equilibrium capacity for EG. An interesting feature of Figure 7.6-1 is that the $\mathrm{Ox} 50^{\circ} \mathrm{C} / 2 \mathrm{hr}$ bed seems to have a larger degree of tailing than the heat-treated bed. This suggests that in addition to lower equilibrium capacity, surface oxidation may cause a more sluggish water-to-acetone transition during focusing, due to the greater affinity of the carbon for water.

\subsubsection{Effect of Volumetric Flowrate}

Eq. (7.2-1) suggests that for a given bed, an optimum flowrate exists such that the competing effects of axial dispersion and mass-transfer resistance are balanced. A similar line of reasoning was used to describe the shape of the breakthrough curves in section 7.2.2. To study the effects of volumetric flowrate on the degree of focusing, each of the loaded beds from Figure 7.2.2 was regenerated by acetone. The results are shown in Figure 7.6-2. 


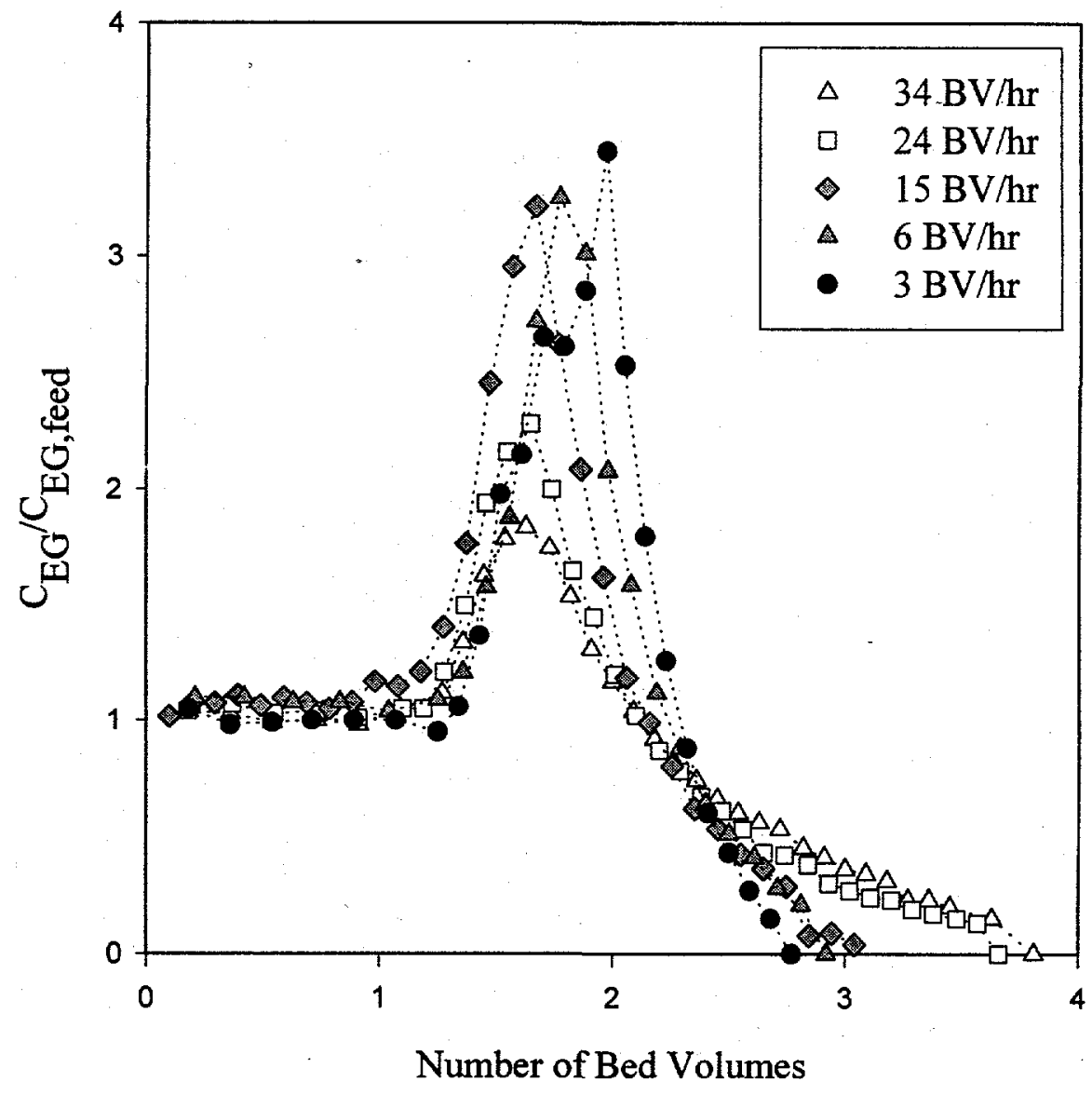

Figure 7.6-2. Comparison of ethylene glycol (EG) focusing by acetone elution for beds packed with heat-treated F400 carbon, employing different volumetric flowrates. 
Figure 7.6-2 confirms the notion that the efficiency of the bed (hence the shape of the elution profile) can be largely affected by the volumetric flowrate. An EG-focusing effect of $3-3.3 x$ is observed for a flowrate range of $3-15$ bed volumes/hr. This appears to be the optimum range of flowrates during the regeneration stage. Lower flowrates would be tedious on the laboratory scale, and likely impractical on the industrial scale. When larger flowrates are used (24-34 bed volumes/hr), the focusing effect drops to about $2 \mathrm{x}$.

In addition, there is a greater degree of tailing observed at higher flowrates; that is, more bed volumes are required to reduce the effluent EG concentration to zero. These results suggest that during the regeneration stage, mass-transfer limitations are far more important than those from axial dispersion of the solute. Sufficient residence time is obviously required for: (1) transport of the acetone into the carbon, and (2) diffusion of the displaced EG from the carbon into the liquid stream. The parameter, $H_{d}$ in eq. (7.2-1) can therefore be considered non-controlling. In their work with methanol regeneration of phenol-loaded Pittsburgh CAL (Calgon), Cooney et al. (1982) observed a twofold increase in focusing when the flowrate was reduced from $20 \mathrm{~mL} / \mathrm{min}$ to $6 \mathrm{~mL} / \mathrm{min}$.

\subsubsection{Effects of Particle-Sizc Distribution}

A smaller and/or more uniform particle size could also result in a lower HETP, and hence a more pronounced focusing effect. As discussed in section 7.2.2, efficient packing of the bed is required to minimize the effects of channeling and reduce the non-uniformity of multiple paths for flow. This section presents an experiment to compare an asreceived batch of carbon against one that is sieved to a narrower particle size. In another 
experiment, the optimum focusing conditions on F400/HT are compared with the performance of A572 for EG recovery by acetone. The latter adsorbent has a smaller and nearly uniform particle size.

Figure 7.6-3 shows acetone regeneration of EG-loaded beds, packed from two batches of heat-treated F400. The as-received batch had a particle size range of about 0.45 to $2 \mathrm{~mm}$ diameter. The other batch was sieved to a narrower distribution of 0.45 to $0.85 \mathrm{~mm}$ diameter. Both experiments used similar flowrates and bed lengths, and had similar degrees of loading $\left(\mathrm{M}_{\mathrm{reg}}\right.$ is 1.27 and $1.18 \mathrm{~g}$ for the sieved and as-received batch, respectively). The results indicate that a slight improvement of focusing $(\sim 10 \%)$ was realized with the more uniform particle sizes. In addition, and probably more important, the degree of tailing for the sieved particles was also reduced relative to the as-received batch. A sharper focusing effect might be obtained with an even narrower particle distribution.

Figure 7.6-4 compares acetone regeneration of EG from a bed packed with F400/HT and one with Ambersorb 572. Table 7.6-2 summarizes some of the operating parameters.

TABLE 7.6-2

Fixed-Bed Operating Parameters for Data in Figure 7.6-4

\begin{tabular}{||c|c|c|c|c|}
\hline ADSORBENT & $\begin{array}{c}\text { SIZE OF 1 BED } \\
\text { VOLUME }\left(\mathrm{cm}^{3}\right)\end{array}$ & $\begin{array}{c}\mathrm{C}_{\text {feed }} \\
(\mathrm{g} / \mathrm{mL})\end{array}$ & $\begin{array}{c}\text { FLOWRATE } \\
(\mathrm{mL} / \mathrm{min})\end{array}$ & $\mathrm{M}_{\mathrm{reg}}(\mathrm{g})$ \\
\hline $\mathrm{F} 400 / \mathrm{HT}$ & 6.43 & 0.05096 & 0.67 & 1.18 \\
\hline $\mathrm{A} 572$ & 6.5 & 0.0575 & 1.11 & 1.47 \\
\hline
\end{tabular}




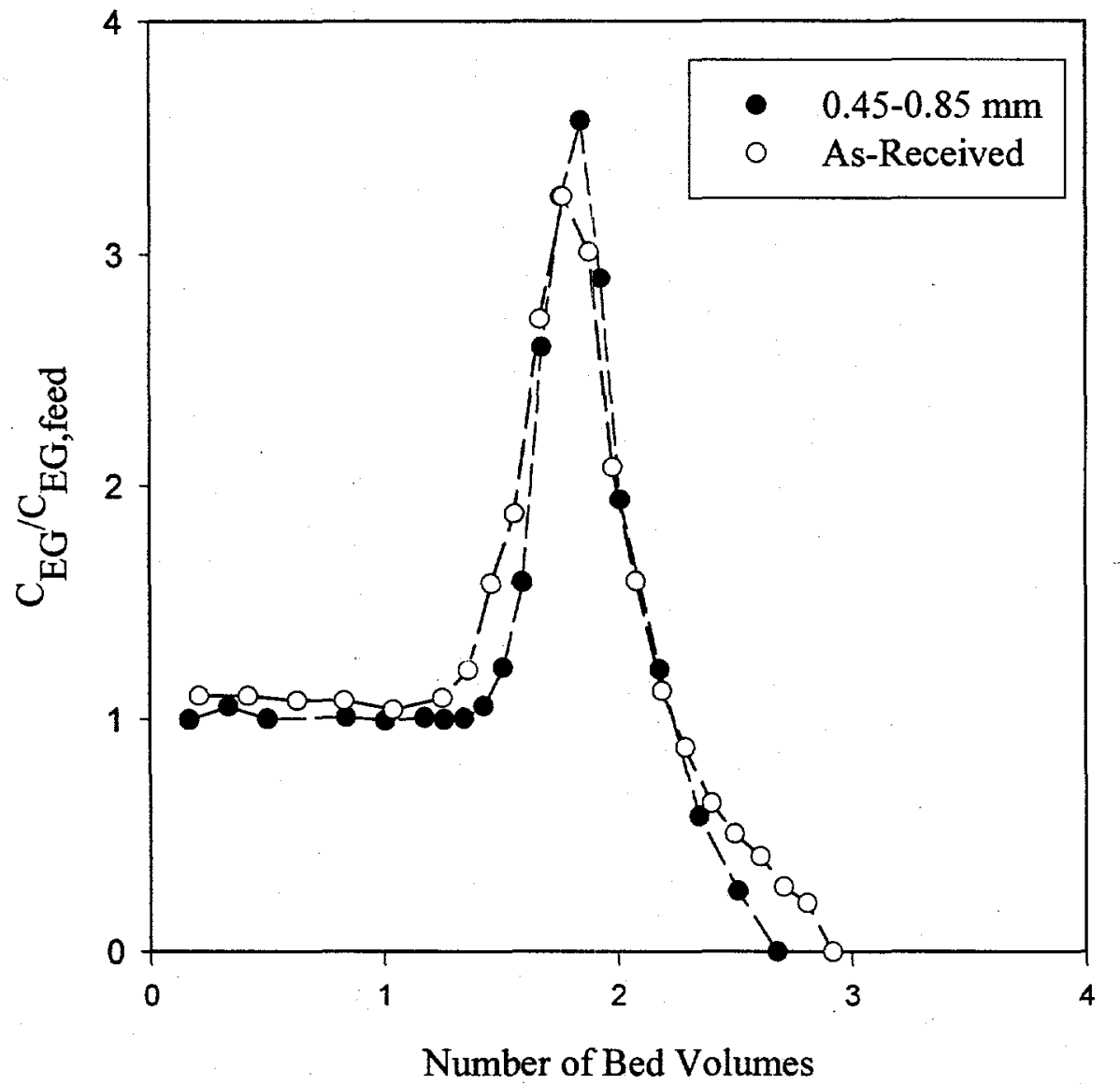

Figure 7.6-3. Comparison of ethylene glycol (EG) focusing by acetone elution for beds packed with heat-treated F400 carbon, employing two different particle-size distributions. 


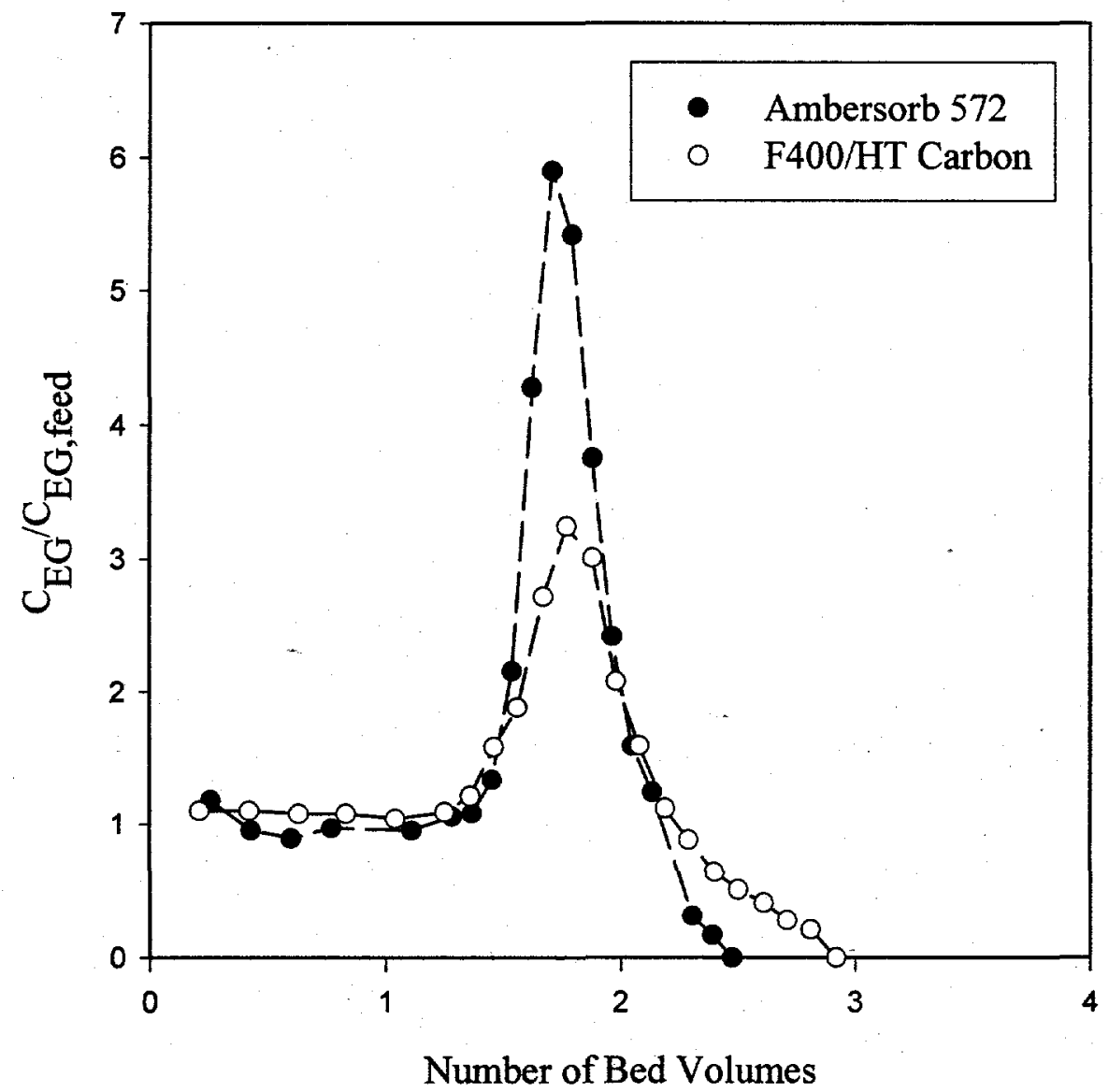

Figure 7.6-4. Comparison of ethylene glycol (EG) focusing by acetone elution for beds packed with Ambersorb 572 versus heat-treated F400 carbon. 
The differences in the EG-focusing effect between F400/HT and A572 are striking. Although the equilibrium capacity for EG of A572 is no more than $50 \%$ higher than F400/HT, in a fixed-bed mode an EG-focusing effect of 6x was observed for A572. This confirms that particle size and/or size uniformity largely influence the focusing effect. Whereas the $\mathrm{F} 400 / \mathrm{HT}$ had a particle size distribution between 0.45 to $2.0 \mathrm{~mm}$ diameter, the particles of A572 are all nearly spherical, with diameter between 0.25 to $0.45 \mathrm{~mm}$. Also, only 2.5 bed volumes are required for full removal of EG using A572 compared to 3 bed volumes with the carbon.

Although it appears that smaller and more uniform particle sizes invariably lead to better packing and sharper focusing effects, actual design of fixed beds in practice may be limited by the pressure drop across the bed. In HPLC operation, the overall pressure drop is linearly proportional to the flowrate, but inversely proportional to the square of the particle diameter (Johnson and Stevenson, 1978). In addition, the price of the adsorbent is also important. Although the focusing effect of A572 is about twice as high as the best activated carbon, A572 is currently 10-20 times more expensive on a per-pound basis.

\subsection{Cycling of Adsorption/Regeneration Stages}

\subsubsection{Acetone as the Regenerant}

As shown in Table 7.4-1, nearly all ( $>90 \%$ ) of any of the aqueous multi $-\mathrm{OH}$ solutes loaded onto the bed is recovered by solvent leaching during a single cycle of fixed-bed operation. Another important issue to address is whether the capacity and completeness of regeneration can be sustained through many cycles with the same bed. We present two 
sets of experiments on beds packed with F400/HT, with EG as the solute, to study the effects of cycling. One experiment used acetone as the regenerant, whereas the other used methanol. For both experiments, the spent beds were flushed with many bed volumes of water to remove regenerant in preparation for the next loading stage. In practice, a more intensive wash procedure might be done, for example, with steam or a high-temperature nitrogen or water purge.

The fixed bed used in the acetone-cycling experiment was $19.5 \mathrm{~cm}$ long. An EG feed concentration of $0.04637 \mathrm{~g} / \mathrm{mL}$ was used for all loading cycles. During regeneration, flowrates of $0.26-0.47 \mathrm{~mL} / \mathrm{min}$ were used. Table $7.7-1$ tallies the amount of water flushed through the spent bed during the rinse stage of each cycle:

TABLE 7.7-1

Water Usage during Rinse Stages $\left(25^{\circ} \mathrm{C}\right)$ of Fixed-Bed Cycling: Acetone Regeneration of EG-Loaded F400/HT Bed

\begin{tabular}{|c|c|}
\hline CYCLE & $\begin{array}{c}\text { BED VOLUMES } \\
\text { OF WATER }\end{array}$ \\
\hline 1 & 23 \\
\hline 2 & 21 \\
\hline 3 & 23 \\
\hline 4 & 22 \\
\hline 5 & 21 \\
\hline 6 & 20 \\
\hline 7 & 19 \\
\hline 8 & 17 \\
\hline 9 & 18 \\
\hline 10 & $\sim 30-40$ \\
\hline
\end{tabular}


Figure 7.7-1 summarizes the results for ten cycles of EG adsorption and acetone regeneration for a bed packed with F400/HT. Plotted for each cycle on the bar graph is the bed capacity (g EG/g dry carbon) during the loading stage, as defined by eq. (7.4-1). The EG capacity was highest for the first cycle, but diminished by $30 \%$ on all subsequent cycles. Cycles 2 through 10 show a nearly constant loading for the most part, with slightly lower values for the $8^{\text {th }}$ and $9^{\text {th }}$ cycles. The reason for the observed capacity losses is probably due to the difficulty in completely removing the acetone from the bed. This acetone remains on the bed after the preceding wash cycle, which is insufficient to remove the acetone completely. A $15 \%$ decrease in the bed volumes of water used to wash the column during the $8^{\text {th }}$ and $9^{\text {th }}$ cycle probably accounts for the higher amounts of residual acetone in the effluent, along with the lower observed EG capacity.

Figure 7.7-2 shows a clearer picture of the wash stage, and plots the actual mass fraction of acetone in the effluent during the loading stage for all ten cycles. For each cycle, the residual acetone from the bed was focused by the adsorption of EG during the loading stage, displacing acetone. As noted in Chapter 5, equilibrium studies have shown that EG adsorbs weakly, but positively from acetone solutions. A small focusing effect therefore results from the shift in acetone-carbon to acetone-EG-water-carbon equilibrium. The size of the peak for residual acetone was larger for cycles 7 through 9 due to insufficient washing, and smallest for cycle 10 because substantially more water was used in the preceding wash. 


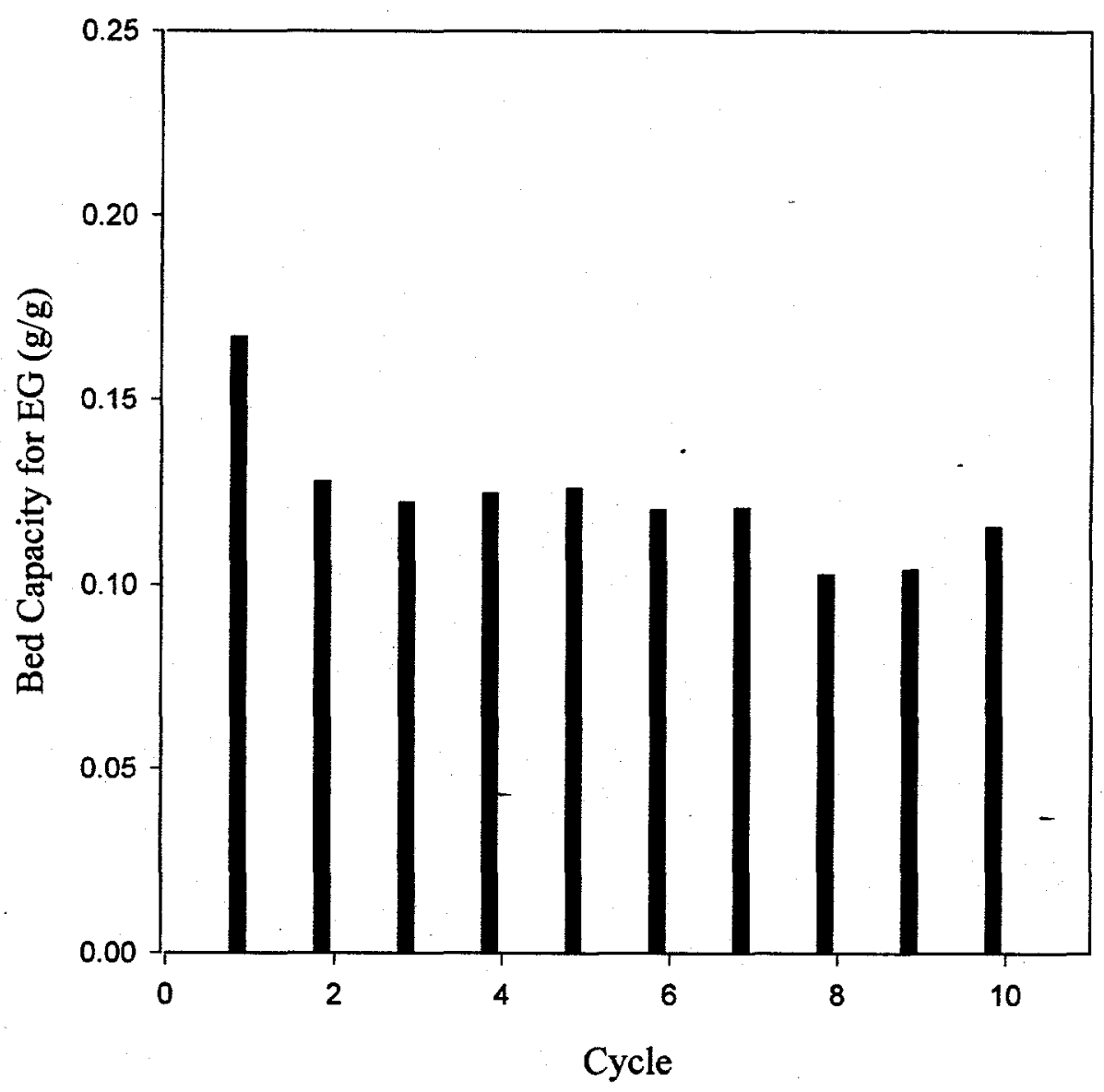

Figure 7.7-1. Bed capacity of heat-treated F400 carbon for ethylene glycol (EG) for each loading cycle. Regeneration was done by acetone, followed by rinsing with $25^{\circ} \mathrm{C}$ water. 


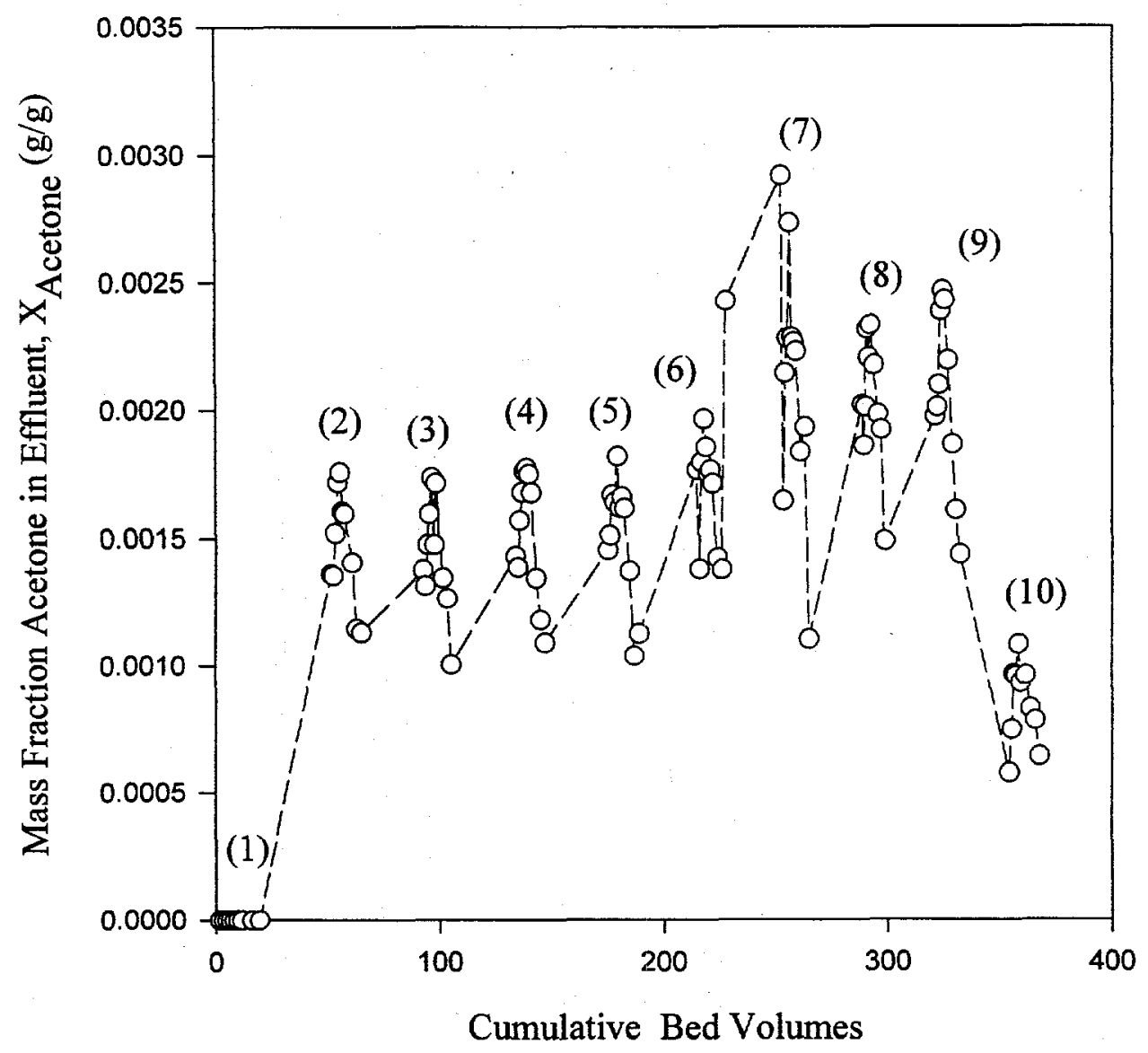

Figure 7.7-2. Residual acetone found in the effluent during ethylene glycol (EG) loading throughout all ten cycles. 
Overall, these results show that water washing of the sort used here is insufficient for sustaining the bed capacity for EG, when acetone is used as the regeneration solvent. The reduced capacities observed for all cycles are due to the residual amount of acetone left on the bed, which likely occupy sites on the surface originally meant for EG. The relative difficulty of removing acetone was also observed in TGA (see Figure 6.2-1), where temperatures of up to $200^{\circ} \mathrm{C}$ are required to desorb acetone from carbons. In a similar study of acetone regeneration of phenol-loaded Witco 940 carbon, a solventremoval stage using 5 psig steam still resulted in a $15 \%$ capacity loss after the first cycle (Sutikno and Himmelstein, 1983).

\subsubsection{Methanol as Regenerant}

The fixed-bed used in the methanol-cycling experiment was $18.7 \mathrm{~cm}$ long. An EG feed concentration of $0.04637 \mathrm{~g} / \mathrm{mL}$ was used for all loading cycles. During regeneration, flowrates of $0.5 \mathrm{~mL} / \mathrm{min}$ were used. From $20-22$ bed volumes of water were flushed through the spent bed during the rinse stage.

Different results arise when methanol, rather than acetone, is chosen as the regenerant. Figure 7.7-3 summarizes the bed capacity for EG over four cycles. Unlike the case with acetone, the capacity appears to be sustained. In addition, no residual methanol was detected in the effluent stream during any loading cycle. This suggests that all of the methanol was removed during the water-wash stage. The ease in removing methanol, relative to acetone, was not too surprising based on the results from TGA. Also, Cooney et al. (1982) identified methanol as the optimum solvent for cyclic fixed-bed recovery of 


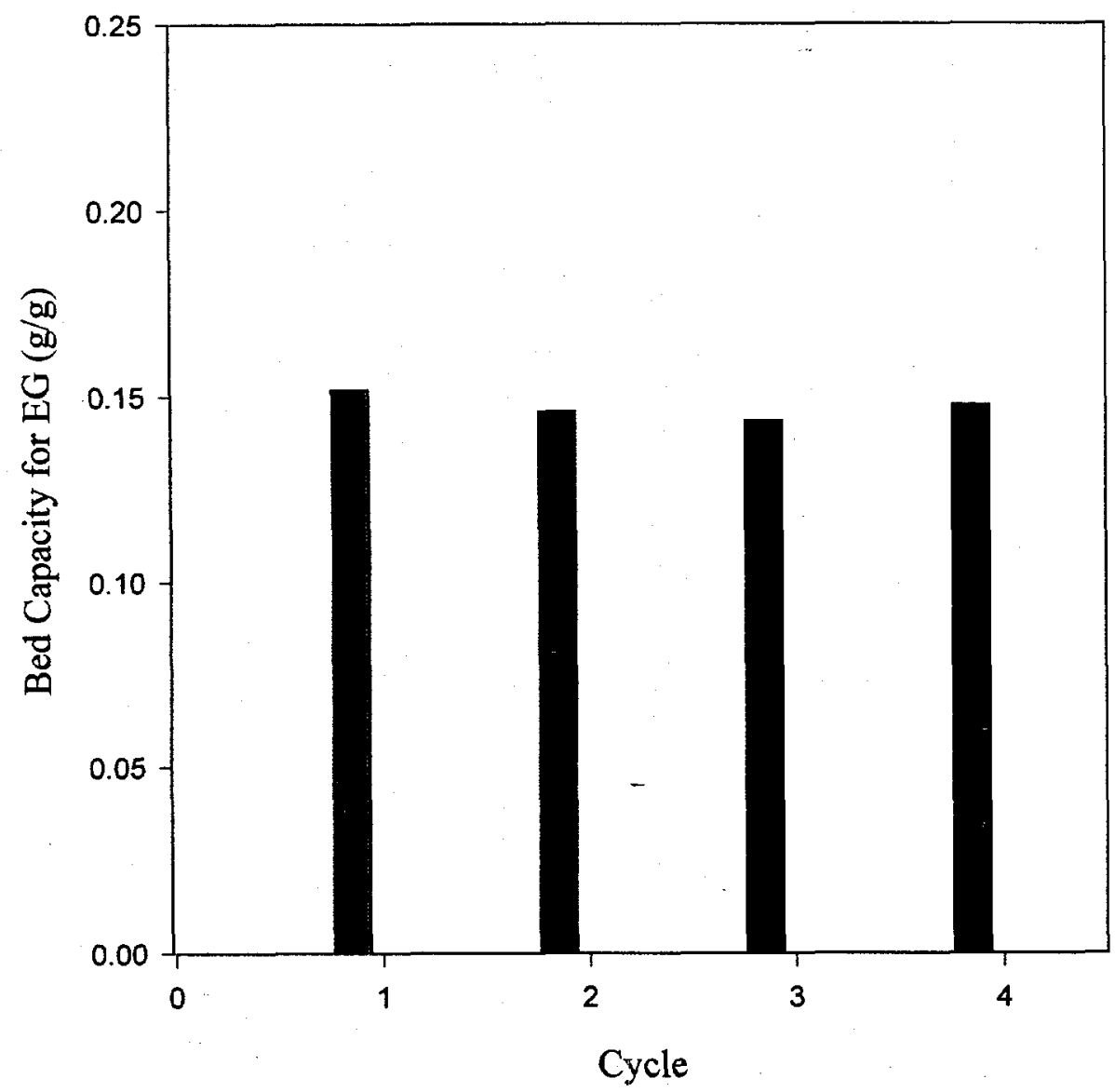

Figure 7.7-3. Bed capacity of heat-treated F400 carbon for ethylene glycol (EG) for each loading cycle. Regeneration was done by methanol, followed by rinsing with $25^{\circ} \mathrm{C}$ water. 
phenol from Pittsburgh CAL (Calgon). However, since the authors did not use an excess of water during the rinse stage, a $12 \%$ capacity loss was observed after the first cycle.

\subsection{Two-Solute Systems for Fixed-Bed Processes}

A likely scenario for applications in the fermentation and corn wet-milling industries is that a mixture of aqueous multi $-\mathrm{OH}$ compounds is found in the process streams. It is therefore of interest to see how our present findings apply in the case of two adsorbing solutes from aqueous solution. The goal is to determine the degree of fractionation between solutes during the regeneration stage, and what operating parameters might be used to achieve a better separation. In working with mixtures, we have chosen solutes differing in affinities for the carbon, such as propylene glycol and glycerol. As in the single-solute work, all beds are packed with heat-treated F400 as the adsorbent, using the optimum range of flow as determined from section 7.6.2.

\subsubsection{Differential Displacement with Concentrated Regenerants}

Although possessing a high adsorption capacity, activated carbons are fairly nonselective. With regards to multi $-\mathrm{OH}$ solutes, the affinity and uptake capacity onto carbons are largely affected by solution-phase nonidealities and the size of the solute, with largersized species having stronger dispersion interactions. Sucrose has the highest heat of adsorption and the highest capacity among all multi $-\mathrm{OH}$ solutes studied in our work, and would therefore be expected to be adsorbed preferentially over other multi $-\mathrm{OH}$ solutes. 
Figure 7.8-1 shows the elution profile of a bed loaded from a solution of 4.7 wt. $\%$ sucrose / 4.19 wt. \% glycerol in water, with a $50 \mathrm{wt} . \%$ ethanol in water as the regenerant. Since the carbon has such a greater affinity for the sucrose $\left(\mathrm{M}_{\mathrm{reg}}=1.7 \mathrm{~g}\right)$ than glycerol $\left(M_{\text {reg }}=0.75 \mathrm{~g}\right)$, it is somewhat surprising that only the sucrose exhibited a noticeable focusing effect. One possible reason was that the ethanol front was capable of completely displacing sucrose, had more difficulty in displacing glycerol than stronger regenerants, such as acetone.

Figure 7.8-2 shows a similar experiment to that of Figure 7.8-1, but with beds loaded from an aqueous solution of 4.5 wt. \% PG / 4.3 wt. \% glycerol, and with 50 wt. \% acetone in water as the regenerant. The elution profiles show that although PG is adsorbed to a greater extent $\left(\mathrm{M}_{\mathrm{reg}}=1.21 \mathrm{~g}\right)$ than glycerol $\left(\mathrm{M}_{\mathrm{reg}}=0.75 \mathrm{~g}\right)$, noticeable focusing was observed for both solutes; albeit there was not much fractionation between the solutes. Unlike the case shown in Figure 7.8-1, acetone is strong enough to displace completely both PG and glycerol.

Neither of these results have shown that differential displacement is effective for fractionation among multiple solutes during regeneration. Possibly, there are regenerants that have displacing power intermediate between the solutes of interest. It is also possible that a better degree of fractionation might be achieved with less concentrated regenerants. This could allow a quantitative amount of adsorbed solute to be displaced at a time, with the low-affinity solute desorbing ahead of the high-affinity solute. 


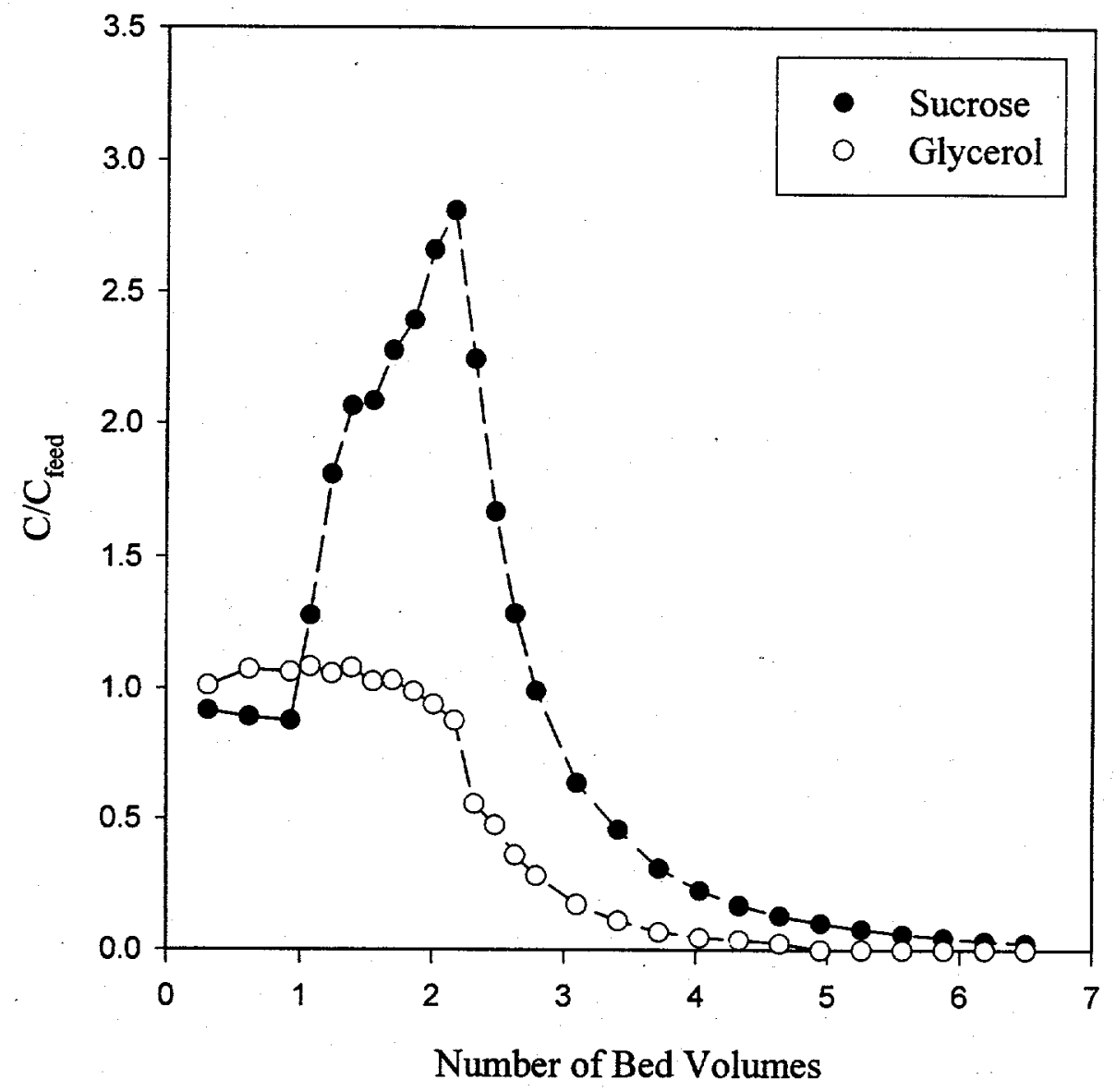

Figure 7.8-1. Elution profile of a heat-treated F400 bed loaded from a $4.7 \mathrm{wt} . \%$ sucrose $/ 4.2$ wt. \% glycerol aqueous solution. Regeneration was done using 50 wt. \% aqueous ethanol. 


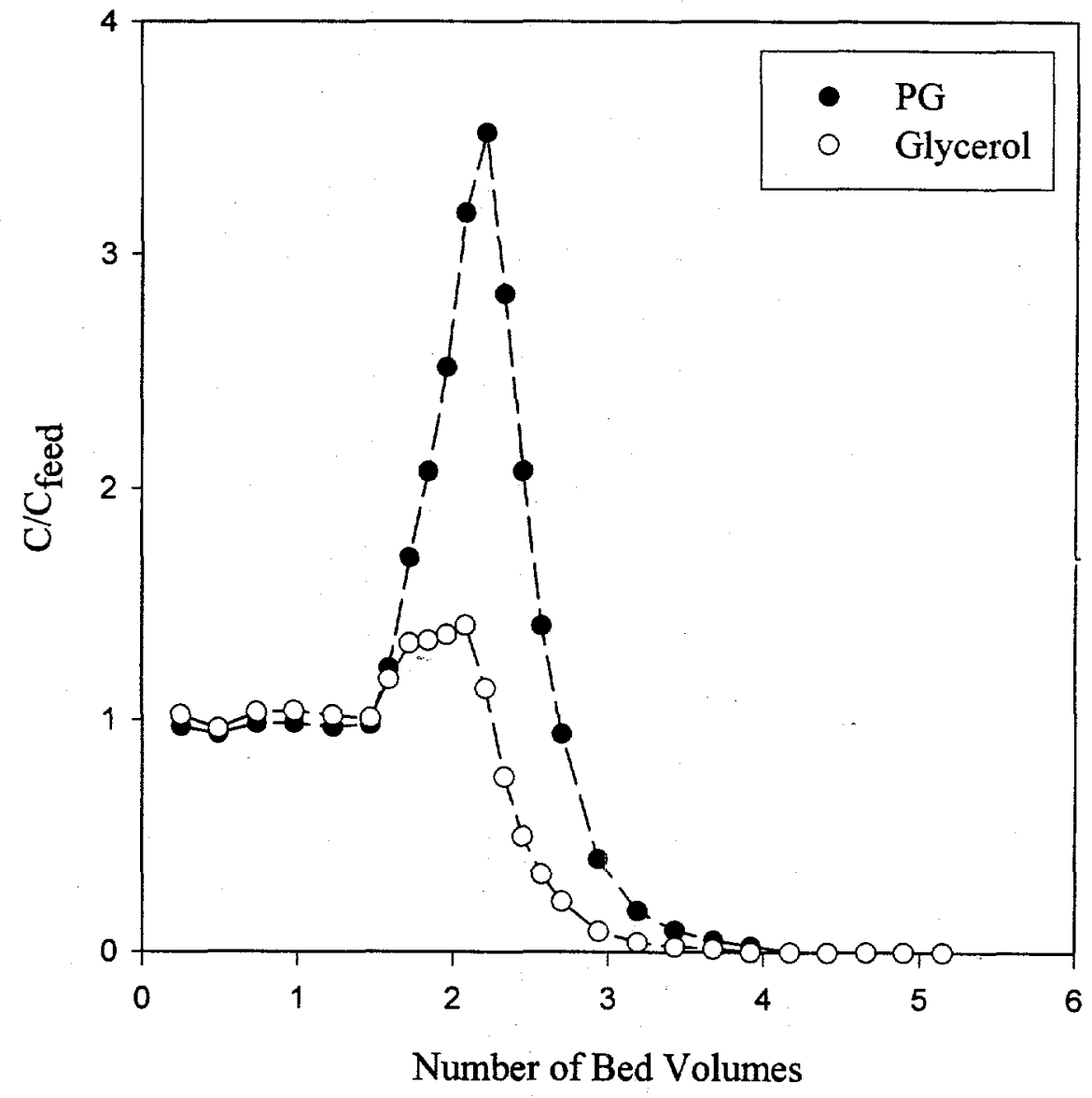

Figure 7.8-2. Elution profile of a heat-treated F400 bed loaded from a $4.5 \mathrm{wt}$. \% propylene glycol (PG)/4.3 wt. \% glycerol aqueous solution. Regeneration was done using $50 \mathrm{wt}$. \% aqueous acetone. 


\subsubsection{Differential Displacement with Dilute Regenerants}

Figure 7.8-3 shows the elution profile of a F400/HT bed loaded from an aqueous $6.7 \mathrm{wt}$. $\%$ PG / 5.2 wt. \% glycerol solution, with 2 wt. \% acetone in water as the regenerant. Since the bed is not yet saturated with acetone after displacing the first bed volume of fluid, a diffuse wave for glycerol breakthrough results up to the fourth bed volume. The diffuse wave is caused by desorption of solute into water, so naturally the concentrations will begin to decrease since the sorption equilibria has not changed (as opposed to the case of focusing). Between the sixth and eighth bed volumes, most of the glycerol has been desorbed from the bed, and a "plateau" in PG concentration is observed. This plateau probably results because a constant amount of acetone becomes adsorbed per unit time, which in turn results in a constant displacement in the amount of PG from the bed. Once the acetone has finally broken through near the eighth bed volume, a diffuse wave results where the $\mathrm{PG}$ concentration decays to zero.

A partial separation of PG and glycerol was therefore possible between the fourth and eighth bed volume; however, the PG product stream is at a much lower concentration. Also, the bulk of the glycerol was desorbed after the first four bed volumes, which also contain a substantial amount of PG. This portion of the effluent may have to be recycled and reprocessed.

Figure 7.8-4 shows the elution profile of a F400/HT bed loaded from an aqueous $4.2 \mathrm{wt}$. \% PG / 3.7 wt. \% glycerol solution, with $5 \mathrm{wt} . \%$ acetone in water as the regenerant. The results are similar to those of Figure 7.8-3, only the plateau region for PG occurs at an 


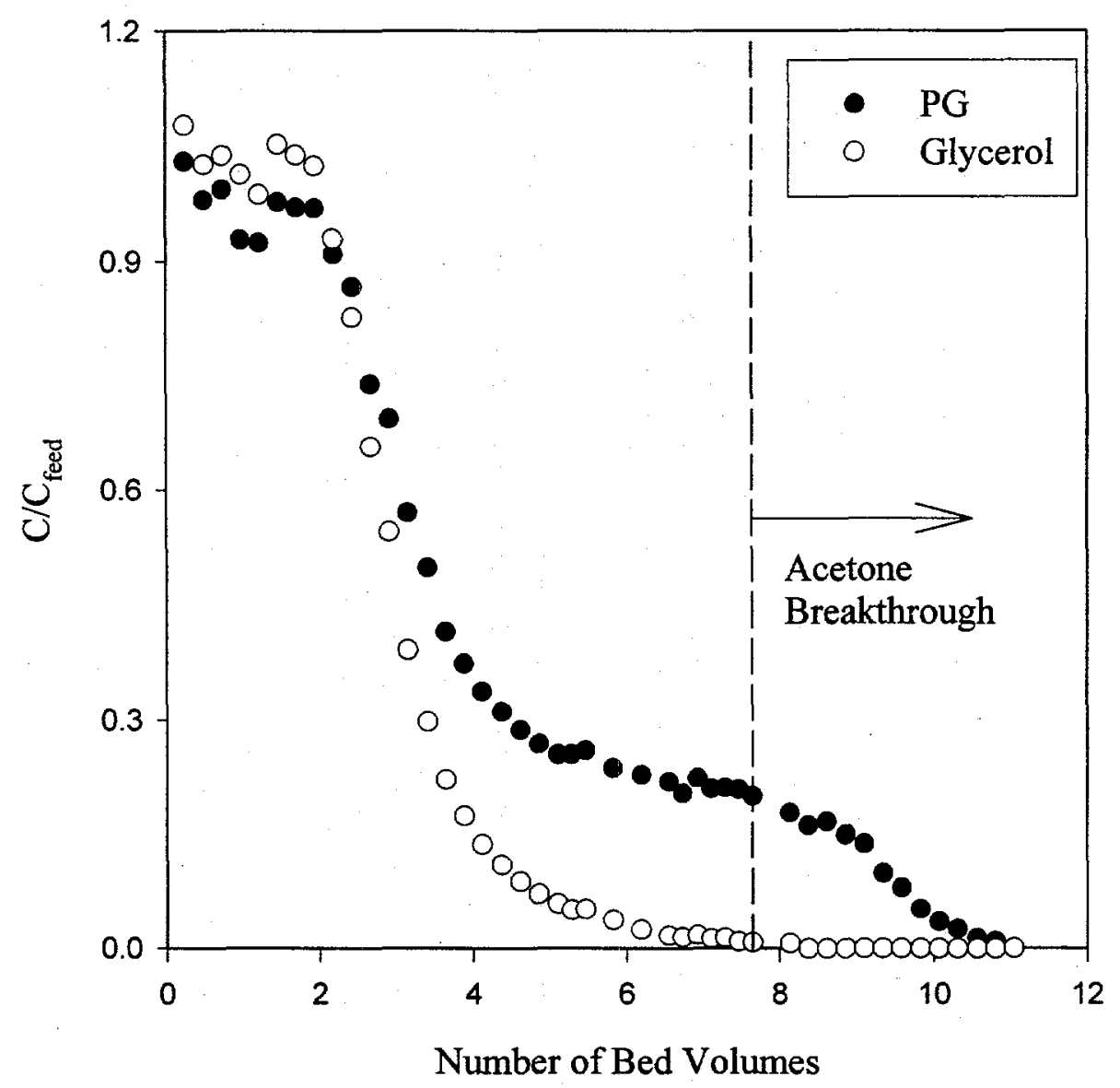

Figure 7.8-3. Elution profile of a heat-treated F400 bed loaded from a $6.7 \mathrm{wt} . \%$ propylene glycol (PG)/5.2 wt. \% glycerol aqueous solution. Regeneration was done using 2 wt. \% aqueous acetone. Note: Acetone breakthrough determined from one point. 


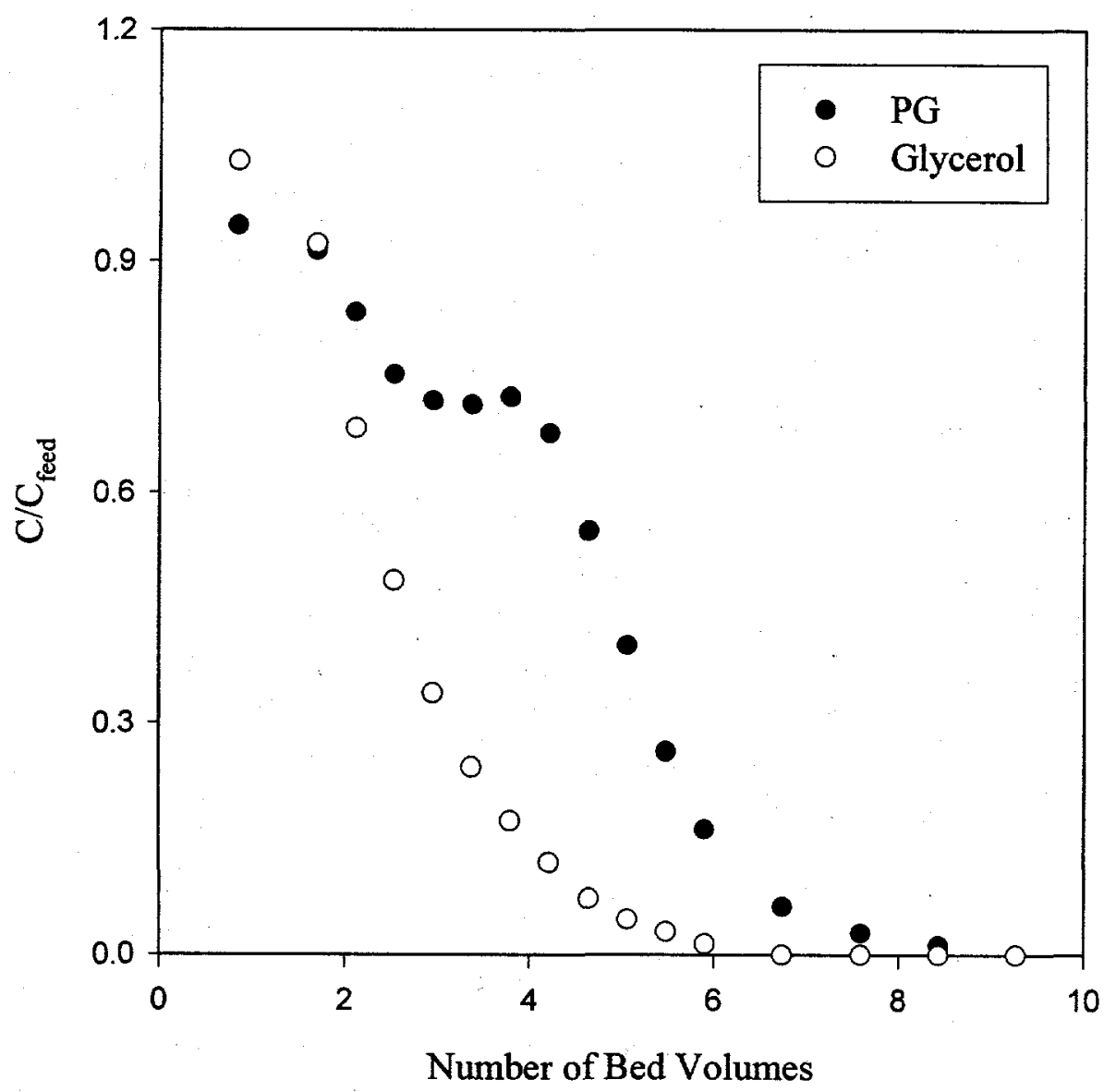

Figure 7.8-4. Elution profile of a heat-treated F400 bed loaded from a $4.2 \mathrm{wt} . \%$ propylene giycol (PG)/3.7 wt. \% glycerol aqueous solution. Regeneration was done using 5 wt. \% aqueous acetone. Note: Acetone breakthrough not measured. 
earlier bed volume and at a higher concentration. However, the plateau region also coincides with the diffuse wave of the glycerol. At best, these results show that a partial fractionation between PG and glycerol is achieved.

\subsubsection{Solute Fractionation: Summary and Recommendations}

It is clear that multicomponent systems present new problems for a fixed-bed recovery process based on activated carbon. One possible method of fractionation between several solutes is to run the fixed-bed in a displacement-chromatography mode. In this process, a pulse of feed solution is introduced into the bed, followed by a step-input of regenerant (displacer) solution. As the solutes, water, and displacer travel through the remainder of the (unused) carbon bed, the individual solutes fractionate according to their affinities for the surface. Of course, this mode of operation has an inherently low capacity compared to step-loading, and is probably best reserved for extremely high-value multi -OH solutes (proteins, amino acids, etc.).

The Ambersorb adsorbents (A563, A572, A575), used to only a limited extent in our research, may have greater potential for fractionating among solutes. Although they appear to be chemically and functionally similar to active carbons, the Ambersorbs possess a more homogeneous surface and uniform particle-size distribution. The latter characteristic is especially helpful for reducing the degree of axial dispersion, which can prove to be an even greater problem in the case of multiple solutes. 
Other adsorption-based methods that may have better potential for fractionating among solutes include moving-bed or simulated-moving-bed processes. Rather than recovering the multi $-\mathrm{OH}$ solutes in a cyclic mode, the moving-bed processes attempt to establish countercurrent staged contact between the adsorbent, feed, and regenerant. This mode is more efficient than the cyclic mode because every part of the bed performs a useful function at all times (Gembicki et al., c1991-1998). 
Cooney, D.O.; Nagerl, A.; Hines, A.L. Water Res., 1983, 17(4), 403-410.

Fogler, H.S. Elements of Chemical Reaction Engineering, $2^{\text {nd }}$ edition, Prentice-Hall, Inc.: New Jersey, 1992.

Gembicki, S.A.; Oroskar, A.R.; Johnson, J.A. "Adsorption, Liquid Separation." In KirkOthmer Encyclopedia of Chemical Technology, $4^{\text {th }}$ edition; Kroshwitz, J.I.; Howe-Grant, M., Eds., John Wiley and Sons: New York, c1991-1998, Vol. 1, 573-600.

Himmelblau, D.M. Basic Principles and Calculations in Chemical Engineering, $4^{\text {th }}$ edition, Prentice-Hall, Inc.: New Jersey, 1982.

Husson, S.M. Regeneration of Basic Adsorbents in the Recovery of Carboxylic Acids from Dilute Aqueous Solution and Multiple-acid Equilibria in Adsorption of Carboxylic Acids from Dilute Aqueous Solution. Ph.D. Dissertation, University of California, Berkeley, 1998.

Johnson, E.; Stevenson, B. Basic Liquid Chromatography, Varian Associates, Inc.: Palo Alto, 1978.

Rixey, W.G. Non-Wet Adsorbents for the Selective Recovery of Polar Organic Solutes from Dilute Aqueous Solution. Ph.D. Dissertation, University of California, Berkeley, CA, 1987.

Sherwood, T.K.; Pigford, R.L.; Wilke, C.R. Mass Transfer, Mcgraw-Hill, 1975.

Sutikno, T.; Himmelstein, K.J. Ind. Eng. Chem. Fundam., 1983, 22, 420-425.

Wankat, P.C. Rate-Controlled Separations, Elsevier Applied Science: London and New York, 1990. 
Chapter 8. Conclusions and Process Implications

\subsection{Adsorption Mechanisms}

Based on the present research, the mechanisms of adsorption of glycols, sugars, and related multi $-\mathrm{OH}$ compounds from water onto activated carbons are characterized by: (1) attractive dispersion interactions between surface and solute, and (2) secondary, competitive interactions of the solute $-\mathrm{OH}$ group(s) and/or surface oxygen groups with water. Results from batch adsorption experiments and thermogravimetric analysis (TGA) of loaded carbons support these conclusions. Although our work mainly focused on F400 (Calgon) carbon, a bituminous coal-based carbon, the mechanistic findings should be applicable to most, if not all, types of carbonaceous adsorbents.

The influence of the $-\mathrm{OH}$ group(s) on the aqueous solute upon adsorption onto carbons was apparent from comparing the equilibrium uptakes $\left(25^{\circ} \mathrm{C}\right)$ of the glycols and alcohol analogs. Solutes with greater positive deviations from solution-phase ideality exhibited greater uptake capacity (molar basis) and affinity (larger isotherm slope) on F400. The sugars, despite having many - $\mathrm{OH}$ groups, had among the highest uptakes on carbons. When measurements were made with F400 carbons that were modified systematically by acid oxidation, it was observed that the uptake capacities for glycerol, glycols, lactic acid, and sugars decreased. These results suggested that competitive adsorption with water is largely unfavorable for the adsorption of multi - $\mathrm{OH}$ solutes. Competitive adsorption could arise from either the oxygen surface groups present on the surface, or in the case of glycols and glycerol, the $-\mathrm{OH}$ group on the solute itself. 
Further mechanistic understanding was obtained by measuring isosteric enthalpies of adsorption on carbons for sugars, glycols, and alcohol analogs. The method involved measuring the shift in adsorption isotherm with temperature, where both solute activity coefficient and volumetric displacement of water were accounted for. The measured enthalpies were all exothermic, with the magnitude dictated primarily by the solute molecular weight. A secondary, competing effect is that the heat of adsorption appears to decrease with increasing number of $-\mathrm{OH}$ groups on the solute. Thus, measured enthalpies were largest for sucrose and propylene glycol, followed by glucose and propanol, and finally ethanol, ethylene glycol, and glycerol. Values of the isosteric heats of adsorption ranged form -40 to $-5 \mathrm{~kJ} / \mathrm{mol}$; therefore, it appears that the adsorption is physical, rather than chemical in nature. Thus, adsorption of aqueous multi - $\mathrm{OH}$ solutes on carbons should be readily reversible.

TGA was introduced as a novel method of characterizing the adsorbed phase of active carbons. The method consisted of measuring the sample weight continuously with a linear increase in temperature. Combined with related work from the literature, our results showed that alkanes and alcohols adsorbed on carbons desorb at temperatures substantially greater than their normal boiling points. The glycols and glycerols had higher volatilities in comparison with the liquid state, and usually desorbed at temperatures close to, or even below the normal boiling points. A first-order kinetic model for thermal desorption was derived to explain the shift in desorption profiles with heating rate. From the data, a correlation was found between the activation energy for desorption and the molecular weight of the solute. These results confirmed the 
importance of dispersion-force interactions with the carbon surface and hydrophobic exclusion from the solution phase for adsorption of these compounds onto carbons.

\subsection{Carbon Regenerability and Product Recovery}

Solvent regeneration was found to be an effective means of recovering the adsorbed solutes from carbons. Batch regeneration experiments identified acetone and methanol as effective solvents. Initially, results indicated that regeneration was nearly complete in the absence of water entrained within the carbon, but incomplete in the presence of entrained water. TGA (a more precise tool for analyzing the adsorbed phase) has confirmed, however, that the completeness of regeneration is not affected by entrained water. Although a small fraction of solute appeared to be resistant to solvent regeneration, TGA showed that the carbons may be regenerated to a large degree and subsequently reloaded without capacity loss. Also, it was found from TGA that methanol was easily desorbed from carbons, while acetone remained on the carbons to temperatures as high as $200^{\circ} \mathrm{C}$.

Fixed-bed adsorption and (solvent) regeneration experiments demonstrated that glycols and sugars may be concentrated to 3 to 6 times the original feed concentration. This "focusing" effect occurs because of the sharp shift in adsorption/desorption equilibrium of the bound solute upon the transition from an aqueous to organic environment. We also found that the product recovery is nearly complete ( $>90 \%)$ for all solutes. With methanol as the regenerant, the fixed-bed process may be cycled many times with minimal loss of capacity. 


\subsection{Process Considerations}

On the basis of our work, an adsorption-based technology for separating multi-OH compounds from aqueous solution should employ carbonaceous adsorbents of low oxygen content. This is important for maximizing the attractive hydrophobic/dispersion interactions between solute and surface, while simultaneously minimizing competitive adsorption of water. Adsorbents based on bituminous coal or peat, or synthesized from pyrolyzed polymer were found to be most effective. Heat treatment in an inert atmosphere will remove surface oxygen groups as $\mathrm{CO}$ and $\mathrm{CO}_{2}$, and could improve the performance of carbons with a naturally high oxygen content, such as those derived from wood.

As a product recovery process, fixed-bed adsorption and regeneration affords an economical alternative to the evaporation of all the water. The savings are enhanced by the focusing effect, which results in a more concentrated product and lower heat of vaporization for final purification. In order to optimize the focusing effect, one should use relatively uniform and/or small particle sizes to minimize channeling and axial dispersion during fixed-bed operation. As internal mass-transfer kinetics appear to be dominant, the focusing effect during regeneration is sustainable only when low flowrates of 3 to 15 bed volumes/hour are used. Methanol is a superior choice of regenerant in comparison with acetone, as the former is much more easily removed from the bed during cycling. 
Fractionation of mixtures of aqueous multi $-\mathrm{OH}$ solutes remains a problem. A partial separation was observed for aqueous propylene glycol-glycerol mixtures when a 2 to 5 wt. \% acetone in water solution was used as the regenerant. Fractionation may be possible by running the fixed-bed in a displacement-chromatography mode, but with loss of capacity. Other adsorption-based methods such as moving-bed or simulated-movingbed processes may be more promising for fractionation. The Ambersorb pyrolyzed polymers, studied to only a limited extent in our work, may also have greater potential for the difficult problem of fractionation. Despite being chemically and functionally similar to activated carbons, these adsorbents have a more homogeneous surface and superior shape and size uniformity, which may reduce axial dispersion considerably. 


\section{Appendix A. List of Chemicals}

\begin{tabular}{|c|c|c|}
\hline Chemical & Vendor & Description \\
\hline Acetone & Fisher & 99.4 wt. $\%$, Certified A.C.S. \\
\hline Acid, Hydrochloric & Fisher & 37.4 wt. $\%$, Certified A.C.S. \\
\hline Acid, Lactic & Aldrich & Monomer, 85 wt. $\%$ \\
\hline Acid, Nitric & Fisher & 69.4 wt. $\%$, Certified A.C.S. \\
\hline Acid, Sulfuric & Fisher & 98 wt. \%, Certified A.C.S. \\
\hline Diethylene Glycol & Aldrich & 99 wt. \% \\
\hline Dipropylene Glycol & Aldrich & 99 wt. $\%$ \\
\hline Ethanol & U.C. Berkeley Chemistry Dept. & Absolute ethanol \\
\hline Ethyl Acetate & Fisher & 99.9 wt. \%, HPLC Grade \\
\hline Ethylene Glycol & Fisher & Purified \\
\hline Glucose, $\mathrm{D}(+)$ & Fluka Chemie & Monohydrate USP \\
\hline Glycerol & Mallinckrodt & Spectrophotometric Grade \\
\hline Methanol & Fisher & 99.9 wt. \%, Certified A.C.S. \\
\hline Methyl Acetate & Aldrich & 99 wt. \% \\
\hline Nitrogen, Compressed & Air Liquide & 99.999 vol. \% \\
\hline Nitrogen, Liquid & U.C. Berkeley Chemistry Dept. & N/A \\
\hline Propanediol (1,2-) & Aldrich & 99 wt. \% \\
\hline Propanol (1-) & Aldrich & 99 wt. \% \\
\hline Propanol (2-) & Fisher & 99 wt. \% \\
\hline Sodium Hydroxide & Aldrich & Pellets, 97 wt. \% \\
\hline Sorbitol & Kodak & Chemical Purpose \\
\hline Sucrose & $\mathrm{C} \& \mathrm{H}$ & Pure Cane Sugar \\
\hline Tripropylene Glycol & Aldrich & 97 wt. \% \\
\hline
\end{tabular}




\section{B-1. Introduction}

The error bars reported with the data presented in Chapters 4 and 5 were calculated using the standard error-propagation formula given by Hall (1977). For example, a calculated quantity $u=f(x, y, z)$ that depends on the experimentally observed variables, $x, y$, and, $z$ will have a standard error of:

$$
e_{u}=\left|\frac{\partial f}{\partial x}\right| e_{x}+\left|\frac{\partial f}{\partial y}\right| e_{y}+\left|\frac{\partial f}{\partial z}\right| e_{z}
$$

where $e_{i}$ is the absolute error associated with the quantity, $i$.

In our work, this type of analysis is applied to calculated quantities such as the composite and individual uptakes, irreversible uptake, and percent regeneration. Since the precision of our Mettler AG204 balance is $\pm 0.0001 \mathrm{~g}$, we assume an absolute error of \pm 0.0002 for all measurements of mass. We assume of relative error of $2 \%$ for all concentration measurements obtained by HPLC, since this is the usual degree of reproducibility in peak-area integration for two replicate runs. 
B-2. Error Associated with the Composite Uptake, $\mathbf{q}_{2}$.

In accord with eq. (2.4.3-5), the composite uptake will depend on the concentration variable $X_{2 f}$, and the quantities determined by weighing: $X_{i}, m$, and $W_{0}$. Application of eq. (B-1) to eq. (2.5.3-5) yields this expression of the error in $q_{2}$ :

$$
\mathrm{dq}_{2}=\frac{\mathrm{w}_{\mathrm{o}}}{\mathrm{m}} \mathrm{dX} \mathrm{X}_{2 \mathrm{f}}+\frac{\mathrm{W}_{\mathrm{o}}}{\mathrm{m}} \mathrm{dX} \mathrm{X}_{2 \mathrm{i}}+\frac{\mathrm{q}_{2}}{\mathrm{~W}_{\mathrm{o}}} \mathrm{dW_{ \textrm {o } }}+\frac{\mathrm{q}_{2}}{\mathrm{~m}} \mathrm{dm}
$$

The term, $\mathrm{X}_{2 \mathrm{i}}$, is set at the beginning of each batch-adsorption experiment. The error term $\mathrm{dX}_{2 \mathrm{i}}$, is associated with errors from weighing:

$$
\mathrm{dX}_{2 \mathrm{i}}=\frac{1}{\mathrm{~m}_{\mathrm{t}}} \mathrm{dm}_{\mathrm{s}}+\frac{\mathrm{m}_{\mathrm{s}}}{\mathrm{m}_{\mathrm{t}}^{2}} \mathrm{dm}_{\mathrm{t}}
$$

where $m_{s}$ is the mass of solute used to formulate the initial, standard solution and $m_{t}$ is the total mass of the standard solution (solute + water).

A sensitivity analysis is now in order. We use the following values, taken from a data point of an EG-F400/HT isotherm at $25^{\circ} \mathrm{C}$, for the calculations: $\mathrm{m}_{\mathrm{s}}=1.030 \mathrm{~g}$, $\mathrm{m}_{\mathrm{t}}=10 \mathrm{~g}, \mathrm{X}_{2 \mathrm{i}}=0.103 \mathrm{~g} / \mathrm{g}, \mathrm{X}_{2 \mathrm{f}}=0.069 \mathrm{~g} / \mathrm{g}, \mathrm{W}_{\mathrm{o}}=4 \mathrm{~g}, \mathrm{~m}=1 \mathrm{~g}$, and $\mathrm{q}_{2}=0.136 \mathrm{~g} / \mathrm{g}$.

Applying eqs. (B-1.1) and (B-1.2), we find the relative magnitude of each term contributing to the error in $\mathrm{q}_{2}$. The results are tallied below: 
Term in eq. $(\mathrm{B}-2.1)$

Magnitude (g/g)

\begin{tabular}{ll}
$\mathrm{W}_{\mathrm{o}} \mathrm{dX}_{2 \mathrm{f}} / \mathrm{m}$ & $5.5 \times 10^{-3}$ \\
$\mathrm{~W}_{0} \mathrm{dX}_{2 \mathrm{i}} / \mathrm{m}$ & $8.8 \times 10^{-5}$ \\
$\mathrm{q}_{2} \mathrm{dW}_{0} / \mathrm{m}$ & $6.8 \times 10^{-6}$ \\
$\mathrm{q}_{2} \mathrm{dm} / \mathrm{m}$ & $2.7 \times 10^{-5}$ \\
\hline Total error: $\mathrm{dq}_{2}$ & \\
\hline
\end{tabular}

Clearly, the calculation demonstrates that the uncertainties in $\mathrm{X}_{2 \mathrm{f}}$ are 2-3 orders of magnitude larger than the errors associated from weighing. For this reason, all error bars shown on isotherms are well approximated by:

$$
\mathrm{dq}_{2}=\frac{\mathrm{w}_{\mathrm{o}}}{\mathrm{m}} \mathrm{dX}_{2 \mathrm{f}}
$$

It is also evident from eq. (B-2.3) that using small phase ratios solution to carbon leads to results of higher precision.

\section{B-3. Error Associated with the Individual Uptake, $\mathbf{Q}_{2}$.}

In using eq. (2.4.3-6) to estimate the individual uptake $\left(\mathrm{Q}_{2}\right)$ from the composite uptake $\left(q_{2}\right)$, we have a new measured parameter $\mathrm{m}_{\text {wet. }}$ Using eq. (B-1) on eq. (2.4.3-6), we have: 


$$
\mathrm{dQ}_{2}=\mathrm{dq}_{2}+\left(\frac{\mathrm{m}_{\mathrm{wet}}-\mathrm{m}}{\mathrm{m}}\right) \mathrm{dX} 2 \mathrm{f}+\frac{\mathrm{X}_{2 \mathrm{f}}}{\mathrm{m}} \mathrm{dm}_{\mathrm{wet}}+\frac{\mathrm{m}_{\mathrm{wet}} \mathrm{X}_{2 \mathrm{f}}}{\mathrm{m}^{2}} \mathrm{dm}
$$

Using the same parameters as in the previous example, we calculate for $\mathrm{q}_{2}=0.136 \mathrm{~g} / \mathrm{g}$, (and assuming $\mathrm{m}_{\text {wet }}=1.78 \mathrm{~g}$ ), $\mathrm{Q}_{2}=0.190 \mathrm{~g} / \mathrm{g}$. We also have the following sensitivity results:

Term in eq. (B-3.1)

$\mathrm{dq}_{2}$

$\left(\mathrm{m}_{\text {wet }}-\mathrm{m}\right) \mathrm{dX} \mathrm{X}_{2 \mathrm{f}} / \mathrm{m}$

$\mathrm{X}_{2 \mathrm{f}} \mathrm{dm}_{\text {wet }} / \mathrm{m}$

$\mathrm{m}_{\text {wet }} \mathrm{X}_{2 \mathrm{f}} \mathrm{dm} / \mathrm{m}^{2}$

Total error: $\quad \mathrm{dQ}_{2}$
Magnitude (g/g)

$5.6 \times 10^{-3}$

$1.1 \times 10^{-3}$

$1.4 \times 10^{-5}$

$2.5 \times 10^{-5}$

$6.7 \times 10^{-3}$

Once again, the uncertainties in weighing are much less significant that the uncertainties of $\mathrm{q}_{2}$ and $\mathrm{X}_{2 \mathrm{f}}$. Errors in calculating the individual uptakes could therefore be closely determined by:

$$
\mathrm{dQ}_{2}=\mathrm{dq}_{2}+\left(\frac{\mathrm{m}_{\mathrm{wet}}-\mathrm{m}}{\mathrm{m}}\right) \mathrm{dX} 2 \mathrm{f}
$$




\section{B-4. Error Associated with the Residual Uptake, $\mathbf{q}_{2}{ }^{\prime}$.}

The residual uptake, $\mathrm{q}_{2}{ }^{\prime}$, depends on two more additional terms: $\mathrm{X}_{2 \mathrm{f}}$ and $\mathrm{W}_{\mathrm{o}}{ }^{\prime}$.

Application of eq. (B-1) to eq. (2.4.3-8) yields the following expression for $\mathrm{dq}_{2}{ }^{\prime}$ :

$$
\begin{aligned}
& \mathrm{dq}_{2}{ }^{\prime}=\mathrm{dQ}_{2}+\left(\frac{\mathrm{w}_{\mathrm{o}}^{\prime}+\mathrm{m}_{\mathrm{wet}}-\mathrm{m}}{\mathrm{m}}\right) \mathrm{dX_{2f }}+\frac{\mathrm{X}_{2 \mathrm{f}^{\prime}}}{\mathrm{m}} \mathrm{dW}_{\mathrm{o}}{ }^{\prime}+\frac{\mathrm{X}_{2 \mathrm{f}^{\prime}}}{\mathrm{m}} \mathrm{dm} \mathrm{wet}_{\text {w }} \\
& +\left(\frac{w_{0}^{\prime} X_{2 f}+m_{w e t} X_{2 f}^{\prime}}{m^{2}}\right) d m
\end{aligned}
$$

Now, suppose the carbon from the previous examples $\left(q_{2}=0.136 \mathrm{~g} / \mathrm{g}, \mathrm{Q}_{2}=0.190 \mathrm{~g} / \mathrm{g}\right)$ is batchwise regenerated by methanol $\left(\mathrm{W}_{\mathrm{o}}^{\prime}=7.8 \mathrm{~g}\right)$. We will keep all parameter and error values as before, but in addition find that at equilibrium, $\mathrm{X}_{2 \mathrm{f}^{\prime}}=0.0178 \mathrm{~g} / \mathrm{g}$ in the organic phase. This means that $\mathrm{q}_{2}^{\prime}=0.037 \mathrm{~g} / \mathrm{g}$. A term-by-term analysis of eq. (B-4.1) yields:

Term in eq. $(B-4.1)$

$$
\mathrm{dQ}_{2}
$$$$
\left(W_{0}^{\prime}+m_{\text {wet }}-m\right) d X_{2 f^{\prime}} / m
$$$$
\mathrm{X}_{2 \mathrm{f}^{\prime}} \mathrm{dW}_{\mathrm{o}}^{\prime} / \mathrm{m}
$$$$
\mathrm{X}_{2 \mathrm{f}} \mathrm{dm}_{\mathrm{wet}} / \mathrm{m}
$$$$
\left(W_{o}^{\prime} X_{2 f}+m_{\text {wet }} X_{2 f^{\prime}}\right) \mathrm{dm} / \mathrm{m}^{2}
$$

Total Error: $\quad \mathrm{dq}_{2}{ }^{\prime}$
Magnitude (g/g)

$6.7 \times 10^{-3}$

$3.1 \times 10^{-3}$

$3.6 \times 10^{-6}$

$3.6 \times 10^{-6}$

$1.1 \times 10^{-4}$

$9.9 \times 10^{-3}$ 
As expected, the greatest contributors to $\mathrm{dq}_{2}{ }^{\prime}$ are the errors associated with the individual uptake from the previous loading stage and from $\mathrm{X}_{2 \mathrm{f}}$. The contribution of the $\mathrm{dm}$ term is also greater than in the previous examples; however, neglecting it will not alter the calculations significantly. Hence, a simplified form of eq. (B-4.1) is:

$$
\mathrm{dq}_{2}{ }^{\prime}=\mathrm{dQ}_{2}+\left(\frac{\mathrm{w}_{\mathrm{o}}{ }^{\prime}+\mathrm{m}_{\text {wet }}-\mathrm{m}}{\mathrm{m}}\right) \mathrm{dX} \mathrm{X}_{2 \mathrm{f}}{ }^{\prime}
$$

\section{B-5. Error Associated with the Percent Regenerability, \%RE.}

Lastly, errors in the percent regenerability, as defined by eq. (2.4.3-10), could be determined from knowing the errors in $q_{2}$ and $q_{2}{ }^{\prime}$ :

$$
d(\% \text { RE })=\frac{100}{q} d q^{\prime}+\frac{100 q^{\prime}}{q^{2}} d q
$$

In our example, with $\mathrm{q}_{2}=0.136 \mathrm{~g} / \mathrm{g}$ and $\mathrm{q}_{2}^{\prime}=0.037 \mathrm{~g} / \mathrm{g}$, we have $\% \mathrm{RE}=73$. However, the standard error, $d(\% \mathrm{RE})$ has significant contributions from both terms. Application of eq. $(B-5.1)$ yields $d(\% R E)=8$.

\section{References:}

Hall, C.S. Errors in Experimentation, Matrix Publishers, Inc.: Illinois, 1977. 


\section{Appendix C. Curve Fitting of Isotherms}

\section{C-1 Freundlich Isotherm}

Most of our adsorption data were correlated to the Freundlich equation:

$$
q=K_{F} X_{f}^{n}
$$

where $\mathrm{X}_{\mathrm{f}}$ is the equilibrium solute mass fraction $(\mathrm{g} / \mathrm{g}), \mathrm{q}$ is the composite uptake $\left(\mathrm{mg} / 1000 \mathrm{~m}^{2}\right)$, and $\mathrm{K}_{\mathrm{F}}$ and $\mathrm{n}$ are empirical fitting parameters. The Freundlich equation is based on assuming an exponential distribution of adsorption-site energies, with the parameter $\mathrm{n}$ representing the width of the distribution (Mattson and Mark, 1971; DeryloMarczewska et al., 1984). A value of unity for $\mathrm{n}$ signifies a homogeneous surface. The parameter $\mathrm{K}_{\mathrm{F}}$ represents the adsorption capacity at an arbitrary and often hypothetical solute concentration of unity. Although this equation does not reduce to Henry's Law at low concentrations, it describes portions of many experimental isotherms of organics and weak electrolytes from dilute aqueous solution (Mattson and Mark, 1971).

The regression curves shown for isotherms presented in Chapter 4 were derived by means of the nonlinear Marquardt-Levenberg algorithm through Sigma Plot 3.0 (Jandel Scientific) software. A linearized form of eq. (C-1.2) could also be used for data regression: 


$$
\ln (q)=\ln \left(K_{F}\right)+n \ln \left(X_{f}\right)
$$

Tabulated below are the parameter values (along with standard errors) for the isotherms presented in Chapter 4, using both nonlinear and linear of the Freundlich equation. As can be seen, several different combinations of values for $\mathrm{K}_{\mathrm{F}}$ and $\mathrm{n}$ are capable of describing a given set of data well. Although this obviously makes comparison between different data sets difficult, curve fitting does provide the engineer with a convenient means to calculate data.

Key for following tables: $\left({ }^{*}\right) X_{f}$ has units of $g / g$.

$(* *) \mathrm{X}_{\mathrm{f}}$ has units of $\mathrm{mol} / \mathrm{mol}$.

\section{TABLE C-1}

Nonlinear Fit* Linearized Fit*

\begin{tabular}{|c|c|c|c|c|c|}
\hline & FIGURE & $\mathrm{K}_{\mathrm{F}}(\mathrm{mg} / \mathrm{g})$ & $\mathrm{n}$ & $\mathrm{K}_{\mathrm{F}}(\mathrm{mg} / \mathrm{g})$ & $\mathrm{n}$ \\
\hline F400/HT & & & & & \\
\hline EG & $4.1-1$ & $629 \pm 8 \%$ & $0.591 \pm 5 \%$ & $768 \pm 7 \%$ & $0.655 \pm 3 \%$ \\
\hline PG & $4.1-1$ & $531 \pm 8 \%$ & $0.390 \pm 12 \%$ & $664 \pm 8 \%$ & $0.457 \pm 4 \%$ \\
\hline Glycerol & $4.1-1$ & $433 \pm 9 \%$ & $0.437 \pm 6 \%$ & $538 \pm 12 \%$ & $0.499 \pm 6 \%$ \\
\hline
\end{tabular}

TABLE C-2

Nonlinear Fit** Linearized Fit**

\begin{tabular}{|c|c|c|c|c|c|}
\hline & FIGURE & $\mathrm{K}_{\mathrm{F}}(\mathrm{mmol} / \mathrm{g})$ & $\mathrm{n}$ & $\mathrm{K}_{\mathrm{F}}(\mathrm{mmol} / \mathrm{g})$ & $\mathrm{n}$ \\
\hline F400 & & & & & \\
\hline EtOH & $4.2-2$ & $60.48 \pm 27 \%$ & $0.635 \pm 8 \%$ & $91.63 \pm 36 \%$ & $0.714 \pm 9 \%$ \\
\hline 1-PrOH & $4.2-2$ & $26.78 \pm 21 \%$ & $0.400 \pm 8 \%$ & $34.73 \pm 23 \%$ & $0.441 \pm 8 \%$ \\
\hline $2-$ PrOH & $4.2-2$ & $23.25 \pm 33 \%$ & $0.400 \pm 14 \%$ & $35.27 \pm 38 \%$ & $0.467 \pm 12 \%$ \\
\hline EG & $4.2-2$ & $19.13 \pm 11 \%$ & $0.574 \pm 5 \%$ & $25.66 \pm 10 \%$ & $0.642 \pm 3 \%$ \\
\hline PG & $4.2-2$ & $10.62 \pm 11 \%$ & $0.379 \pm 7 \%$ & $14.56 \pm 11 \%$ & $0.449 \pm 5 \%$ \\
\hline Glycerol & $4.2-2$ & $8.90 \pm 13 \%$ & $0.425 \pm 6 \%$ & $12.33 \pm 16 \%$ & $0.489 \pm 6 \%$ \\
\hline lactic acid & $4.2-2$ & $12.88 \pm 16 \%$ & $0.320 \pm 9 \%$ & $11.12 \pm 17 \%$ & $0.295 \pm 9 \%$ \\
\hline
\end{tabular}


TABLE C-3

Nonlinear Fit**

Linearized Fit**

\begin{tabular}{|c|c|c|c|c|c|}
\hline F400 & FIGURE & $\mathrm{K}_{\mathrm{F}}(\mathrm{mmol} / \mathrm{g})$ & $\mathrm{n}$ & $\mathrm{K}_{\mathrm{F}}(\mathrm{mmol} / \mathrm{g})$ & $\mathbf{n}$ \\
\hline Sucrose & & & & & \\
\hline $25^{\circ} \mathrm{C}$ & $4.3-1$ & $4.92 \pm 22 \%$ & $0.234 \pm 10 \%$ & $5.52 \pm 24 \%$ & $0.246 \pm 10 \%$ \\
\hline $45^{\circ} \mathrm{C}$ & $4.3-1$ & $3.58 \pm 15 \%$ & $0.213 \pm 8 \%$ & $3.69 \pm 13 \%$ & $0.216 \pm 6 \%$ \\
\hline $65^{\circ} \mathrm{C}$ & $4.3-1$ & $6.27 \pm 21 \%$ & $0.292 \pm 8 \%$ & $7.98 \pm 26 \%$ & $0.317 \pm 8 \%$ \\
\hline & & & & & \\
\hline EG & & & & & \\
\hline $25^{\circ} \mathrm{C}$ & $4.3-2$ & $32.77 \pm 38 \%$ & $0.668 \pm 11 \%$ & $54.16 \pm 51 \%$ & $0.758 \pm 11 \%$ \\
\hline $65^{\circ} \mathrm{C}$ & $4.3-2$ & $115 \pm 35 \%$ & $0.915 \pm 7 \%$ & $252 \pm 54 \%$ & $1.05 \pm 9 \%$ \\
\hline & & & & & \\
\hline PG & & & & & \\
\hline $25^{\circ} \mathrm{C}$ & $4.3-2$ & $13.65 \pm 41 \%$ & $0.412 \pm 17 \%$ & $16.38 \pm 26 \%$ & $0.444 \pm 10 \%$ \\
\hline $65^{\circ} \mathrm{C}$ & $4.3-2$ & $28.39 \pm 14 \%$ & $0.574 \pm 4 \%$ & $37.69 \pm 17 \%$ & $0.620 \pm 4 \%$ \\
\hline
\end{tabular}

TABLE C-4

Nonlinear Fit* Linearized Fit*

\begin{tabular}{|c|c|c|c|c|c||}
\hline & FIGURE & $\begin{array}{c}\mathrm{K}_{\mathrm{F}} \\
\left(\mathrm{mg} / 1000 \mathrm{~m}^{2}\right)\end{array}$ & $\mathrm{n}$ & $\begin{array}{c}\mathrm{K}_{\mathrm{F}} \\
\left(\mathrm{mg} / 1000 \mathrm{~m}^{2}\right)\end{array}$ & $\mathrm{n}$ \\
\hline EG & & & & & \\
\hline F400/HT & $4.4-1$ & $776 \pm 17 \%$ & $0.594 \pm 10 \%$ & $1081 \pm 25 \%$ & $0.697 \pm 9 \%$ \\
\hline OX50/2 & $4.4-1$ & $908 \pm 20 \%$ & $0.727 \pm 12 \%$ & $1500 \pm 51 \%$ & $0.874 \pm 15 \%$ \\
\hline OX70/2 & $4.4-1$ & $142 \pm 43 \%$ & $0.365 \pm 37 \%$ & $203 \pm 51 \%$ & $0.484 \pm 29 \%$ \\
\hline & & & & & \\
\hline PG & & & & & \\
\hline F400/HT & $4.4-2$ & $928 \pm 15 \%$ & $0.495 \pm 11 \%$ & $981 \pm 24 \%$ & $0.516 \pm 12 \%$ \\
\hline OX & $4.4-2$ & $1348 \pm 21 \%$ & $0.752 \pm 10 \%$ & $1272 \div 25 \%$ & $0.737 \pm 8 \%$ \\
\hline Glycerol & & & & & \\
\hline F400/HT & $4.4-3$ & $417 \pm 8 \%$ & $0.441 \pm 6 \%$ & $522 \pm 12 \%$ & $0.505 \pm 6 \%$ \\
\hline OX50/2 & $4.4-3$ & $449 \pm 23 \%$ & $0.553 \pm 14 \%$ & $858 \pm 71 \%$ & $0.765 \pm 24 \%$ \\
\hline OX70/2 & $4.4-3$ & $302 \pm 15 \%$ & $0.476 \pm 10 \%$ & $379 \pm 27 \%$ & $0.544 \pm 13 \%$ \\
\hline & & & & & \\
\hline Lac. Acid & & & & & \\
\hline F400/HT & $4.4-5$ & $491 \pm 9 \%$ & $0.316 \pm 9 \%$ & $594 \pm 14 \%$ & $0.367 \pm 8 \%$ \\
\hline OX50/2 & $4.4-5$ & $413 \pm 13 \%$ & $0.346 \pm 12 \%$ & $513 \pm 15 \%$ & $0.408 \pm 8 \%$ \\
\hline OX70/2 & $4.4-5$ & $436 \pm 6 \%$ & $0.395 \pm 5 \%$ & $496 \pm 12 \%$ & $0.432 \pm 6 \%$ \\
\hline
\end{tabular}




\section{C-2 Langmuir Isotherm}

Several multi -OH solutes in our work, namely the sugars (glucose, sucrose) and the hydrogenated sugar (sorbitol) exhibit Langmuir-type isotherms:

$$
q=\frac{\mathrm{q}_{m} \mathrm{~K}_{\mathrm{L}} \mathrm{X}_{\mathrm{f}}}{1+\mathrm{K}_{\mathrm{L}} \mathrm{X}_{\mathrm{f}}}
$$

where $\mathrm{q}$ is the composite uptake $\left(\mathrm{mg} / 1000 \mathrm{~m}^{2}\right), \mathrm{X}_{\mathrm{f}}$ is the equilibrium solute mass fraction $(\mathrm{g} / \mathrm{g}), \mathrm{q}_{\mathrm{m}}$ is the solute loading at monolayer coverage $\left(\mathrm{mg} / 1000 \mathrm{~m}^{2}\right)$, and $\mathrm{K}_{\mathrm{L}}$ is a fitting parameter $(\mathrm{g} / \mathrm{g})$ related to the heat of adsorption at low solute concentrations. The Langmuir equation assumes a uniform site energy for the surface, and is thermodynamically consistent since it reduces to Henry's Law at low concentrations.

Curve-fitting with the Langmuir equation was also done using Sigma Plot 3.0 (Jandel Scientific) software. The well-known linearized form of the Langmuir is:

$$
\frac{1}{q} \doteq \frac{1}{q_{m}}+\frac{1}{q_{m} K_{L} X_{f}}
$$

Tabulated below are the parameter values (along with standard errors) for the isotherms presented in Chapter 4, using both nonlinear and linear of the Langmuir equation. 
TABLE C-5

Nonlinear Fit*

\begin{tabular}{||c|c|c|c|c|c||}
\hline SOLUTE & FIGURE & $\begin{array}{c}\mathrm{K}_{\mathrm{L}} \\
(\mathrm{g} / \mathrm{g})\end{array}$ & $\mathrm{q}_{\mathrm{m}}(\mathrm{mg} / \mathrm{g})$ & $\begin{array}{c}\mathrm{K}_{\mathrm{L}} \\
(\mathrm{g} / \mathrm{g})\end{array}$ & $\mathrm{q}_{\mathrm{m}}(\mathrm{mg} / \mathrm{g})$ \\
\hline F400/HT & & & & & \\
\hline Glucose & $4.1-1$ & $185 \pm 24 \%$ & $220 \pm 7 \%$ & $410 \pm 20 \%$ & $167 \pm 14 \%$ \\
\hline Sorbitol & $4.1-1$ & $105 \pm 23 \%$ & $314 \pm 6 \%$ & $373 \pm 23 \%$ & $217 \pm 18 \%$ \\
\hline Sucrose & $4.1-1$ & $778 \pm 6 \%$ & $289 \pm 1 \%$ & $837 \pm 3 \%$ & $283 \pm 2 \%$ \\
\hline
\end{tabular}

TABLE C-6

Nonlinear Fit*

Linearized Fit*

\begin{tabular}{||c|c|c|c|c|c||}
\hline SOLUTE & FIGURE & $\begin{array}{c}\mathrm{K}_{\mathrm{L}} \\
(\mathrm{g} / \mathrm{g})\end{array}$ & $\begin{array}{c}\mathrm{q}_{\mathrm{m}} \\
\left(\mathrm{mg} / 1000 \mathrm{~m}^{2}\right)\end{array}$ & $\begin{array}{c}\mathrm{K}_{\mathrm{L}} \\
(\mathrm{g} / \mathrm{g})\end{array}$ & $\begin{array}{c}\mathrm{q}_{\mathrm{m}} \\
\left(\mathrm{mg} / 1000 \mathrm{~m}^{2}\right)\end{array}$ \\
\hline Glucose & & & & & \\
\hline F400/HT & $4.4-4$ & $158 \pm 21 \%$ & $222 \pm 5 \%$ & $369 \pm 19 \%$ & $171 \pm 13 \%$ \\
\hline OX50/2 & $4.4-4$ & $89 \pm 12 \%$ & $193 \pm 3 \%$ & $164 \pm 17 \%$ & $155 \pm 11 \%$ \\
\hline OX70/2 & $4.4-4$ & $66 \pm 22 \%$ & $188 \pm 7 \%$ & $120 \pm 14 \%$ & $151 \pm 10 \%$ \\
\hline WVB & $4.4-7$ & $28 \pm 11 \%$ & $196 \pm 5 \%$ & $32 \pm 8 \%$ & $183 \pm 6 \%$ \\
\hline RO 0.8 & $4.4-7$ & $190 \pm 9 \%$ & $229 \pm 2 \%$ & $272 \pm 8 \%$ & $209 \pm 5 \%$ \\
\hline F400 & $4.4-7$ & $202 \pm 8 \%$ & $194 \pm 2 \%$ & $229 \pm 5 \%$ & $188 \pm 3 \%$ \\
\hline
\end{tabular}

\section{References}

Derylo-Marczewska, A.; Jaroniec, M.; Gelbin, D.; Seidel, A. Chemica Scripta, 1984, 24, 239.

Mattson, J.S.; Mark, Jr., H.B. Activated Carbon, Surface Chemistry and Adsorption from Solution, Marcel Dekker, Inc.: New York, 1971. 


\section{D-1 Simpson's Rule}

One straightforward method of integrating a function, $\mathrm{f}(\mathrm{x})$ numerically is Simpson's rule.

Simpson's rules states that for $\mathrm{N}+1$ data points, where $\mathrm{N}$ is even:

$$
\int_{x_{0}^{N}}^{x} f(x) d x=\frac{h}{3}\left(f_{0}+4 f_{1}+2 f_{2}+4 f_{3}+2 f_{4}+\ldots+4 f_{N-1}+f_{N}\right)
$$

where $\mathrm{X}_{\mathrm{O}}$ and $\mathrm{X}_{\mathrm{N}}$ are the limits of integration, $\mathrm{h}$ is the length of each interval defined as $\mathrm{h}$ $=\left(X_{N}-X_{O}\right) / N$, and $f_{i}$ is the function evaluated at position $X=i h$.

For $N+1$ points, where $(\mathrm{N} / 3)$ is an integer:

$$
\int_{x_{0}}^{\mathrm{x}} \mathrm{f}(\mathrm{x}) \mathrm{dx}=\frac{3 \mathrm{~h}}{8}\left(\mathrm{f}_{\mathrm{o}}+3 \mathrm{f}_{1}+3 \mathrm{f}_{2}+2 \mathrm{f}_{3}+3 \mathrm{f}_{4}+3 \mathrm{f}_{5}+2 \mathrm{f}_{6} \ldots+3 \mathrm{f}_{\mathrm{N}-1}+\mathrm{f}_{\mathrm{N}}\right)
$$

\section{D-2 Sample Calculation - Loading}

As an example, the use of Simpson's rule will be demonstrated for the fixed-bed loading of EG onto heat-treated F400 (Figure 7.2-1). A solution of $0.0459 \mathrm{~g} / \mathrm{mL}$ EG was passed 
through the bed at a flowrate of $1.58 \mathrm{~mL} / \mathrm{min}$. Table D-1 summarizes the procedure for evaluation of $\mathrm{M}_{\mathrm{load}}$ in accord to eq. (7.2-2).

\section{TABLE D-1}

Raw Data Data for Simpson's Rule

\begin{tabular}{||c|c|c|c|c|c|}
\hline $\mathbf{t}(\mathbf{m i n})$ & $\mathbf{C} / \mathbf{C}_{\text {feed }}$ & $\mathbf{x}(\mathbf{m i n})$ & $\mathbf{f}(\mathbf{x})$ & $\mathbf{m}$ & $\mathbf{m f}(\mathbf{x})$ \\
\hline 2 & 0 & 3.09 & 0 & 1 & 0 \\
\hline 4 & 0 & 6.18 & 0 & 4 & 0 \\
\hline 6 & 0 & 9.27 & 0 & 2 & 0 \\
\hline 8 & 0 & 12.36 & 0.09411 & 4 & 0.3764 \\
\hline 10 & 0 & 15.45 & 0.2542 & 2 & 0.5084 \\
\hline 12 & 0.07859 & 18.54 & 0.4851 & 4 & 1.940 \\
\hline 14 & 0.1648 & 21.63 & 0.6884 & 2 & 1.377 \\
\hline 16 & 0.2881 & 24.72 & 0.8257 & 4 & 3.303 \\
\hline 18 & 0.4461 & 27.81 & 0.8839 & 2 & 1.768 \\
\hline 20 & 0.5905 & 30.90 & 0.9460 & 4 & 3.784 \\
\hline 22 & 0.7106 & 33.99 & 0.9734 & 2 & 1.947 \\
\hline 24 & 0.8038 & 37.08 & 0.9929 & 4 & 3.971 \\
\hline 26 & 0.8646 & 40.17 & 0.991 & 2 & 1.982 \\
\hline 28 & 0.8859 & 43.26 & 0.9958 & 4 & 3.983 \\
\hline 30 & 0.9380 & 46.35 & 0.9973 & 2 & 1.995 \\
\hline 34 & 0.9735 & 49.44 & 0.9991 & 4 & 3.996 \\
\hline 38 & 0.9987 & 52.53 & 1.000 & 2 & 2.002 \\
\hline 42 & 0.9952 & 55.62 & 1.002 & 4 & 4.008 \\
\hline 46 & 0.9972 & 58.71 & 1.003 & 2 & 2.006 \\
\hline 54 & 1.002 & 61.80 & 1.010 & 4 & 4.041 \\
\hline 62 & 1.004 & 64.89 & 1.009 & 2 & 2.017 \\
\hline 66 & 1.010 & 67.98 & 1.005 & 4 & 4.021 \\
\hline 70 & 1.000 & 71.07 & 1.000 & 1 & 1.000 \\
\hline
\end{tabular}

The columns $\left(\mathrm{t}, \mathrm{C} / \mathrm{C}_{\mathrm{feed}}\right)$ under "raw data" are actual measurements obtained from the loading experiment using the fraction collector. The column " $x$ " corresponds to the equally-spaced time increments used for the integration. Column $f(x)$ shows the value of $f$ that is expected at time " $x$ ". The parameter " $m$ " is simply the weighing coefficient of eq. (D-1.1), having values of 1,2 , or 4 . In our work, an approximate value of $f(x)$ is obtained by linear interpolation of from neighboring values of $\mathrm{C} / \mathrm{C}_{\text {feed }}$. 
After summing up the values in column " $\mathrm{mf}(\mathrm{x})$ " and multiplying by $\mathrm{h} / 3$, we find the value of the integral equal to 51.54 . With the parameters $t_{F}=70 \mathrm{~min}, \mathrm{~V}_{\mathrm{o}}=1.58 \mathrm{~mL} / \mathrm{min}$, and $\mathrm{C}_{\text {feed }}=0.0459 \mathrm{~g} / \mathrm{mL}$, we find $\mathrm{M}_{\text {load }}$ from eq. $(7.2-2)$ as $1.42 \mathrm{~g} \mathrm{EG}$.

\section{D-3 Sample Calculation - Regeneration}

The integration procedure will now be demonstrated for the fixed-bed regeneration of the EG-loaded F400/HT bed by acetone. The flowrate of acetone was kept at $1.58 \mathrm{~mL} / \mathrm{min}$. The elution profile is shown in Figure 7.3-1. Table D-1 (see following page) summarizes the procedure for evaluation of $\mathrm{M}_{\mathrm{reg}}$ in accord to eq. $(7.3-2)$. Here, we are fortunate in that all data collected are within equal time increments (Hence, $t=x$, and $C=f(x)$ for all points). In cases where part of the data are not reported in equal increments, it is necessary to estimate values through linear interpolation, as described in the previous data set.

After summing up the values in column " $m f(x)$ " and multiplying by $h / 3$, we find the value of the integral equal to 0.8544 . With $\mathrm{V}_{\mathrm{o}}=1.58 \mathrm{~mL} / \mathrm{min}$, we find $\mathrm{M}_{\text {reg }}$ from eq. (7.3-1) as $1.38 \mathrm{~g} \mathrm{EG}$, which is within $5 \%$ of the value determined from the loading experiment. 
TABLE D-2

Raw Data

Data for Simpson's Rule

\begin{tabular}{|c|c|c|c|c|c|}
\hline$t(\min )$ & $C(\mathrm{~g} / \mathrm{mL})$ & $x(\min )$ & $f(x)$ & $\mathbf{m}$ & $\operatorname{mf}(x)$ \\
\hline 0 & 0.04668 & 0 & 0.04668 & 1 & 0.04668 \\
\hline 0.5 & 0.04668 & 0.5 & 0.04668 & 4 & 0.01867 \\
\hline 1 & 0.04931 & 1 & 0.04931 & 2 & 0.09862 \\
\hline 1.5 & 0.04941 & 1.5 & 0.04941 & 4 & 0.1976 \\
\hline 2 & 0.05010 & 2 & 0.05010 & 2 & 0.1020 \\
\hline 2.5 & 0.04885 & 2.5 & 0.04885 & 4 & 0.1954 \\
\hline 3 & 0.05043 & 3 & 0.05043 & 2 & 0.1009 \\
\hline 3.5 & 0.04934 & 3.5 & 0.04934 & 4 & 0.1973 \\
\hline 4 & 0.04820 & 4 & 0.04820 & 2 & 0.09641 \\
\hline 4.5 & 0.04954 & 4.5 & 0.04954 & 4 & 0.1982 \\
\hline 5 & 0.05371 & 5 & 0.05371 & 2 & 0.1074 \\
\hline 5.5 & 0.05275 & 5.5 & 0.05275 & 4 & 0.2110 \\
\hline 6 & 0.05565 & 6 & 0.05565 & 2 & 0.1113 \\
\hline 6.5 & 0.06459 & 6.5 & 0.06459 & 4 & 0.2583 \\
\hline 7 & 0.08121 & 7 & 0.08121 & 2 & 0.1624 \\
\hline 7.5 & 0.1128 & 7.5 & 0.1128 & 4 & 0.4512 \\
\hline 8 & 0.1356 & 8 & 0.1356 & 2 & 0.2712 \\
\hline 8.5 & 0.1475 & 8.5 & 0.1475 & 4 & 0.5899 \\
\hline 9 & 0.1203 & 9 & 0.1203 & 2 & 0.2406 \\
\hline 9.5 & 0.09583 & 9.5 & 0.09583 & 4 & 0.3833 \\
\hline 10 & 0.07455 & 10 & 0.07455 & 2 & 0.1491 \\
\hline 10.5 & 0.05449 & 10.5 & 0.05449 & 4 & 0.2179 \\
\hline 11 & 0.04537 & 11 & 0.04537 & 2 & 0.09074 \\
\hline 11.5 & 0.03674 & 11.5 & 0.03674 & 4 & 0.1470 \\
\hline 12 & 0.02841 & 12 & 0.02841 & 2 & 0.05681 \\
\hline 12.5 & 0.02437 & 12.5 & 0.02437 & 4 & 0.09747 \\
\hline 13 & 0.01938 & 13 & 0.01938 & 2 & 0.03876 \\
\hline 13.5 & 0.01667 & 13.5 & 0.01667 & 4 & 0.06668 \\
\hline 14 & 0.01321 & 14 & 0.01321 & 2 & 0.02642 \\
\hline 14.5 & 0.003544 & 14.5 & 0.003544 & 4 & 0.01418 \\
\hline 15 & 0.003998 & 15 & 0.003998 & 2 & 0.00800 \\
\hline 15.5 & 0.001791 & 15.5 & 0.001791 & 4 & 0.00717 \\
\hline 16 & 0 & 16 & 0 & 1 & 0 \\
\hline
\end{tabular}




\section{Appendix E. Experimental Data}

TABLE E-1

Adsorption Isotherms $\left(25^{\circ} \mathrm{C}-65^{\circ} \mathrm{C}\right)$ on Untreated $\mathrm{F} 400$ Carbons

(Figures 4.2-2, 4.3-1, 4.3-2, 4.3-3, and 4.3-4)

\begin{tabular}{|c|c|c|c|c|c|c|c|}
\hline $\begin{array}{l}\mathrm{m}_{\mathrm{dry}} \\
(\mathrm{g})\end{array}$ & $\begin{array}{l}W_{0} \\
(g)\end{array}$ & $\begin{array}{c}\mathrm{X}_{\mathrm{i}} \\
(\mathrm{g} / \mathrm{g})\end{array}$ & $\begin{array}{c}\mathrm{X}_{\mathrm{i}} \\
(\mathrm{mol} / \mathrm{mol})\end{array}$ & $\begin{array}{c}X_{f} \\
(g / g)\end{array}$ & $\begin{array}{c}\mathrm{X}_{\mathrm{f}} \\
(\mathrm{mol} / \mathrm{mol})\end{array}$ & $\underset{(m g / g)}{q}$ & $\begin{array}{c}\mathrm{q} \\
(\mathrm{mmol} / \\
\mathrm{g})\end{array}$ \\
\hline \multicolumn{8}{|c|}{ EtOH $\left(25^{\circ} \mathrm{C}\right)$} \\
\hline 1.0062 & 5.0481 & 0.0102 & $4.02 \mathrm{E}-03$ & 0.0034 & $1.34 \mathrm{E}-03$ & 34 & 0.74 \\
\hline 1.0169 & 5.0871 & 0.0223 & $8.84 \mathrm{E}-03$ & 0.0076 & $2.99 \mathrm{E}-03$ & 73 & 1.60 \\
\hline 1.0605 & 5.0661 & 0.0267 & $1.06 \mathrm{E}-02$ & 0.0093 & $3.65 \mathrm{E}-03$ & 83 & 1.81 \\
\hline 1.068 & 5.0598 & 0.0425 & $1.71 \mathrm{E}-02$ & 0.0176 & $6.97 \mathrm{E}-03$ & 118 & 2.56 \\
\hline 1.0197 & 5.0069 & 0.0508 & $2.05 \mathrm{E}-02$ & 0.0226 & $8.98 \mathrm{E}-03$ & 138 & 3.00 \\
\hline \multicolumn{8}{|c|}{ EtOH $\left(50^{\circ} \mathrm{C}\right)$} \\
\hline 1.0497 & 5.015 & $1.02 \mathrm{E}-02$ & $4.02 \mathrm{E}-03$ & 0.0036 & $1.42 \mathrm{E}-03$ & 31 & 0.68 \\
\hline 1.0371 & 4.9655 & $2.23 \mathrm{E}-02$ & $8.84 \mathrm{E}-03$ & 0.0086 & $3.40 \mathrm{E}-03$ & 65 & 1.42 \\
\hline 1.0531 & 5.0192 & $2.67 \mathrm{E}-02$ & $1.06 \mathrm{E}-02$ & 0.0108 & $4.25 \mathrm{E}-03$ & 76 & 1.65 \\
\hline 1.0524 & 5.054 & 0.04248 & $1.71 \mathrm{E}-02$ & 0.0201 & $7.95 \mathrm{E}-03$ & 108 & 2.34 \\
\hline 1.0329 & 5.2141 & 0.05077 & $2.05 \mathrm{E}-02$ & 0.0255 & $1.01 \mathrm{E}-02$ & 128 & 2.78 \\
\hline \multicolumn{8}{|l|}{$\begin{array}{c}\text { 1-PrOH } \\
\left(25^{\circ} \mathrm{C}\right)\end{array}$} \\
\hline 1.0352 & 5.2537 & $1.12 \mathrm{E}-02$ & $3.39 \mathrm{E}-03$ & 0.0009 & $2.74 \mathrm{E}-04$ & 52 & 0.87 \\
\hline 1.0651 & 5.2015 & $1.95 \mathrm{E}-02$ & $5.94 \mathrm{E}-03$ & 0.0020 & $6.14 \mathrm{E}-04$ & 85 & 1.42 \\
\hline 1.0685 & 5.3261 & $3.01 \mathrm{E}-02$ & $9.22 \mathrm{E}-03$ & 0.0052 & $1.55 \mathrm{E}-03$ & 124 & 2.07 \\
\hline 1.0893 & 5.04 & $3.94 \mathrm{E}-02$ & $1.21 \mathrm{E}-02$ & 0.0075 & $2.26 \mathrm{E}-03$ & 147 & 2.46 \\
\hline 1.0842 & 5.2338 & $5.20 \mathrm{E}-02$ & $1.62 \mathrm{E}-02$ & 0.0148 & $4.49 \mathrm{E}-03$ & 179 & 2.99 \\
\hline \multicolumn{8}{|l|}{$\begin{array}{c}\text { 1-PrOH } \\
\left(50^{\circ} \mathrm{C}\right)\end{array}$} \\
\hline 1.0352 & 5.0548 & 0.0112 & $3.39 \mathrm{E}-03$ & 0.0012 & $3.74 \mathrm{E}-04$ & 49 & 0.81 \\
\hline 1.0607 & 5.0802 & 0.0195 & $5.94 \mathrm{E}-03$ & 0.0028 & $8.28 \mathrm{E}-04$ & 80 & 1.34 \\
\hline 1.0996 & 5.0081 & 0.0301 & $9.22 \mathrm{E}-03$ & 0.0056 & $1.70 \mathrm{E}-03$ & 111 & 1.86 \\
\hline 1.0874 & 5.1046 & 0.0394 & $1.21 \mathrm{E}-02$ & 0.0093 & $2.81 \mathrm{E}-03$ & 141 & 2.35 \\
\hline 1.0761 & 4.981 & 0.0520 & $1.62 \mathrm{E}-02$ & 0.0149 & $4.53 \mathrm{E}-03$ & 171 & 2.86 \\
\hline \multicolumn{8}{|l|}{$\begin{array}{c}2-\mathrm{PrOH} \\
\left(25^{\circ} \mathrm{C}\right)\end{array}$} \\
\hline 1.0576 & 5.0196 & 0.0106 & $3.21 \mathrm{E}-03$ & 0.0011 & $3.36 \mathrm{E}-04$ & 45 & 0.75 \\
\hline 1.0945 & 5.1257 & 0.0181 & $5.51 \mathrm{E}-03$ & 0.0022 & $6.50 \mathrm{E}-04$ & 75 & 1.25 \\
\hline 1.0337 & 5.1446 & 0.0276 & $8.43 \mathrm{E}-03$ & 0.0050 & $1.50 \mathrm{E}-03$ & 112 & 1.87 \\
\hline 1.0935 & 5.1209 & 0.0385 & $1.19 \mathrm{E}-02$ & 0.0087 & $2.64 \mathrm{E}-03$ & 139 & 2.32 \\
\hline 1.0362 & 4.994 & 0.0500 & $1.55 \mathrm{E}-02$ & 0.0166 & $5.05 \mathrm{E}-03$ & 161 & 2.68 \\
\hline \multicolumn{8}{|l|}{$\begin{array}{c}\text { 2-PrOH } \\
\left(50^{\circ} \mathrm{C}\right)\end{array}$} \\
\hline 1.0856 & 5.049 & 0.0106 & $3.21 \mathrm{E}-03$ & 0.0013 & $3.96 \mathrm{E}-04$ & 43 & 0.72 \\
\hline 1.0772 & 5.0144 & 0.0181 & $5.51 \mathrm{E}-03$ & 0.0030 & $9.08 \mathrm{E}-04$ & 70 & 1.17 \\
\hline 1.0743 & 5.1624 & 0.0276 & $8.43 \mathrm{E}-03$ & 0.0062 & $1.86 \mathrm{E}-03$ & 103 & 1.71 \\
\hline 1.0517 & 5.3396 & 0.0385 & $1.19 \mathrm{E}-02$ & 0.0117 & $3.55 \mathrm{E}-03$ & 136 & 2.27 \\
\hline 1.0962 & 5.0307 & 0.0500 & $1.55 \mathrm{E}-02$ & 0.0162 & $4.91 \mathrm{E}-03$ & 155 & 2.58 \\
\hline
\end{tabular}




\begin{tabular}{|c|c|c|c|c|c|c|c|}
\hline \multicolumn{8}{|l|}{ EG $\left(25^{\circ} \mathrm{C}\right)$} \\
\hline 1.0185 & 4.9514 & 0.0056 & $1.63 \mathrm{E}-03$ & 0.0029 & 8.31E-04 & 13 & 0.22 \\
\hline 1.078 & 4.9798 & 0.0127 & $3.72 \mathrm{E}-03$ & 0.0056 & $1.63 \mathrm{E}-03$ & 33 & 0.53 \\
\hline 1.0018 & 4.995 & 0.0182 & $5.36 \mathrm{E}-03$ & 0.0100 & $2.91 \mathrm{E}-03$ & 41 & 0.66 \\
\hline 1.0524 & 4.864 & 0.0241 & $7.13 \mathrm{E}-03$ & 0.0136 & $3.97 \mathrm{E}-03$ & 49 & 0.79 \\
\hline 1.0965 & 4.9885 & 0.0297 & $8.79 \mathrm{E}-03$ & 0.0167 & $4.91 \mathrm{E}-03$ & 59 & 0.95 \\
\hline 1.0352 & 4.9775 & 0.0340 & $1.01 \mathrm{E}-02$ & 0.0202 & $5.96 \mathrm{E}-03$ & 66 & 1.06 \\
\hline \multicolumn{8}{|l|}{ EG $\left(65^{\circ} \mathrm{C}\right)$} \\
\hline 1.0806 & 4.9707 & $5.31 \mathrm{E}-03$ & $1.55 \mathrm{E}-03$ & 0.0033 & $9.73 E-04$ & 9 & 0.15 \\
\hline 1.0664 & 4.9778 & $1.13 \mathrm{E}-02$ & $3.30 \mathrm{E}-03$ & 0.0062 & $1.80 \mathrm{E}-03$ & 24 & 0.38 \\
\hline 1.0978 & 4.9183 & $1.59 \mathrm{E}-02$ & $4.68 \mathrm{E}-03$ & 0.0088 & $2.58 \mathrm{E}-03$ & 32 & 0.51 \\
\hline 1.0454 & 4.9527 & $2.07 \mathrm{E}-02$ & $6.11 \mathrm{E}-03$ & 0.0120 & $3.52 \mathrm{E}-03$ & 41 & 0.66 \\
\hline 1.0472 & 4.9562 & $2.56 \mathrm{E}-02$ & $7.56 \mathrm{E}-03$ & 0.0152 & $4.47 \mathrm{E}-03$ & 49 & 0.79 \\
\hline 1.021 & 4.9932 & $3.13 \mathrm{E}-02$ & $9.29 \mathrm{E}-03$ & 0.0188 & $5.52 \mathrm{E}-03$ & 61 & 0.99 \\
\hline \multicolumn{8}{|l|}{ PG $\left(25^{\circ} \mathrm{C}\right)$} \\
\hline 1.0212 & 4.9533 & $1.07 \mathrm{E}-02$ & $2.55 \mathrm{E}-03$ & 0.0021 & $4.91 \mathrm{E}-04$ & 42 & 0.55 \\
\hline 1.0067 & 4.9455 & $2.00 \mathrm{E}-02$ & $4.81 \mathrm{E}-03$ & 0.0062 & $1.47 \mathrm{E}-03$ & 68 & 0.89 \\
\hline 1.0341 & 5.0261 & $3.06 \mathrm{E}-02$ & $7.43 \mathrm{E}-03$ & 0.0118 & $2.82 \mathrm{E}-03$ & 91 & 1.20 \\
\hline 1.0245 & 4.9448 & $4.07 \mathrm{E}-02$ & $9.94 \mathrm{E}-03$ & 0.0161 & $3.86 \mathrm{E}-03$ & 118 & 1.56 \\
\hline 1.0349 & 5.0011 & $5.01 E-02$ & $1.23 \mathrm{E}-02$ & 0.0255 & $6.16 \mathrm{E}-03$ & 119 & 1.57 \\
\hline \multicolumn{8}{|l|}{$\mathrm{PG}\left(45^{\circ} \mathrm{C}\right)$} \\
\hline 1.0416 & 4.5406 & 0.0059 & $1.40 \mathrm{E}-03$ & 0.0012 & $2.87 \mathrm{E}-04$ & 20 & 0.27 \\
\hline 1.0423 & 4.5383 & 0.0117 & $2.80 \mathrm{E}-03$ & 0.0025 & $5.96 \mathrm{E}-04$ & 40 & 0.53 \\
\hline 1.0364 & 4.4246 & 0.0183 & $4.38 \mathrm{E}-03$ & 0.0052 & $1.24 \mathrm{E}-03$ & 56 & 0.73 \\
\hline 1.005 & 4.507 & 0.0248 & $5.98 \mathrm{E}-03$ & 0.0086 & $2.06 \mathrm{E}-03$ & 72 & 0.95 \\
\hline 1.0322 & 4.5787 & 0.0310 & $7.52 \mathrm{E}-03$ & 0.0123 & $2.94 \mathrm{E}-03$ & 83 & 1.09 \\
\hline 1.0796 & 4.4994 & 0.0363 & $8.84 \mathrm{E}-03$ & 0.0150 & $3.59 \mathrm{E}-03$ & 89 & 1.17 \\
\hline \multicolumn{8}{|l|}{ PG $\left(65^{\circ} \mathrm{C}\right)$} \\
\hline 1.0868 & 4.55 & 0.0059 & $1.40 \mathrm{E}-03$ & 0.0014 & 3.27E-04 & 19 & 0.25 \\
\hline 1.0109 & 4.8343 & 0.0117 & $2.80 \mathrm{E}-03$ & 0.0036 & 8.61E-04 & 39 & 0.51 \\
\hline 1.0734 & 4.8368 & 0.0183 & $4.38 \mathrm{E}-03$ & 0.0064 & $1.53 \mathrm{E}-03$ & 53 & 0.70 \\
\hline 1.0458 & 4.4285 & 0.0248 & $5.98 \mathrm{E}-03$ & 0.0093 & $2.21 \mathrm{E}-03$ & 66 & 0.86 \\
\hline 1.0732 & 4.5345 & 0.0310 & $7.52 \mathrm{E}-03$ & 0.0126 & $3.02 \mathrm{E}-03$ & 78 & 1.02 \\
\hline 1.0626 & 4.5405 & 0.0363 & 8.84E-03 & 0.0159 & $3.82 \mathrm{E}-03$ & 87 & 1.14 \\
\hline \multicolumn{8}{|l|}{$\begin{array}{l}\text { glycerol } \\
\left(25^{\circ} \mathrm{C}\right)\end{array}$} \\
\hline 1.0759 & 5.0785 & 0.0059 & $1.15 \mathrm{E}-03$ & 0.0021 & $4.05 \mathrm{E}-04$ & 18 & 0.19 \\
\hline 1.0589 & 5.1093 & 0.0121 & $2.39 \mathrm{E}-03$ & 0.0048 & $9.36 \mathrm{E}-04$ & 35 & 0.39 \\
\hline 1.0593 & 5.1432 & 0.0204 & $4.05 \mathrm{E}-03$ & 0.0090 & $1.78 \mathrm{E}-03$ & 55 & 0.60 \\
\hline 1.0079 & 4.9279 & 0.0234 & $4.66 \mathrm{E}-03$ & 0.0109 & $2.15 \mathrm{E}-03$ & 61 & 0.66 \\
\hline 1.0747 & 5.035 & 0.0278 & $5.57 \mathrm{E}-03$ & 0.0129 & $2.54 \mathrm{E}-03$ & 70 & 0.76 \\
\hline 1.0246 & 5.108 & 0.0359 & $7.23 \mathrm{E}-03$ & 0.0184 & $3.65 \mathrm{E}-03$ & 87 & 0.95 \\
\hline \multicolumn{8}{|l|}{$\begin{array}{c}\text { glycerol } \\
\left(45^{\circ} \mathrm{C}\right)\end{array}$} \\
\hline 1.0741 & 4.9992 & 0.0059 & $1.15 \mathrm{E}-03$ & 0.0025 & $4.85 \mathrm{E}-04$ & 16 & 0.17 \\
\hline 1.0992 & 5.0598 & 0.0120 & $2.38 \mathrm{E}-03$ & 0.0045 & $8.93 \mathrm{E}-04$ & 34 & 0.37 \\
\hline 1.0894 & 5.0139 & 0.0180 & $3.58 \mathrm{E}-03$ & 0.0082 & $1.62 \mathrm{E}-03$ & 45 & 0.49 \\
\hline 1.0108 & 5.3126 & 0.0234 & $4.66 \mathrm{E}-03$ & 0.0121 & $2.39 \mathrm{E}-03$ & 59 & 0.64 \\
\hline 1.0679 & 5.0177 & 0.0278 & $5.57 \mathrm{E}-03$ & 0.0141 & $2.79 \mathrm{E}-03$ & 64 & 0.70 \\
\hline 1.0772 & 5.0333 & 0.0359 & $7.23 \mathrm{E}-03$ & 0.0186 & $3.70 \mathrm{E}-03$ & 81 & 0.88 \\
\hline
\end{tabular}




\begin{tabular}{|c|c|c|c|c|c|c|c|}
\hline $\begin{array}{c}\text { glycerol } \\
\left(65^{\circ} \mathrm{C}\right)\end{array}$ & & & & & & & \\
\hline 1.0022 & 5.0522 & 0.0059 & $1.15 \mathrm{E}-03$ & 0.0029 & $5.72 \mathrm{E}-04$ & 15 & 0.16 \\
\hline 1.0123 & 5.0185 & 0.0120 & $2.38 \mathrm{E}-03$ & 0.0062 & $1.22 \mathrm{E}-03$ & 29 & 0.32 \\
\hline 1.038 & 5.0789 & 0.0180 & $3.58 \mathrm{E}-03$ & 0.0096 & $1.89 \mathrm{E}-03$ & 41 & 0.45 \\
\hline 1.0547 & 5.0562 & 0.0234 & $4.66 \mathrm{E}-03$ & 0.0127 & $2.50 \mathrm{E}-03$ & 51 & 0.56 \\
\hline 1.06 & 5.1494 & 0.0278 & $5.57 \mathrm{E}-03$ & 0.0160 & $3.16 \mathrm{E}-03$ & 58 & 0.63 \\
\hline 1.0002 & 4.9778 & 0.0359 & $7.23 \mathrm{E}-03$ & 0.0212 & $4.22 \mathrm{E}-03$ & 73 & 0.79 \\
\hline \multicolumn{8}{|l|}{$\begin{array}{l}\text { glucose } \\
\left(25^{\circ} \mathrm{C}\right)\end{array}$} \\
\hline 1.0040 & 10.5025 & 0.006 & $6.13 \mathrm{E}-04$ & 0.0013 & $1.30 \mathrm{E}-04$ & 50 & 0.279 \\
\hline 1.0048 & 10.6188 & 0.012 & $1.22 \mathrm{E}-03$ & 0.0038 & $3.81 \mathrm{E}-04$ & 88 & 0.491 \\
\hline 1.0061 & 10.636 & 0.018 & $1.78 \mathrm{E}-03$ & 0.007 & $7.04 \mathrm{E}-04$ & 111 & 0.616 \\
\hline 1.0054 & 10.6847 & 0.023 & $2.39 \mathrm{E}-03$ & 0.0109 & $1.10 \mathrm{E}-03$ & 133 & 0.739 \\
\hline 1.0069 & 10.7034 & 0.029 & $2.96 \mathrm{E}-03$ & 0.0152 & $1.54 \mathrm{E}-03$ & 144 & 0.801 \\
\hline 1.0045 & 10.6998 & 0.034 & $3.51 \mathrm{E}-03$ & 0.0192 & $1.95 \mathrm{E}-03$ & 157 & 0.874 \\
\hline \multicolumn{8}{|l|}{$\begin{array}{l}\text { glucose } \\
\left(45^{\circ} \mathrm{C}\right)\end{array}$} \\
\hline 1.0067 & 10.6437 & 0.006 & $6.13 \mathrm{E}-04$ & 0.0016 & $1.60 \mathrm{E}-04$ & 48 & 0.266 \\
\hline 1.0076 & 10.5867 & 0.012 & $1.22 \mathrm{E}-03$ & 0.0043 & $4.32 \mathrm{E}-04$ & 82 & 0.455 \\
\hline 1.0038 & 10.6389 & 0.018 & $1.78 \mathrm{E}-03$ & 0.0077 & $7.75 \mathrm{E}-04$ & 104 & 0.576 \\
\hline 1.0091 & 10.6881 & 0.023 & $2.39 \mathrm{E}-03$ & 0.0119 & $1.20 \mathrm{E}-03$ & 122 & 0.678 \\
\hline 1.0068 & 10.7226 & 0.029 & $2.96 \mathrm{E}-03$ & 0.016 & $1.62 \mathrm{E}-03$ & 135 & 0.749 \\
\hline 1.0024 & 10.6203 & 0.034 & $3.51 \mathrm{E}-03$ & 0.0199 & $2.03 E-03$ & 148 & 0.823 \\
\hline \multicolumn{8}{|l|}{$\begin{array}{l}\text { sucrose } \\
\left(25^{\circ} \mathrm{C}\right)\end{array}$} \\
\hline 1.0724 & 5.0905 & $2.44 \mathrm{E}-02$ & $1.32 \mathrm{E}-03$ & $2.7 \mathrm{E}-04$ & $1.40 \mathrm{E}-05$ & 115 & 0.34 \\
\hline 1.0235 & 4.9827 & $2.80 \mathrm{E}-02$ & $1.51 \mathrm{E}-03$ & $3.8 \mathrm{E}-04$ & $2.00 \mathrm{E}-05$ & 134 & 0.39 \\
\hline 1.0819 & 5.21 & $3.43 \mathrm{E}-02$ & $1.86 \mathrm{E}-03$ & $6.7 \mathrm{E}-04$ & $3.51 \mathrm{E}-05$ & 162 & 0.47 \\
\hline 1.0065 & 5.1211 & $3.68 \mathrm{E}-02$ & $2.01 \mathrm{E}-03$ & $1.2 \mathrm{E}-03$ & $6.37 \mathrm{E}-05$ & 181 & 0.53 \\
\hline 1.0628 & 5.0267 & $4.22 \mathrm{E}-02$ & $2.31 \mathrm{E}-03$ & $1.9 \mathrm{E}-03$ & $1.00 \mathrm{E}-04$ & 191 & 0.56 \\
\hline 1.0512 & 4.9363 & $4.69 \mathrm{E}-02$ & $2.58 \mathrm{E}-03$ & $2.6 \mathrm{E}-03$ & $1.37 \mathrm{E}-04$ & 208 & 0.61 \\
\hline 1.0285 & 5.0289 & 5.72E-02 & $3.18 \mathrm{E}-03$ & $8.2 E-03$ & $4.36 \mathrm{E}-04$ & 239 & 0.70 \\
\hline \multicolumn{8}{|l|}{$\begin{array}{c}\text { sucrose } \\
\left(45^{\circ} \mathrm{C}\right)\end{array}$} \\
\hline 1.0353 & 4.5097 & $3.68 \mathrm{E}-02$ & $2.00 \mathrm{E}-03$ & $1.1 \mathrm{E}-03$ & $5.57 \mathrm{E}-05$ & 155 & 0.45 \\
\hline 1.0634 & 4.6459 & $4.37 \mathrm{E}-02$ & $2.40 \mathrm{E}-03$ & $2.3 \mathrm{E}-03$ & $1.24 \mathrm{E}-04$ & 181 & 0.53 \\
\hline 1.0312 & 5.0309 & $2.44 \mathrm{E}-02$ & $1.32 \mathrm{E}-03$ & $3.4 \mathrm{E}-04$ & $1.79 \mathrm{E}-05$ & 117 & 0.34 \\
\hline 1.0674 & 5.2128 & $3.43 \mathrm{E}-02$ & $1.86 \mathrm{E}-03$ & 1.3E-03 & $6.89 \mathrm{E}-05$ & 161 & 0.47 \\
\hline 1.0183 & 5.12 & $3.69 \mathrm{E}-02$ & $2.01 \mathrm{E}-03$ & $2.4 \mathrm{E}-03$ & $1.26 \mathrm{E}-04$ & 174 & 0.51 \\
\hline 1.0377 & 5.1661 & $4.22 \mathrm{E}-02$ & $2.31 \mathrm{E}-03$ & $3.1 \mathrm{E}-03$ & $1.66 \mathrm{E}-04$ & 194 & 0.57 \\
\hline \multicolumn{8}{|l|}{$\begin{array}{l}\text { sucrose } \\
\left(65^{\circ} \mathrm{C}\right)\end{array}$} \\
\hline 1.0764 & 4.7581 & $1.25 \mathrm{E}-02$ & $6.68 \mathrm{E}-04$ & $1.1 \mathrm{E}-04$ & $5.66 \mathrm{E}-06$ & 55 & 0.16 \\
\hline 1.0604 & 4.4343 & $2.16 \mathrm{E}-02$ & $1.16 \mathrm{E}-03$ & $3.0 \mathrm{E}-04$ & $1.58 \mathrm{E}-05$ & 89 & 0.26 \\
\hline 1.0711 & 4.7473 & $2.78 \mathrm{E}-02$ & $1.50 \mathrm{E}-03$ & $8.1 \mathrm{E}-04$ & $4.29 \mathrm{E}-05$ & 119 & 0.35 \\
\hline 1.0614 & 4.8102 & $3.68 \mathrm{E}-02$ & $2.00 \mathrm{E}-03$ & 2.3E-03 & $1.19 \mathrm{E}-04$ & 156 & 0.46 \\
\hline 1.0321 & 4.569 & $4.37 \mathrm{E}-02$ & $2.40 \mathrm{E}-03$ & $3.9 \mathrm{E}-03$ & $2.04 \mathrm{E}-04$ & 176 & 0.52 \\
\hline
\end{tabular}


TABLE E-2

Data for EG Adsorption $\left(25^{\circ} \mathrm{C}\right.$ ) onto Modified F400 Carbons (Figure 4.4-1)

\begin{tabular}{|c|c|c|c|c|c|c|c|}
\hline $\begin{array}{l}\mathrm{m}_{\text {dyy }} \\
(\mathrm{g})\end{array}$ & $\begin{array}{l}W_{0} \\
\text { (g) }\end{array}$ & $\begin{array}{c}X_{i} \\
(g / g)\end{array}$ & $\begin{array}{c}\mathrm{X}_{\mathrm{i}} \\
(\mathrm{mol} / \mathrm{mol})\end{array}$ & $\begin{array}{c}X_{f} \\
(g / g)\end{array}$ & $\begin{array}{c}\mathrm{X}_{\mathrm{f}} \\
(\mathrm{mol} / \mathrm{mol})\end{array}$ & $\begin{array}{c}\mathrm{q} \\
(\mathrm{mg} / \mathrm{g})\end{array}$ & $\frac{q}{q}\left(\mu \mathrm{g} / \mathrm{m}^{2}\right)$ \\
\hline \multicolumn{8}{|l|}{ F400/HT } \\
\hline 1.0239 & 4.0557 & 0.0119 & $3.47 \mathrm{E}-03$ & 0.0056 & $1.63 \mathrm{E}-03$ & 25 & 24 \\
\hline 1.0008 & 4.022 & 0.0209 & $6.15 \mathrm{E}-03$ & 0.0089 & $2.59 \mathrm{E}-03$ & 48 & 46 \\
\hline 1.0081 & 4.037 & 0.0298 & $8.83 \mathrm{E}-03$ & 0.0146 & $4.28 \mathrm{E}-03$ & 61 & 58 \\
\hline 1.0437 & 4.0255 & 0.0606 & $1.84 \mathrm{E}-02$ & 0.0303 & $9.00 \mathrm{E}-03$ & 117 & 111 \\
\hline 1.0771 & 4.0044 & 0.1027 & $3.22 \mathrm{E}-02$ & 0.0598 & $1.81 \mathrm{E}-02$ & 159 & 151 \\
\hline 1.0795 & 4.2637 & 0.1405 & $4.53 \mathrm{E}-02$ & 0.0922 & $2.87 \mathrm{E}-02$ & 191 & 181 \\
\hline \multicolumn{8}{|c|}{ F400/OX50/2 } \\
\hline 1.0118 & 4.0087 & 0.0119 & $3.47 \mathrm{E}-03$ & 0.0076 & $2.22 \mathrm{E}-03$ & 17 & 16 \\
\hline 1.0679 & 4.032 & 0.0209 & $6.15 \mathrm{E}-03$ & 0.0109 & 3.19E-03 & 38 & 36 \\
\hline 1.042 & 4.0048 & 0.0298 & $8.83 \mathrm{E}-03$ & 0.0171 & $5.02 \mathrm{E}-03$ & 49 & 47 \\
\hline 1.0227 & 4.0106 & 0.0606 & $1.84 \mathrm{E}-02$ & 0.0364 & $1.08 \mathrm{E}-02$ & 95 & 91 \\
\hline 1.0356 & 4.0349 & 0.1027 & $3.22 \mathrm{E}-02$ & 0.0690 & $2.11 \mathrm{E}-02$ & 131 & 126 \\
\hline \multicolumn{8}{|c|}{ F400/0X70/2 } \\
\hline 1.0093 & 4.022 & 0.0119 & $3.47 \mathrm{E}-03$ & 0.0084 & $2.46 \mathrm{E}-03$ & 14 & 13 \\
\hline 1.0203 & 4.0347 & 0.0209 & $6.15 \mathrm{E}-03$ & 0.0125 & $3.67 \mathrm{E}-03$ & 33 & 30 \\
\hline 1.0298 & 4.0361 & 0.0298 & 8.83E-03 & 0.0185 & $5.43 \mathrm{E}-03$ & $\overline{44}$ & 41 \\
\hline 1.0486 & 4.0069 & 0.0606 & $1.84 \mathrm{E}-02$ & 0.0476 & $1.43 \mathrm{E}-02$ & 50 & 46 \\
\hline 1.0552 & 4.1301 & 0.1027 & $3.22 \mathrm{E}-02$ & 0.0903 & $2.80 \mathrm{E}-02$ & 49 & 45 \\
\hline 1.0395 & 5.0059 & 0.0477 & $1.43 \mathrm{E}-02$ & 0.0375 . & $1.12 \mathrm{E}-02$ & 49 & 45 \\
\hline 1.0195 & 5.073 & 0.0899 & $2.79 \mathrm{E}-02$ & 0.0748 & $2.29 \mathrm{E}-02$ & 75 & 69 \\
\hline
\end{tabular}

TABLE E-3

Data for PG Adsorption ( $25^{\circ} \mathrm{C}$ ) onto Modified F400 Carbons (Figure 4.4-2)

\begin{tabular}{|c|c|c|c|c|c|c|c|}
\hline $\begin{array}{c}\mathrm{m}_{\text {dry }} \\
(\mathrm{g})\end{array}$ & $\begin{array}{c}\mathrm{W}_{\mathrm{o}} \\
(\mathrm{g})\end{array}$ & $\begin{array}{c}\mathrm{X}_{\mathrm{i}} \\
(\mathrm{g} / \mathrm{g})\end{array}$ & $\begin{array}{c}\mathrm{X}_{\mathrm{i}} \\
(\mathrm{mol} / \mathrm{mol})\end{array}$ & $\begin{array}{c}\mathrm{X}_{\mathbf{f}} \\
(\mathrm{g} / \mathrm{g})\end{array}$ & $\begin{array}{c}\mathrm{X}_{\mathrm{f}} \\
(\mathrm{mol} / \mathrm{mol})\end{array}$ & $\begin{array}{c}\mathrm{q} \\
(\mathrm{mg} / \mathrm{g})\end{array}$ & $\begin{array}{c}\mathrm{q} \\
\left(\mu \mathrm{g} / \mathrm{m}^{2}\right)\end{array}$ \\
\hline $\mathrm{F400/HT}$ & & & & & & & \\
\hline 1.0595 & 4.0415 & 0.021 & $5.05 \mathrm{E}-03$ & 0.0036 & $8.54 \mathrm{E}-04$ & 66 & 63 \\
\hline 1.0439 & 4.0397 & 0.024 & $5.79 \mathrm{E}-03$ & 0.0077 & $1.84 \mathrm{E}-03$ & 63 & 60 \\
\hline 1.062 & 4.0636 & 0.061 & $1.52 \mathrm{E}-02$ & 0.0206 & $4.96 \mathrm{E}-03$ & 155 & 147 \\
\hline 1.0224 & 4.0198 & 0.1 & $2.56 \mathrm{E}-02$ & 0.0428 & $1.05 \mathrm{E}-02$ & 225 & 213 \\
\hline 1.6948 & 4.0523 & 0.14 & $3.71 \mathrm{E}-02$ & 0.0723 & $1.81 \mathrm{E}-02$ & 251 & 238 \\
\hline 1.0425 & 4.1512 & 0.188 & $5.20 \mathrm{E}-02$ & 0.1065 & $2.74 \mathrm{E}-02$ & 325 & 308 \\
\hline F400/OX50/2 & & & & & & & \\
\hline 1.0809 & 4.0599 & 0.01 & $2.39 \mathrm{E}-03$ & 0.0046 & $1.10 \mathrm{E}-03$ & 20 & 19 \\
\hline 1.0667 & 4.0912 & 0.021 & $5.05 \mathrm{E}-03$ & 0.0092 & $2.19 \mathrm{E}-03$ & 45 & 44 \\
\hline 1.0299 & 4.0227 & 0.0224 & $5.40 \mathrm{E}-03$ & 0.0132 & $3.16 \mathrm{E}-03$ & 42 & 41 \\
\hline 1.0372 & 4.0404 & 0.061 & $1.52 \mathrm{E}-02$ & 0.0385 & $9.38 \mathrm{E}-03$ & 88 & 84 \\
\hline 1.1901 & 4.0426 & 0.1 & $2.56 \mathrm{E}-02$ & 0.0541 & $1.34 \mathrm{E}-02$ & 156 & 150 \\
\hline 1.0625 & 4.1356 & 0.14 & $3.71 \mathrm{E}-02$ & 0.0819 & $2.07 \mathrm{E}-02$ & 226 & 217 \\
\hline F400/OX70/2 & & & & & & & \\
\hline 1.0575 & 4.042 & 0.01 & $2.39 \mathrm{E}-03$ & 0.0040 & $9.58 \mathrm{E}-04$ & 23 & 21 \\
\hline 1.0514 & 4.082 & 0.021 & $5.05 \mathrm{E}-03$ & 0.0068 & $1.62 \mathrm{E}-03$ & 55 & 50 \\
\hline 1.035 & 4.1194 & 0.024 & $5.79 \mathrm{E}-03$ & 0.0116 & $2.77 \mathrm{E}-03$ & 49 & 45 \\
\hline 1.029 & 4.0214 & 0.061 & $1.52 \mathrm{E}-02$ & 0.0278 & $6.73 \mathrm{E}-03$ & 130 & 119 \\
\hline
\end{tabular}




\begin{tabular}{||l|l|l|l|l|l|l|l|}
\hline 1.0345 & 4.0286 & 0.1 & $2.56 \mathrm{E}-02$ & 0.0569 & $1.41 \mathrm{E}-02$ & 168 & 154 \\
\hline 1.0028 & 4.0325 & 0.14 & $3.71 \mathrm{E}-02$ & 0.0841 & $2.13 \mathrm{E}-02$ & 225 & 206 \\
\hline
\end{tabular}

TABLE E-4

Data for Glycerol Adsorption $\left(25^{\circ} \mathrm{C}\right.$ ) onto Modified F400 Carbons (Figure 4.4-3)

\begin{tabular}{|c|c|c|c|c|c|c|c|}
\hline $\begin{array}{l}m_{\text {dry }} \\
(\mathrm{g})\end{array}$ & $\begin{array}{l}W_{0} \\
(g)\end{array}$ & $\begin{array}{c}X_{i} \\
(g / g)\end{array}$ & $\begin{array}{c}\mathrm{X}_{\mathrm{i}} \\
(\mathrm{mol} / \mathrm{mol})\end{array}$ & $\begin{array}{c}X_{f} \\
(g / g)\end{array}$ & $\begin{array}{c}\mathrm{X}_{\mathrm{f}} \\
(\mathrm{mol} / \mathrm{mol})\end{array}$ & $\begin{array}{c}\mathrm{q} \\
(\mathrm{mg} / \mathrm{g})\end{array}$ & $\begin{array}{c}q \\
\left(\mu \mathrm{g} / \mathrm{m}^{2}\right)\end{array}$ \\
\hline \multicolumn{8}{|c|}{ F400/HT } \\
\hline 1.0561 & 4.981 & 0.0113 & $2.23 \mathrm{E}-03$ & 0.0043 & $8.52 \mathrm{E}-04$ & 33 & 31 \\
\hline 1.0398 & 5.0433 & 0.0265 & $5.31 E-03$ & 0.0124 & $2.44 \mathrm{E}-03$ & 69 & 65 \\
\hline 1.0518 & 5.5171 & 0.0481 & $9.78 \mathrm{E}-03$ & 0.0285 & $5.72 \mathrm{E}-03$ & 102 & 97 \\
\hline 1.0857 & 5.5867 & 0.0855 & $1.80 \mathrm{E}-02$ & 0.0612 & $1.26 \mathrm{E}-02$ & 125 & 119 \\
\hline 1.0824 & 5.1262 & 0.1189 & $2.57 \mathrm{E}-02$ & 0.0874 & $1.84 \mathrm{E}-02$ & 149 & 142 \\
\hline 0.9624 & 4.0422 & $9.21 \mathrm{E}-03$ & $1.82 \mathrm{E}-03$ & 0.0031 & $6.12 E-04$ & 26 & 24 \\
\hline 0.9951 & 4.0143 & $1.75 \mathrm{E}-02$ & $3.48 \mathrm{E}-03$ & 0.0068 & $1.34 \mathrm{E}-03$ & 43 & 41 \\
\hline 1.0186 & 4.0084 & $3.05 \mathrm{E}-02$ & $6.12 \mathrm{E}-03$ & 0.0130 & $2.58 \mathrm{E}-03$ & 69 & 65 \\
\hline 1.0009 & 4.0316 & $4.37 \mathrm{E}-02$ & $8.85 \mathrm{E}-03$ & 0.0223 & $4.43 \mathrm{E}-03$ & 86 & 82 \\
\hline 1.0027 & 3.9946 & $5.32 \mathrm{E}-02$ & $1.09 \mathrm{E}-02$ & 0.0297 & $5.95 \mathrm{E}-03$ & 94 & 89 \\
\hline 1.0175 & 4.0583 & $9.78 \mathrm{E}-02$ & $2.08 \mathrm{E}-02$ & 0.0662 & $1.37 \mathrm{E}-02$ & 126 & 120 \\
\hline \multicolumn{8}{|c|}{ F400/0X50/2 } \\
\hline 1.0024 & 4.027 & 0.0206 & $4.10 \mathrm{E}-03$ & 0.0093 & $1.83 \mathrm{E}-03$ & 46 & 44 \\
\hline 1.0058 & 4.0193 & 0.0309 & $6.20 \mathrm{E}-03$ & 0.0176 & $3.50 \mathrm{E}-03$ & 53 & 51 \\
\hline 1.083 & 4.0073 & 0.0608 & $1.25 \mathrm{E}-02$ & 0.0372 & $7.50 \mathrm{E}-03$ & 87 & 84 \\
\hline 1.0239 & 4.037 & 0.1021 & $2.18 \mathrm{E}-02$ & 0.0693 & $1.44 \mathrm{E}-02$ & 129 & 124 \\
\hline 1.034 & 4.0179 & 0.1401 & $3.09 \mathrm{E}-02$ & 0.1076 & $2.31 \mathrm{E}-02$ & $\overline{126}$ & 121 \\
\hline 1.0015 & 4.0508 & 0.0092 & $1.82 \mathrm{E}-03$ & 0.0049 & $9.54 \mathrm{E}-04$ & 18 & 17 \\
\hline 1.0045 & 4.029 & 0.0175 & $3.48 \mathrm{E}-03$ & 0.0095 & $1.87 \mathrm{E}-03$ & 32 & 31 \\
\hline 1.0167 & 4.317 & 0.0305 & $6.12 \mathrm{E}-03$ & 0.0183 & $3.64 \mathrm{E}-03$ & 52 & 50 \\
\hline 1.0123 & 4.0334 & 0.0437 & $8.85 \mathrm{E}-03$ & 0.0262 & $5.25 \mathrm{E}-03$ & 69 & 67 \\
\hline 1.0305 & 4.1521 & 0.0532 & $1.09 \mathrm{E}-02$ & 0.0345 & $6.95 \mathrm{E}-03$ & 75 & 72 \\
\hline 1.0604 & 4.0394 & 0.0978 & $2.08 \mathrm{E}-02$ & 0.0733 & $1.52 \mathrm{E}-02$ & 94 & 90 \\
\hline \multicolumn{8}{|c|}{ F400/0X70/2 } \\
\hline 1.02 & 4.2244 & 0.0117 & $2.31 \mathrm{E}-03$ & 0.0068 & $1.34 \mathrm{E}-03$ & 20 & 19 \\
\hline 1.0705 & 4.2094 & 0.0246 & $4.91 \mathrm{E}-03$ & 0.0133 & $2.64 \mathrm{E}-03$ & 44 & $\overline{41}$ \\
\hline 1.0937 & 4.0456 & 0.0344 & $6.93 \mathrm{E}-03$ & 0.0204 & $4.05 \mathrm{E}-03$ & 52 & 48 \\
\hline 1.0724 & 4.3033 & 0.0678 & $1.40 \mathrm{E}-02$ & 0.0496 & $1.01 \mathrm{E}-02$ & 73 & 67 \\
\hline 1.0398 & 4.2197 & 0.1155 & $2.49 \mathrm{E}-02$ & 0.0890 & $1.88 \mathrm{E}-02$ & 107 & 99 \\
\hline 1.0331 & 4.0347 & 0.0102 & $2.02 \mathrm{E}-03$ & 0.0051 & $1.00 \mathrm{E}-03$ & 20 & 18 \\
\hline 1.0054 & 4.0421 & 0.0206 & $4.10 \mathrm{E}-03$ & 0.0098 & $1.93 \mathrm{E}-03$ & 43 & 40 \\
\hline 1.0177 & 4.0335 & 0.0309 & $6.20 \mathrm{E}-03$ & 0.0165 & $3.27 \mathrm{E}-03$ & 57 & 52 \\
\hline 1.0166 & 4.0117 & 0.1021 & $2.18 \mathrm{E}-02$ & 0.0781 & $1.63 \mathrm{E}-02$ & 95 & 87 \\
\hline
\end{tabular}


TABLE E-5

Data for Glucose Adsorption $\left(25^{\circ} \mathrm{C}\right.$ ) onto Modified F400 Carbons (Figure 4.4-4)

\begin{tabular}{||c|c|c|c|c|c|c|c||}
\hline $\begin{array}{c}\mathrm{m}_{\text {dry }} \\
(\mathrm{g})\end{array}$ & $\begin{array}{c}\mathrm{W}_{\mathrm{o}} \\
(\mathrm{g})\end{array}$ & $\begin{array}{c}\mathrm{X}_{\mathrm{i}} \\
(\mathrm{g} / \mathrm{g})\end{array}$ & $\begin{array}{c}\mathrm{X}_{\mathrm{i}} \\
(\mathrm{mol} / \mathrm{mol})\end{array}$ & $\begin{array}{c}\mathrm{X}_{\mathrm{f}} \\
(\mathrm{g} / \mathrm{g})\end{array}$ & $\begin{array}{c}\mathrm{X}_{\mathrm{f}} \\
(\mathrm{mol} / \mathrm{mol})\end{array}$ & $\begin{array}{c}\mathrm{q} \\
(\mathrm{mg} / \mathrm{g})\end{array}$ & $\begin{array}{c}\mathrm{q} \\
\left(\mu \mathrm{g} / \mathrm{m}^{2}\right)\end{array}$ \\
\hline $\mathrm{F400/HT}$ & & & & & & & \\
\hline 1.0094 & 4.0415 & 0.01021 & $1.03 \mathrm{E}-03$ & 0.0007 & $7.42 \mathrm{E}-05$ & 38 & 36 \\
\hline 1.0153 & 4.0364 & 0.02131 & $2.17 \mathrm{E}-03$ & 0.0025 & $2.50 \mathrm{E}-04$ & 75 & 71 \\
\hline 1.0067 & 4.0289 & 0.0302 & $3.10 \mathrm{E}-03$ & 0.0050 & $5.00 \mathrm{E}-04$ & 101 & 96 \\
\hline 1.018 & 4.0746 & 0.06064 & $6.41 \mathrm{E}-03$ & 0.0204 & $2.08 \mathrm{E}-03$ & 161 & 153 \\
\hline 1.0158 & 4.0888 & 0.1016 & $1.12 \mathrm{E}-02$ & 0.0496 & $5.20 \mathrm{E}-03$ & 209 & 198 \\
\hline 1.0281 & 4.0727 & 0.1456 & $1.68 \mathrm{E}-02$ & 0.0879 & $9.55 \mathrm{E}-03$ & 228 & 217 \\
\hline F400/OX50/2 & & & & & & & \\
\hline 1.0277 & 4.0997 & 0.01021 & $1.03 \mathrm{E}-03$ & 0.0016 & $1.63 \mathrm{E}-04$ & 34 & 33 \\
\hline 1.0152 & 4.1406 & 0.02131 & $2.17 \mathrm{E}-03$ & 0.0052 & $5.23 \mathrm{E}-04$ & 66 & 63 \\
\hline 1.0196 & 4.0024 & 0.0302 & $3.10 \mathrm{E}-03$ & 0.0088 & $8.86 \mathrm{E}-04$ & 84 & 81 \\
\hline 1.0131 & 4.1084 & 0.06064 & $6.41 \mathrm{E}-03$ & 0.0270 & $2.77 \mathrm{E}-03$ & 136 & 131 \\
\hline 1.0145 & 4.0325 & 0.1016 & $1.12 \mathrm{E}-02$ & 0.0583 & $6.15 \mathrm{E}-03$ & 172 & 166 \\
\hline 1.0141 & 4.0726 & 0.1456 & $1.68 \mathrm{E}-02$ & 0.1006 & $1.11 \mathrm{E}-02$ & 181 & 174 \\
\hline F400/0X70/2 & & & & & & & \\
\hline 1.0206 & 4.2331 & 0.01021 & $1.03 \mathrm{E}-03$ & 0.0021 & $2.10 \mathrm{E}-04$ & 34 & 31 \\
\hline 1.0088 & 4.0213 & 0.02131 & $2.17 \mathrm{E}-03$ & 0.0057 & $5.76 \mathrm{E}-04$ & 62 & 57 \\
\hline 1.0127 & 4.0265 & 0.0302 & $3.10 \mathrm{E}-03$ & 0.0098 & $9.90 \mathrm{E}-04$ & 81 & 74 \\
\hline 1.0111 & 4.1585 & 0.06064 & $6.41 \mathrm{E}-03$ & 0.0307 & $3.16 \mathrm{E}-03$ & 123 & 113 \\
\hline 1.0113 & 4.1258 & 0.1016 & $1.12 \mathrm{E}-02$ & 0.0624 & $6.62 \mathrm{E}-03$ & 160 & 147 \\
\hline 1.0066 & 4.0365 & 0.1456 & $1.68 \mathrm{E}-02$ & 0.0987 & $1.08 \mathrm{E}-02$ & 188 & 173 \\
\hline
\end{tabular}

TABLE E-6

Data for Lactic Acid Adsorption $\left(25^{\circ} \mathrm{C}\right.$ ) onto Modified F400 Carbons (Figure 4.4-5)

\begin{tabular}{|c|c|c|c|c|c|c|c|}
\hline $\begin{array}{c}\mathrm{m}_{\text {dry }} \\
(\mathrm{g})\end{array}$ & $\begin{array}{c}\mathrm{W}_{\mathrm{o}} \\
(\mathrm{g})\end{array}$ & $\begin{array}{c}\mathrm{X}_{\mathrm{i}} \\
(\mathrm{g} / \mathrm{g})\end{array}$ & $\begin{array}{c}\mathrm{X}_{\mathrm{i}} \\
(\mathrm{mol} / \mathrm{mol})\end{array}$ & $\begin{array}{c}\mathrm{X}_{\mathrm{f}} \\
(\mathrm{g} / \mathrm{g})\end{array}$ & $\begin{array}{c}\mathrm{X}_{\mathrm{f}} \\
(\mathrm{mol} / \mathrm{mol})\end{array}$ & $\begin{array}{c}\mathrm{q} \\
(\mathrm{mg} / \mathrm{g})\end{array}$ & $\begin{array}{c}\mathrm{q} \\
\left(\mu \mathrm{g} / \mathrm{m}^{2}\right)\end{array}$ \\
\hline $\mathbf{F 4 0 0 / H T}$ & & & & & & & \\
\hline 1.0053 & 4.2125 & 0.03136 & $6.43 \mathrm{E}-03$ & 0.0057 & $5.75 \mathrm{E}-04$ & 107 & 102 \\
\hline 1.0008 & 4.2185 & 0.04104 & $8.48 \mathrm{E}-03$ & 0.0097 & $9.81 \mathrm{E}-04$ & 132 & 125 \\
\hline 1.0321 & 4.0188 & 0.05842 & $1.22 \mathrm{E}-02$ & 0.0182 & $1.85 \mathrm{E}-03$ & 157 & 149 \\
\hline 1.0205 & 3.984 & 0.08121 & $1.74 \mathrm{E}-02$ & 0.0318 & $3.28 \mathrm{E}-03$ & 193 & 183 \\
\hline 1.0462 & 4.1226 & 0.1009 & $2.19 \mathrm{E}-02$ & 0.0446 & $4.65 \mathrm{E}-03$ & 222 & 210 \\
\hline 1.0149 & 4.1025 & 0.1343 & $3.01 \mathrm{E}-02$ & 0.0700 & $7.48 \mathrm{E}-03$ & 260 & 246 \\
\hline F400/0X50/2 & & & & & & & \\
\hline 1.052 & 4.2801 & 0.03136 & $6.43 \mathrm{E}-03$ & 0.0094 & $9.45 \mathrm{E}-04$ & 89 & 86 \\
\hline 1.0363 & 3.9995 & 0.04104 & $8.48 \mathrm{E}-03$ & 0.0121 & $1.22 \mathrm{E}-03$ & 112 & 108 \\
\hline 1.0071 & 4.0403 & 0.05842 & $1.22 \mathrm{E}-02$ & 0.0260 & $2.66 \mathrm{E}-03$ & 130 & 125 \\
\hline 1.0479 & 3.9139 & 0.08121 & $1.74 \mathrm{E}-02$ & 0.0386 & $4.00 \mathrm{E}-03$ & 159 & 153 \\
\hline 1.0264 & 3.952 & 0.1009 & $2.19 \mathrm{E}-02$ & 0.0517 & $5.42 \mathrm{E}-03$ & 189 & 182 \\
\hline 1.0245 & 3.9974 & 0.1343 & $3.01 \mathrm{E}-02$ & 0.0831 & $8.99 \mathrm{E}-03$ & 200 & 192 \\
\hline F400/0X70/2 & & & & & & & \\
\hline 1.0029 & 4.1739 & 0.03136 & $6.43 \mathrm{E}-03$ & 0.0114 & $1.15 \mathrm{E}-03$ & 83 & 76 \\
\hline 1.0172 & 4.1572 & 0.04104 & $8.48 \mathrm{E}-03$ & 0.0169 & $1.71 \mathrm{E}-03$ & 99 & 91 \\
\hline 1.017 & 4.0169 & 0.05842 & $1.22 \mathrm{E}-02$ & 0.0283 & $2.90 \mathrm{E}-03$ & 119 & 109 \\
\hline 1.0121 & 3.9443 & 0.08121 & $1.74 \mathrm{E}-02$ & 0.0435 & $4.53 \mathrm{E}-03$ & 147 & 135 \\
\hline
\end{tabular}




\begin{tabular}{|l|l|l|l|l|l|l|l|}
\hline 1.0211 & 4.0584 & 0.1009 & $2.19 \mathrm{E}-02$ & 0.0574 & $6.06 \mathrm{E}-03$ & 173 & 158 \\
\hline 1.0244 & 4.0509 & 0.1343 & $3.01 \mathrm{E}-02$ & 0.0897 & $9.75 \mathrm{E}-03$ & 176 & 162 \\
\hline
\end{tabular}

TABLE E-7

EG and Glucose Adsorption $\left(25^{\circ} \mathrm{C}\right.$ ) onto Carbons of Various Source Materials

(Figures 4.4-6, 4.4-7, and 4.4-8)

\begin{tabular}{|c|c|c|c|c|c|c|c|}
\hline $\begin{array}{l}m_{d r y} \\
(g)\end{array}$ & $\begin{array}{l}W_{0} \\
\text { (g) }\end{array}$ & $\begin{array}{c}X_{i} \\
(g / g)\end{array}$ & $\begin{array}{c}\mathrm{X}_{\mathrm{i}} \\
(\mathrm{mol} / \mathrm{mol})\end{array}$ & $\begin{array}{c}X_{f} \\
(g / g)\end{array}$ & $\begin{array}{c}\mathrm{X}_{\mathrm{f}} \\
(\mathrm{mol} / \mathrm{mol})\end{array}$ & $\begin{array}{c}\mathrm{q} \\
(\mathrm{mg} / \mathrm{g})\end{array}$ & $\begin{array}{c}\mathrm{q} \\
\left(\mu \mathrm{g} / \mathrm{m}^{2}\right)\end{array}$ \\
\hline \multicolumn{8}{|l|}{ EG(F400) } \\
\hline 1.0017 & 10.507 & 0.0126 & 3.69E-03 & 0.0097 & $2.84 \mathrm{E}-03$ & 30 & 28 \\
\hline 1.0067 & 10.521 & 0.0181 & $5.33 \mathrm{E}-03$ & 0.0140 & $4.10 \mathrm{E}-03$ & 43 & 39 \\
\hline 1.0016 & 10.626 & 0.0218 & $6.43 \mathrm{E}-03$ & 0.0172 & $5.07 \mathrm{E}-03$ & 49 & 44 \\
\hline 1.0018 & 10.663 & 0.0256 & $7.57 \mathrm{E}-03$ & 0.0206 & $6.08 \mathrm{E}-03$ & 53 & 48 \\
\hline 1.0066 & 10.677 & 0.0289 & $8.55 \mathrm{E}-03$ & 0.0235 & $6.94 \mathrm{E}-03$ & 57 & 51 \\
\hline 1.0015 & 10.618 & 0.0375 & $1.12 \mathrm{E}-02$ & 0.0311 & $9.23 \mathrm{E}-03$ & 68 & 61 \\
\hline 1.0028 & 10.65 & 0.0527 & $1.59 \mathrm{E}-02$ & 0.0453 & $1.36 \mathrm{E}-02$ & 79 & 72 \\
\hline 1.0052 & 10.533 & 0.0686 & $2.09 \mathrm{E}-02$ & 0.0593 & $1.80 \mathrm{E}-02$ & 98 & 88 \\
\hline 1.0036 & 10.753 & 0.0897 & $2.78 \mathrm{E}-02$ & 0.0790 & $2.43 \mathrm{E}-02$ & 115 & 104 \\
\hline 1.0085 & 10.755 & 0.1073 & $3.37 \mathrm{E}-02$ & 0.0959 & $2.99 \mathrm{E}-02$ & 122 & 110 \\
\hline 1.0026 & 10.726 & 0.1282 & $4.09 \mathrm{E}-02$ & 0.1154 & $3.65 \mathrm{E}-02$ & 137 & 124 \\
\hline \multicolumn{8}{|l|}{ EG(RO 0.8) } \\
\hline 0.5004 & 4.8297 & 0.0122 & $3.56 \mathrm{E}-03$ & 0.0092 & $2.70 \mathrm{E}-03$ & 31 & 28 \\
\hline 0.5049 & 5.0009 & 0.0175 & $5.16 \mathrm{E}-03$ & 0.0133 & $3.91 \mathrm{E}-03$ & 46 & 42 \\
\hline 0.5003 & 5.0009 & 0.0211 & $6.23 \mathrm{E}-03$ & 0.0167 & $4.90 \mathrm{E}-03$ & 49 & 44 \\
\hline 0.5059 & 4.9551 & 0.0248 & $7.32 \mathrm{E}-03$ & 0.0197 & $5.80 \mathrm{E}-03$ & 55 & 49 \\
\hline 0.5017 & 4.8923 & 0.0279 & $8.26 \mathrm{E}-03$ & 0.0222 & $6.56 \mathrm{E}-03$ & $\overline{61}$ & 55 \\
\hline 0.5009 & 4.986 & 0.0363 & $1.08 \mathrm{E}-02$ & 0.0298 & $8.85 \mathrm{E}-03$ & 71 & 64 \\
\hline 0.5008 & 4.9338 & 0.0509 & $1.53 \mathrm{E}-02$ & 0.0435 & $1.30 \mathrm{E}-02$ & 81 & 73 \\
\hline 0.5009 & 4.8131 & 0.0662 & $2.02 \mathrm{E}-02$ & 0.0576 & $1.74 \mathrm{E}-02$ & 91 & 83 \\
\hline 0.5004 & 5.0472 & 0.0866 & $2.68 \mathrm{E}-02$ & 0.0792 & $2.43 \mathrm{E}-02$ & 83 & 75 \\
\hline 0.5014 & 5.0921 & 0.1240 & $3.95 \mathrm{E}-02$ & 0.1126 & $3.55 \mathrm{E}-02$ & 127 & 115 \\
\hline \multicolumn{8}{|l|}{ EG (WVB) } \\
\hline 1.0091 & 9.9824 & 0.0102 & $2.98 \mathrm{E}-03$ & 0.0086 & $2.50 \mathrm{E}-03$ & 18 & 13 \\
\hline 1.0052 & 9.9793 & 0.0150 & $4.40 \mathrm{E}-03$ & 0.0130 & $3.79 \mathrm{E}-03$ & 23 & 17 \\
\hline 1.0083 & 10.009 & 0.0193 & $5.67 \mathrm{E}-03$ & 0.0166 & $4.88 \mathrm{E}-03$ & 30 & 22 \\
\hline 1.004 & 9.9915 & 0.0226 & $6.67 \mathrm{E}-03$ & 0.0196 & $5.76 \mathrm{E}-03$ & 35 & 25 \\
\hline 1.0043 & 9.9971 & 0.0257 & $7.61 \mathrm{E}-03$ & 0.0220 & $6.50 \mathrm{E}-03$ & 42 & 31 \\
\hline 1.0082 & 10.095 & 0.0340 & $1.01 \mathrm{E}-02$ & 0.0285 & $8.45 \mathrm{E}-03$ & 63 & 46 \\
\hline 1.0049 & 10.027 & 0.0441 & $1.32 \mathrm{E}-02$ & 0.0393 & $1.17 \mathrm{E}-02$ & 55 & 40 \\
\hline 1.0072 & 9.9242 & 0.0560 & $1.69 \mathrm{E}-02$ & 0.0483 & $1.45 \mathrm{E}-02$ & 86 & 63 \\
\hline 1.0045 & 9.8809 & 0.0710 & $2.17 \mathrm{E}-02$ & 0.0627 & $1.90 \mathrm{E}-02$ & 95 & 69 \\
\hline 1.0059 & 10.089 & 0.0924 & $2.87 \mathrm{E}-02$ & 0.0827 & $2.55 \mathrm{E}-02$ & 112 & 82 \\
\hline 1.0045 & 10.172 & 0.1163 & $3.68 \mathrm{E}-02$ & 0.1039 & $3.26 \mathrm{E}-02$ & 144 & 105 \\
\hline \multicolumn{8}{|l|}{$\mathrm{EG}(\mathrm{A572})$} \\
\hline 0.9966 & 4.9818 & 0.0060 & $1.76 \mathrm{E}-03$ & 0.0023 & $6.62 \mathrm{E}-04$ & 19 & 17 \\
\hline 0.9979 & 4.9587 & 0.0117 & $3.43 \mathrm{E}-03$ & 0.0047 & $1.36 \mathrm{E}-03$ & 35 & 32 \\
\hline 1.0113 & 4.9781 & 0.0264 & $7.82 \mathrm{E}-03$ & 0.0125 & $3.66 \mathrm{E}-03$ & 69 & 62 \\
\hline 1.0014 & 4.9975 & 0.0400 & $1.20 \mathrm{E}-02$ & 0.0216 & $6.38 \mathrm{E}-03$ & 92 & 84 \\
\hline 0.9957 & 4.996 & 0.0728 & $2.23 \mathrm{E}-02$ & 0.0437 & $1.31 \mathrm{E}-02$ & 146 & 133 \\
\hline 1.0546 & 5.0537 & 0.1305 & $4.18 \mathrm{E}-02$ & 0.0883 & $2.74 \mathrm{E}-02$ & 202 & 184 \\
\hline
\end{tabular}




\begin{tabular}{|c|c|c|c|c|c|c|c|}
\hline $\begin{array}{c}\text { Glucose } \\
\text { (F400) }\end{array}$ & & & & & & & \\
\hline 1.0038 & 9.9666 & 0.0075 & $4.17 \mathrm{E}-04$ & 0.0016 & $9.16 \mathrm{E}-05$ & 58 & 52 \\
\hline 1.0077 & 9.9983 & 0.0119 & $6.64 \mathrm{E}-04$ & 0.0033 & $1.84 \mathrm{E}-04$ & 85 & 77 \\
\hline 1.0034 & 10.016 & 0.0166 & $9.31 \mathrm{E}-04$ & 0.0053 & $2.96 \mathrm{E}-04$ & 113 & 102 \\
\hline 1.0029 & 10.022 & 0.0233 & $1.31 \mathrm{E}-03$ & 0.0098 & 5.47E-04 & 135 & 122 \\
\hline 1.0065 & 10.069 & 0.0329 & $1.86 \mathrm{E}-03$ & 0.0170 & $9.53 \mathrm{E}-04$ & 159 & 144 \\
\hline 1.0008 & 10.077 & 0.0473 & $2.70 \mathrm{E}-03$ & 0.0280 & $1.58 \mathrm{E}-03$ & 194 & 176 \\
\hline 1.0072 & 10.079 & 0.0618 & $3.56 \mathrm{E}-03$ & 0.0425 & $2.42 \mathrm{E}-03$ & 194 & 176 \\
\hline 1.0097 & 10.102 & 0.0772 & $4.48 \mathrm{E}-03$ & 0.0577 & $3.31 \mathrm{E}-03$ & 195 & 177 \\
\hline 1.0053 & 10.303 & 0.0975 & $5.73 \mathrm{E}-03$ & 0.0777 & $4.51 \mathrm{E}-03$ & 203 & 184 \\
\hline 1.0034 & 10.270 & 0.1208 & $7.19 \mathrm{E}-03$ & 0.1013 & $5.97 \mathrm{E}-03$ & 199 & 181 \\
\hline \multicolumn{8}{|l|}{$\begin{array}{c}\text { Glucose } \\
\text { (RO 0.8) }\end{array}$} \\
\hline 1.0106 & 9.8538 & 0.0075 & $4.17 \mathrm{E}-04$ & 0.0013 & $7.00 \mathrm{E}-05$ & 61 & 55 \\
\hline 1.0158 & 9.899 & 0.0119 & $6.64 \mathrm{E}-04$ & 0.0026 & $1.43 \mathrm{E}-04$ & 91 & 82 \\
\hline 1.0078 & 9.9908 & 0.0166 & $9.31 \mathrm{E}-04$ & 0.0047 & $2.62 \mathrm{E}-04$ & 118 & 107 \\
\hline 1.0016 & 10.029 & 0.0233 & $1.31 \mathrm{E}-03$ & 0.0088 & $4.91 \mathrm{E}-04$ & $\overline{145}$ & 132 \\
\hline 1.0008 & 10.065 & 0.0329 & $1.86 \mathrm{E}-03$ & 0.0147 & $8.24 \mathrm{E}-04$ & 183 & 166 \\
\hline 1.0085 & 9.979 & 0.0473 & $2.70 \mathrm{E}-03$ & 0.0261 & $1.47 \mathrm{E}-03$ & 210 & 190 \\
\hline 1.0131 & 10.152 & 0.0618 & $3.56 \mathrm{E}-03$ & 0.0401 & $2.28 \mathrm{E}-03$ & 217 & 197 \\
\hline 1.002 & 10.182 & 0.0772 & $4.48 \mathrm{E}-03$ & 0.0537 & $3.08 \mathrm{E}-03$ & 238 & 216 \\
\hline 1.0059 & 10.2 & 0.0975 & $5.73 \mathrm{E}-03$ & 0.0738 & $4.28 \mathrm{E}-03$ & 240 & 218 \\
\hline 1.0055 & 10.371 & 0.1208 & $7.19 \mathrm{E}-03$ & 0.0977 & $5.74 \mathrm{E}-03$ & 239 & 216 \\
\hline \multicolumn{8}{|l|}{$\begin{array}{l}\text { Glucose } \\
\text { (WVB) }\end{array}$} \\
\hline 1.0037 & 9.9876 & 0.0088 & $4.92 \mathrm{E}-04$ & 0.0055 & $3.05 \mathrm{E}-04$ & 38 & 28 \\
\hline 1.0067 & 10.012 & 0.0135 & $7.56 \mathrm{E}-04$ & 0.0089 & $4.95 \mathrm{E}-04$ & 53 & 39 \\
\hline 1.0035 & 10.076 & 0.0184 & $1.03 \mathrm{E}-03$ & 0.0123 & $6.90 \mathrm{E}-04$ & -70 & 51 \\
\hline 1.0049 & 10.056 & 0.0214 & $1.20 \mathrm{E}-03$ & 0.0147 & $8.24 \mathrm{E}-04$ & 76 & 56 \\
\hline 1.0081 & 10.854 & 0.0255 & $1.44 \mathrm{E}-03$ & 0.0180 & $1.01 \mathrm{E}-03$ & 92 & 67 \\
\hline 1.0079 & 9.996 & 0.0343 & $1.94 \mathrm{E}-03$ & 0.0245 & $1.38 \mathrm{E}-03$ & 111 & 81 \\
\hline 1.0057 & 10.043 & 0.0442 & $2.52 \mathrm{E}-03$ & 0.0337 & $1.91 \mathrm{E}-03$ & 119 & 87 \\
\hline 1.0042 & 10.145 & 0.0533 & $3.05 \mathrm{E}-03$ & 0.0407 & $2.31 \mathrm{E}-03$ & 146 & 106 \\
\hline 1.0072 & 10.226 & 0.0657 & $3.79 \mathrm{E}-03$ & 0.0510 & $2.91 \mathrm{E}-03$ & 171 & 125 \\
\hline 1.0043 & 10.320 & 0.0925 & $5.42 \mathrm{E}-03$ & 0.0763 & $4.43 \mathrm{E}-03$ & 190 & 139 \\
\hline 1.0093 & 10.402 & 0.1153 & $6.84 \mathrm{E}-03$ & 0.0992 & $5.83 \mathrm{E}-03$ & 190 & 138 \\
\hline \multicolumn{8}{|c|}{$\begin{array}{c}\text { Glucose } \\
\text { (WVB/HT) }\end{array}$} \\
\hline 0.998 & 4.9695 & 0.0112 & $1.13 \mathrm{E}-03$ & 0.0056 & $5.58 \mathrm{E}-04$ & 28 & 24 \\
\hline 0.9947 & 5.0057 & 0.0252 & $2.58 \mathrm{E}-03$ & 0.0101 & $1.01 \mathrm{E}-03$ & 76 & 65 \\
\hline 0.9973 & 4.985 & 0.0341 & $3.52 \mathrm{E}-03$ & 0.0144 & $1.46 \mathrm{E}-03$ & 98 & 84 \\
\hline 0.9969 & 5.0304 & 0.0669 & $7.12 \mathrm{E}-03$ & 0.0286 & $2.93 \mathrm{E}-03$ & 193 & 166 \\
\hline 1.001 & 5.1579 & 0.1101 & $1.22 \mathrm{E}-02$ & 0.0656 & $6.97 \mathrm{E}-03$ & 230 & 197 \\
\hline 1.0005 & 5.1172 & 0.1422 & $1.63 \mathrm{E}-02$ & 0.0915 & $9.97 \mathrm{E}-03$ & 259 & 222 \\
\hline
\end{tabular}


TABLE E-8

Miscellaneous Data for Adsorption $\left(25^{\circ} \mathrm{C}\right)$ onto Carbons

(Figures 4.1-1 and 4.2-2)

\begin{tabular}{|c|c|c|c|c|c|c|c|}
\hline $\begin{array}{c}\mathrm{m}_{\text {dry }} \\
(\mathrm{g})\end{array}$ & $\begin{array}{c}\mathrm{W}_{\mathrm{o}} \\
(\mathrm{g})\end{array}$ & $\begin{array}{c}\mathrm{X}_{\mathrm{i}} \\
(\mathrm{g} / \mathrm{g})\end{array}$ & $\begin{array}{c}\mathrm{X}_{\mathrm{i}} \\
(\mathrm{mol} / \mathrm{mol})\end{array}$ & $\begin{array}{c}\mathrm{X}_{\mathrm{f}} \\
(\mathrm{g} / \mathrm{g})\end{array}$ & $\begin{array}{c}\mathrm{X}_{\mathrm{f}} \\
(\mathrm{mol} / \mathrm{mol})\end{array}$ & $\begin{array}{c}\mathrm{q} \\
(\mathrm{mg} / \mathrm{g})\end{array}$ & $\begin{array}{c}\mathrm{q} \\
\left(\mu \mathrm{g} / \mathrm{m}^{2}\right)\end{array}$ \\
\hline $\begin{array}{c}\text { Sorbitol } \\
(\mathrm{F} 400 / \mathrm{HT})\end{array}$ & & & & & & & \\
\hline 1.0859 & 4.2698 & 0.0100 & $9.89 \mathrm{E}-04$ & 0.0005 & $5.43 \mathrm{E}-05$ & 37 & 35 \\
\hline 1.0903 & 4.0277 & 0.0319 & $3.15 \mathrm{E}-03$ & 0.0039 & $3.88 \mathrm{E}-04$ & 103 & 98 \\
\hline 1.031 & 4.4305 & 0.0473 & $4.68 \mathrm{E}-03$ & 0.0114 & $1.12 \mathrm{E}-03$ & 154 & 146 \\
\hline 1.0122 & 4.1223 & 0.1209 & $1.20 \mathrm{E}-02$ & 0.0540 & $5.34 \mathrm{E}-03$ & 272 & 258 \\
\hline 1.024 & 4.2036 & 0.1560 & $1.54 \mathrm{E}-02$ & 0.0870 & $8.61 \mathrm{E}-03$ & 283 & 269 \\
\hline & & & & & & & \\
\hline $\begin{array}{c}\text { Lactic Acid } \\
\text { (F400) }\end{array}$ & & & & & & & \\
\hline 1.0134 & 4.2971 & 0.03136 & $6.43 \mathrm{E}-03$ & 0.0047 & $4.74 \mathrm{E}-04$ & 113 & 102 \\
\hline 1.012 & 3.9675 & 0.04104 & $8.48 \mathrm{E}-03$ & 0.0099 & $9.97 \mathrm{E}-04$ & 122 & 111 \\
\hline 1.0387 & 4.0873 & 0.05842 & $1.22 \mathrm{E}-02$ & 0.0190 & $1.94 \mathrm{E}-03$ & 155 & 141 \\
\hline 1.0106 & 3.9894 & 0.08121 & $1.74 \mathrm{E}-02$ & 0.0354 & $3.66 \mathrm{E}-03$ & 181 & 164 \\
\hline 1.0394 & 4.0566 & 0.1009 & $2.19 \mathrm{E}-02$ & 0.0466 & $4.87 \mathrm{E}-03$ & 212 & 192 \\
\hline 1.0033 & 4.1099 & 0.1343 & $3.01 \mathrm{E}-02$ & 0.0724 & $7.75 \mathrm{E}-03$ & 254 & 230 \\
\hline
\end{tabular}

